\title{
THE INDIANS OF TIERRA DEL FUEGO
}

13)

SAMUEL KIRKLAND LOTHROP

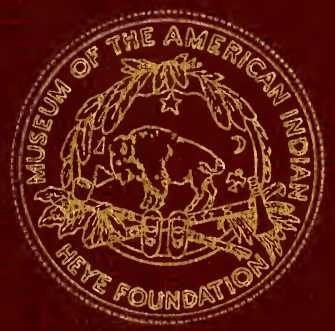

NEW YORK

MUSEUM OF THE AMERICAN INDIAN

HEYE FOUNDATION

1928 




<smiles>C1=CCCC1</smiles> 


\section{CONTRIBUTIONS}

FROM THE

MUSEUM OF THE AMERICAN INDIAN

HEYE FOUNDATION

VOLUME $\mathrm{X}$ 


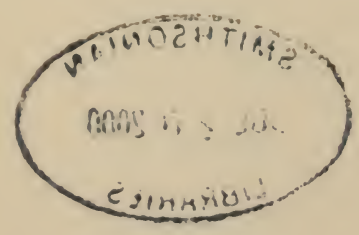




\title{
THE INDIANS OF TIERRA DEL FUEGO
}

\author{
BY \\ SAMUEL KIRKLAND LOTHROP
}

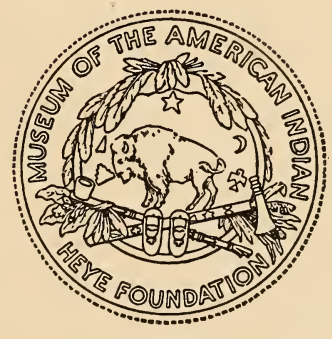

NEW YORK

MUSEUM OF THE AMERICAN INDIAN

HEYE FOUNIDATION

1928

SMITHSONIA JUL 202000 LIBRARIES 
LANCASTER PRESS, IN 


\section{CONTENTS}

Illustrations . .............................................

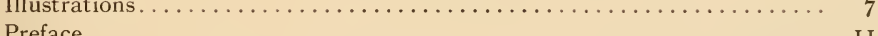

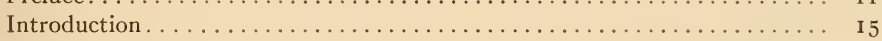

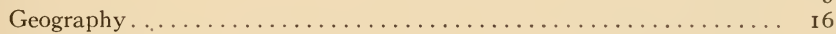

Cartography ........................ 8

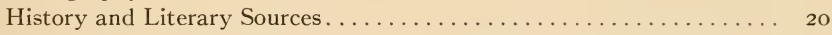

The Indians of Tierra del Fuego . . . . . . . . . . . . . . . 24

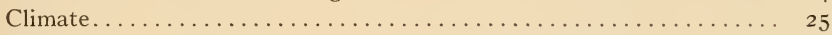

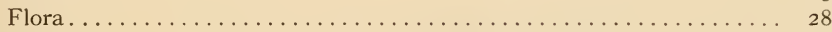

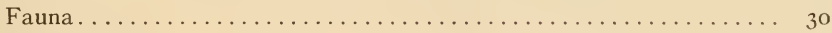

Culture Status. . . . . . . . . . . . . . . . . . . . . . . . 35

Physical Type.................................. 38

Note on the Anthropometric Characters of the Yahgan and the Ona, by Prof. E. A. Hooton................. 4 I

\section{PART I-FOOT INDIANS}

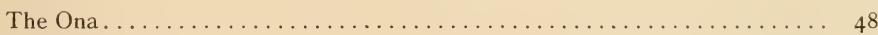

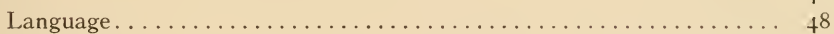

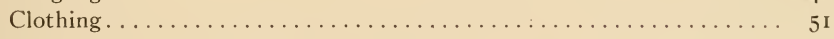

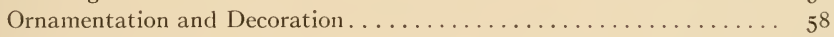

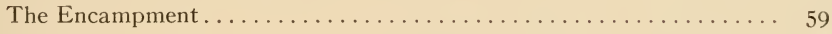

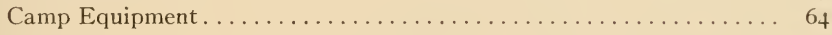

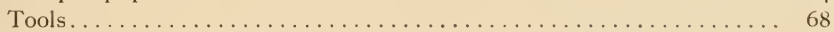

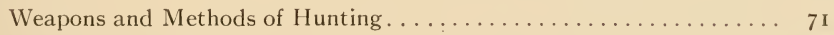

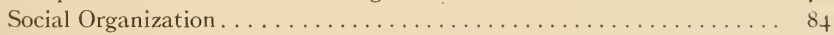

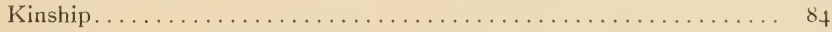

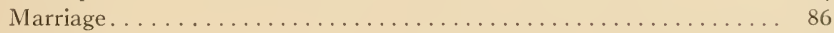

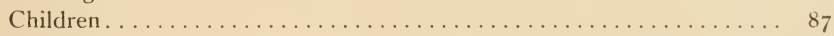

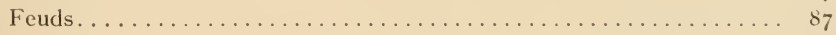

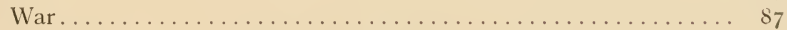

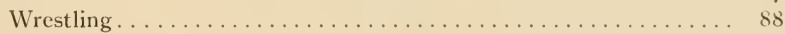

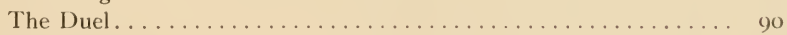

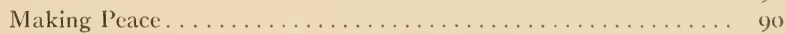

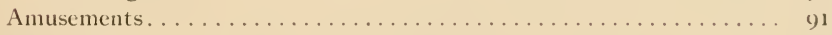

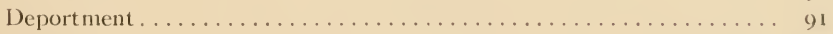

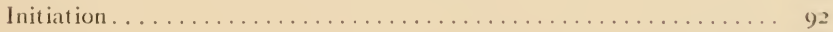

Religion . . . . . . . . . . . . . . . . . . . . . . .

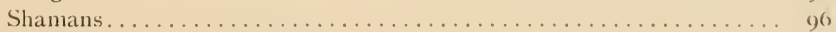

Beliefs Concerning the Dead . . . . . . . . . . . . . . . . .

Mythology . . . . . . . . . . . .

The Haush . . . . . . . . . . . . . . . . . . . . . . . . 100 
Archeology of Eastern Tierra del Fuego .

P.IGE

Camp-sites.

IIO

East-coast Archeological Finds.

\section{PART II-CANOE INDIANS}

The Vahgan ................................. 116

Language . . . . . . . . . . . . . . . . . . . . . . . . $\ldots \ldots \ldots$

Clothing . . . . . . . . . . . . $\ldots \ldots \ldots \ldots \ldots \ldots \ldots \ldots \ldots \ldots \ldots \ldots \ldots$

Ornamentation ..................... 124

The Encampment ........................ 127

Camp Equipment ............................. 129

Tools................................ 139

Boats and Boating. ........................ I 43

Weapons and Methods of Hunting .................. 148

Social Organization. . . . . . . . . . . . . . . . . . . . . 6 .

Kinship...........................

Marriage. . . . . . . . . . . . . . . . . . . 162

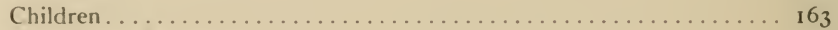

Games and Amusements.......................... $16_{3}$

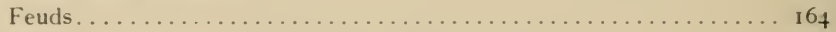

Initiation . . . . . . . . . . . . . . . .

Religion. . . . . . . . . . . . . . .

The Shaman........................... 172

Death . . . . . . . . . . . . . . .

Mythology . . . . . . . .

The Alacaluf . . . . . . . . . . . . . . . . . . . . . . . . . .

Archeology of Southern Tierra del Fuego . . . . . . . . . . . . . I 78

Camp-sites. . . . . . . . . . . . . . . . . . . . .

Archeological Finds. . . . . . . . . . . . . . . . . . . . . 89

Age of Archeological Remains. . . . . . . . . . . . . . . . . . 192

\section{PART III-CONPARISONS AND CONCLLSIONS}

Origin of the Fuegians . . . . . . . . . . . .

Fuegian Culture Status. . . . . . . . . . . . . . . . . . . . . 202

Fuegians Compared with Primitive Europeans............... 202

Fuegians Compared with the Seri...................... 204

Fuegians Compared with the Eskimo.................. 209

\section{APPENDIX}

Ona locabulary . . . . . . . . . . . . . . . . . . .

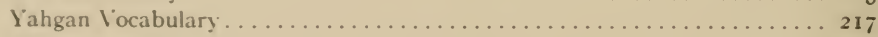

Bibliography. ....................... 2 I9

Index. . . . . . . . . . . . . 


\section{ILLUSTRATIONS}

\section{PLATES}

PAGE

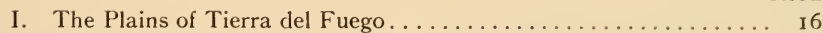

II. Fuegian mountains seen from the Harberton-Lake Fagnano trail. . I 8

III. South coast of Tierra del Fuego . . . . . . . . . . . . . . 20

IV. Ethnographical map of Tierra del Fuego............... 24

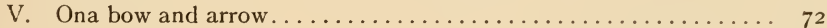

VI. Haush encampment ......................... I06

VII. Stone blades found in corral, Estancia Viamonte........... II 2

VIII. Scrapers.......................... I 4

IX. Yahgan painted decoration . . . . . . . . . . . . $\ldots \ldots$

$\mathrm{X}$. Yahgan scrapers....................... 40

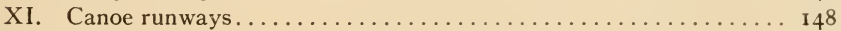

XII. Fish-spear heads. . . . . . . . . . . . . . . . . . . 150

XIII. Ancient Yahgan bows . . . . . . . . . . . . . . . . . $\ldots \ldots \ldots$

XIV. Yahgan ceremonial lodge................... I66

$\mathrm{XV}$. Yahgan heron-plume headbands.................. I68

XVI. Gable Island shellheaps...................... I 80

XVII. Shellheaps on Cambaceres and Varela bays............... I 8 t

XVIII. Kunboto shellheap, Puerto Mejillones................. I 88

XIX. Stone blades, Wápisatumánakulum, Harberton . . . . . . . . . I 90

\section{FIGURES}

1. Magellan discovering Tierra del Fuego.............. 18

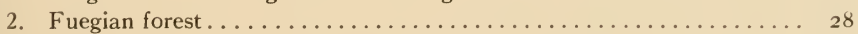

3. Fungi dried on a rod for winter use . . . . . . . . . $\ldots \ldots \ldots \ldots \ldots$

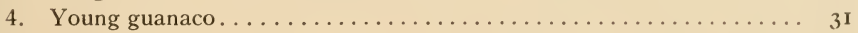

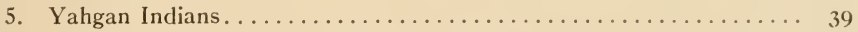

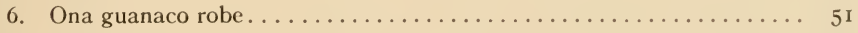

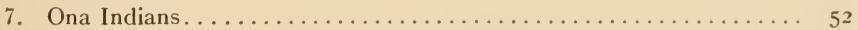

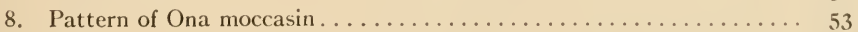

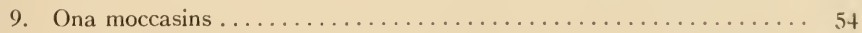

10. Ona headband . . . . . . . . . . . . . 55

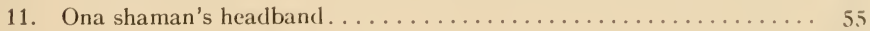

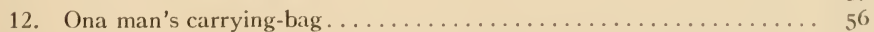

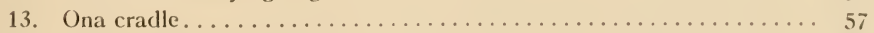

14. Ona braided grass anklet. . . . . . . . . . . . $\ldots \ldots \ldots \ldots \ldots \ldots$

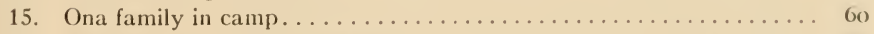

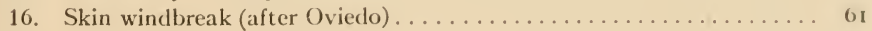

17. Ona family on a journey .......................... 62

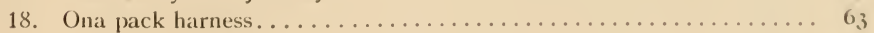


P.IGE:

19. Ona fire-tongs, hide-beater, and $\log$-leash $\ldots \ldots \ldots \ldots \ldots \ldots \ldots . \ldots \ldots$

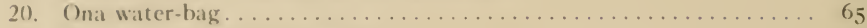

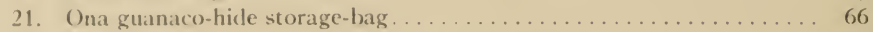

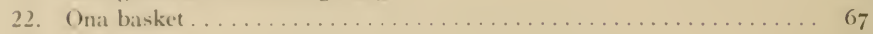

23. Ona knife. . . . . . . . . . . . . . . . 68

24. Ona flesher without lashings.................... 69

25. Ona scraper and flesher. . . . . . . . . . .

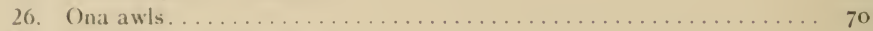

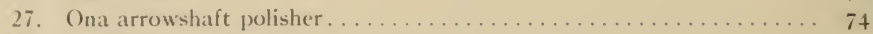

28. Ona polisher of skin...................... 74

29. Thong of guanaco-hide $(a)$; guanaco back sinew $(b) \ldots \ldots \ldots \ldots \ldots 75$

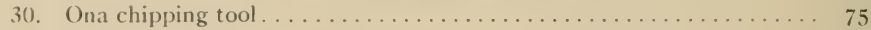

31. Ona sharpening stones. . . . . . . . .

32. Ona and Patagonian arrowpoints................... 77

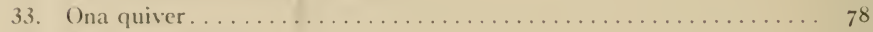

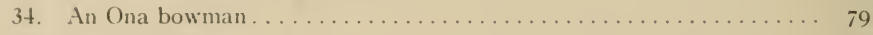

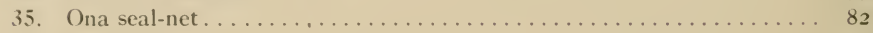

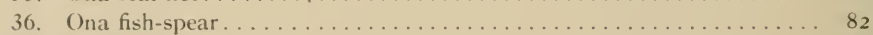

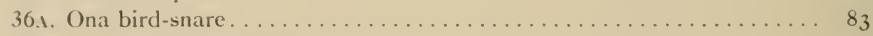

37. Ona wrestling contest . . . . . . . . . . . . . . . . . . . . . . . .

38. Ona ceremonial lodge . . . . . . . . . . . . . . . . 93

39. Abandoned Ona camp . . . . . . . . . . . . . . . . . . . 97

40. Stone blade, Estancia Viamonte. . . . . . . . . . . . . . . . . II3

41. Bola, Estancia Viamonte. . . . . . . . . . . . . . . . . .

42. Yahgan Indian ....................... II

43. Yahgan guanaco cape ................... 122

44. Yahgan pubic covering ..................... I 23

45. Yahgan moccasin. .................. 124

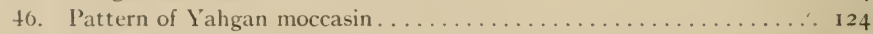

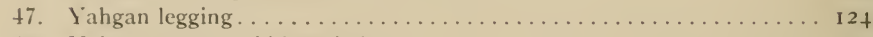

48 . Yahgan guanaco-hide wristlet ................. 125

49. Jahgan shell necklace....................... 125

50. Detail of Yahgan shell necklace................... I 26

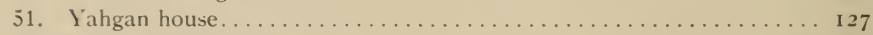

52. Modern Yahgan house. . . . . . . . . . . . . .

53. lahgan fire-making apparatus. . . . . . . . . . . $\ldots \ldots \ldots$

5t. Yahgan combs and seal-throat pouch................... I 30

55. Vahgan bark bucket....................... I 3 I

50. Yahgan women: $(a)$ Rope making; $(b)$ Making a bark bucket...... I 32

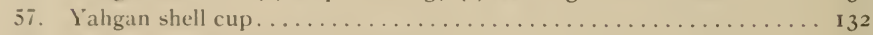

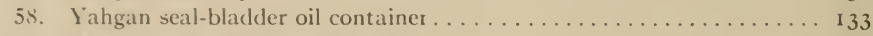

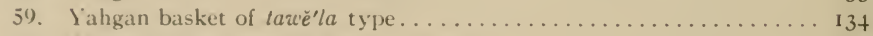

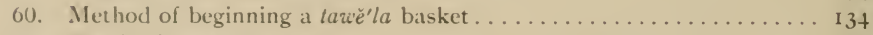

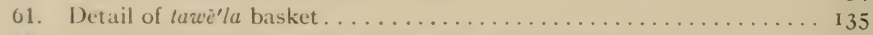

62. lahgan baskets of gaiichim and ulocinastaba types............ 136

63. Detail of ulocinastába basket ..................... I 37

04. Yahgan basket of gaichim type................... 
65. Detail of gaiichim basket....................... I 39

66. Yahgan scraper and whetstone........................ I40

67. Yahgan man's bark-working tool . . . . . . . . . . . . . I I

68. Yahgan woman's bark-working tool................. I4I

69. Yahgan awls and spatula . . . . . . . . . . . . . . . . . . 42

70. Yahgan hammerstone. . . . . . . . . . . . . . . $\ldots \ldots \ldots$ I 2

71. Yahgan pumice polisher . . . . . . . . . . . . . . . . . 43

72. The last Yahgan bark canoe...................... I 43

73. Model of Yahgan canoe. . . . . . . . . . . . . . . . . . . . I 44

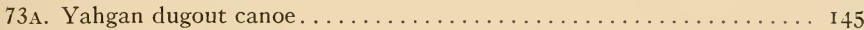

74. Modern Yahgan boat. . . . . . . . . . . . . . . . . . I 46

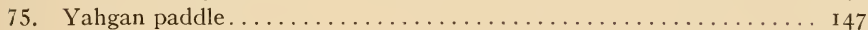

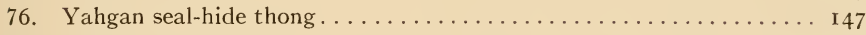

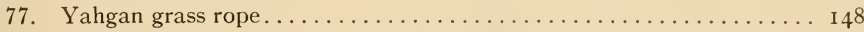

78. Yahgan bark bailer. . . . . . . . . . . . . . . . . . . . 48

79. Yahgan spears. . . . . . . . . . . . . . . . . . . . . . . . 49

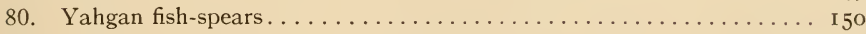

81. Yahgan seal and guanaco spearheads............... I5I

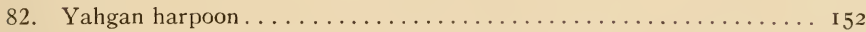

83. Yahgan spearpoint case ...................... I 53

84. Yahgan limpet- and crab-spears . . . . . . . . . . . . . . . . I 54

85. Yahgan bone arrowpoint . . . . . . . . . . . . $55 \ldots \ldots \ldots \ldots$

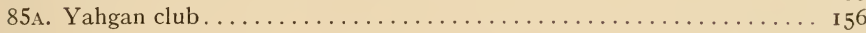

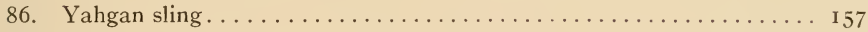

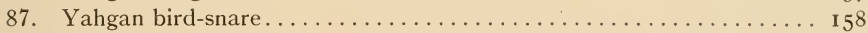

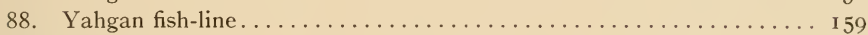

89. Yahgan dip-net. . . . . . . . . . . . . . . $6 \ldots \ldots \ldots \ldots$

90. Eastern Yahgan initiate's headband and scratching-stick (a); Kelpgoose down headband $(b) \ldots \ldots \ldots \ldots \ldots \ldots \ldots \ldots \ldots \ldots \ldots \ldots$

91. Yahgan painted ceremonial wands . . . . . . . . . . . . . I67

92. Yahgan dance masks......................... I

93. Model Yahgan dance masks..................... I7

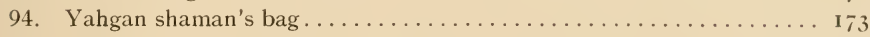

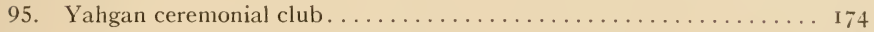

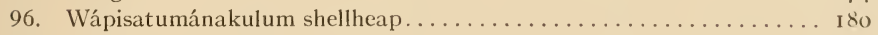

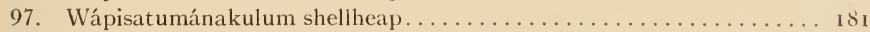

98. Camp-sites and place-names near Harberton . . . . . . . . . . . 1 s 2

99. Approximate cross-section of shellheap 17 , Imiwaia bay . . . . . . I Is5

100. Location of shellheaps on the channel between Gable island and Tierra del Fuego. . . . . . . . . . . . . . . . . . . . . . 8.5

101. Puerto Mejillones and Porto P'iedra shellheaps. . . . . . . . . . . I 86

102. Róbalo bay, Navarin island, showing the location of shellheaps...... I 8 s

103. Akawalakirrh shellheap, Róbalo bay . . . . . . . . . . . . . I s

104. Scrapers from Wápisatumánakulum, Harberton . . . . . . . . . 190

105. Stone blades from various camp-sites. . . . . . . . . . . I9 I 


\section{T.ABLES}

PAGE

1. Fconomically important flora of Tierra del Fuego ............. 29

1I. Fuegian foods.......................... 32

1II. Statistical constants for the Ona and the Yahgan ........... 4 I

IV: Ona relationship terms...................... 85

1. Yahgan relationship terms . . . . . . . . .

11. lahgan camp-sites and huts near Harberton .............. I 84 


\section{PREFACE}

$\mathrm{T}$

1HIS account of the natives of Tierra del Fuego is the result of a three months' visit to the island, accompanied by Mr. J. Linzee Weld, during the summer of 1924-25. We studied Ona Indians at three settlements: one at the southeast corner of Lake Fagnano, one to the northeast of the same lake, and the third lying east of the Laguna de Pescados. Yahgan Indians were encountered at Tierra Mayor, Cambaceres bay, Gable island, and Puerto Mejillones on Navarin island.

Although the time available was short, aids to study were unusual. Thus, Cooper's "Bibliography" offered in a readily available form an accurate analysis of previous work, with an exception to be noted presently. Furthermore, the help of three intelligent white men-Messrs. Lucas and William Bridges and Fred. Lawrence,all intimately acquainted with the Indian lore and languages, made it possible to procure accurate data with unusual celerity and facility. All the information thus obtained was checked by the Indians and vice versa, while just before I left the island $\mathrm{Mr}$. William Bridges most kindly went over all my notes and vocabularies. Therefore I feel confident that they are detailed and accurate.

In planning my work, owing to the limited time available it seemed wise to concentrate on obvious and concrete problems which could be covered with reasonable thoroughness. Although the studies of Gusinde and Koppers ${ }^{1}$ had not then appeared in print, I was told that they had worked chiefly on the religion, initiation ceremonies, folklore, and linguistics. Hence my most profitable course was to devote myself primarily to the material culture and technology. This decision was fostered by the fact that both tribes had been reduced almost to extinction by a recent epidemic of influenza, so that the older men who once took part in native rites had died almost without exception. Secondly, on Beagle channel a thorough examination of camp-sites was undertaken with a view of determining their nature and age so far as

\footnotetext{
${ }^{1}$ Consult the Bibliography in the appendix.
} 
was possible without extensive excavation. In addition, customs and ceremonial practices were noted as opportunity offered. In preparing this account of the Indians I have followed my own notes even when at variance with previous studies; yet I have tried to incorporate enough material gathered by other observers to present a reasonably complete picture, at least of the material culture.

Tierra del Fuego is a land where the frontier traditions of hospitality still reign, so that acknowledgment of the help received seems stiff and formal in the light of the generosity and kindness to be found there. To the Bridges family is due primarily the success of our trip and also a deep debt of gratitude not only for technical and material aid but for kindly hospitality and sumptuous fare on the justly famous Estancia Viamonte. My mouth still waters when I think of poached wild-goose eggs on mutton steak or califate pie with clotted cream. Mr. John Goodall, manager of the frigorifico at Rio Grande, was also a most kindly host. At Harberton Captain and Mrs. Sigurd Nielson, Mrs. John Lundberg, their many children, and Mr. Eric Fugellie not only offered us their unstinted hospitality but supplied every facility for travel and work. At Remolino Mr. Fred. Lawrence was both my host and a mine of information. The American and Belgian consuls at Punta Arenas, Mr. John Sharp and Mr. Charles Kwanten, the latter our traveling companion southward from New York, gave us most useful advice and helped us ship our collections northward. Mr. John IVilliams of Punta Arenas furnished important information. Mr. Thomas Constanduros and Mr. R. H. Oerton motored us across vast stretches of southern Patagonia, while Mr. John Hamilton most kindly allowed us to inspect his large and important archeological collection. I have space to mention but a few of the many who went out of their way to be helpful to us, but to all I give my most sincere thanks. Most particularly I am indebted to Mr. J. Linzee Weld for help and support under circumstances of many kinds and for genial companionship during many months in distant lands.

In this country, I wish to thank Mr. George G. Heye for the opportunity to take a most interesting journey and for making possible this publication. Mr. F. IV. Hodge has both edited and aided in the preparation of the manuscript, as has also my wife. Prof. E. A. Hooton, assisted by Mr. Walter Cline and Miss Barbara Clark, have worked over all available data on somatology, while 
Professor Hooton has most kindly written his impressions of the statistics thus prepared. The American Geographical Society has courteously allowed me to use the base-map prepared by that institution.

Of the illustrations, the drawings were prepared by Mr. William Baake, Mr. Louis Schellbach, and myself, and the maps were drawn by Mr. Schellbach and myself. Through the courtesy of Mr. L. IV. Jenkins and the Peabody Museum at Salem I am able to illustrate two bows housed in that institution. To Mr. John Williams of Punta Arenas I am indebted for a picture of a Yahgan bark canoe. The great majority of the photographs were taken by Mr. J. Linzee Weld and myself in Tierra del Fuego and by Mr. Fred. P. Orchard in New York. Illustrations from other sources are acknowledged in their individual places.

New YORK

S. K. Lothrop

December, 1927 



\section{INTRODUCTION}

$\mathrm{T}$

VIERRA DEL FUEGO and the many adjacent islands are the southernmost inhabited land in the world, a distinction they have enjoyed from time immemorial. Discovered in 1520 by Magellan on the first hazardous voyage of circumnavigation, these wind-swept shores and their savage inhabitants have overwhelmed all European would-be settlers until the last quarter of the nineteenth century. Yet during the long years between discovery and colonization Fuegia did not remain isolated from outside contact, for its storm-vexed waters were traversed by later circumnavigators, by vessels engaged in the China and the Northwest Coast fur-trade, and by tall clipper ships carrying gold-seekers to California.

The Straits of Magellan, the Straits of Le Maire, and the passage of the Horn-all are peculiarly difficult for sailing ships, especially voyaging westward. Even today charts are incomplete and inaccurate; tides range from four to forty-two feet, so strong and vicious currents must be met; anchors, entangled in huge beds of unyielding kelp, may be lost; winters are long, dark, and cold. But above all, storms are common: the mountainous seas off Cape Horn, flowering with foam, and the violent prevailing westerly winds prove a stumbling-block for square-rigged vessels inherently slow in working to windward. "Our passage of the straits [of Magellan] had consumed fifty-one days, and had been effected without accident," writes a nineteenth-century traveler. ${ }^{1}$ Owing to the conditions we have described, many a ship was cast ashore on Tierra del Fuego and other islands, there to be greedily plundered by the Indians.

Sometimes shipwrecked crews were slaughtered or otherwise maltreated. In retrospect it is but just to say that the land was then thickly settled in relation to its food supply, and the Inclians resented any trespassing on their hunting rights, dealing a similar fate to one another under the same provocation. However, the natives of the Magellanic archipelago acquired a dreadful reputation

'Bourne (1853), p. 210. 
for savagery and ferocity, which their uncouth appearance and hardiness no little augmented. Indeed even today Tierra del Fuego is regarded by many of the world's inhabitants as a strange and romantic land, peopled by unmitigated cannibals, inhospitable, forlorn, and barren. The very distance of Tierra del Fuego from the places where most of us live is a gap not easily overleaped by the mind, and indeed this gap is not only geographical, but racial and cultural as well.

The very fundamentals of Europe, racially and culturally, have for the greater part come directly from the Asiatic continent, so that historians in a philosophic vein have assumed that the march of civilization is constantly westward. Ex oriente lux. However, the current anthropological viewpoint is that man developed his peculiar physical and his primitive cultural attributes within the continent of Asia, and, thus primed with hitherto unknown powers to survive and to perpetuate the species, expanded in all directions with great rapidity. This expansion we may liken to the ripples spreading from a stone dropped into a pond, and of such ethnocultural waves the first settlers of Europe and the Fuegians mark the marginal extremes in opposite directions. In other words, until the application of the compass made the oceans a highway instead of a barrier, the western Europeans and the Fuegians were the most widely separated peoples in the world.

To students of human culture the Indians of Tierra del Fuego prove of unusual interest because with such tribes as the Tasmanians they are reputed among the world's most primitive inhabitants. Such isolated and backward peoples may exhibit, through cultural stagnation or degeneration, an early stage in the development of our own and of other complex civilizations. Moreover, the natives of Fuegia afford a clue as to the state of the first men to attain the shores of the Western Hemisphere.

\section{GEOGRAPHY}

The term Tierra del Fuego is loosely applied to the large archipelago lying south of the mainland of South America; more strictly the name is assigned to the main island, shaped like an irregular triangle. It measures about 240 miles along the south coast, the base of the triangle, and 170 miles from north to south.

South of the main island, separated from it by the narrow waters of Beagle channel, are three large islands (Gordon, Hoste, Navarin) 


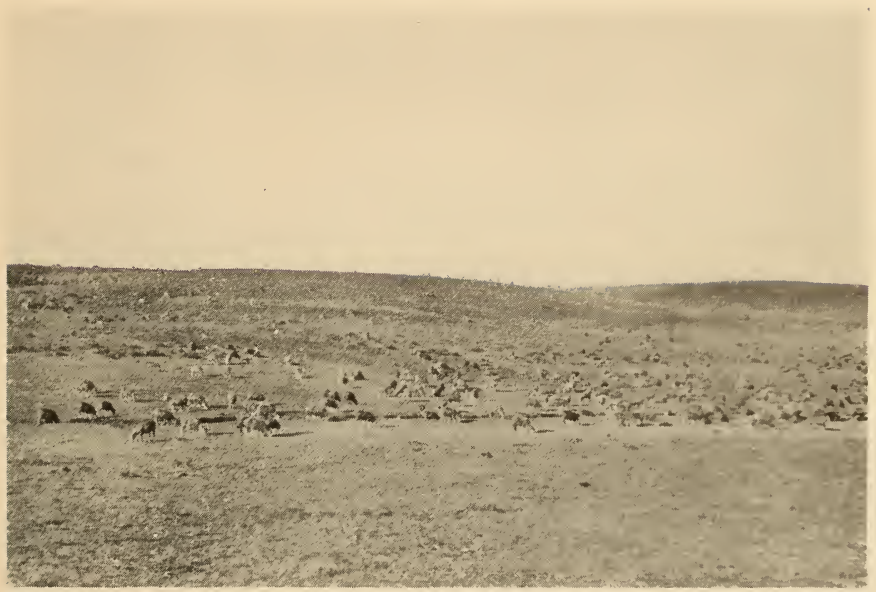

ESTANCIA SEGUNDA ARGENTINA

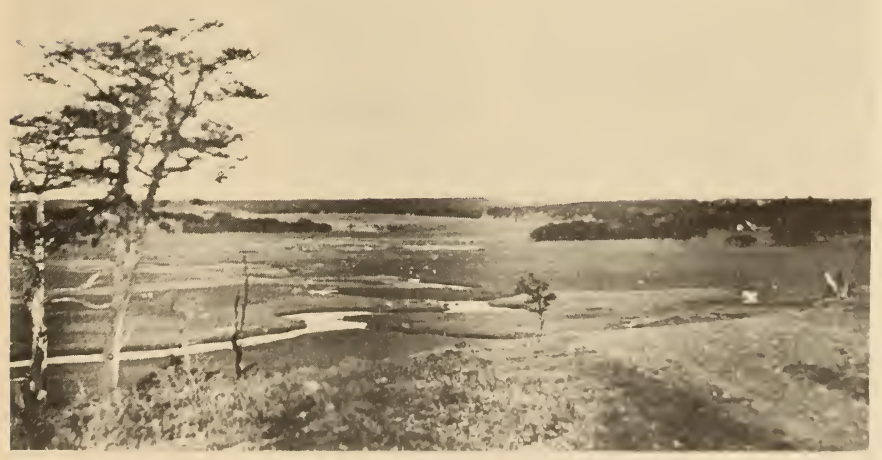

ESTANCIA VIAMONTE, NEAR NEW HARBERTON

THE PLAINS OF TIERRA DEL FUEGo 

and a host of smaller ones (Gable, Picton, Lennox, New, etc.). Still farther south lie the Wollaston islands. Of these the southernmost is Horn island, terminating in the well-known Cape Horn. This isolated, sea-girt landmark faces the unquiet waters of the Antarctic ocean about seventy miles off the south shores of Tierra del Fuego.

Westward from the main island of Tierra del Fuego, across the Straits of Magellan, is the Brunswick peninsula, whose ultimate tip, Cape Froward, boldly marks the end of continental South America. Nearby are Dawson island, Clarence island, Santa Inés island, and others too numerous to mention.

The main island of Tierra del Fuego presents two types of topography: plains and mountains. The northern and eastern parts are a rolling plain, bare except for grass and small bushes, hummocked by glacial ice, of the same Tertiary formation as the Patagonian plains (pl. I). In the northwest the land rises abruptly and Mesozoic rocks appear as in the Pre-Cordillera range in South America. The western and southern coasts are almost completely isolated from the rest of the island by Admiralty sound, an arm of the sea, and Lake Fagnano, a freshwater lake lying in the same axis. Between these two submerged valleys and the Antarctic ocean pass the Andes, which, after running north and south through the continent, here bend eastward to disappear beneath the waters of the South Atlantic. Their peaks in Tierra del Fuego reach an average height of 3500 feet, but numerous passes exist at about the 2000-foot level, where snow-pockets linger even in summer (pl. II). Glaciers nourished by beds of eternal snow creep to the sea on the west and south.

The Magellanic archipelago then falls in three geographic entities, and each of these was occupied not long ago by corresponding kinds of Indians, speaking unrelated tongues. These divisions are: (1) Tierra del Fuego, occupied by the Ona and IIaush; (2) the southern islands and the south shore of Tierra del Fuego (pl. III), peopled by the Yahgan; and (3) the western islands, where lived the Alacaluf. The Yahgan and Alacaluf were separated by Brecknock peninsula, a barren headland, sea-girt, with no protecting island fringe, and therefore exposed to the full fury of storms sweeping across the Pacific ocean. 


\section{CARTOGRAPHY}

After the discovery, Tierra del Fuego fell heir to a veil of romantic mysticism spun long ago by Grecian philosophers and embroidered by scholars of the Middle Ages, for it became linked with the fabulous Terra Australis, the antichthon or counter-world of the ancients. Here, it was reasoned, dwelt the Antipodes, who walked foot to foot with the peoples of Europe, in a land where the trees grew downward and the rains and snows fell upward. With the coming of Christianity this postulated continent was banned by

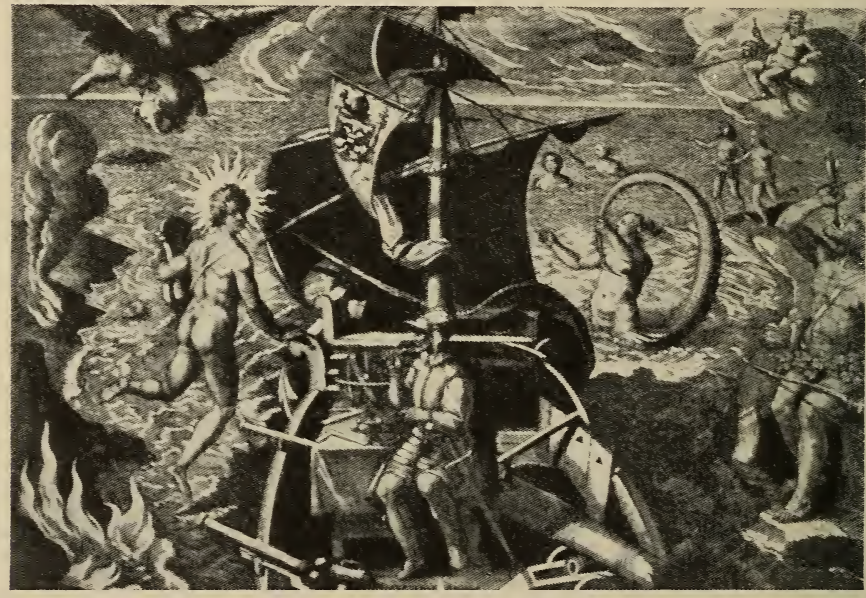

FIG. 1.-Magellan discovering Tierra del Fuego.

the church, ${ }^{1}$ for theologians were "scandalized by the suggestion that somewhere on the face of the sphere there existed a race of men who were not of the seed of Adam, and therefore outside the scope of human redemption."'2 Yet belief in this southern continent did not die, but lingered in men's minds. Dante placed his "Hill of Purgatory" in the center of a southern continent.

With the discovery of the Straits of Magellan an accomplished fact, European geographers believed that the Terra Australis of

${ }^{1}$ Augustine, De Civitate Dei, xvi, 9: "Quod vero et Antipodes esse fabulantur, id est homines a contraria parte terrae ubi sol oritur quando occidit nobis, adversa pedibus nostris calcare vestigia, nulla ratione credendum est."

2 Payne, History of the New World called America, I, p. 45. 


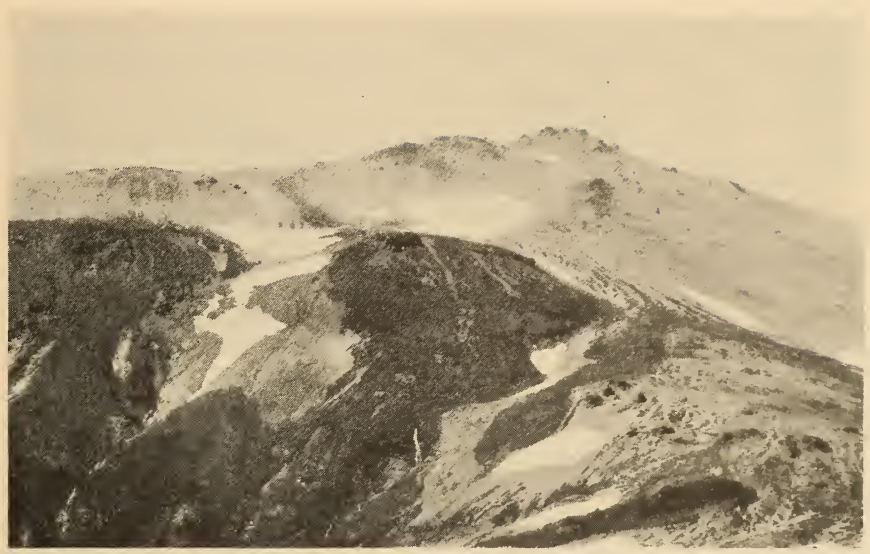

NORTH CREST OF THE PASS

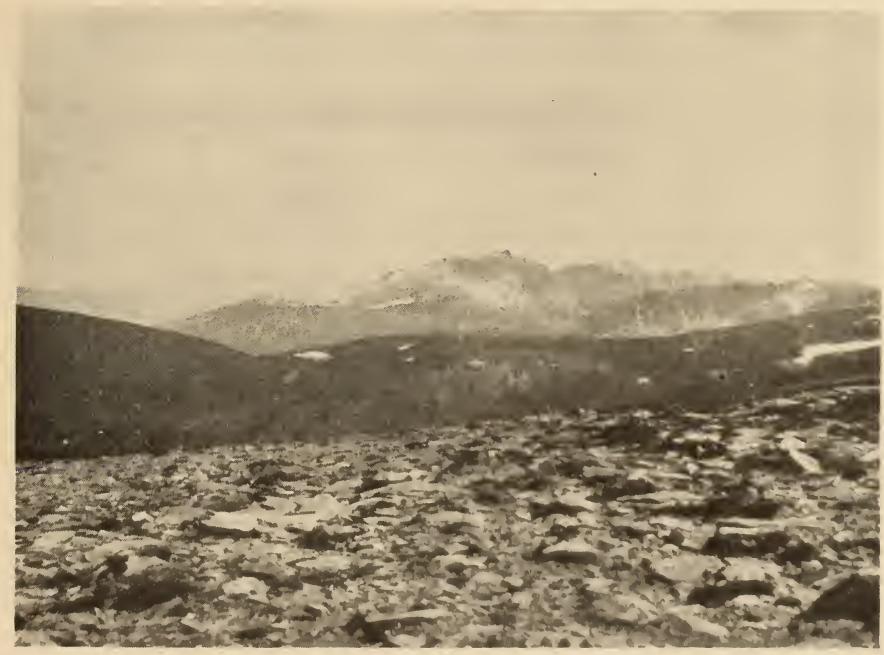

SOUTH CREST OF THE PASS

FUEGIAN MOUNTAINS SEEN FROM THE HARBERTON LAKE FAGNANO TRAIL 

the ancients had emerged from the realm of fancy, and they showed Tierra del Fuego on their maps as part of a vast circumpolar antarctic continent, separated from South America by the straits Magellan discovered. The vagueness of their ideas is brought out by illustrations such as fig. 1, which pictures an elephantbearing roc in flight over the masthead of Magellan's Victoria, while enticing mermaidens disport alongside in the waters called Pacific from a rare moment of tranquillity.

That the cartographers were at fault might soon have been suspected, for in 1526 one of the ships under the command of Loaysa ran southward along the east coast of Tierra del Fuego to "where it appeared there was an end to the land." 1 In 1540 one of the ships of Camargo sailed through the Straits of Le Maire and passed the winter somewhere on the south side of Tierra del Fuego, perhaps in Beagle channel, before returning to Spain. The name of this ship and of its captain is unknown, but part of the $\log$ has been preserved. ${ }^{2}$ Neither of these voyages, however, attracted the attention of geographers. In 1578 Sir Francis Drake, having successfully passed the Straits of Magellan, was blown southward from Cape Pilar to the Wollaston islands, and the result of his unwilling course is reflected in a map published in Amsterdam by Cornelius Clarz in 1598. In 1616 the Dutchmen Schouten and Le Maire weathered the surf-ringed headland which they named Cape Horn, and, continuing their voyage across the Pacific, thereby definitely established that Tierra del Fuego is an island. When this voyage came to the attention of the Spanish crown, its importance was at once admitted, because it opened to the Far East a road over which Spain had no claim. Hence an expedition was despatched in 1619 under the brothers Nodal to gather exact information for their government. The resultant voyage was favored with fortune and the ships were the first completely to circumnavigate Tierra del Fuego, and also, I believe, the first to complete a voyage in Magellanic waters without loss of life. In 1643 another Dutchman, Brouwer, sailed along the eastern and southern coast of Staaten island. With this voyage the unreality of an antarctic continent near South America was fully established, yet the misconception, or at any rate the old

\footnotetext{
1 Relación of Andrés de Urdanete, in Fernández de Navarrete's Colceción de los V'iages y Descubrimientos, v, p. 402, Matlrid, 1837.

${ }^{2}$ Early Voyages to the Straits of Magellan, Sir Clements Markham, tr. et ed., Hakluyt Soc., ser. 11, vol. xxvin, I.ondon, 1911.
} 
map plates, persisted in Europe until well into the eighteenth century. For instance, the map in the 1730 edition of Herrera's Descripción depicts Tierra del Fuego as extending indefinitely to the south.

Traditionally Tierra del Fuego received its name from the flickering lights of camp-fires seen by Magellan. A variant tale is that Magellan called it Tierra del Humo, "Land of Smoke," and that Charles $V$ changed the name to Tierra del Fuego, jocosely remarking that where there was smoke there must be fire. However, I suspect that some idea of Dante's Purgatory underlies the name, because an active volcano (actually non-existent) appears on maps of the sixteenth, seventeenth, and even eighteenth centuries. I have before me a 1799 edition of Anson in which the map shows a "Volcan de Brandende Berg" in active eruption on the south coast of Tierra del Fuego.

\section{HISTORY AND LITERARY SOURCES}

In the preceding section we have mentioned several voyages, which were of importance in the development of geographical knowledge. This list might be greatly extended. Fagalde (1901) summarizes more than fifty voyages of scientific interest, completed before the end of the eighteenth century, but unfortunately with all ethnological data omitted. Much of this information may be gleaned, however, from De Brosses' Histoire des Navigations or Barclay's The Land of Magellan. Yet in truth it must be said that early contact with the natives was casual and brief, while the descriptions of ethnological significance apply usually to Indians north of the Straits of Magellan.

During the second half of the eighteenth century a general awakening to the importance of scientific investigations permeated Europe, with the result that various scholars were despatched to Latin America by the Spanish government. Fuegian waters were visited at this time by several surveying parties, and the basis of an accurate knowledge of the region was laid down. The general results of these investigations will be found in De Vargas Ponce's Relacion. With the rise of Napoleon, however, Spain had no resources to spare for continuing this work, while the collapse of Spanish authority in the New World brought a definite end to it.

Great Britain had emerged from the Napoleonic wars as the dominant sea power. With growing colonial and commercial 

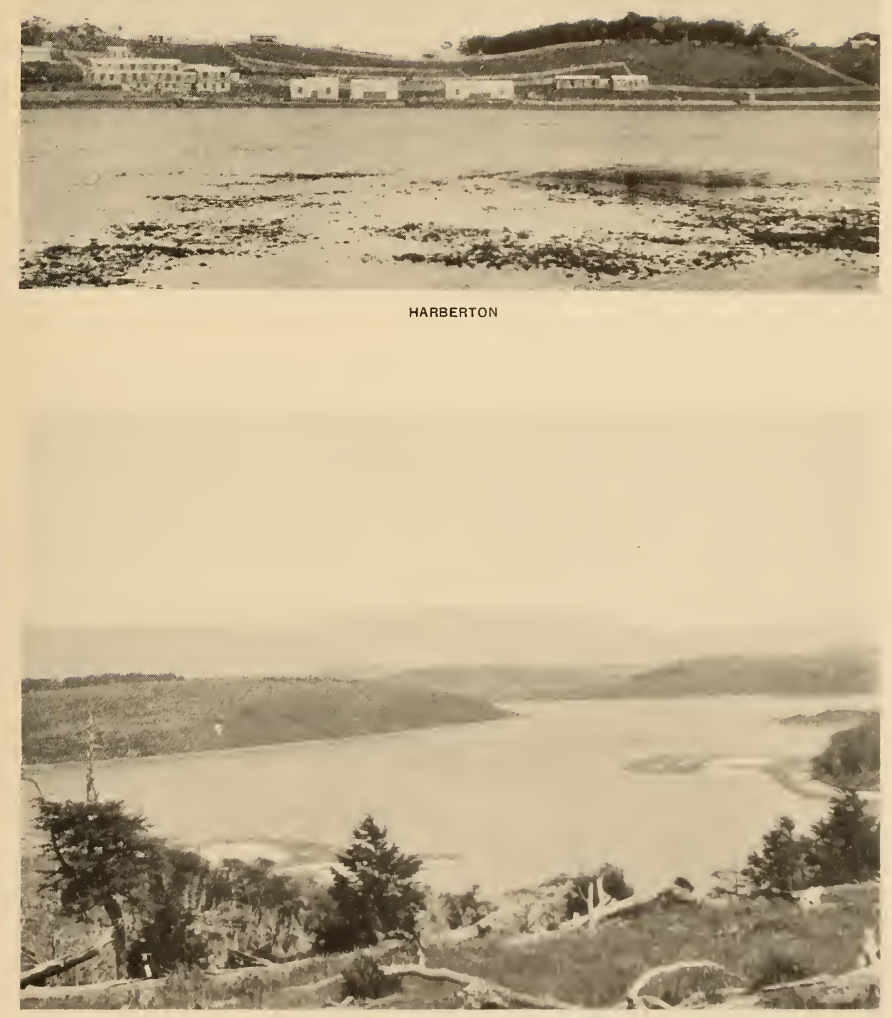

IMIWAIA BAY WITH BEAGLE CHANNEL AND NAVARIN ISLAND IN THE DISTANCE SOUTH COAST OF TIERRA DEL FUEGO 

interests in the Far East, the route thither by way of Tierra del Fuego became a matter of national importance, so that surveying expeditions under the command of Captain King and later Captain Fitzroy were despatched to Magellanic waters. ${ }^{1}$ Captain Fitzroy brought back to England after his first voyage a Yahgan and three Alacaluf Indians. On his second voyage he was accompanied by Charles Darwin, the celebrated naturalist. The era of exact and scientific study of the natives of Tierra del Fuego was thus initiated.

Fitzroy's and Darwin's account of the Fuegians attracted wide notice in England, while the primitive society, destitution, and ferocity they pictured engendered a desire to Christianize that far-off people. The public in England were further roused by the fate of Captain Allen Gardiner and his companions, amateur missionaries who died of privation and exposure under tragic circumstances in $1851 .^{2}$ As a result the South American Missionary Society was organized and a mission station was set up on Keppel island (IVest Falklands). In 1856 this station was placed in charge of Canon G. Pakenham Despard, who brought with him a thirteen-year-old adopted boy, Thomas Bridges. Young Bridges soon learned to speak the Yahgan tongue fluently. In 1869 he returned to England, where he was ordained and married. The following year he founded at Ushuaia the first mission station on Tierra del Fuego. With him he brought as an assistant John Lawrence. ${ }^{3}$ After many years' labor as a missionary $\mathrm{Mr}$. Bridges retired, and in recognition of his services in opening up the country was given a land grant at Harberton by the Argentine government where he raised sheep. Mr. Lawrence received a similar grant at Remolino.

Bridges and Lawrence children were born on Beagle channel on the south coast of Tierra del Fuego, and were reared in close association with the Yahgan Indians. The Lawrence family, who still live at Remolino, today have an unsurpassed knowledge of Yahgan customs and linguistics. The Bridges brothers, as they grew up, began to explore to the north and east across the mountains, and finally secured for themselves a vast property on the east coast, today a flourishing sheep ranch known as the Estancia

\footnotetext{
1 See Narrative of the Surveying Voyages of H. M. S. Adventure and Bergle, 3 vols., London, 1839.

${ }^{2}$ For a full but sentimental account of this event see Jesse l'age, "Captain Allen Gardiner," London, 11.d.

${ }^{3} \mathrm{~A}$ full account of these events is given in the booklet by John U. Marsh, First Fruits of the South American Mission, London, 1873.
} 
Viamonte. Their peregrinations through the heart of the island brought them in close contact with the Ona tribe. Indeed, they were the first white men to establish friendly relations with the Ona, and two of the brothers, Messrs. Lucas and William Bridges, have been formally initiated as members of the tribe by the klókten ceremony herein described.

We have related this story at some length because so much literature of ethnological interest depends on it. The elder Mr. Bridges has left among his reports to the missionary society a mine of ethnological information, while Mr. Lawrence's observations are also valuable. In addition Mr. Bridges has written several articles dealing directly with native life, published in various scientific journals, and he has left a monument to himself in what is probably the most intensive study of primitive linguistics ever carried out. Of this we shall have more to say.

Beside the contributions from the pen of Mr. Bridges, he aided greatly the success of the scientific studies made by the Argentine, French, and Italian governments in Tierra del Fuego during the last quarter of the nineteenth century. The important works of Hyades and Bove gain authority from this association. In recent years the Bridges' children, especially Messrs. Lucas and William Bridges, have sponsored practically all the information about the Ona tribe which has found its way into print. Indeed (without detracting from the merits of any writer) it may be said that the importance of most published data on the Ona varies according to whether or not the information was obtained from this generous and hospitable family.

After the Argentine government had established itself at Ushuaia a gold rush to Tierra del Fuego took place, which caused the coming of many undesirables. The result of this sudden contact with Europeans was disastrous to the native tribes.

The history of white settlement of the island emanating from the missionary post in the south is one of kindly dealing with the native races. Unfortunately the same cannot be said for the north. Sheep were introduced into the northern part of Tierra del Fuego in 1878, and trouble with the natives immediately ensued, for while the Indians had no objection to somebody stocking their game tracts, at the same time they maintained their right to hunt the "white guanaco" on lands which they regarded as their own. Naturally the hard-pressed pioneers of what has now become a 
great industry objected to having their sheep killed, and they retaliated by killing the Indians.

Thus there soon sprang into being a class of professional headhunters, recruited from the shepherds and miners, who received one pound sterling from the ranchers for each Indian head-man, woman, or child. The Indians, on foot and armed with bows and arrows, had little chance in the open plains against horsemen with rifles. Some of the atrocities committed in the ' 80 's are recounted by Fuentes Rabe; ${ }^{1}$ the writer heard from discrete and trustworthy sources many similar tales of brutality.

In 1891 a Salesian mission was established on Dawson island, and in 1893 a second station was set up at Cape Peñas and later transferred to Rio Grande. Although dedicated for three-quarters of a century to the eradication of troublesome Indians, the Government decided to stop the scandals arising from head-hunting by turning the Indians over to the missions. To this end troops scoured the country, rounded up the natives, and drove them like cattle to the mission stations. Families were mercilessly broken up. Strange foods caused sickness and implanted the belief that they were being poisoned. Unaccustomed European clothes and indoor quarters - as in so many well-intended missionary effortsbrought pneumonia and tuberculosis, and augmented the effect of their vitamin-deficient diet. Liquor and venereal diseases, against which Indians have surprisingly little resistance, both took their toll. Few indeed survived the "civilizing" process. Today the Dawson Island mission has been abandoned. The east-coast mission still existed in 1924 , ostensibly to support two aged native women in idleness, in reality as a prosperous sheep ranch.

The record of the white settlers in Tierra del Fuego, with of course certain splendid exceptions, is not one to be reviewed with pride; not the Indians but Europeans have proved the greater savages. Missionary efforts, however well intended, have hastened the course of their neophytes to the grave. No more striking example can be adduced of the importance of anthropological and medical training for those who would change the religion and alter the habits of heathen peoples.

One of the chief ethnological results of the northern missions has been the establishment of the Museo Rejional "Milyorino Borgatello" at Punta Arenas. Infortunately the ethnological

\footnotetext{
1 1923, II, 177-183.
} 
section of this institution, especially rich in Alacaluf and Ona material, has never been adequately organized, so that in 1924 it was musty, moth-eaten, and unlabeled. A more permanent result of the Salesian efforts is the detailed linguistic study of Father José Maria Beauvoir. Also we must mention the most extraordinary photographic record of Alberto M. De Agostini.

A more detailed discussion of Fuegian anthropological literature by the present writer would be superfluous in view of the very thorough and critical study published in 1917 by the Reverend Dr. John M. Cooper, now of the Catholic University of America at Washington. In the appended bibliography I have listed those works to which reference is made in this volume and have added thereto all the titles I can find which have appeared in the last ten years in order to form a supplement to Father Cooper's admirable treatment of the subject.

\section{THE INDIANS OF TIERRA DEL FUEGO}

The natives of Tierra del Fuego were divided into three linguistic stocks or four tribal groups known to modern students as the Ona and Haush, Yahgan, and Alacaluf (pl. Iv). These terms, of which variously spelled versions are found, come for the greater part from the Yahgan tongue because of the early missionary contact with that tribe. Haush is an Ona word. Alacaluf seems to have been employed by the group thus named to designate themselves and was also used by the Yahgan. The intertribal nomenclature is as follows:

\begin{tabular}{lll} 
EngLish & YAHgan & \multicolumn{1}{c}{ ONa } \\
Yahgan & Yámana ${ }^{1}$ & $\left\{\begin{array}{l}\text { Wówun (man) } \\
\text { Aílen (woman) }\end{array}\right.$ \\
Ona & Óna & Shílknam \\
Alacaluf & Alacaluf & Aírro \\
Haush & Italum Óna & Haúsh
\end{tabular}

\footnotetext{
${ }^{1}$ In recent years several writers have used this word to designate the tribe in place of the older term Yahgan. Were the tribe to be named for the first time, current practice would dictate the choice of Yamana, but Yahgan has been the accepted name of the group for many years and is found in most ethnological literature; hence I have continued to use it. For similar reasons I have used Ona instead of Shilknam ${ }^{n}$. Likewise I have retained the tribal name Alacaluf in place of the recently introduced and no doubt more phonetically correct Halakwúlup. Such changes of terms long recorded in print form a stumbling-block to the general reader and at the same time contribute little or nothing to the specialist.
} 


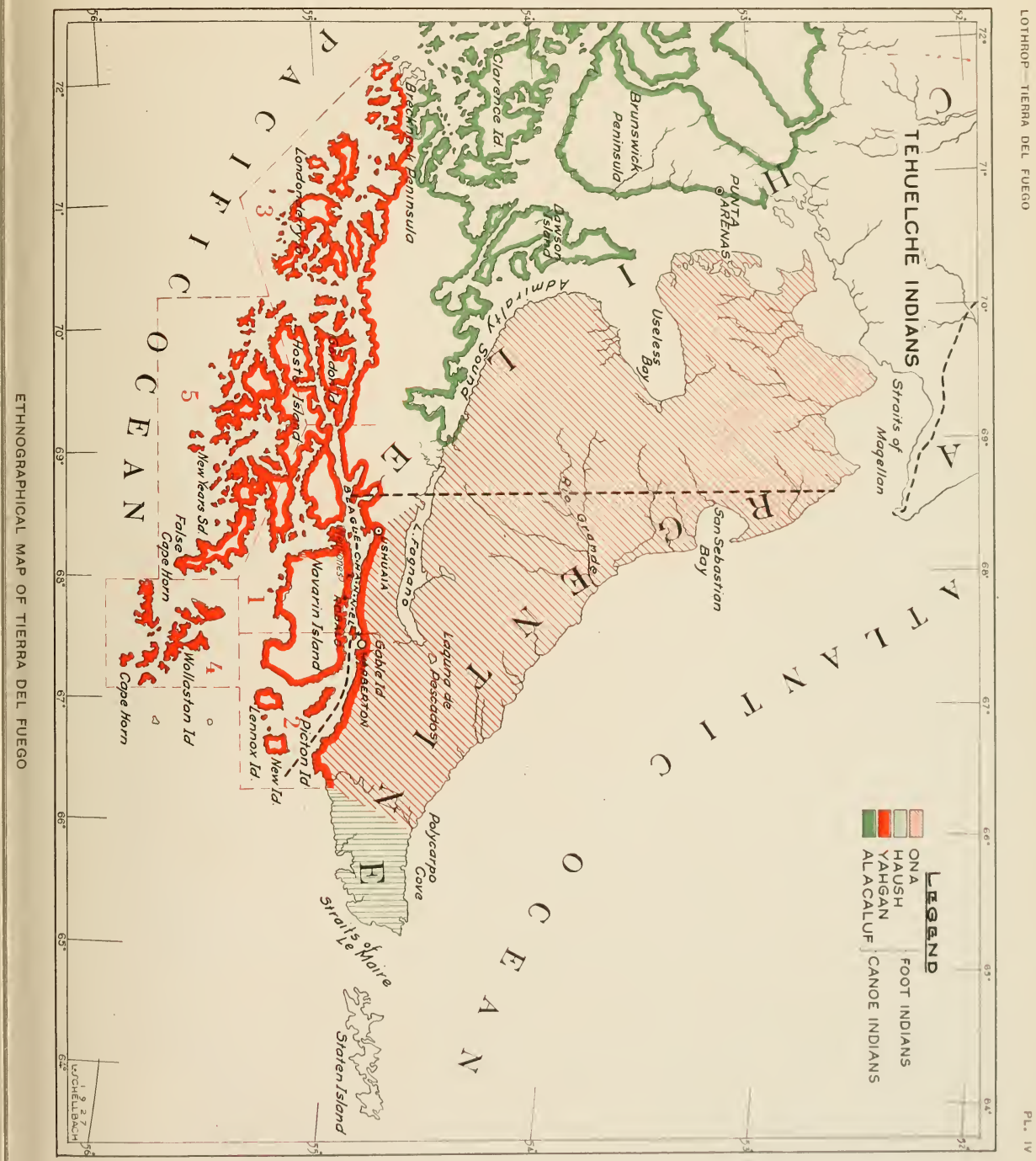



The Ona and the Haush spoke related dialects and occupied the interior of the main island of Tierra del Fuego; they are often called the Foot Indians because of their manner of living. The Yahgan frequented the south coast of the main island and the islands to the south; the Alacaluf formerly lived at the western end of the Straits of Magellan but have moved northward to Ración sound. The habitat of each tribe as it was half a century ago is shown in pl. IV.

No census of the indigenous population in the old days was ever taken, but from several different estimates the numbers of each tribe seventy-five years ago were approximately:

Ona, 3600

Haush, 300
Yahgan, 2800-3000

Alacaluf, 3500-4000

Since at least half of the Alacaluf lived north of the Straits of Magellan, the total native population of Tierra del Fuego and the adjacent islands can scarcely have been more than 9000 .

At the time of the writer's visit (1924-25) the Indian population, including mixed-bloods, was approximately:

$$
\begin{aligned}
& \text { Ona, 60-70 } \\
& \text { Haush, 2- } 3 \\
& \text { Yahgan, 40-50 } \\
& \text { Alacaluf, } \quad 150
\end{aligned}
$$

Of the Alacaluf only two were seen south of the Straits of Magellan, as they now live far to the north, for the greater part in the vicinity of Ración sound. The figure for their numbers is the estimate of the Rev. John Williams of Punta Arenas.

Later in the same year (1925) an epidemic of measles ravaged Tierra del Fuego. What happened to the Yahgan I do not know, but Mr. William Bridges wrote me that more than twenty adult Ona and an unknown number of children had died. With the exception of a few mixed-bloods the Indians of Tierra del Fuego are probably extinct.

Because the writer saw little of the Alacaluf and Haush, it is principally of the Ona and Yahgan we shall speak below. Before beginning a detailed description we shall discuss their environment and physical peculiarities, and shall list the features of their culture.

\section{CLIMATE}

Tierra del Fuego lies between $53^{\circ}$ and $56^{\circ}$ south latitude, corresponding to the position in the northern hemisphere of the Aleutian islands, southern Labrador, or the central part of Great Britain. 
The shores of Tierra del Fuego are washed by an Antarctic current which ranges in temperature during the year between $40^{\circ}$ and $50^{\circ}$ Fahrenheit. Hence the land temperature is low, but there are no great extremes.

Let us examine some figures. At Ushuaia, the southernmost town in the world, according to Argentine government reports the mean summer temperature is $50^{\circ}$ Fahrenheit, while the winter mean is $25^{\circ}$. In summer the thermometer rarely registers above $65^{\circ}$, yet in winter the mercury seldom falls below $10^{\circ}$. At Punta Arenas on the Straits of Magellan the summer mean is $51^{\circ}$ and the winter mean is $28^{\circ}$. Although I have no figures to support the assertion, I believe the eastern side of the island is colder than the western.

As to rainfall, at Ushuaia it amounts to 24.8 inches annually, while in Punta Arenas there are 16 inches, to which must be added 14 inches of snow. In the east rain is more frequent, and about 50 inches are said to fall on Staaten island annually. It is quite surprising that the comparatively light rainfall of Ushuaia and Punta Arenas should foster the growth of forests almost tropical in their density. The controlling factor probably is the feebleness of evaporation, owing to low average temperatures.

The figures cited for rainfall and temperature show that extremes are absent from Tierra del Fuego, yet they do not give a just picture of the climate as it affects human life. For instance, the writer witnessed snowfalls at sea-level in December, January, and February, the three summer months. Two of Captain Cook's men were actually frozen to death near Good Success bay on the night of January 16, 1769. ${ }^{1}$ To be sure, Cook's men may be criticized with some justice for allowing night to overtake them in a strange land at a place where no firewood was nearby; yet the incident shows that even in the Fuegian summer one must prepare to face cold. In winter, snow piles deep in the wooded portions of the island, but on the open plains it often turns to sheet-ice.

In some years the frosts never leave the ground in Tierra del Fuego. Grains never ripen except occasionally in the vicinity of Porvenir on the north coast.

Owing to the ecliptic orbit and inclined axis of the earth, summer is eight days shorter and winter eight days longer in the southern than in the northern hemisphere. The upper photograph in pl. II

\footnotetext{
${ }^{1}$ See Hawkesworth, II, chap. IV.
} 
was taken at an elevation of 2020 feet on December 22. It shows midsummer snow-pockets above the tree-line at an elevation of only 1800 feet. At 3000 to 3500 feet one reaches fields of eternal snow from which numerous glaciers descend to the sea. Glaciers reach sea-level not only in Tierra del Fuego but for hundreds of miles northward on the west coast of Chile, as far in fact as the Gulf of Peñas, which corresponds in latitude to the position of Duluth, Seattle, Budapest, or Geneva. This is about 1250 miles nearer the equator than the most southerly coastal glacier in Norway.

In addition to cold, wind is an unfavorable factor on human life in Tierra del Fuego. Cape Horn gales are world famous; squalls are sudden and savage; even the prevailing westerly winds blow with enough vigor to make life in the open unpleasant. To the Foot Indians of the interior the winds were more disagreeable than dangerous, but to the Canoe Indians they were fraught with peril. Not only might treacherous williwaws sweep from the mountains to overwhelm their bark canoes, but prolonged gales might isolate them on barren islands for days or even weeks till they starved to death.

The picture we have painted of the Fuegian climate is a most unpleasant one. In the mind of the writer it is mitigated by the memory of warm summer days with motionless air and brightly shining sun. On such days sea-bathing is no more uncomfortable than on the coast of Maine or the English channel. However, one must pick a place where the incoming tide sweeps across sunwarmed sands.

The most unusual aspect of the Fuegian summer climate is the rapidity with which it changes. At one moment it will be a clear bright day with no wind, while half an hour later it may be blowing a gale and snowing. This summer climate-except for the rapid changes-is not unlike a New England October, blessed with "Indian summer" and not infrequent frosts. It is bracing and invigorating, however, and in Tierra del Fuego causes both men and animals, domestic or foreign, to grow robustly.

When the climate of Tierra del Fuego has been pictured, the most unfavorable aspect of the environment on human beings has been described, for the flora and fauna both supply many economic assets to the inhabitants. 


\section{FLORA}

The northern and eastern parts of Tierra del Fuego, as we have said, are open rolling plains covered with short grass and small shrubs. South of the Rio Fuego small clumps of trees surrounded by grass-lands are encountered. These clumps gradually increase in size and height until they finally form a solid forest broken only by pantanos, or peat-bogs, which are found in the valley bottoms and above the tree-line on the mountainsides. All the slopes of the Andes up to an elevation of 1400 feet or more, the south coast, and the nearby islands are covered by forest. And these forests

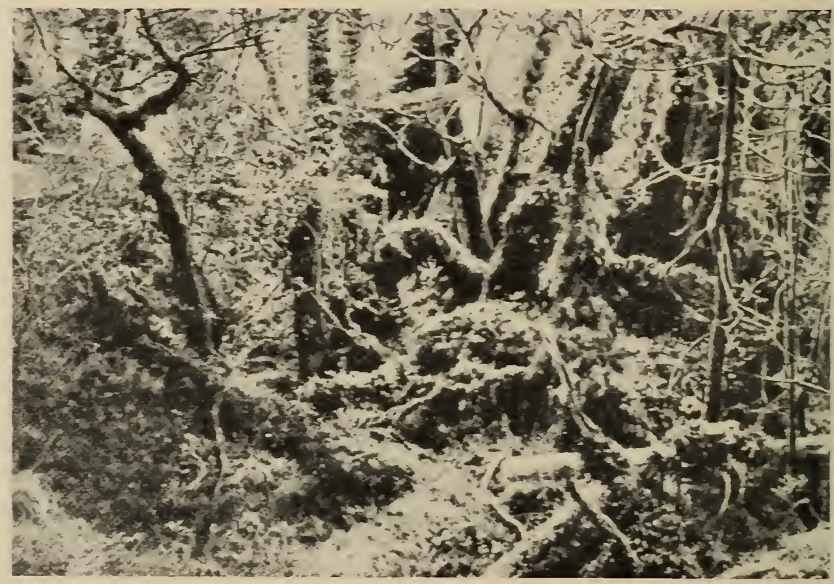

FIG. 2.-Fuegian forest. (From Alberto De Agostini, I Miei Tiaggi nella Terra del Fuoco.)

are surprisingly dense, damp, luxuriant, and impenetrable (fig. 2). Fostered by snow-fed streams and mists, dampness encourages the growth of lichens, mosses, fungi, and orchids. Travel through virgin woods is impeded by fallen trunks, thick underbrush, and mud, but, owing to the relative absence of spiny growth, is not so disconcerting as in the tropics.

The trees and bushes of prime economic use to the Indians we list below. The various purposes to which they are put we shall discuss together with the manufacture of the articles used by the Indians. These trees and shrubs are: 
TABLE I.-ECONOMICALLY IMPORTANT FLORA OF TIERRA DEL FUEGO

\begin{tabular}{|c|c|c|c|c|}
\hline ENGLISH & SPANISH & LATIN & ONA & YAHGAN \\
\hline $\begin{array}{l}\text { beech } \\
\text { beech } \\
\text { beech }^{1} \\
\text { pickwood } \\
\text { Winter's bark } \\
\text { cypress }\end{array}$ & $\begin{array}{l}\text { ñire } \\
\text { coiguë } \\
\text { roble } \\
\text { leña dura } \\
\text { canelo } \\
\text { ciprés }\end{array}$ & $\begin{array}{l}\text { Nothofagus antarctica } \\
\text { Nothofagus betuloides } \\
\text { Nothofagus pumilio } \\
\text { Maytenus magellanica } \\
\text { Drimys winteri } \\
\text { Libocedrus tetragona }\end{array}$ & $\begin{array}{l}\text { charn }^{\mathrm{n}} \\
\text { yínyon } \\
\text { kawaltchénk } \\
\text { haíko }{ }^{2} \\
\text { chóel }\end{array}$ & $\begin{array}{l}\text { kurtúran } \\
\text { súschi } \\
\text { hámo } \\
\text { aíaku }{ }^{2} \\
\text { ukúshta }\end{array}$ \\
\hline $\begin{array}{l}\text { holly } \\
\text { barberry } \\
\text { barberry } \\
\text { fashine } \\
\end{array}$ & $\begin{array}{l}\text { chaura } \\
\text { califate } \\
\text { califate } \\
\text { ciruelillo }\end{array}$ & $\begin{array}{l}\text { Pernettya mucronata } \\
\text { Berberis buxifolia } \\
\text { Berberis ilicifolia } \\
\text { Chiliotrichum amelloideum } \\
\text { Embothrium coccineum }\end{array}$ & $\begin{array}{l}\text { yahn }^{\mathrm{n}} \\
\text { metq } \\
\text { góorrh } \\
\text { shíterhén }\end{array}$ & $\begin{array}{l}\text { gus } \\
\text { úmash } \\
\text { chélia } \\
\text { yéya } \\
\text { mŭ'gu } \\
\text { upúsh }\end{array}$ \\
\hline grass & juncos & Juncus magellanicus & tai & mápi \\
\hline fungus & - & Cyttaria darwinii & yóken & awachiq \\
\hline
\end{tabular}

Although the Indians of Tierra del Fuego subsisted chiefly by hunting and fishing, they did not overlook the food value of various berries which grow on the island. Of these the most easily obtainable is the barberry, which flourishes everywhere. It is a variety different from the red-berried barberry (Berberis vulgaris) found in northern climes, for it looks and tastes not unlike our blueberry and makes an excellent stewed fruit. Then there is the red berry of an arbutus, similar to our cranberry in size and shape but rather tasteless; also what is locally called a "strawberry" (Rubus geoides) looks like a raspberry, tastes like a blend of peach and papaya, and grows half underground.

The Ona are said to collect grass-seeds (called tai) which they grind to a paste and eat, but this I did not see.

There are ten or more kinds of fungi on Tierra del Fuego, which, according to Rev. Thomas Bridges (1886), were eaten at various times of year by the Yahgan. Of these the most important both to the Ona and the Yahgan was a brilliant orange growth ( $C$ yttaria darwinii) found on beech trees. When ripe, it is mucilaginous and rather insipid. The Yahgan still dry this fungus on rods and preserve it for winter use (fig. 3). Darwin remarks that since

1 This tree is an evergreen.

${ }^{2}$ Word-borrowing is suggested by the similarity of Ona and Yahgan terms. 
the introduction of the potato to New Zealand, Tierra del Fuego is the only part of the world where cryptogamic plants form the chief vegetal diet.

However, the Fuegian Indians failed to utilize many native food plants of value, such as wild celery, two kinds of cress, wild seapink, wild parsnip, scurvy grass, and mushrooms.

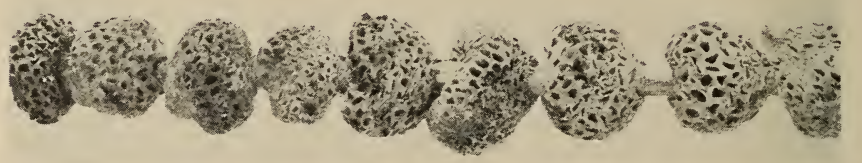

FIG. 3.-Fungi dried on a rod for winter use. Length, 8 in. (14/2279)

No description of the flora of Tierra del Fuego can omit mention of the gigantic kelp (Fucus giganteus) which almost everywhere fringes the coasts. Though the stems are not thick, they often exceed a hundred feet in length. Darwin ${ }^{1}$ picturesquely writes: "I can only compare these great aquatic forests of the southern hemisphere with the terrestrial ones in the intertropical regions. Yet if the latter should be destroyed in any country, I do not believe that nearly so many species of animals would perish, as, under similar circumstances would happen with the kelp. Amidst the leaves of this plant numerous species of fish live, which nowhere else would find food or shelter; with their destruction the many cormorants, divers, and other fishing birds, the otters, seals, and porpoises, would soon perish also; and lastly the Fuegian savage, the miserable lord of this miserable land, would redouble his cannibal feast, decrease in numbers, and perhaps cease to exist." The kelp forms an excellent breakwater and mooring for canoes, but it is an impenetrable barrier to swimmers and has prevented many unfortunate occupants of overturned canoes from safely reaching the shore. Its appearance on the surface of the water may be seen in pl. III, top, and pl. xI, top.

\section{FAUNA}

From the Indian point of view what made Tierra del Fuego a suitable land for habitation was the edible fauna, which in turn

\footnotetext{
${ }^{1} 1838$, p. 303.
} 
depended on the flora, especially the grasses on land and the kelp along the shore.

Of the land animals first place in economic importance falls to the guanaco, one of the four New World varieties of camel (fig. 4).

The guanaco is closely related to the llama of Peru, but, whereas the llama is found only as a domestic animal, the guanaco has never been successfully domesticated, although easily tamed. The guanaco has been succinctly described as having "the neigh of a horse, the wool of a sheep, the neck of a camel, the feet of a deer, and the swiftness of the devil." 1 In Tierra del Fuego, guanaco attain a much larger size than in Patagonia, while on Navarin island they are nearly as large as a cow.

Material culture of the Ona is based on the

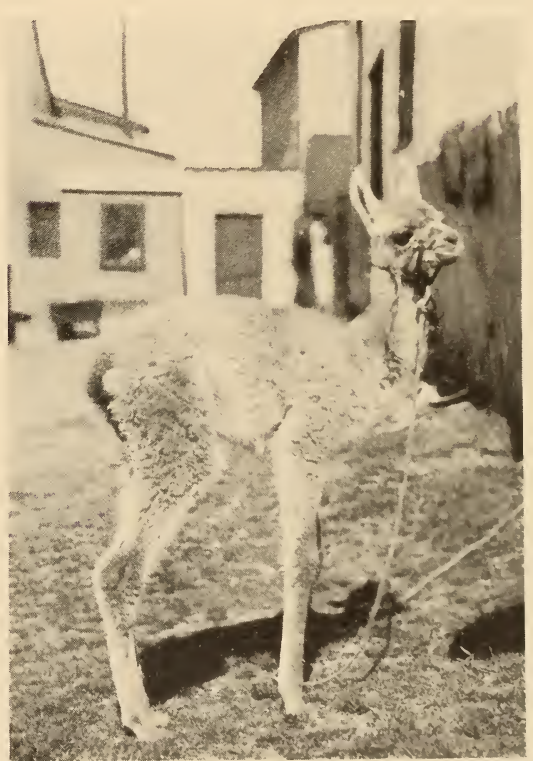

FIG. 4.-Young guanaco. guanaco, and the importance of this animal in their economic life is emphasized by the highly specialized vocabulary used to describe it. Fur from new-born guanaco is exceedingly soft, and the Tehuelche of Patagonia used it for robes. The Fuegians, however, confronting greater cold, made their robes from skins of the adult animal. From guanaco-hide the Ona made their windbreaks (which served as houses), storage-bags, water-bags, and thongs; from the forehead they fabricated caps; from the sinews they made twine; from a leg bone they manufactured a chipping tool; from the hocks they fashioned moccasins. Guanaco meat, rather dry, stringy, and

${ }^{1}$ Musters, p. 127. 
tasteless to our notions, formed the principal meat diet of the Foot Indians. Wool was the only asset of the guanaco not utilized by the Ona, for lacking knowledge of weaving and ability to organize in large numbers, they never rounded up the wild guanaco to shear them, as was done to the llama on a large scale under the Inca dynasty in Peru.

For the Ona, second place in importance among the land animals falls to the fox (Ona: uash), one of the two varieties of which grows to an unusual size. I have been told that on occasions of great scarcity the foxes in Tierra del Fuego have combined to form packs in the fashion of wolves, and it is then well for a man to avoid them. Fox was sometimes eaten by the Ona, and the skin was occasionally used for robes, if guanaco were scarce. Two kinds of bags (hásin and kólwe) found in every Ona household were made of fox-skin.

A small burrowing rodent (Ctenomys fueginus), known in Spanish as the tucotuco or cururo, was eaten by the Ona, who dug up the burrows with sticks. In places large areas of the Fuegian plains,

TABLE II.-FUEGIAN FOODS ${ }^{1}$

\begin{tabular}{|c|c|c|c|}
\hline & ONA & \multicolumn{2}{|c|}{ YAHGAN } \\
\hline animal & $\begin{array}{l}\text { guanaco****** } \\
\text { fox (two kinds) } \\
\text { tucotuco } \\
\text { seal (four kinds) } \\
\text { whale } \\
\text { rat (rare) }\end{array}$ & $\left.\begin{array}{l}\text { seal*** } \\
\text { porpoise** } \\
\text { whale* } \\
\text { otter (chiefl } \\
\text { guanaco (on }\end{array}\right\}$ & $\begin{array}{l}\text { oil stored } \\
\text { y in west) } \\
\text { ly in east) }\end{array}$ \\
\hline fish & chiefly eels** & many kinds & $* * *$ \\
\hline shellfish, etc. & $\begin{array}{l}\text { mussels* } \\
\text { limpets } \\
\text { crabs }\end{array}$ & $\begin{array}{l}\text { mussels***** } \\
\text { limpets* } \\
\text { conchs } \\
\text { crabs* } \\
\text { sea-urchins* }\end{array}$ & \\
\hline $\begin{array}{l}\text { birds } \\
\text { (chiefly in summer) }\end{array}$ & $\begin{array}{l}\text { goose (four kinds)** } \\
\text { duck (five kinds) } \\
\text { cormorant* }\end{array}$ & $\begin{array}{l}\text { goose* } \\
\text { duck } \\
\text { gulls** } \\
\text { penguin* } \\
\text { cormorant* }\end{array}$ & $\begin{array}{r}\text { and their } \\
\text { eggs** }\end{array}$ \\
\hline $\begin{array}{l}\text { vegetal } \\
\quad \text { (in summer) }\end{array}$ & $\begin{array}{l}\text { fungus (several kinds) } \\
\text { berries (three kinds) } \\
\text { grass-seeds }\end{array}$ & $\begin{array}{l}\text { fungus* } \\
\text { berries }\end{array}$ & \\
\hline
\end{tabular}

1 Putative relative importance of foods is indicated by asterisks. 
undermined by this animal, recall the gopher burrows in western North America.

The Fuegian dog is not known in a wild state, and today it is extinct, although much blood of the native breed must run in the veins of the innumerable sheep dogs and hounds to be found on the island. In height the native $\mathrm{dog}$ ranged from 11 to 20 inches. Their ears were pointed, muzzles sharp, and skulls broad. The markings were black and white, with tan running-gear. Like most Indian dogs they lived largely on such garbage as they could pick up around the encampment, but in times of plenty they were given meat or mussels by their masters. Also occasionally they might pull down a guanaco and enjoy a square meal before the arrival of the hunter, as illustrated in the legend of Kuanip, presented later.

Of the sea animals, the four kinds of seal found in Fuegian waters formed the principal meat diet of the Yahgan. Not only did they eat the seal, but they used its hide for capes, moccasins, house-tops, and thongs. It is surprising they never invented a hide boat, which would have been much less perishable than their bark canoes. The Haush also ate a great many seal, and the Ona ate seal but did not specialize in its pursuit.

Otter of three kinds, one living on land and two in the sea, were prized by both Yahgan and Alacaluf, who used their skins for clothing. Both these peoples attacked porpoises, and at times, when some innate instinct assured them of good weather, they pursued them far into the open sea.

To the Fuegian tribes whale was a great delicacy, and by all accounts this leviathan existed in large numbers in Fuegian waters until recently. Sometimes the Canoe Indians ventured to attack whales that had blundered into shallow water, but usually they were secured dead on the beaches. These were gala occasions, and feuds and animosities were forgotten as great numbers gathered to gorge themselves on the often putrid, diseased, and stinking flesh. When satiated, the Yahgan sometimes buried a meat supply far under ground where, were there frost, it might be preserved for many months. This custom recalls the burying of salmon on the northwest coast of North America, where the decomposed fish was mixed with oil and eaten with gusto.

Fuegian waters abound in fish, both large and small, which were eaten by all the tribes. The Ona took fish from pools at low tide, 
while the Yahgan speared them in deep water or drew them with bait to the surface where they could be seized by hand. Failure to utilize fully the fish supply must be regarded as a great deficiency of the Fuegian economic system. a lack which might have been overcome by the invention of fish-traps and the fish-hook.

Both Foot and Canoe Indians ate great numbers of mussels. conchs, and limpets, and ancient camp-sites often are indicated by large piles of shells. This is especially true in the Yahgan country: because all their camp-sites were on the beach where shellfish were easily obtained.

The Canoe Indians ate a species of sea-urchin some three or four inches in diameter, and also crabs. Of these the most succulent is a giant spider crab (Lithodes antarctica), so good to eat that today it is canned and exported from Punta Arenas.

Birds abound in Tierra del Fuego. Many; to be sure, have a fishy taste, but to a palate not over-delicate they offer an abundant food supply. Among birds of economic use to the Indians we should mention four kinds of goose and five kinds of duck. The upland goose and the pin-tail duck are the best eating. Also there are many kinds of gull (including the albatross), penguins, vultures, eagles, doves, plover, and, curiously enough, a paroquet and a hummingbird.

As to the environment in general, it is much more suitable for supporting human life than is realized by those who have not visited Tierra del Fuego. The public mind. we believe, is unduly impressed by the romantic place of the island in history, by adventurous accounts of midwinter weatherings of the Horn in sailing vessels, by modern travelers elated at the length and labor of their journeys. Glaciers descend to the sea in Tierra del Fuego, but the land also nourishes orchids, mushrooms, paroquets, hummingbirds, and butterflies. Prosperous sheep ranches with their comfortable and commodious houses and their well-stocked regetable and flower gardens show that European standards of living can be achieved on the island. And these settlements, were over-sea transportation to be cut off, could probably maintain themselves better on local resources than most European settlements in the tropics.

The climate of Tierra del Fuego, to be sure, is severe, but it is not so extreme as inhabited regions of Europe, Asia, North America, and Greenland. Agriculture within certain limits is entirely 
feasible. Timber of many kinds is available-and with this we may contrast the condition of certain Eskimo who must rely on driftwood for some of their manufactures and on oil for their heat. Furthermore, animal foods are found by land and by sea in sufficient quantities to support a relatively large population of a non-agricultural, hunting class.

Clearly then some of the very primitive features we shall describe were not forced on the natives by their environment, but rather were the result of lack of ingenuity or of inertia.

\section{CULTURE STATUS}

Fuegian culture ranks among the most primitive that has been known within the limits of recorded history. To emphasize this statement we subjoin a list of all the articles and materials observed among the Ona and the Yahgan. This list at first glance seems fairly long, but one must consider that it embraces not only the individual but a complete family including both sexes and all ages. Further, it includes not what appeared for any given occasion but everything with which any Indian normally came in contact during an entire lifetime. In contrast, if the reader will list the objects he makes use of between bed and breakfast, he will find that in half an hour of daily routine he has utilized more articles and more materials than a Fuegian ever manipulated.

More justly, however, we should compare the Fuegian culture with the status usually found among Indian hunting tribes. On this basis we find that the Fuegians lacked such simple implements as the drill, the ax, the spear-thrower, fish-hooks, and cooking containers. They had no pottery, no weaving, no method of softening skins except by use, nor had they more than a rudimentary art of painting, while sculpture was beyond them. They rarely stored food against a time of stress. Their games, their social organization and ceremonies, were but slightly developed. Religion was largely a negative affair, for they indulged less in religious acts probably than any people known in the world in recent times. Animistic beliefs they had, but scarcely a trace of fetishism has been noted, and of totemism-so widely developed throughout the Americas - there is not a vestige.

In estimating this list it must also be borne in mind that the Ona and Yahgan cultures have intermingled especially along the frontier. In some instances, such as the initiation ceremonies or 
basket (one kind)

frame cradle

dog leash

comb

knife

flesh-scraper

wood-scraper

sharpening stone

awl

chipping tool

stone shaft-polisher

skin polisher baskets (three kinds)

feather broom (recent?)

comb

face-painting stick

Tools

knife

flesh-scraper (rare)

wood-scraper

sharpening stone

awl

?

pumice

barking tools (two kinds)

Weapons and Hunting Equipment

bow and arrow

spear (rudimentary)

sling (rare)

bird-snare

net (rare, two kinds)

bark torch bow and arrow (rare)

spears (five kinds)

sling

club

bird-snare

net (rare)

grass dip-net

fish-line

bark torch

Games

ball

ball

circular grass target (rare)

Religious and Ceremonial Paraphernalia

masks

feather headband

kelp-goose down headband masks

feather headband

kelp-goose down headband painted sticks painted thong guanaco-hide headband tickling stick

ceremonial spear 


\begin{tabular}{ll} 
& Materials \\
wood & wood \\
sinew & sinew \\
skin & skin \\
stone & stone \\
bone & bone \\
whalebone (rare) & whalebone \\
\hline grass & kelp \\
feathers & grass \\
\hline white clay & feathers \\
red burnt earth & pumice \\
charcoal & white clay \\
pitch (post-European) & red burnt earth \\
iron (post-European) & charcoal \\
glass (post-European) & iron (post-European) \\
& glass (post-European)
\end{tabular}

\section{PHYSICAL TYPE}

The writer engaged in no anthropometric investigation in Tierra del Fuego, but certain measurements are available by which the physical types there to be found may be determined. The most important study yet published is that of Hyades (1891) on the Yahgan prepared in coöperation with Deniker, a work surprisingly sound in method considering how long ago it appeared. A series of measurements on the Ona taken many years ago but printed recently (1927) by Dr. Lehmann-Nitsche is also of prime importance. Somatological data collected by Gusinde and Koppers in recent years is beginning to appear in print, but with a single exception it has not been possible to obtain copies in time to incorporate the material here. Other studies of smaller scope are available and have been listed by Cooper (1917, pp. 138-140) and Dixon (1923, pp. 454-455). Even when concentrated into a single group, Fuegian somatological material is not abundant.

Primary division of the Indians of Tierra del Fuego into groups, Foot Indians and Canoe Indians, is made on cultural grounds. This classification might also be based on physical type, and, in case of the Foot Indians, on linguistic relationship. As with the cultural evidence, physical data on the Alacaluf and Haush are so scanty that we shall confine our discussion to the Ona and the Yahgan. 
To casual observation the Ona impress one by their great height, their barrel-like chests, their splendidly upstanding carriage, and their patent strength and endurance (figs. 7 and 37). Their hair grows abundantly on the head, but sparsely on the face and body, from which in the old days they plucked it with a pair of musselshells. Their feet, ankles, hands, and wrists are surprisingly delicate in proportion to their great stature. A peculiar physical characteristic which has escaped comment is the not infrequent presence of purpleblack patches like birthmarks on the skin. These may appear on any part of the body, but are especially common on the base of the neck, where an example was noted among the Yahgan. As the Indians are sensitive about such nævi, examination is difficult.

In sharp contrast to the Ona the Yah. gan are exceedingly short. Their stature approximates closely

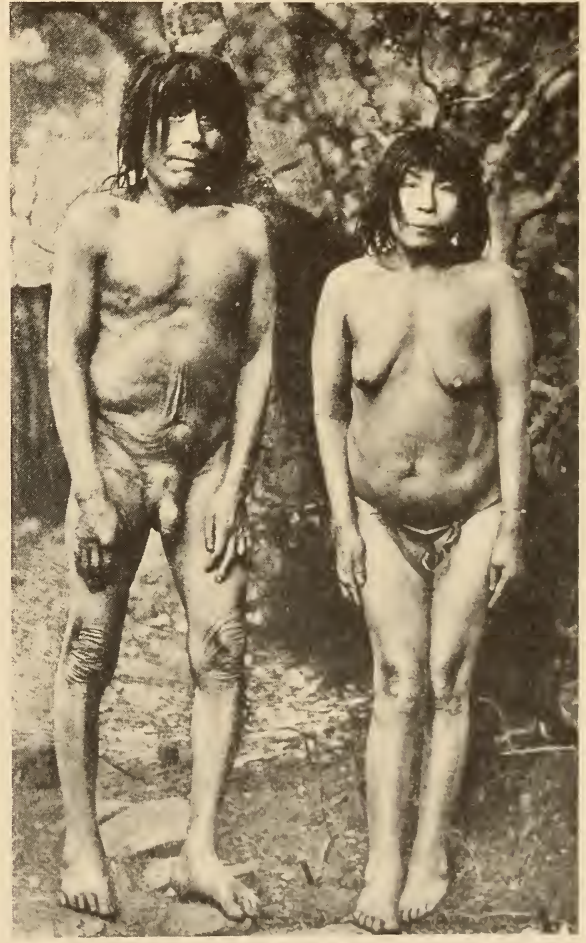

Fıg. 5.-Yahgan Indians. (After Iyades and Deniker.) that of the Alacaluf, among whom Hyades (1891, p. 120) found an average of 157.4

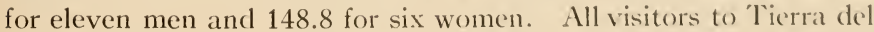
Fuego have commented on the corpulence of the Yahgan in relation to their slender legs, a characteristic attributed to long hours spent 
in the cramped positions compulsory in their canoes. The eastern Yahgan, it is asserted, had better developed legs than the other groups because they hunted more frequently on shore. Like the Ona, the Yahgan had little hair on their faces and removed this growth with mussel-shell pincers. It is stated ${ }^{1}$ that on the arrival of the French scientific expedition in 1883 the Yahgan mistook the beards of the Frenchmen for tobacco, and in that belief tried to pull them off.

We should also mention a curious Yahgan anomaly noted by Hyades and Deniker (1891, p. 167) that these Indians tended to put on fat with unusual rapidity in times of plenty, and were able to live on this reserve when food was scarce. Yahgans of age before the white settlement resulted in a less erratic food supply exhibited skin hanging in folds on underfed individuals (fig. 5). The ability to store unusual amounts of fat, most developed in modern races among the Hottentot, has been thought a survival of a hibernating stage in the development of man. Its existence in Paleolithic Europe is deduced from steatopygous figurines among the most ancient carvings produced by human hands. Anatomically, Hyades and Deniker explain this feature by long intestines coupled with a small stomach, leading to rapid and frequent digestion of small amounts of food. The Yahgan stomach was found to contain $1800 \mathrm{cc}$. as against $3700 \mathrm{cc}$. for Europeans, presumably Frenchmen, while the Yahgan intestines were six times the length of the body as compared with five times the length of the body in Europeans. These observations and conclusions, it may be mentioned, are not in accord with more recent investigations which reveal a correlation between long intestines and a vegetal diet.

We can say little about the physique of Haush and Alacaluf. the former clearly were related to the Ona, while the latter were short in stature like the Yahgan.

Turning to more exact data, in the accompanying table we give statistical constants for the Ona and the Yahgan, based on all available material. For the preparation of this table I am indebted to Prof. E. A. Hooton of Harvard University, to Mr. Walter Cline, and to Miss Barbara Clark. I am further indebted to Professor Hooton for the subjoined comment.

${ }^{1}$ Capt. Le Clerk in the South American Missionary Magazine, 1884, p. 58. 
TABLE III.-STATISTICAL CONSTANTS FOR THE ONA AND THE YAHGAN

\begin{tabular}{|c|c|c|c|c|c|c|}
\hline & & $\begin{array}{l}\text { Numbe } \\
\text { of } \\
\text { Cases }\end{array}$ & Mean & $\begin{array}{l}\text { Standard } \\
\text { Deviation }\end{array}$ & $\begin{array}{c}\text { Coefficient } \\
\text { of } \\
\text { Variation }\end{array}$ & Range \\
\hline $\begin{array}{l}\text { tature } \\
\text { Onas } \\
\text { Yahgans }\end{array}$ & Adult Males & $\begin{array}{l}25 \\
67\end{array}$ & $\begin{array}{l}175.44 \pm .64 \\
158.10 \pm .43\end{array}$ & $\begin{array}{l}4.71 \pm .45 \\
5.23 \pm .30\end{array}$ & $\begin{array}{l}2.68 \pm .26 \\
3.31 \pm .19\end{array}$ & $\begin{array}{l}168-186 \\
146-169\end{array}$ \\
\hline $\begin{array}{l}\text { Onas } \\
\text { Yahgans }\end{array}$ & Adult Females & $\begin{array}{l}34 \\
56\end{array}$ & $\begin{array}{l}159.24 \pm .58 \\
147.54 \pm .34\end{array}$ & $\begin{array}{l}5.02= \\
3.82=\end{array}$ & $\begin{array}{l}3.15 \pm \\
2.59 \pm\end{array}$ & $\begin{array}{l}149-169 \\
141-157\end{array}$ \\
\hline $\begin{array}{l}\text { Head Length } \\
\text { Onas } \\
\text { Yahgans }\end{array}$ & Adult Males & $\begin{array}{l}22 \\
27\end{array}$ & $\begin{array}{l}198.77 \pm .51 \\
190.04 \pm .87\end{array}$ & & & $\begin{array}{l}192-205 \\
175-207\end{array}$ \\
\hline $\begin{array}{l}\text { Onas } \\
\text { Yahgans }\end{array}$ & Adult Females & $\begin{array}{l}30 \\
26\end{array}$ & $\begin{array}{l}190.37 \pm .60 \\
180.38 \pm .74\end{array}$ & & & $\begin{array}{l}182-200 \\
168-193\end{array}$ \\
\hline $\begin{array}{c}\text { Head Bread } \\
\text { Onas } \\
\text { Yahgans }\end{array}$ & Males & $\begin{array}{l}22 \\
27\end{array}$ & $\begin{array}{l}158.91 \pm .48 \\
150.78 \pm .64\end{array}$ & $\begin{array}{l}3.31 \pm .34 \\
4.95 \pm .45\end{array}$ & $\begin{array}{l}2.09 \pm .21 \\
3.29 \pm .30\end{array}$ & $\begin{array}{l}152-164 \\
145-163\end{array}$ \\
\hline $\begin{array}{l}\text { Onas } \\
\text { Yahgans }\end{array}$ & Adult Females & $\begin{array}{l}30 \\
26\end{array}$ & $\begin{array}{l}153.20 \pm .62 \\
142.46 \pm .35\end{array}$ & $\begin{array}{l}5.06 \\
2.63\end{array}$ & $\begin{array}{l}3.30 \\
1.85\end{array}$ & $\begin{array}{l}142-163 \\
138-147\end{array}$ \\
\hline $\begin{array}{l}\text { Length-breac } \\
\text { Onas } \\
\text { Yahgans }\end{array}$ & $\begin{array}{l}\text { th of head } \\
\text { Adult Males }\end{array}$ & $\begin{array}{l}22 \\
26\end{array}$ & $\begin{array}{l}80.05 \pm .32 \\
79.27 \pm .37\end{array}$ & $\begin{array}{l}2.20= \\
2.78=\end{array}$ & $\begin{array}{l}2.75 \\
3.51\end{array}$ & $\begin{array}{l}77-85 \\
74-88\end{array}$ \\
\hline $\begin{array}{l}\text { Onas } \\
\text { Yahgans }\end{array}$ & Adult Females & $\begin{array}{l}30 \\
26\end{array}$ & $\begin{array}{l}80.57 \pm .34 \\
79.04 \pm .34\end{array}$ & & & $\begin{array}{l}74-86 \\
73-84\end{array}$ \\
\hline $\begin{array}{l}\text { Nasal Index } \\
\text { Onas } \\
\text { Onas }\end{array}$ & $\begin{array}{l}\text { Adult Males } \\
\text { Adult Females }\end{array}$ & $\begin{array}{l}22 \\
30\end{array}$ & $\begin{array}{l}71.18 \pm 1.00 \\
70.30 \pm .79\end{array}$ & $\begin{array}{l}6.93= \\
6.45=\end{array}$ & $\begin{array}{l}9.73 \pm .99 \\
9.17 \pm .80\end{array}$ & $\begin{array}{l}58-84 \\
60-87\end{array}$ \\
\hline $\begin{array}{l}\text { Facial Indes } \\
\text { Onas } \\
\text { Onas }\end{array}$ & $\begin{array}{l}\text { Adult Males } \\
\text { Adult Females }\end{array}$ & $\begin{array}{l}20 \\
30\end{array}$ & $\begin{array}{l}85.50 \pm .75 \\
85.80 \pm .53\end{array}$ & $\begin{array}{l}4.95 \pm .53 \\
4.30 \pm .37\end{array}$ & $\begin{array}{l}5.78 \pm .62 \\
5.01 \pm .44\end{array}$ & $\begin{array}{l}78-97 \\
75-91\end{array}$ \\
\hline
\end{tabular}

\section{NOTE ON THE ANTHROPOMETRIC CHARACTERS OF THE YAHGAN AND THE ONA}

By Prof. E. A. Ноoтon

THE statistical constants in the accompanying table are derived from the data of Lehmann-Nitsche and Gusinde in the case of the Ona, and from the data of Hyades and Deniker, Bove, and Hahn in the case of the Yahgan.

The difference in size between these adjacent tribes, both of which live almost exclusively on animal food, is prodigious. Twentyfive adult male Ona yield a mean stature of $175.44 \mathrm{~cm}$., which is 
probably the highest to be found among American Indians. It is, of course, possible that the neighboring Patagonians equal this figure. On the other hand the stature of 67 adult male Yahgans is only 158.10 , which ranks them among the shortest of American Indian groups. Even more remarkable than the means are the standard deviations and coefficients of variation for stature. In a series of 540 full-blood Sioux, Sullivan ${ }^{1}$ found a standard deviation of $5.64 \mathrm{~cm}$. and a coefficient of variation of 3.27 per cent. The corresponding figures are somewhat lower in the Yahgan and significantly lower in the Ona. Davenport ${ }^{2}$ lists the standard deviations of stature for eight samples of males of military age of various nationalities. All of these standard deviations exceed $6 \mathrm{~cm}$. It is then apparent that the variability of the Fuegians in stature is low.

It may also be observed from the table that the variabilities of the short Yahgan with respect to stature are somewhat higher than those of the tall Ona. The reverse is true however in the female series.

The head lengths of both groups show similar statistical features. The mean of the dimension for Ona males, $198.77 \mathrm{~mm}$., is the largest known to the present writer, and the variability of this measurement is wonderfully small. The Yahgan too have long heads, but are much more variable than the Ona in this respect. Similar observations apply to the head breadth.

The means of the cephalic indices indicate a predominance of mesocephaly in both groups. The Ona show slightly higher means than the Yahgan. Here again variabilities are extraordinarily low. The Ona range in males is from 77 to 85 , and the Yahgan from 74 to 88. In case of the females the ranges are: Ona 74-86; Yahgan 73-84. The variabilities of the female groups with respect to this index do not differ significantly.

Data for the nasal and total facial indices are available only for the Ona series. In both of these cases the standard deviations and variabilities are rather large. All varieties of nasal and facial proportions occur. One expects, however, to find a large measure of variability in both of these indices; first, because of the extreme difficulty in locating the nasion point from which both nasal height

${ }^{1}$ L. R. Sullivan, Anthropometry of the Siouan Tribes, Proc. Nat. Acad. Sci., vi, no. 3, pp. 131-134, Mar. 1920.

2 Charles B. Davenport and Albert G. Love, Army Anthropology, p. 113, 1921. The Medical Department of the U. S. Army in the World War, xv, Statistics, pt. 1. 
and facial height are measured; second, because of age changes in the individual which affect these parts. The length of the nose increases with age and the length of the face tends to diminish with wear and loss of teeth. Nevertheless it would appear that these indices in the Ona group by their dispersion indicate a lack of homogeneity of the group when compared with the measurements and indices previously considered.

It is proposed to consider here the problem of Ona and Yahgan anthropometry only so far as deductions may be made from the accompanying table and from information as to the environmental factors which seem to be important. First of all it is apparent that the Yahgan as a group are less homogeneous than the Ona, particularly in the case of the males. How may this difference in variability be explained? The conditions of diet, occupation, climate, etc., are somewhat different from those obtaining in the case of the Ona, but presumably quite uniform for the entire Yahgan group. Indeed it would appear that the life of the Ona is much more varied than that of the adjoining tribe. The Yahgan are canoe people, but it does not seem probable that their life in boats and on the shore would tend to diversify them in physical type any more than the roaming life of the Ona. I think we must admit that the Yahgan owe their greater variability probably to the presence of more diverse physical types of an hereditary character than are found among the Ona. By this I mean that two or three, or more perhaps, of the various elements which have blended to form the composite "Indian" race in America, are found among the Yahgan, whereas in the Ona we have to deal either with a single type or with a group in which one single type overwhelmingly predominates.

In a "refuge" area one may expect to find all sorts of samples of the weaker and more primitive populations which have, from time to time, inhabited the continent. These odds-and-ends are likely to have been reduced to a certain homogeneity through isolation which brings about inbreeding and through selection. Both of these factors are notably operative in Tierra del Fuego. I think that it is an assumption justified by the evidence that the earliest inhabitants of the New World were short dolichocephals and that these were followed by short brachycephals. Among the Yahgan we have a fusion of two such elements, just as we have, to cite another instance, in Pueblo peoples of southwestern United States. 
We must however consider the possibility that the canoe life of the Yahgan has tended to exercise a selective influence on their stature. Small men are less likely to fall out of small and primitive canoes than are large and unwieldy men. Great length of legs (which always distinguishes tall persons) is a great disadvantage in such craft. We are given to understand that the Yahgan women swim well and the men not at all. If this is true, it is conceivable that the shorter elements in this population have survived because the larger men proved to be too awkward for canoeing and were consequently eliminated by drowning. But this would necessitate the assumption that the large women were also eliminated or that they failed to transmit their large stature. While it is perfectly true that a large woman and a small canoe make a bad combination, it is equally true that a large woman makes as good a floater or swimmer as a small woman, and even a better.

However, there is another possibility that is worthy at least of mention. The legs of the Yahgan may have been shortened as a result of their boating habits. It is perfectly easy to suppose that a man who spends most of his time sitting in a canoe will have poorly developed legs, as have the Yahgan. It is not at all certain, however, that disuse of the legs for purposes of locomotion would necessarily decrease their length. And it is altogether improbable that such a decrease in leg length would establish itself as an hereditary characteristic. Moreover, the Yahgan are not merely "sawed-off" counterparts of the Ona. Not only are their legs shorter, but they are smaller in every way than their neighbors.

On the whole I am inclined to believe that the stocks which have blended to form the Yahgan were originally short-statured, shortlegged peoples, and that, although canoe life may have operated to some extent to eliminate the taller individuals, the stunted stature of this people is in the main a characteristic of the original stocks from which they sprung.

The Ona are one of the tallest people in the world if any reliance can be placed upon our compiled figures and upon the estimates of various writers. They are exceptionally homogeneous in stature and in cephalic dimensions and indices, but not especially so in facial measurements and indices. They are not canoe people, but range over a wide area on foot. Apparently they have a harder time in gaining their subsistence than do the Yahgan. Are we to suppose that these people have attained their commanding 
height by the exercise of their lower limbs in walking? We do not know that walking increases the length of the legs. Very tall men are not especially good walkers in the experience of modern armies; short men march more rapidly and endure better. On the other hand, there is nothing to lead us to suppose either that walking shortens the legs or that a life of wandering about on foot would tend to eliminate by some process of selection the shortlegged strains. If one were to attribute the maximum imaginable effect to natural selection or to processes of atrophy and hypertrophy in altering either by selection or by the transmission of functional adaptations the hereditary leg-lengths of Ona and Yahgan, and if we brought ourselves to believe that some environmental agency had radically shortened the legs of the latter and lengthened those of the former, we should still be faced by a difference in stature between the two groups altogether beyond the adequacy of such an explanation. The Ona males are more than $17 \mathrm{~cm}$. taller than the Yahgans!

At this point we may inquire with Cassius:

\footnotetext{
"Now, in the name of all the gods at once, Upon what meat doth this our Caesar feed That he is grown so great?"
}

If we take into consideration the dietetic differences between the Ona and the Yahgan (see Table II), we observe that the outstanding fact is the dependence on the flesh of the guanaco by the Ona as contrasted with a reliance on mussels as a staple on the part of the Yahgan. Guanaco seems also to have been the principal article of diet of the Patagonian Tehuelche, who, according to reports, were as tall as the Ona, if not taller (mean stature of males $175 \mathrm{~cm}$., according to Moreno and Lista). Yet it is hardly worth while to toy with the supposition that the statural differences between these groups are a matter of camel-meat versus shell-fish, especially since the ethnographic authorities seem to think that the Ona have a harder time in getting sufficient food than their stunted neighbors.

More promising perhaps is the factor of artificial selection in the warlike pursuits of the Ona. If it could be shown that the smaller and weaker of these people had been eliminated as a result of warfare, our problem would be solved. But in spite of the fact that the Ona are said to be more warlike than the lahgan, it does not seem reasonable to ascribe their stature to military selection. There is no evidence, so far as I know, which would justify such a 
conclusion. Nevertheless, the statistical homogeneity of this group does argue that some sort of selection has been at work. The Ona men are said sometimes to take Yahgan wives, and if this is true we should expect some at least of the offspring of such unions to be short. The Ona women are, however, almost as tall for their sex as are the men. Could it be possible that the Ona practise infanticide upon undergrown specimens of their race? There is no evidence that such is the case.

It is reported that the Ona of Tierra del Fuego are not alone in their attainment of an unusual bodily size, since animals transported to this region far exceed the size and bulk to which they ordinarily grow in other places. For example, it is stated that the guanaco in Tierra del Fuego is larger than the same animal farther north in the Andean area. Also it is said that foxes grow large and that imported English cattle produce gigantic offspring. If this be the case, it is very difficult to account for the stunted Yahgan who have practically the same environment as the Ona.

Most anthropologists ascribe the size of the Ona to their probable relationship with the Patagonian Tehuelche, to whom they are also allied culturally. In other words, the size of the Ona is thought to be a matter of heredity. As a matter of fact this explanation seems to be the only possible one unless some physiologist can demonstrate that the slight differences between Yahgan and Ona diets are directly responsible for their disparity in size. Even more striking instances of statural difference within the same environment occur in East Africa and the Lake region where the shortest pygmies known live cheek-by-jowl with gigantic HamitoNegroids, the tallest people in the world.

Tall stature is generally a matter of heredity, and it is thought by Davenport that certain growth-repressing factors are dominant over their absence, inasmuch as he found high variability in short families as contrasted with tall families. If this is correct it is possible that the stature of the Ona is an expression of a recessive feature in a relatively pure stock. But the Ona are said occasionally to take Yahgan wives, and the variability of their facial and nasal indices is scarcely indicative of purity of race. We must consider also the hypothesis of heterosis or hybrid vigor, whereby hybrid offspring often exceed both parents in bodily size. But heterosis does not manifest itself always in human crosses. It does not occur, for example, in crosses between Hawaiians and Chinese, 
nor apparently in most Negro-white crosses. There is, moreover, no evidence in the case of the Ona of any recent admixture with another stock except perhaps the Yahgan, who would scarcely be expected to contribute factors making for gigantic stature or even to maintain the average stature of any ordinary group with which they interbred.

I should be inclined to the speculation that the high stature of both Tehuelche and Ona is the result of the predominance in them of a tall and probably brachycephalic strain belonging to one of the later waves of immigrants into South America. I am of the opinion that this tall brachycephalic type, which occurs elsewhere in the New World, resulted from the intermixture of a brachycephalic type of medium stature with a tall dolichocephalic strain. It would appear that in this particular cross tallness was dominant. This is, admittedly, a speculation, but it is not based merely on a short consideration of the inadequate and second-hand anthropometric data on the Fuegians here presented. I do not pretend to be able to prove this contention, nor can I say exactly what "races" were involved in this postulated cross. I think, however, that the Mongoloid element in the American Indians came largely from the brachycephals, and that the tall dolichocephals were neither Negroid nor Mongoloid. Nor do I assume that the crossings which gave rise to this tall "hybrid" type necessarily took place in the New World; many of the American Indian groups included in this type may have originated in Asia.

We really need a good deal more of information about the effect of diet and climate on physical type before we can confidently dismiss the remarkable size contrast between the Ona and the Yahgan as a mere matter of hereditary difference. I should want more precise information about certain morphological characters of these two groups before committing myself finally to the opinion that they represent distinct racial combinations. However, upon the present showing I incline to the opinion that the size differences discussed above are primarily the result of hereditary factors, accentuated perhaps by occupational selection tending to make for shortness in the Yahgan and for great stature in the ()na. 


\section{PART I \\ FOOT INDIANS}

THE ONA

7 HE Ona, today almost extinct, were Foot Indians who half a century ago occupied the northern part of Tierra del Fuego east of Useless bay, practically the whole of the east coast, and the plains and mountains southward almost to the shores of the Antarctic. This distribution is seen in pl. IV. ${ }^{1}$

Being a hunting people the Ona lived in small family groups, for they had to move rapidly to follow the game, and large encampments with many dogs made existence difficult. Only when a whale came ashore or when wrestling bouts were held did large gatherings take place.

Each family group usually controlled a long narrow territory extending from the mountains to the east coast, so that all the various kinds of animals and edible berries could be found in their particular area. These hunting groups were informally governed by their ablest member whose name might be applied to the whole group. More commonly, however, geographical names were used, such as Kámin u chon, "men of Lake Fagnano." Europeans were called $K$ ' óli ot, "his cape is red," on account of the red bayeta blankets used long ago by the police.

\section{LANGUAGE}

Both the Ona and the Haush fall in the same linguistic category as the natives of Patagonia, north of the Straits of Magellan. Lehmann-Nitsche (1914), who has most ably demonstrated this relationship, suggests the term Tshon to designate the whole group.

${ }^{1}$ A map published by C. W. Furlong (1917, fig. 7) shows Ona on Navarin island. According to Mr. William Bridges there were Ona on this island the year of Mr. Furlong's visit, but they had been transported there by the Bridges family to tend sheep. The territory opposite Navarin island marked "unoccupied" on this map was said formerly to have been controlled by an Ona called Teninisk and his family. 
Considerable variation in pronunciation and accent was noted by the writer among the Ona. These differences were not great enough to give rise to separate dialects, and do not approximate the gap between Ona and Haush, which are said to have been mutually intelligible only with difficulty.

As to the Ona tongue, it may be described as harsh, guttural, and explosive. Initial $k$ is almost clicked. Initial $t$ is usually pronounced explosively; so also $p$. There is much individual variation in this quality, and when the voice is raised there is a tendency to emphasize the harsher sounds-or perhaps they grate more raspingly on unaccustomed ears. Both initial and final $h$ are strongly pronounced, so that such words as heurrh, arrowhead, combining explosive $h$ 's with double $r$, are almost impossible to enunciate correctly to one not born to the manner. Perhaps the spelling hheurrhh represents the sound more adequately than the spelling adopted.

There is a soft $c h$ sound in the Ona tongue $(q)$ corresponding to the Scotch ch as in "loch." There is no sound like $b$ or $f$, and several other students give no $d$. However, initial $t$, especially before $a$, so closely approaches to $d$ that the writer found that he had recorded the same word at different times with both a $d$ and a $t$. On showing Mr. William Bridges these inconsistencies he advised leaving the $d$ 's in certain cases, saying that this letter of our alphabet came as close to the Ona sound as $t$. However, though reluctantly, I have eliminated the $d$ 's in the vocabulary herein presented in the belief that the variations in sound noted at different times have no structural value in the language.

Final $n$ in Ona is usually clipped so that it is barely recognizable. The quality of this sound differs much with different individuals, so that no rule can be laid down. In general there is a tendency to place a slight nasal at the end of all words terminating in a vowel, especially $i$, or words ending in $s h$ and $s t$.

The Ona vocabulary, like the Yahgan, is lacking in abstract expressions but is highly specialized in material matters. For instance, the writer found the following words applied to guanaco:

$$
\begin{array}{ll}
\text { yoyen, guanaco at a distance } & \text { tóol or totl, new-born guanaco } \\
\text { marren, old male guanaca } & \text { glátuen, male guanaco one year old } \\
\text { máishe, old female guanaco } & \text { ómte or oné, female guanaco one year old. }
\end{array}
$$

In addition, there are words for sick guanaco and pregnant guanaco. Gallardo (1910) records toholpai for a female accompanied by a 
young animal. These words all apply to guanaco afoot; to them might be added a host of words used to describe different parts of the animal.

As another example of specialized terms, the writer found the following words used for dog:

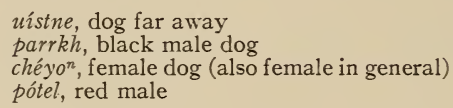

In spite of the richness of the Ona tongue in concrete terms, the Arcadian simplicity of Ona existence is brought home to us by their system of counting, which employed compound numbers or similes for anything above three. The compounds for $7,8,9,11$, 12,20 , etc., given in the vocabulary of Father Beauvoir, appear to be the result of missionary contact, for the Bridges brothers assured the writer that the following numbers were all that the Ona employed in the old days:

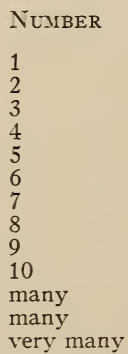

$\quad$ Oxi
sos
shóke
sháuken
kóne shóke
sos chen win
kóne sháuken
[none]
[none]
[none]
shóke chen win
karrh
símien
émele

$\quad$ ExGlish
one
two
three
twice two
one hand like
twice three

two hand like
(of inanimate objects)
(of animals)

In comment on this numeral system we may say that it is based on the powers of perception, for the number of objects up to three (or more in the case of mentally alert people) can be distinguished at a glance without going through the process of counting. This may have caused the Romans to change IIII to IV, as IIII is difficult to distinguish from III. Furthermore, the doubling of 2 and 3 by the Ona is a normal mental process used by people in all stages of development. The use of the hand to designate 5 is common among primitive tribes all over the world and is found in simple systems of notation such as the Aztec. Two hands making 10 is also a world-wide concept, which, combined with placenotation, has given us our decimal system. The Fuegians never 
combined the hands and feet to make a vigesimal system, found among many primitive people, including our own ancestors, as attested by survivals like the French quatre vingt or the English score.

\section{Clothing}

Perhaps no feature of Ona life is more striking to us than their apparent unpreparedness to face the rigors of the Fuegian climate, especially as regards their houses and their clothes. The skin of

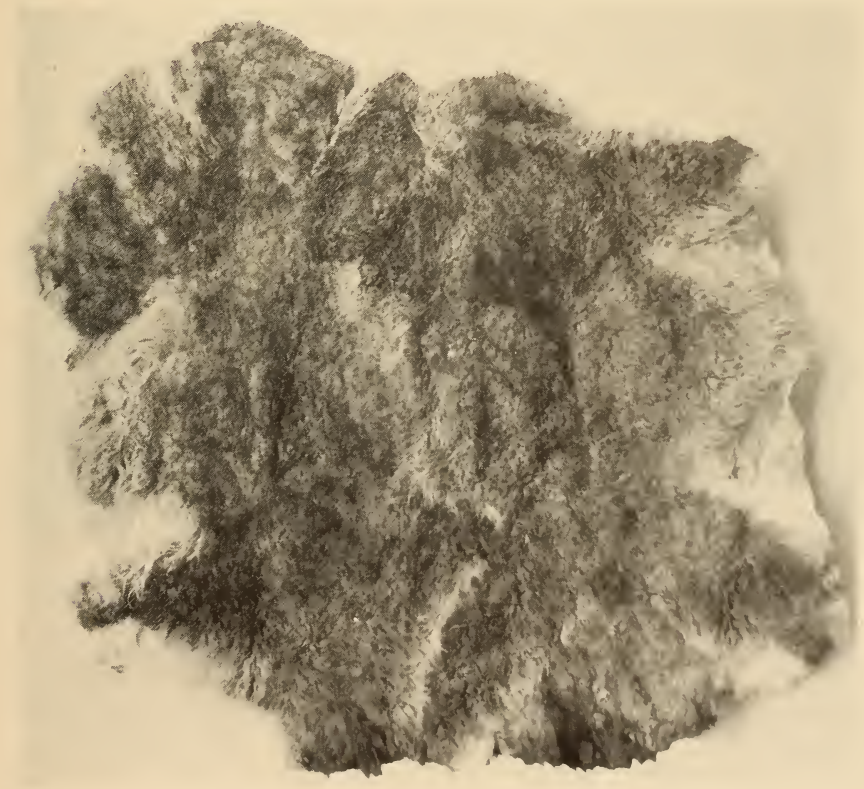

FIG. 6.-Ona guanaco robe. Size, 60 by $63 \mathrm{in.}(14 / 2257)$

the guanaco, however, from which most of their clothing was made, is very suitable for garments, as the thin parchment-like hide soon becomes softened by use without tanning, and the shaggy wool of the adult animal is nearly water-proof and extraordinarily warm.

Direct physical contact with snow is something to which we are not accustomed, it is true, but probably it is stimulating and 
healthful in small quantity, provided one may exercise to keep the blood circulating and one is not oppressed by fatigue. But the Ona had no warm houses to temper the cold, not even a roof to avert the blasts of storms. In the old days the Ona men, wearied by the chase of game, wrapped their robes tight and slept with bare legs in the snow, using a block of frozen meat for a pillow.

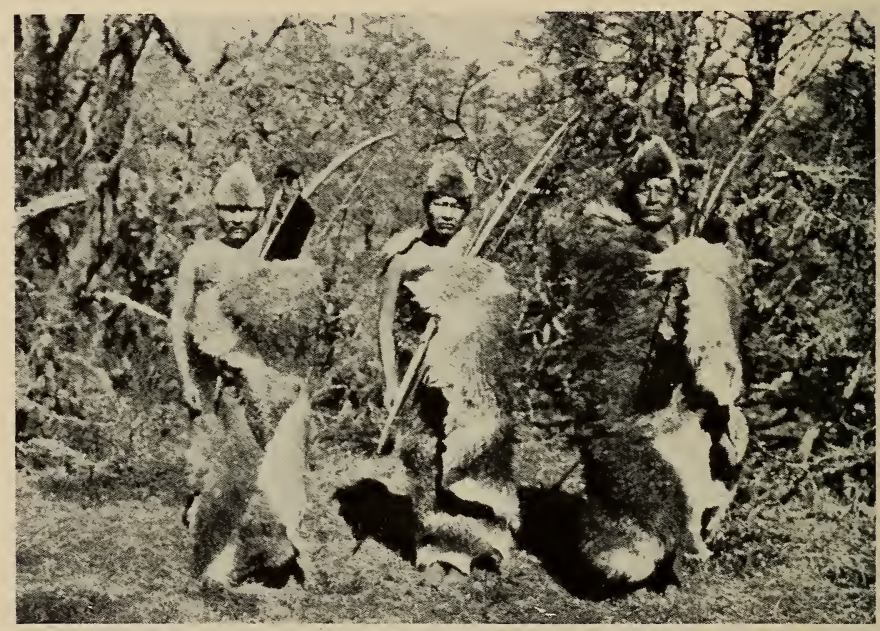

FIg. 7.-Ona Indians. (From Alberto De Agostini, I Miei Viaggi nella Terra del Fuoco.)

To be sure, they were inured to cold from childhood, but only a people of magnificent physique and robust constitution, materially equipped as were the Ona, could have faced the long dark winters of Tierra del Fuego, the deeply piled snow of the forests, the glaring sheet-ice of the open plains.

Men's Clothing.- The chief garment worn by the men was a robe or cape (óli) made from the joined skins of two or sometimes three adult guanaco (fig. 6). These skins were sewn together with guanaco-sinew $(y u h)$ to form an irregular square about five feet across. The skin side of this garment was coated with a mixture of red paint and saliva or grease. Sometimes broad red bands were applied to the fur. 
This robe, the only body-covering of the men, was habitually worn over both shoulders. On the march the left hand projected through the overlapping ends to hold the bow. If work requiring the use of the hands were to be performed, then the robe was wound over the left shoulder and under the right arm. These two positions of the robe are illustrated in fig. 7. When violent action was called for, as in war or hunting, the robe was discarded entirely. Indeed, the mere movement of stringing and drawing an arrow served to cast the robe backward from the shoulders, as may be seen in fig. 34 .

The Ona robe is similar to the robe worn by the Tehuelche of Patagonia in that both are made of guanaco-skins and both are painted. The Tehuelche robe, however, is not made of adult skins, but of the skins of newborn animals. Tehuelche robes are not painted in solid color like those of the Ona, but are covered with elaborate polychrome designs of considerable esthetic merit. The Tehuelche robe was worn with the fur turned toward the body, while the Ona, who encountered more rain than the Tehuelche, turned the fur toward the weather. Furthermore, the Tehuelche held

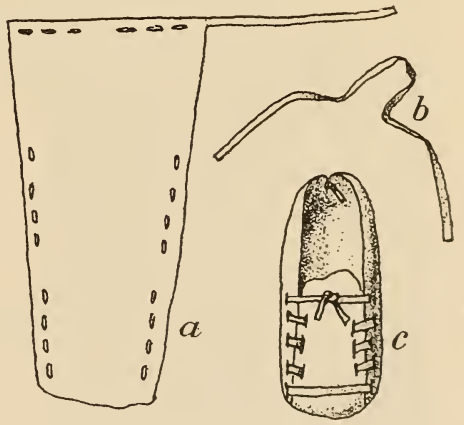

FIG. 8.-Pattern of Ona moccasin. their robes in place at times by a belt, while the Ona robe was not cinctured. In spite of these varied differences one is inclined to see technological relationship in the robes of the two tribes, though only in view of other and more directly related features.

The Ona moccasin (hámni) is made from the foreleg of the guanaco. After the hide had been scraped and soaked in water until soft, a pattern (fig. 8, a) resembling a long truncated cone was cut out, with a thong extending from one side. This thong served to sew together the heel. Next the foot was placed on the hide, the heel in its proper place, and the front of the skin was doubled over the toes and instep. At this point any extra trimming that may have been necessary was done. Holes were now piered 
along the sides. A heavy thong of guanaco neck or seal-hide (fig. $8, b$ ) was next passed over the toes and through the pairs of holes on either side, laced through successive side slits, and finally tied across the instep.

The moccasins were worn fur-side out, and are most attractive in appearance, for the fur is partly white and partly brown (fig. 9, a).

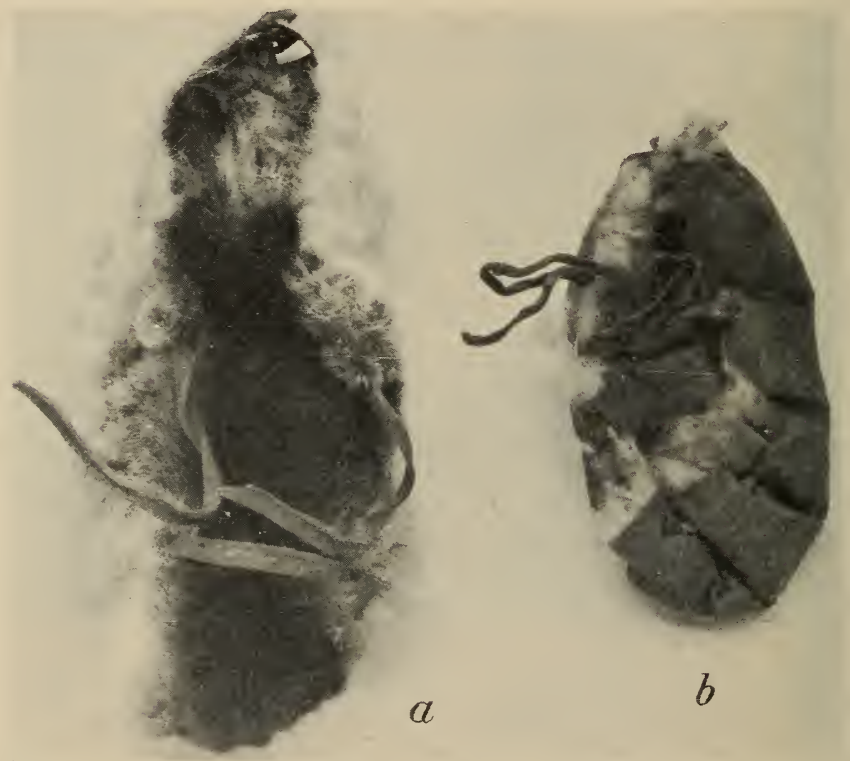

FIG. 9.-Ona moccasins. Length of $a, 101 / 2$ in. $\quad(14 / 2429,2432)$

They were stuffed with grass, which made them warm even when wet. Mr. Weld and the writer wore them at times and found them most comfortable and serviceable, though they tended to stretch when wet. Their smell is all-pervading and unpleasant.

The Ona moccasin bears no resemblance to the recent footgear of the Tehuelche, who in the nineteenth century wore skin boots made from the hocks of pumas or horses. However, the Tehuelche used at times what is described as an overshoe, and these probably were like the Ona moccasins. The Indians encountered by Magel- 
lan at San Julian in 1520 are said to have clad their feet in skins of a strange beast with "a large head, and great eares like unto a

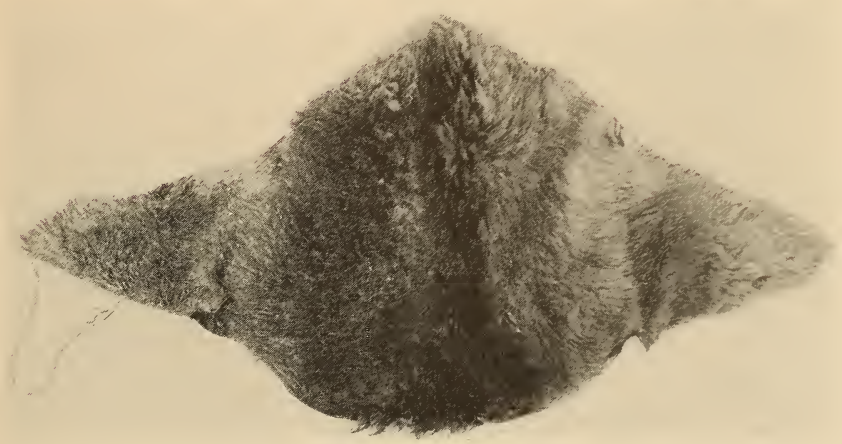

FIG. 10.-Ona headband. Length, 15 in. (14/2427)

Mule, with the body of a Cammell, and the tayle of a Horse." I This can only be the guanaco, and so it seems certain that once

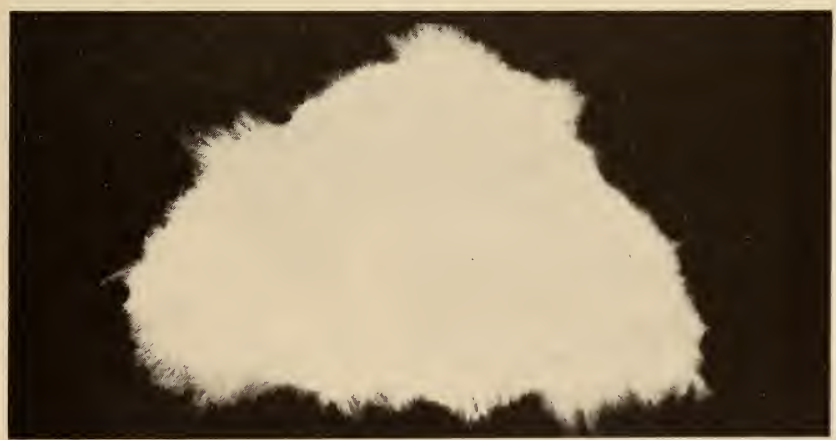

FIG. 11.-Ona shaman's headband. Length, 13 in. (14/2+25)

the Tehuelche wore footgear like that of the ()na. The Yahgan also made moccasins of a kind very much like the Ona.

${ }^{1}$ Purchas His Pilgrimes, ed. 1905, 11, p. 87. 
Robe and moccasins were the only garments regularly used by Ona men. When hunting or engaged in warfare, however, they wore what we may call a headband or fur diadem (gúchilq), consisting of a triangular piece of skin (fig. 10) tied across the forehead. It was made from the forehead of the guanaco, which is dull-gray in color. Combined with the thick hair affected by the Ona it

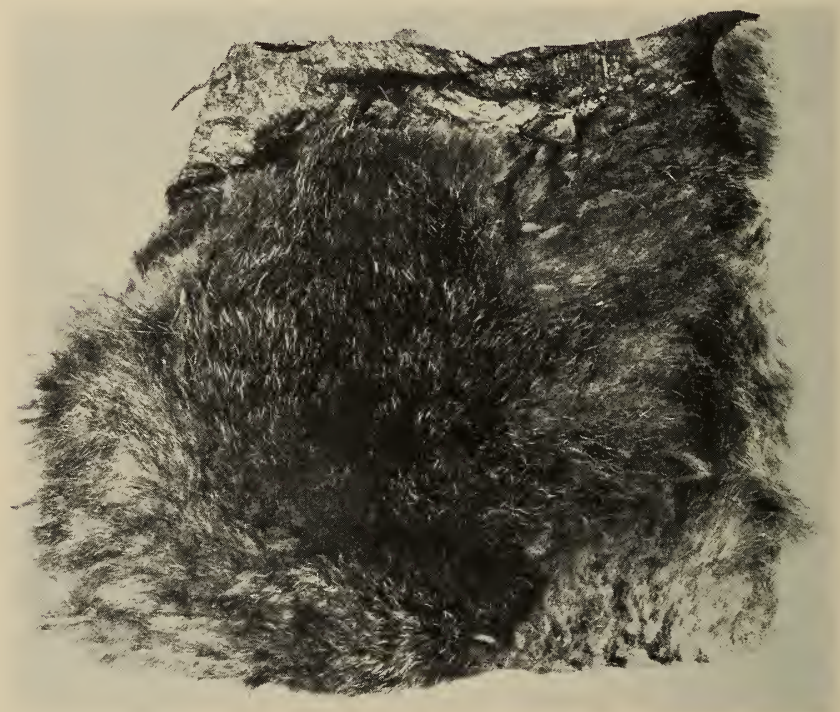

FIG. 12.-Ona man's carrying-bag. Width, 15 in. (14/2324)

afforded some protection from rain and snow, but primarily it was utilized on account of its protective coloring.

The Ona shaman on ceremonial occasions wore a similarly shaped cap $\left(\right.$ póorrh $\left.^{n}\right)$ made from the white down-covered skin of the kelp-goose (fig. 11). This may be a feature introduced from Yahgan sources, as it seems to have been used more frequently by that tribe.

During the winter, when hunting in heavy snow, the Ona occasionally used leggings, which they called $i r s h^{n} k$ ' $i$ l, " quiver of 
the leg." These consist of pieces of guanaco-skin with the hair turned inward; they are laced up the front. The eastern Yahgan also used them, and we illustrate an example (fig. 47) obtained from that source.

When away from camp the Ona man carried a fox-skin bag $\left(\right.$ hásin ${ }^{n}$ tucked under a hide thong encircling the waist. We show an example in fig. 12. Although carried as an article of utility, it undoubtedly provided added warmth, and it served as a pubic covering when the robe was discarded. The normal contents of this bag were: (1) a spare bowstring, (2) fire-making apparatus, (3) red paint, (4) a knife, (5) a scraper, (6) feathers, and (7) glass for making arrowpoints. This constituted a light load, but enabled life to be carried on for a long time away from the base of supplies. Similar bags, according to Vargas Ponce, were worn by the Tehuelche in the eighteenth century.

Women's Clothing. - The Ona women wore robes made like those of the men

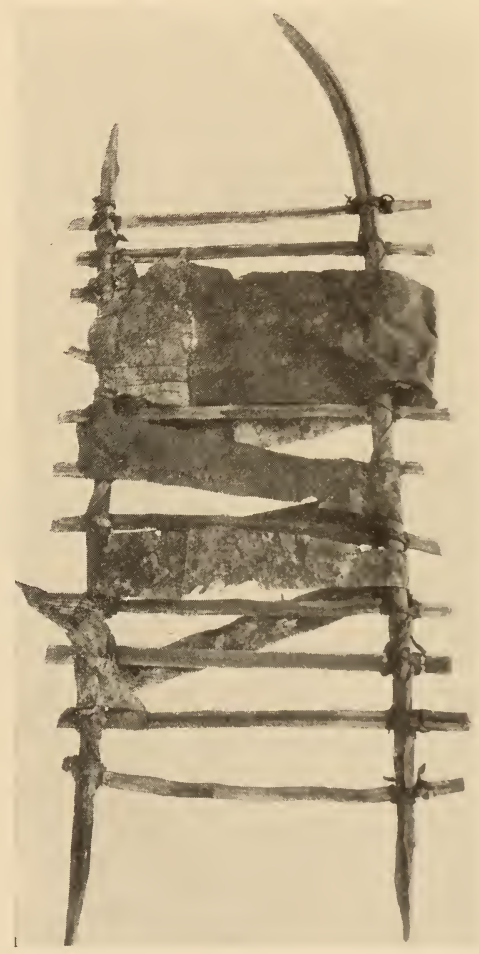

Fig. 13.-Ona cradle. Length, 30 in. $(14 / 2382)$

from two or three skins of the adult guanaco and similarly painted. They were likely, however, to be shorter than the man's robe, and often did not extend much below the knee. As the women had countless tasks to perform, they needed the full use of their hands, and so the robe could not be held in place; hence thongs were sewn to the robe and these were knotted on the chest. The Tehuelche women held their robes in place with a pin. 
While Ona men wore no body-covering but the robe, Ona women, who depended less on exercise for warmth, used as an undergarment a slip of guanaco-skin known as koi áten, "hip tie," which extended from the armpits to the knees. It was worn with the fur turned inward, and was secured around the waist by a thong. A similar garment was used by Tehuelche women, but the unfortunate Yahgan ladies had no such protection from the weather. Ona women always wore a small triangular apron of guanaco-skin (ské) as a pubic covering. It was secured around the waist by a thong. In fig. $4 t$ is illustrated an example of the similar garment found among the Yahgan.

Children's Clothing.-Ona children often ran naked even during the winter. However, they were provided with a guanaco robe of appropriate size. Sometimes they had small moccasins made with the fur turned inward (ónik). One of these is shown in fig. 9, $b$.

Infants were wrapped in skin and lashed with a spiral hide bandage to a cradle (taaq). As seen in fig. 13 this is a ladder-like frame of uprights and cross-bars. The points on the lower end were sharpened so that they might be thrust in the ground and the child kept away from the damp. At the top was placed a flap of hide to protect the infant's eyes from the glare of the sun. Both the Tehuelche and the Araucanians used a cradle, though of a different type from that of the Ona. Fuegian Canoe Indians, however, carried their babes in a fold of their capes.

\section{ORAAMENTATION AND DECORATION}

The Ona affected no form of hair-dressing to beautify their persons, but allowed the hair to grow like a shaggy mane except across the forehead where it was roughtly trimmed to form a bang. As a sign of mourning the top of the head was shaved. Body and facial hair, including the eyebrows, they removed with a pair of mussel-shells serving as tweezers.

Tattooing, found also among the Tehuelche, was limited among the Ona to incisions in the skin of the forearms into which they rubbed charcoal. Similar embellishment was practised by the Haush, but was not known to the Canoe Indians.

Facial and body painting (fig. 34) they practised both on ceremonial occasions and in everyday life. Red and orange paint was obtained by burning suitable earth, found apparently in many places. For white paint they employed pure white clay. Ground 
charcoal supplied black paint. These colors were applied with the hand or finger after mixing the pigment with saliva or grease. The patterns, simple in character, may be studied in the series of portraits published by Gallardo. Among the Ona we noted the widespread New World belief that paint gives protection against the weather and wards off sickness. The Tehuelche told Captain Musters (1871, p. 163) that they painted their faces to "keep off the wind."

The chief ornaments were anklets and wristlets, worn singly or in pairs. Usually they were made of guanaco-sinew finely braided (chemq); sometimes they were of plaited grass (tai), as seen in fig. 14. The Yahgan made no bands of this type, but they braided grass ropes to secure their canoes.

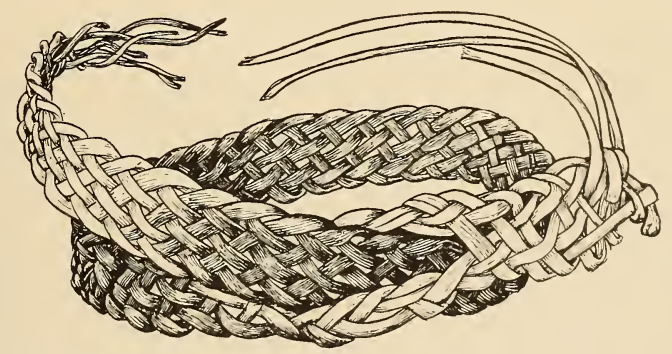

FIG. 14.-Ona braided grass anklet. Width, $5 / 8$ in. (14/2409)

Necklaces were manufactured from braided guanaco-sinew, on which were sometimes strung cylindrical beads cut from the leg. bones of birds.

\section{The Encampuent}

To our eyes the greatest deficiency in the material culture of the Ona was their lack of a dwelling-house. Instead they used a windbreak (káwi) manufactured of guanaco-hides sewn together and painted red. A specimen in the Museum, probably the last ever used in Tierra del Fuego, measures $8_{2}^{\frac{1}{2}}$ by 12 feet, but, as it was set up not in the old-fashioned way but wrapped around a conical log frame, I imagine that it is wider than the usual shelter (fig. 15).

To make camp, the Ona pegged with thorns or else lashed their skin shelter to trees, were any a vailable. For camping in the open 
plains, sticks (léul or árrte) five or six feet long were carried; these they drove into the ground, and to them the shelter was lashed. The windbreak if possible was erected to form an arc of a circle, inward-sloping toward the center, for thus the fire was shielded from the vigor of the wind, and the family secured a meager measure of shelter from rain or snow. Against the walls crowded men, women, children, and dogs in a common search for warmth. A winter night with a gale blowing and snow falling cannot have been comfortable.

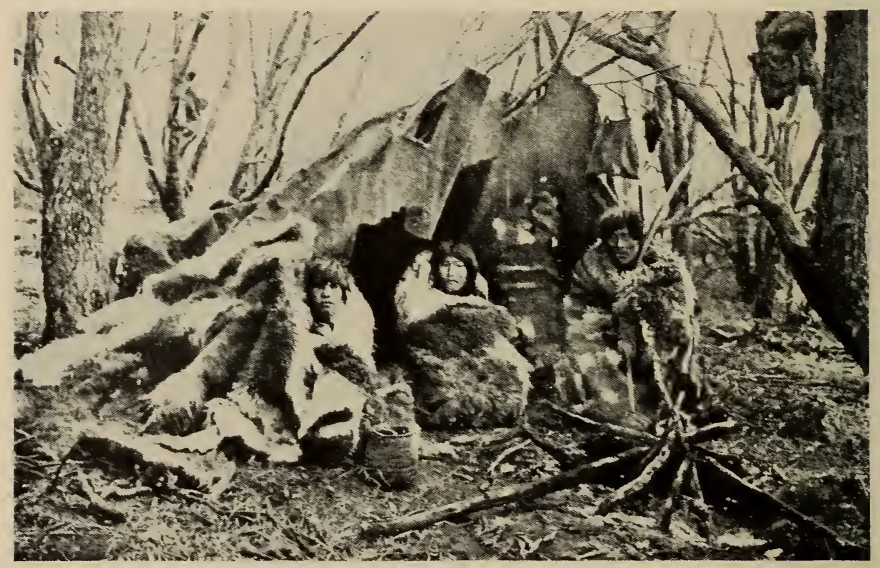

FIG. 15.-Ona family in camp. (From Alberto M. De Agostini, I Miei Viaggi nella Terra del Fuoco.)

Ona windbreaks have been thought to be the prototype of the Tehuelche toldo or kau. This was a skin house with three vertical walls and a sloping roof supported by three rows of stakes. While the fourth side, which faced eastward, i.e., away from the prevailing winds, was normally left open, in very cold weather the Tehuelche sometimes added a fourth row of stakes, an extra section of roof, and a fourth wall. At the back of the toldo hide curtains were hung between the poles to form small sleeping compartments, while the front of the tent formed the common living-quarters. From this brief description the reader will see that about the only resemblance between Tehuelche toldo and Ona windbreak was 
that both were made of guanaco-hide and set on stakes. However, the Tehuelche could not have used these large and heavy houses of skin before the advent of the horse, for unless a man employed a numerous retinue of wives such tents could not have been transported.

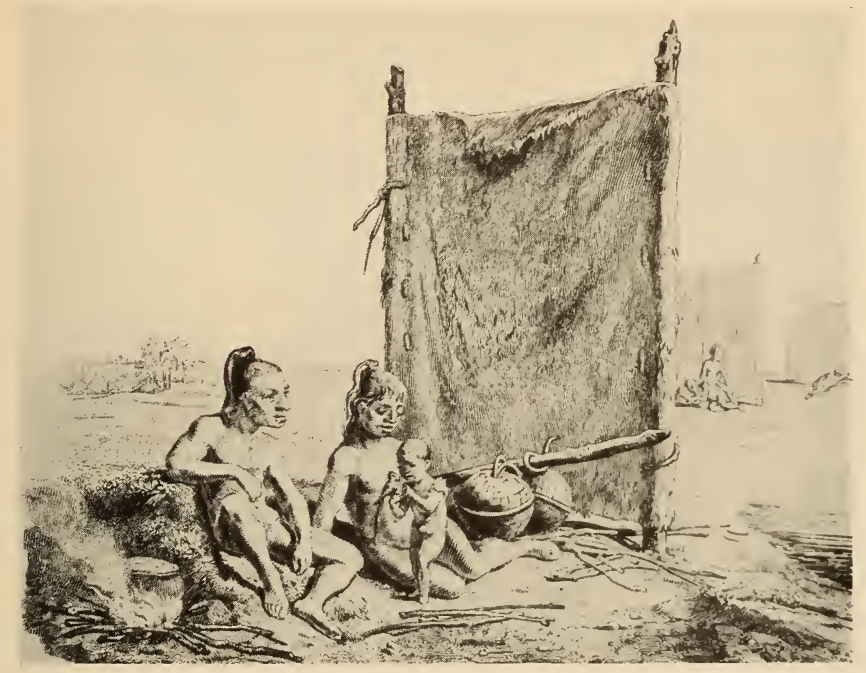

FIG. 16.-Skin windbreak in Patagonia. (After Oviedo.)

Oviedo (lib. Xx, cap. VII), in recording the voyage of Loaysa in 1526, has preserved a description of the natives near Bahía de la Victoria who used a windbreak of Ona type. His illustration we reproduce in fig. 16. It might be argued that this was seen on the Fuegian and not the Patagonia side of the straits, but Oviedo expressly states that no people were encountered by this expedition on the south shore. Bahía de la Victoria is a name rarely found on even the earliest charts, but on the map of Alonso de Santa Cruz ${ }^{1}$ it is shown on the north side of the second narrows, and hence must correspond to the modern Pickett, Withsand, or Oazy bays. The fact that the words used by the ()na (kizi'i) and

${ }^{1}$ Innsbruck ed., 1908, pl. xv; Madrid ed., 1918, pl. 120. 
Tehuelche $(k a u)$ to name their habitations are similar, goes far to substantiate Oviedo's attribution of the windbreak to the Tehuelche.

In moving camp, the Ona household goods, of which we shall speak presently, were packed away in baskets and bags. The shelter was taken down and the irregular edges folded in to form a rectangle. The household effects were then placed in a line along one edge, with the larger objects in the center, and the whole was rolled and lashed to form a cigar-shape pack. This might measure six feet long and weigh as much as two hundred pounds (fig. 17).

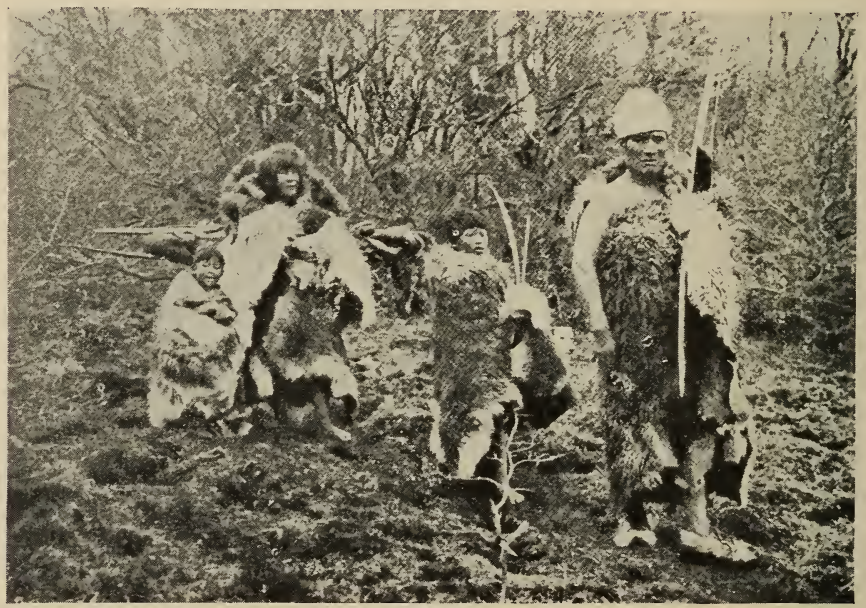

FIG. 17.-Ona family on a journey. (From Alberto M. De Agostini, I Miei Viaggi nella Terra del Fuoco.)

On the march the pack was carried across the woman's back and was suspended by a harness $\left(m o ́ w i^{n}\right)$ which passed over the chest. This consisted of a great many-perhaps thirty-small parallel thongs to support the weight without cutting into the flesh, and a few longer thongs which served to secure the pack (fig. 18). In walking through forests the women often had to turn sideways to pass between the undergrowth: then the pointed ends of the bundle were an advantage. On account of the great weight to be balanced, the women often carried a tall walking-stick, called na kléul. 
Formerly the Ona erected for their ceremonies conical lodges of heavy logs covered with sods (fig. 38). Such houses of course could not be moved, but one wonders why each Ona family did not have one or more log-and-sod houses so situated that they could be occupied during the most extreme weather. They did apparently in rare instances erect such lodges for habitation in the old days, but on the death of any member of the family the

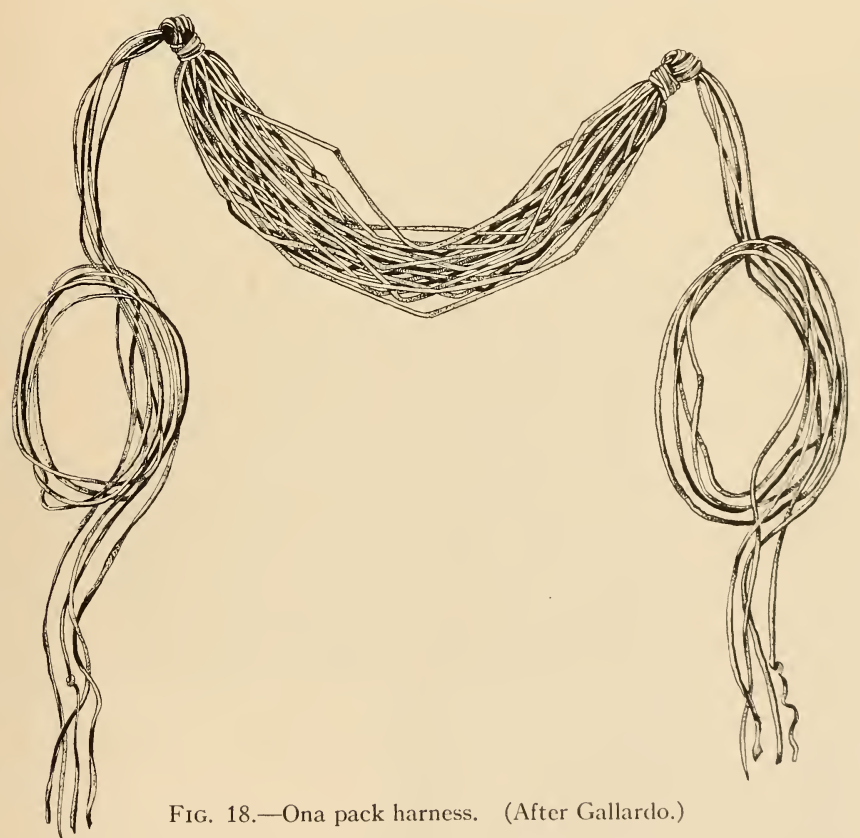

house was burned. Before the white colonization brought metal axes to the island it must have involved much labor to erect logand-sod lodges, and so the Ona preferred their windbreaks. It is not true that the Ona were so superior physically that cold did not affect them; rather it seems to have been a case of shivering and suffering through laziness and lack of initiative.

After the introduction of the ax by Europeans, with the resultant greater ease in obtaining poles, the Ona adopted the practice of 
erecting conical wigwams. These were about ten feet high and were thatched with leaves or burlap to a height of six or seven feet. As such structures did not give complete overhead protection, they might be described as circular windbreaks. As in the case of Yahgan houses, the Ona of ten sunk the floor slightly under ground in order that the fire might gain added protection and that advantage might be taken of the tendency of heat to rise. Bunks they built along the sides by means of logs secured with stakes.

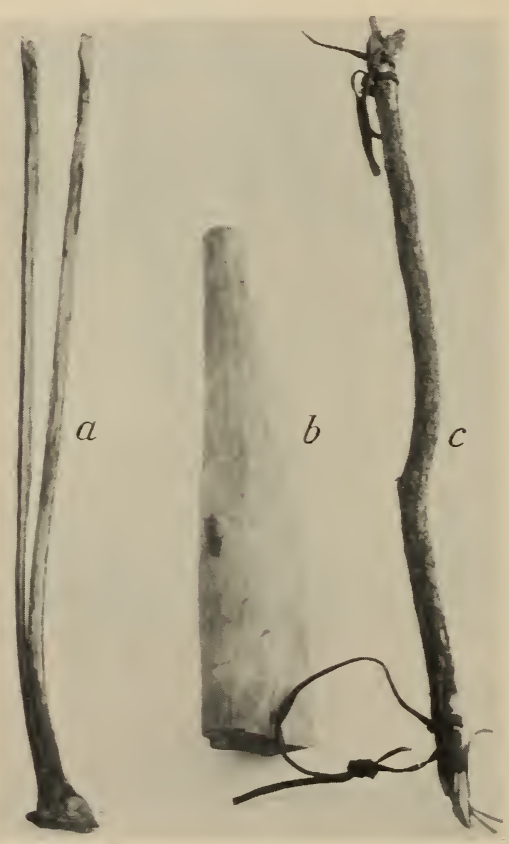

FIG. 19.-Ona fire-tongs, hide-beater, and dog-leash. Length, 29, 18, and 29 in. (14, $2 \pm 01,2 \pm 1 i, 2 \pm 00$ )
On their bunks they piled branches covered with skins.

During recent years a few Ona erected houses of European style from hand-hewn boards. The roofs of these were reasonably tight, but the side-walls were so full of chinks that they scarcely impeded the wind, which was ever redistributing the filth of the soot-blackened interior. Without doubt a migratory hunting people should not attempt to live in permanent quarters until they have learned something of sanitation and hrgiene.

\section{CAMP EQUipMeNT}

Ona household utensils are simple, strong, serviceable, and light in weight, so that they may easily be transported.

1. Fire-Making Apparatus.-All the Fuegian tribes made fire with iron pyrites (yarr hauk), a piece of flint, and a dried fungus (uo) or bird-down for tinder (fig. 53). As pointed out by Dr. 
Cooper this method without doubt is pre-European, because it was observed on the Straits of Magellan as early as 1580 . This appears to be an example of independent invention, for the Tehuelche, Pampas, and Araucanian tribes all made fire by drilling.

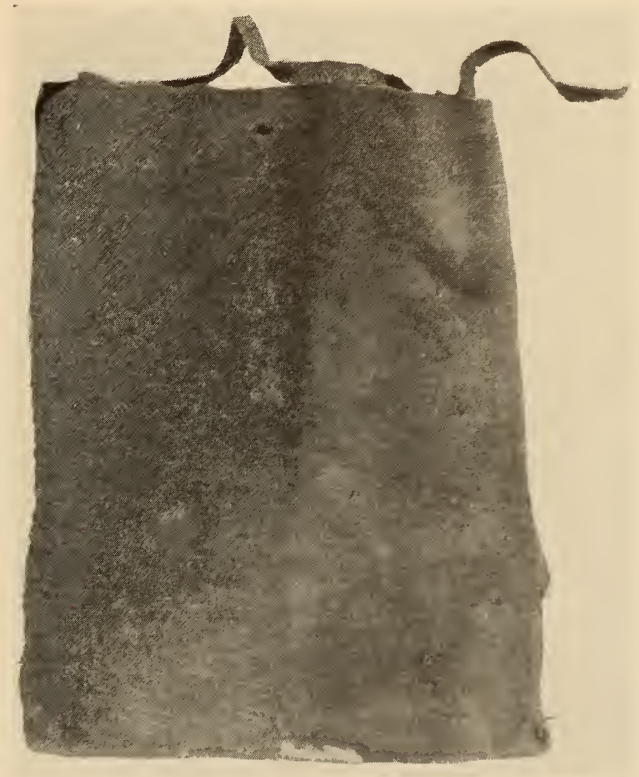

FIG. 20.-Ona water-bag. Width, 9 in. $(14 / 2383)$

In the geological section of the Museum at Punta Arenas pyrites specimens from the Straits of Magellan, Mercury sound, Clarence island, Merton island, Union bay, and near Lake Fagnano are on exhibition. This material seems to be widely distributed, but Rev. Thomas Bridges writes that Clarence island was the principal source of supply, at least for the Yahgan, who obtained it through the Alacaluf. The fungus used for tinder we saw growing in the interior of the island, especially behind Harberton and at the east end of Lake Fagnano. The Tehuelche also used fungus for tinder. 
2. Fire-tongs.-Every Ona household carried a pair of firetongs, such as are illustrated in fig. 19,a. They are simply sticks, usually of barberry wood, split for the greater part of their length. The Ona (lákel) and Yahgan (láka) words for this implement are

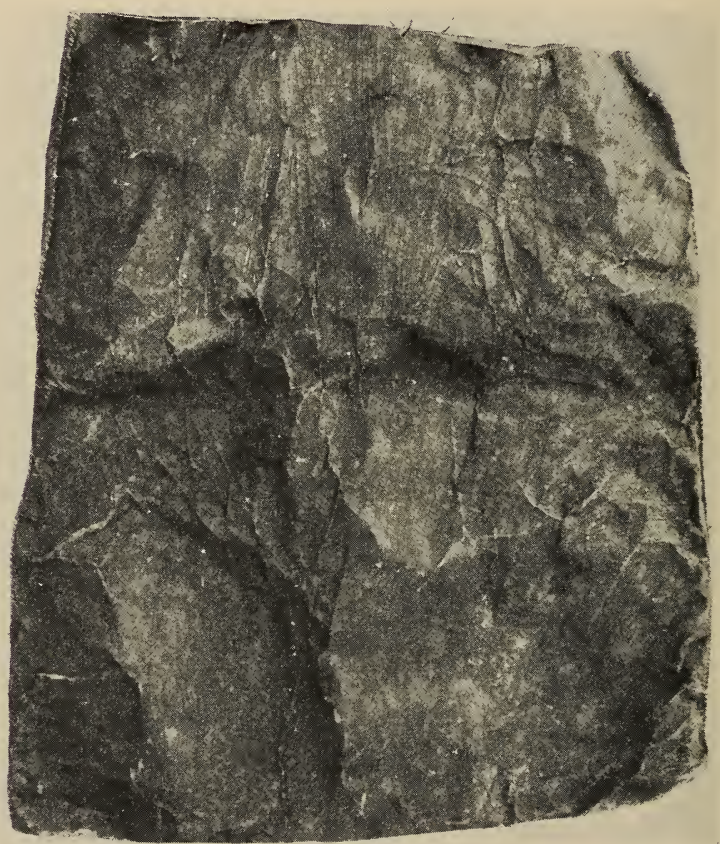

FIG. 21.-Ona guanaco-hide storage-bag. Width, 21 in. (14/2385)

clearly akin, so one tribe must have borrowed it from the other; but we have no way of deciding who originated it.

3. Grease Stone.-Each family carried a smooth, water-worn stone five or six inches in diameter, the primary use of which was to collect marrow by cracking the hot bones on the cold stone on which the grease then congealed, so that it could be scraped off and eaten. This stone served also as an anvil or hammer, and perhaps as a sharpening stone, though a smaller stone 
of the same type usually was carried for whetting tools. The Ona employed the grease stone to cook seeds, heating it in the fire and then scattering seeds over the upper surface.

4. WATER-BAG.-For carrying and storing water the Ona used a bag (sĕ) of guanaco-hide covered with red paint (fig. 20). Both bag and handle were cut from a single piece of hide in much the same pattern as the heel of the moccasin (fig. 8, a). Water is easily obtained in Tierra del Fuego in summer; in winter the Indians filled the bag with snow and hung it near the fire where the snow would melt. The Ona had no kind of drinking-cup, but the Yahgan used a shell. The Tehuelche sometimes used a skin waterbag.

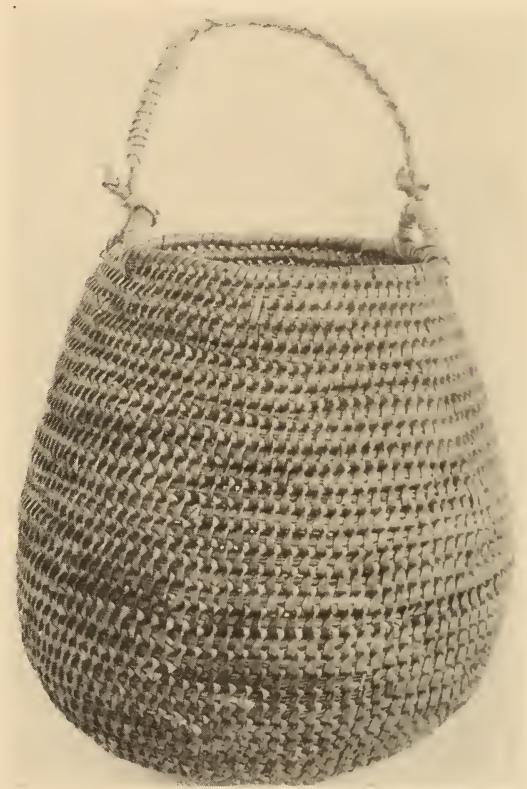

FIG. 22.-Ona basket. Diameter, 7 in. $(1+/ 2430)$

5. Stora GE-BAGs. -

For storage, bags of varying shapes, sizes, names, and materials were used, and also baskets. Three kinds of bags, however, formed part of the equipment of every household:

(a) A large fox-skin bag (hásin) carried by the men on a thong around the waist, illustrated in fig. 12;

(b) A guanaco-hide bag (shetelóli), painted red, used primarily by the women to hold their smaller belongings, illustrated in fig. 21;

(c) A small fox-skin bag (kólwee) employed for storing red paint, which the Ona used to adorn their persons and most of their utensils. 
In addition to the above, bags were made of seal-skin, bird-skin, seal-bladder, whale-intestine, or whatever material was at hand when a bag was needed.

6. Baskets.-The Canoe Indians were the real basket-makers of Fuegia, and the four types in use among the Yahgan are described in detail below. The commonest of these, known to the Yahgan

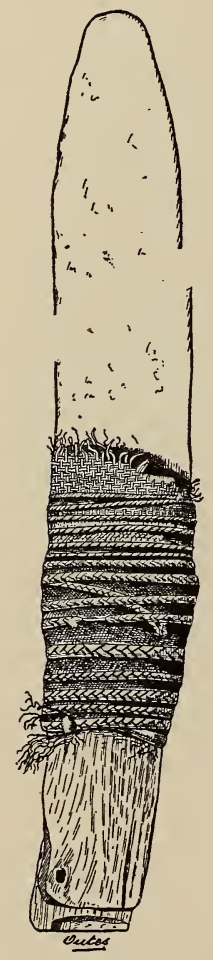

Fig. 23.-Ona knife. Length, $85 \% 8$ in. (After Outes, 1906.) as tawéla, is a coiled basket sewn with half hitches (figs. 59 and 61). This was copied by the southern Ona (fig. 22), who had no name for it beyond that of the grass (tai) from which it was manufactured. That the northern Ona ever made baskets is questionable.

7. Сомв.-Ona combs (ómche) were sometimes cut from a piece of wood or whale-bone; often they used a porpoise or an otter jaw. Yahgan examples of the two types appear in fig. 54 .

8. Dog-LEash.--To secure their dogs in camp, to prevent their stealing food or straying, the Ona employed a stick two or three feet long with thongs attached to grooves in each end (fig. $19, c)$. One thong was tied to the dog's neck and the other to a small tree: thus the animal was free to move about, but could not reach his lashings to gnaw himself loose.

\section{Tools}

Ona tools were few in number and of the simplest types. Descriptions have been published by Outes (1906) and by Gallardo (1910).

1. Knife (péye).-The Ona knifeblade was any obtainable piece of scrap-iron. Barrel-hoops and discarded fragments of European tools were commonly used. Two types of handles were employed. In one the blade was bound with 
a hide thong against the side of a wooden handle; in the other the wooden handle was split and then lashed together again, enclosing the blade between the two pieces (fig. 23). Prehistoric knives are described below (page 112).

2. Flesher (cham).-For cleaning hides the Ona used a wooden handle with a deeply beveled transverse notch at one end. In this, cushioned on hide or moss, was set a piece of glass (fig. 24).

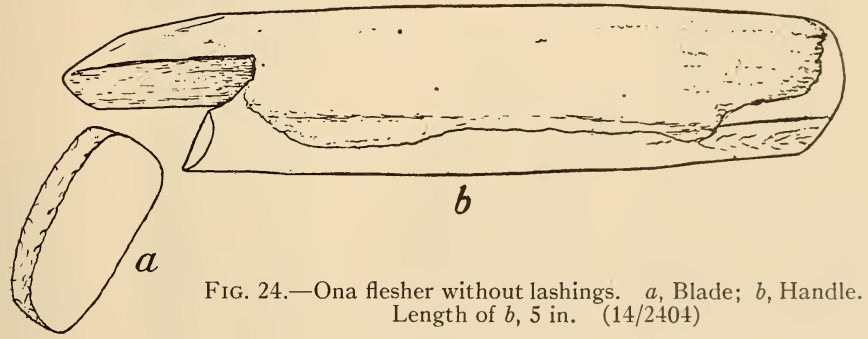

Longitudinal thongs held the blade in place while transverse wrappings secured the whole (fig. 25, b). This form of scraper is evidently very ancient, as stone blades fitted for this type of hafting occur at old camp-sites (pl. viII, $b, c, e$ ). However, one suspects that the first blades thus hafted were mussel-shells, which to this day are also known as cham.

In use the scraper was placed in the hand with the blade under the ball of the thumb, and was pushed across the hide away from the body.

3. Wood Scraper (teklek).-A second type of scraper (fig. 25, a) employed in woodworking consists of a metal blade set on a handle in the same manner as the knife. It differs from the knife in that the cutting edge runs across not the side but the end of the metal. This tool, employed principally for bow and arrow making, was worked toward rather than away from the hody.

4. Awl (móoh).-Awls were employed by the Ona for various purposes, including lasketry. In recent years they were made of metal, set in a bone or wooden handle (fig. 26); but formerly they were of bone.

5. Chipping Tool (ko heurrhásh).-In chipping glass in recent years, and doubtless in working stone long ago, the Ona made use 
of a small leg-bone of the guanaco (fig. 30) sharpened to a dull point.

6. Sharpening Stones.-Metal tools were sharpened on stone. To give the final edge, a small, close-grained, water-worn stone was

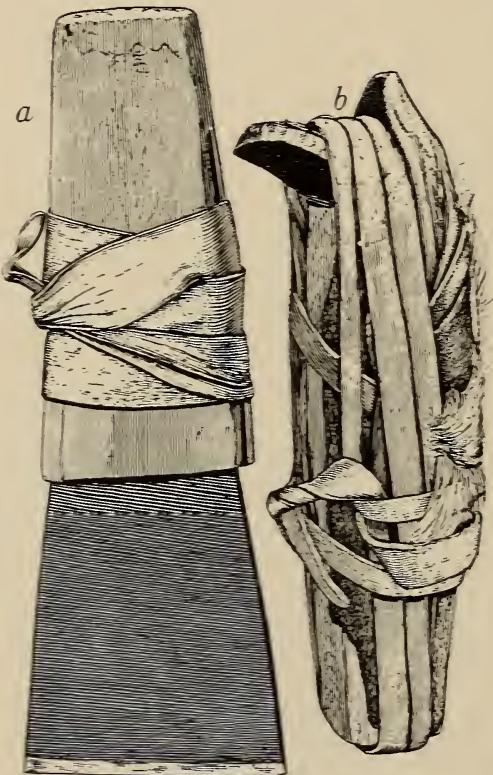

FIG. 25.-Ona scrapers. a. Wood scraper; b. Flesher. Length of $a, 51$, in. $(142412$, $2 \pm 0 \pm$ )

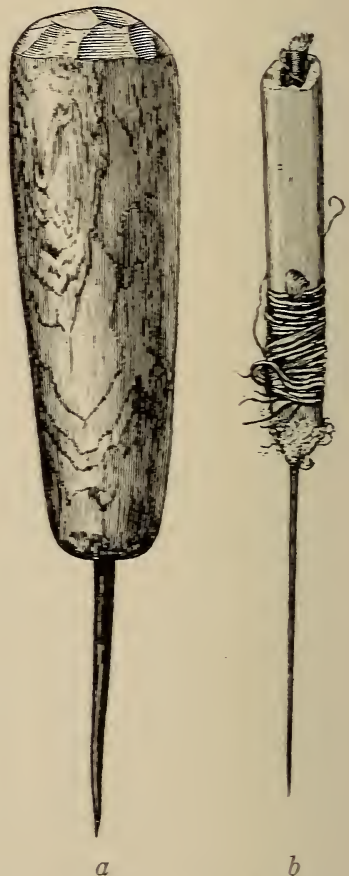

Fig. 26.-Ona amls. Length, 33 and 5 in. $(1 \pm 2 \pm 16,2 \pm 15)$

utilized (fig. 31, a). Another sharpener, known as yarr heuirrhásh. is a coarse-grained stone employed to sharpen the chipping tool (fig. 31, b).

7. Stone Shaft-polisher (ham $k^{\prime}$ yarr). - This type of stone. marked by one or more grooves across its surface, was widely used among primitive arrow-makers. In Tierra del Fuego (fig. 2i) it 
was of a coarse variety. One suspects that stones which had long served to sharpen the chipping tool (fig. $31, b$ ) in time became grooved and were then employed for polishing arrowshafts.

8. Skin Shaft-Polisher (shoshróshtel).-A small bit of fox-skin with a mixture of sand in the fur served the Ona as sandpaper and gave the final polish to their arrows (fig. 28).

9. HidE-BEATER (árrte kaíyekásh).-In recent years these Indians softened skins by beating them with clubs of the type seen in fig. 19, $b$. I was told that this practice was unknown to the natives before the white colonization.

\section{Weapons and Methods of Hunting BOW-MAKING}

As a hunting people the Ona depended for their existence on the bow $(h a)$; and to its manufacture, management, and protection they devoted an extraordinary amount of care. Not every man made bows; rather highly skilled artisans undertook their production, receiving game or some favor in payment for their labor. Almost every man, however, made his own arrows, because the supply might run out and anyone who was dependent on others would be at a great disadvantage.

The bows were made from the wood of the smallest of the three beech trees (Nothofagus antarctica) which grow in Tierra del Fuego. In Spanish it is called ñire; in the Indian tongue it is

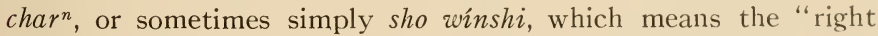
tree," i.e., for making bows. From the selected tree they split a fragment six or seven feet long and three or four inches thick, which must come from just beneath the bark where the wood is most elastic. From it the bow was worked down with a scraper (teklek) until it was from four feet four inches to five feet four inches long and had assumed the requisite outline and form.

The outline is that of the new moon, curved even when unstrung, swelling in the middle, and tapering delicately to the tips. Small flutings cover the entire surface. ( )n bows made years ago they are most carefully fashioned, so that each single fluting runs from tip to tip, swelling and diminishing in accordance with the diameter of the bow. But on more recent bows, made for the greater part to sell to Europeans, the fluting is not executed so faithfully. In 
cross-section the bow is tear-shape ( $\mathrm{pl} . \mathrm{v}, \mathrm{f}$ ), and the point forms the "belly" of the bow which was held toward the archer.

This is a very unusual weapon, for most bows are flattened at a right-angle to the line of pull, in order to make them more flexible; but the Ona did not want a flexible bow, for several reasons. In the first place the bowstring he employed stretched under tension; also he drew the nock of his arrow not to the ear, as in classical archery, but to the chin; furthermore the bow was pulled not against a stiffly extended arm but against a bent arm, which was snapped straight at the moment of discharge to add to the impetus of the arrow.

One cannot but wonder why, how, and where this strange bow of the Ona was devised. Did some individual acquire fame by shooting in this unusual but effective fashion, and hence cause others to imitate him? Was the region where this bow was perfected (perhaps before the settlement of Fuegia) devoid of flexible wood suitable for bows, so that a peculiar style of archery arose? There seems to be no answer. However, the beechwood of Tierra del Fuego is capable of greater flexion than the Ona thought desirable, according to Mr. William Bridges, an expert archer of the Ona school, who told the writer that he had made of this wood for his own use (patterned after a bow from the Paraguayan Chaco) bows which were thinner and more flexible than customary among the Ona.

Bows with the curious Ona cross-section and outline were manufactured by the Yahgan, the Alacaluf, and perhaps the Chono. The writer has never seen a bow of the Tehuelche, who discarded this weapon in favor of the bola during the eighteenth century. In the sixteenth century, according to Oviedo (lib. $\mathrm{xx}$, cap. vI), Tehuelche bows were "short and stout and broad, of very stiff wood." In the Museum there is an ancient weapon (9/7063) suggestive of the Ona bow; it was found in the cave of Chiuchiu in the Atacama desert in northern Chile. Arrowpoints from northern Chile, however, recall Patagonian rather than Fuegian types.

To return to the Ona bow, the bowstring ( $h a k y u h$ ) was made of twisted sinews from the foreleg of the guanaco. This sinew they extracted by passing a noose beneath it and thus working it free from the flesh. It was attached by forming a slip-noose and placing it around the bottom of the bow (pl. v, g). The top of 


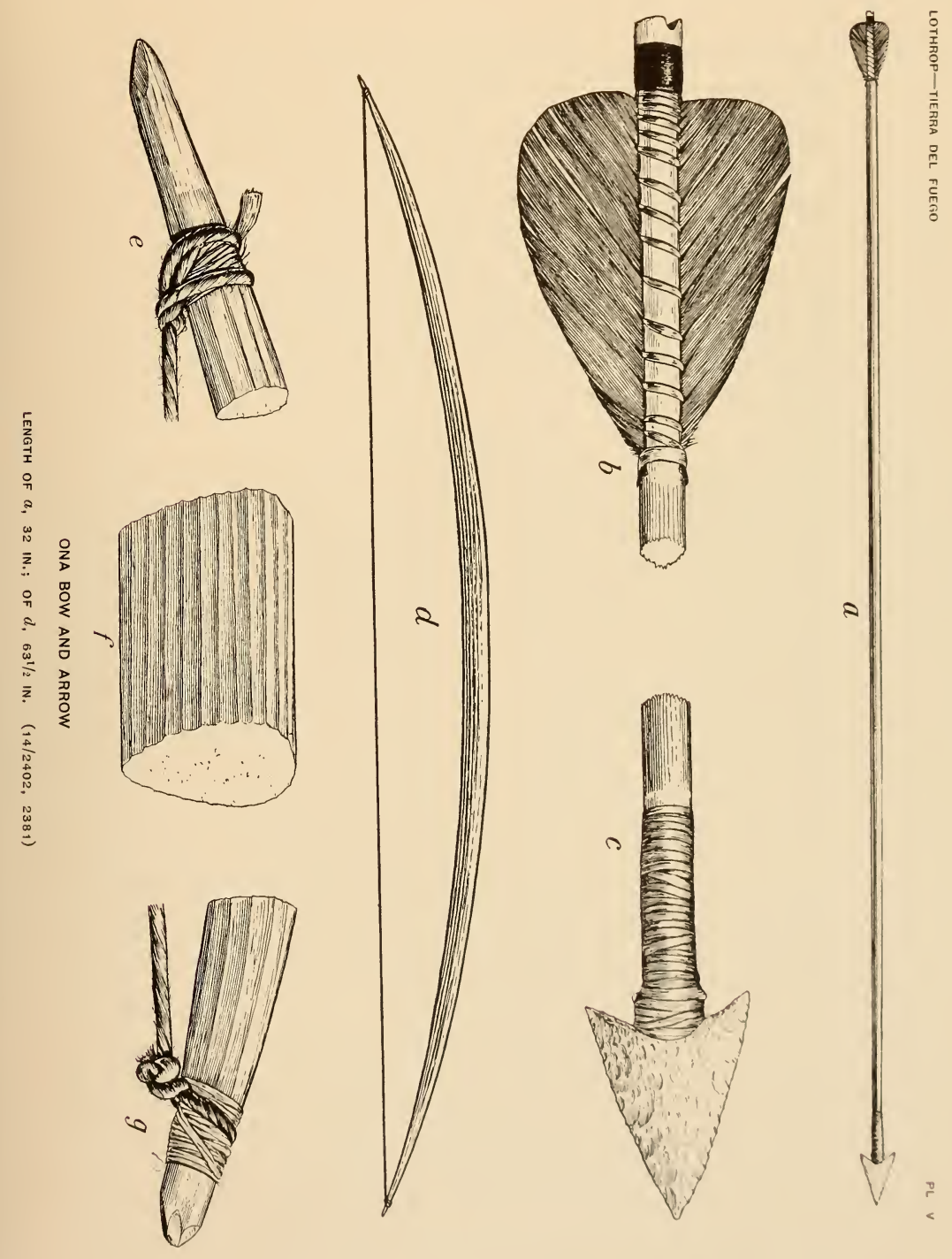



the bow was then grasped in one hand with the forearm running along the "belly"; the bottom was set on the ground against the outside of the foot with the "belly" against the knee. The bow was then flexed slightly by pressing outward with knee and elbow, a turn was taken with the bowstring around the top of the bow and knotted with half-hitches (pl. v, e). On some bows, such as the one shown in pl. $\mathrm{v}$, the bowstring is cushioned at either end on wrappings of guanaco back sinew.

They gave a finishing touch to the bow with a coat of white paint made from clay (kaistrrh) and water. Thereafter both wood and bowstring were frequently greased that they should not become too dry and lose any of their power.

\section{ARROW-MAKING}

While the Ona bow was wrought with great care and is a serviceable weapon, the acme of Ona ingenuity and craftsmanship found expression in the making of arrows $\left(y a h^{n}\right)$. Four kinds of wood were used for the purpose. The best of these was a yellow wood from a holly-like tree (Pernettya mucronata), known to the Ona by the same name as the arrow itself, $y a h^{n}$. When obtainable, this wood was always used for arrows, but it did not grow in the open plains of the north and east, so that substitutes were necessary. The first of these was barberry (Berberis buxifolia), called metq, which is common in the Rio Fuego district. Another, called goorrh, is a fashine (Chiliotrichum amelloideum) found in the northeastern portion of the island. More rarely a kind of currant bush known as shiterhén was employed.

All these woods are strong and light, but they grow twisted and bent. Hence, when they had been split into four pieces of proper length and roughly rounded, it was necessary to straighten them. This was done by heating each piece over a fire and bending it in the teeth.

Next a piece of skin was doubled and placed across the hand to protect it while the arrowshaft was worked down to the proper size with the same scraper (teklek) used in bow-making. Great was the care taken during this operation, for the arrow must be tapered to either end with nicety. The final straightening of the shaft was accomplished with both the scraper and the teeth. At this time the nock was cut.

While the scraping proceeded the smoothing stone (ham k'yarr) 
had been standing near the fire, so that it was now thoroughly warm. This is a block of coarse stone (fig. 27) across which run one or more grooves. In the grooves the arrowshaft was rubbed

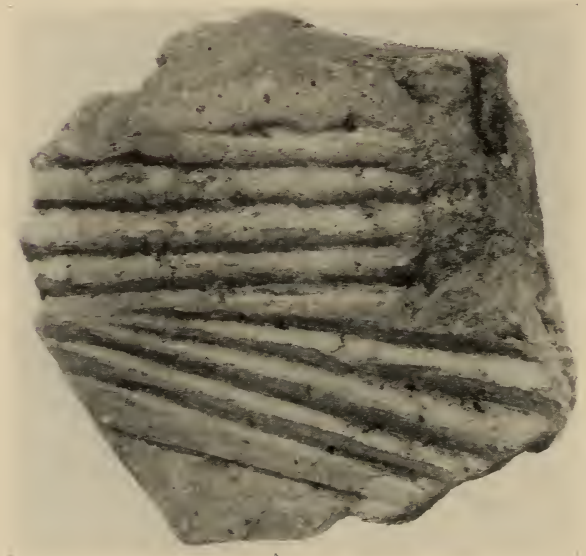

FIG. 27.-Ona arrowshaft polisher. Diameter, 9 in. $(14 / 2399)$

back and forth, pressed against the stone by a bit of foxskin (shoshróshtel). A final polish was given by this skin itself (fig. 28), which soon became impregnated with dust from the smoothing stone. The result was a tapered, balancedshaft with a satin-smooth polish which might well be the envy of a furniture finisher. Next a bit of pitch $(t a k)$ was chewed while the tip of the arrow was warmed

over the fire. When the pitch was softened a little ash was worked into it, and a tiny ring of the mixture attached to the arrowshaft just above the nock in order to insure a better grip (pl. $\mathrm{v}, b)$. This pitch, by the way, comes from the wrecked ships with which the turbulent Magellanic waters have supplied the natives since the sixteenth century. Small bits may be picked up on the beach at times. The

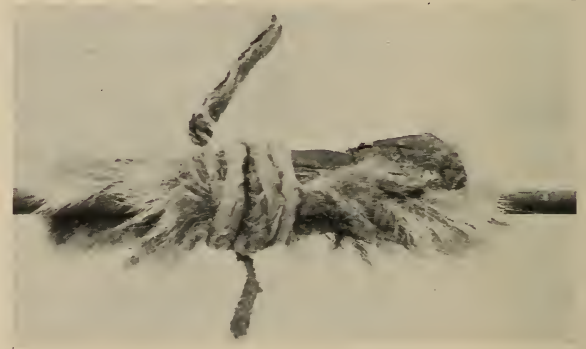

FIG. 28.-Ona polisher of skin. Length, 5 in. $(14 / 2411)$

Ona think it may be the excrement of whales. 
Both ends of the arrowshaft were now coated with white clay diluted in water. This process (kaistrrh yahn timeren) was not esthetic but utilitarian, for the lashings of the head and feathers were thus afforded a firmer grip on the wood.

The two feathers used on arrows normally were those of wild geese, especially the upland goose (kaikén), but swan-, vulture-, and eagle-feathers were also employed. Tehuelche arrows, according to Oviedo (lib. $\mathrm{xx}$, cap. vI), were tipped with three feathers. The Ona word for feather is shitrrh, but the arrow feather is sho shitrrh, meaning the correct feather. This distinction they made because a right-handed man used feathers from the bird's left wing, and vice versa. The proper feather secured, with a knife they split it in two, trimmed

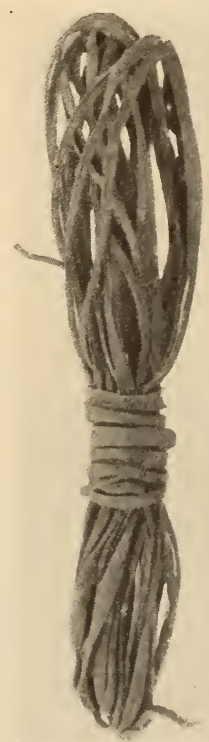

$a$

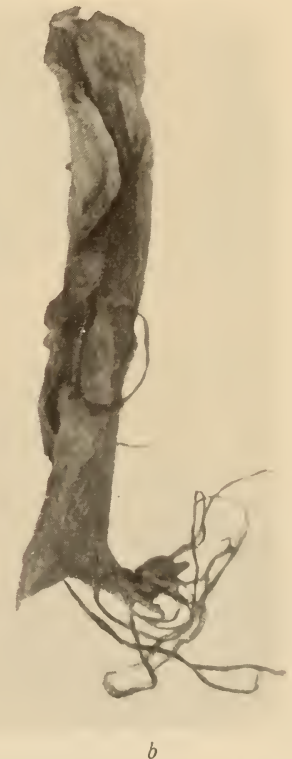

$b$

FIG. 29.- $a$, Thong of guanaco-hide $(1+/ 2+14)$. $b$, Guanaco back sinew (14/2413). Length as shown, 15 and 13 in. it, and attached it to the shaft with spiral lashings (pl. v, $b$ ).

Lashings $(y u h)$ both for feather and point were obtained from the skin muscles on the back of the guanaco (fig. 29,b). The

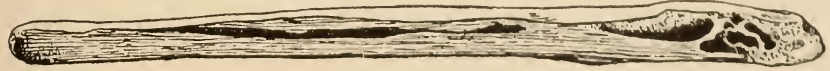

FIG. 30.-Ona chipping tool. (After Gallardo.)

sinew was softened in water and split to paper thinness. The feathers were secured with spiral lashings carefully inserted through the plumes. As many as twenty turns were used to attach feathers 
only an inch and a half long. When the fastening was complete it was dried by propping the arrow on a $\log$ so that it projected

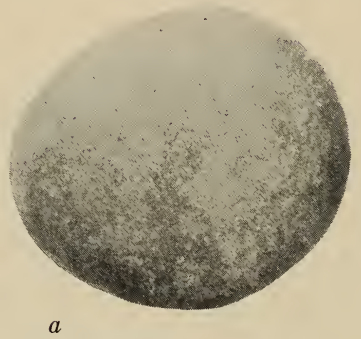

$a$

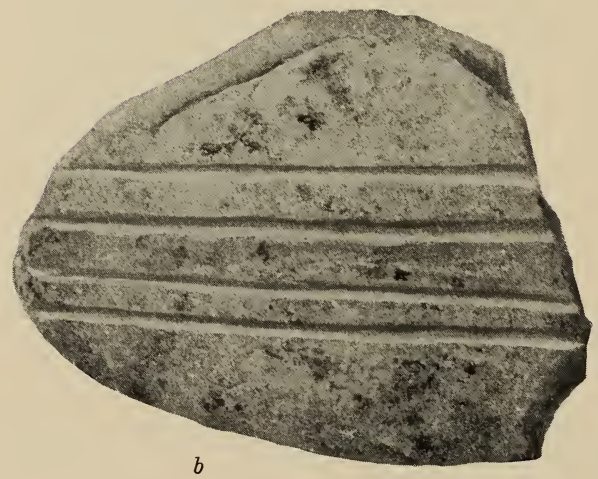

FIG. 31.-Ona sharpening stones: $a$, for steel; $b$, for bone. Length, 4 and 6 in. $(14 / 2419,2386)$ over hot coals or ashes, but far enough away to prevent it from burning.

So much for the arrowshaft; we must now see how the arrowpoint was made. Long ago the Ona used stone points, but after coming in contact with Europeans they made glass points, normally fragments of bottles worked down to the proper shape and size. The Ona chipped by pressure exerted with a small guanaco-bone tool (ko heúrrhásh), illustrated in fig. 30. This implement in time became too blunt and was sharpened again on a piece of coarse stone ( yarr heúrrhásh) shown in fig. $31, b$. When at work they usually protected the hands with a bit of fox-skin in order to avoid being cut by the glass. Usually they worked on several arrowpoints in rotation, holding in their mouths those with which they were not actually occupied. This, they said, warmed the glass, made it less brittle, and therefore easier to flake.

The object of the chipping was to create a razor-sharp triangular blade such as appears in fig. 32, $a$, and to reduce the thickness of the glass to a little more than one-sixteenth of an inch. Diagonal 
notches were then sunk from the corners to make the tang, resulting in the characteristic form seen in fig. 32, b. A good workman could finish such a point in ten or fifteen minutes.

Evidently the shape of the arrowpoint did not change for a long time, for ancient stone blades are like the modern ones. Occasionally points of this type have turned up in Patagonia and central Chile, but the common Patagonian point (fig. 32, c) has its tang and barbs
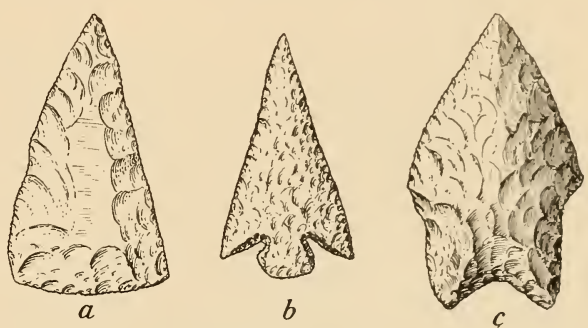

FIG. 32.-Arrowpoints. $a$, Unfinished Ona glass point $(14 / 2408) ; b$, Ona glass point $(5 / 8546) ; c$, Patagonian stone point (12/7377). Length of $a_{\text {, }}$ $11 / 2$ in.

set in a manner totally unlike the Fuegian.

After completion, the arrowhead was attached to the shaft with thin guanaco-sinew (pl. $\mathrm{v}, c$ ), dried over warm ashes in the same manner as in securing the feathers.

Simple as the Ona arrow seems to the eye, we see from the description of its manufacture that the process was complicated beyond all expectation and that many substances were required. To recapitulate, the materials used in each arrow were six in number:
(1) wood
(4) guanaco-sinew
(2) pitch
(5) feather
(3) clay
(6) glass (or stone)

To shape and join these substances the Ona used seven of the nine tools known to them:
(1) wood scraper
(2) sharpening stone for same
(4) fox-skin polisher
(3) straightening stone
(5) chipping tool
(6) sharpening stone for same
(7) knife

With the tools and materials at hand, the steps in the manufacture may be listed as:
(1) splitting wood for shaft
(2) rounding the shaft

(3) straightening the shaft by heat

(4) straightening it by pressure 
(5) tapering the shaft

(6) cutting the nocks

( 7 ) polishing the shaft on stone

(8) polishing the shaft on skin

(9) softening and applying pitch
(10) splitting feathers

(11) softening sinew

(12) attaching feathers

(13) chipping the point

(14) attaching the point

Fully to understand the extraordinary pains and care lavished by the Ona on their arrows we must add to these processes the labor of gathering the six listed materials from the beach, the plains, and the mountains. Only excellent results could justify such painstaking toil, and these the Ona attained.

\section{THE QUIVER}

The Ona quiver, made from the hide of the hair seal, was called inl. a word they also employed for rifle. To manufacture the quiver, a hide was cut in a rectangular pattern of suitable size and shape. This was doubled over and sewn up the side. while at the bottom (as seen in fig. 33) a small oval piece of hide was inserted

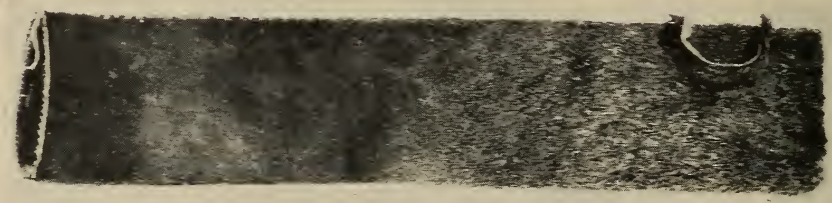

FIG. 33.-Ona quiver. Length, $331 \frac{1}{2}$ in. (1t/2398)

and stitched into place. Were it not for this flat bottom the delicate glass points would have been jammed against one another and thus become broken. On the upper end of the quiver there is a small loop of hide by which it was hung out of reach of dogs when in camp.

The Canoe Indians are said to have used a quiver similar to the Ona type, but the writer has never seen one. The Tehuelche used no quiver, but inserted their arrows in a narrow woven fillet encircling the head so that they projected above like a crown.

\section{USE OF THE BOW}

In shooting (fig. 34), the Ona gripped their bows in the middle, often with the forefinger extended along the path of the arrow; they held them not vertically but diagonally; so that the arrow 
passed not beside but over the bow. The bow-arm was not held straight, but was bent a few inches toward the body and snapped straight at the moment of discharge to add momentum to the arrow. ${ }^{1}$ The nock of the arrow was grasped and pulled with the thumb and forefinger, but, when it was desired to pull strongly, one or more of the other fingers were laid directly to the string. When fast shooting was called for, the quiver or the arrows themselves were held in the teeth so that they could be reached quickly.

On the march the bow and quiver were carried in the left hand, which also held the skin cape wrapped around the body. A single motion of the arms served to bring the bow into position and to cast off the encumbering cape.

Children were given small bows with which they learned not only to shoot but to dodge one

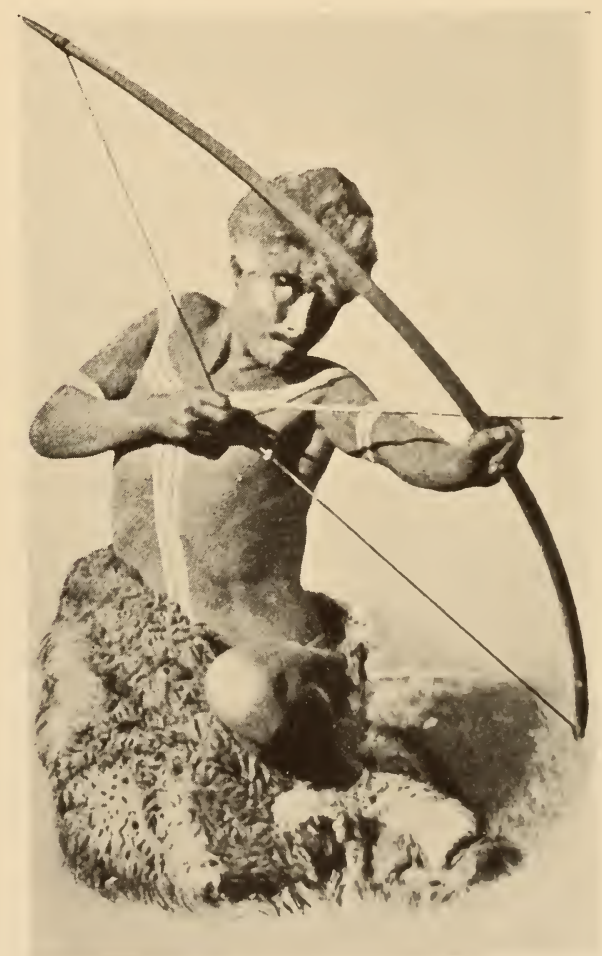

Fig. 34.-An Ona bowman. (From Alberto M. De Agostini, I Miei Viaggi nella Terra del Fuoco.) another's blunted arrows - an art on which their very existence might depend.

The extreme range of the Ona bow was not far short of 250 yards. The longest actually measured arrow-flight known to the writer was made by Mr. William Bridges and covered more than

${ }^{1}$ In fig. 34 the bow-arm is held straight in order to maintain the pose. 
210 yards. But this distance would have been much greater had not the arrow been shot up a hill (seen in pl. III, top), so that it landed nearly 100 feet above the starting point of its flight. However, such extreme distances had no relation to the ordinary hunting range, which was well under 100 yards, because the guanaco is an animal difficult to kill even with bullets, and, as the Ona did not relish having their arrow carried away by a wounded but not incapacitated animal, they fired only when and at such distance that they might expect to make a kill.

As for penetration, the writer has seen a headless arrow, discharged from an old and dried-out bow, carry 165 yards and bury itself for about six inches in hard, sun-baked gravelly soil. A story is told of an Ona, who, running from enemies, stooped to pass beneath a bough. At that instant an arrow struck him in the thigh, passed through, entered his body, and pierced its entire length, so that the head of the arrow protruded beyond his collarbone.

\section{HUNTING AND FISHING}

The Ona are expert trackers. Once a young Ona was employed by the governor at Lshuaia to track an escaped convict, a pair of whose shoes he was shown. For several days the Indian was seen around the outskirts of the town and finally he reported to the police that their quarry had not left Ushuaia. This news was received with scorn and the Ona was accused of being too lazy to go after his man. However, the convict had hidden himself in the town, for he hoped to escape on a ressel that was loading; but as she did not put to sea when expected, his food ran out, and he had to give himself up. The Ona had examined every one of the hundreds of footprints leading out of the town and had correctly deduced that the prisoner had never left it.

Guanaco was the chief game sought by the Ona. It is, as we have said, an animal of great vitality and difficult to kill even with a rifle. Therefore the Indians rarely discharged arrows at the guanaco except at close range. The favorite shot was quartering from behind, so that the arrow might strike behind the ribs and penetrate the viscera without encountering bone. Fox, seal, and sitting birds, especially the upland goose, were also brought down with bow and arrow.

Methods of hunting were essentially simple. In moving camp the women and children followed the valley floors while the men 
kept on higher land on either side. Feeding guanaco startled by the former fled to the heights where the hunters were waiting for them. Guanaco also were stalked. Of the very elaborate pits for bowmen and game drives described by C. IV. Furlong (1912), the writer could learn nothing from either the Ona themselves or old European settlers. It seems improbable that the Ona ever combined in sufficient numbers to execute the drives, and one wonders how they dug the pits in frozen ground during the winter.

When a guanaco had been slain, the hunter immediately cut out the small lumps of fat behind the eye-sockets and ate them as a special delicacy, as did the Tehuelche. If he were hungry he might later eat a certain part of the intestine usually found clean, and perhaps also the heart. Then he set about skinning his kill, which was done in a never-varying order. The young guanaco was not skinned on the spot, but was immediately gutted. The stomach was emptied and edible viscera such as the liver were packed in it. The head and legs were then forced into the abdominal cavity and the whole animal, lashed into a neat bundle, was carried home. The weight thus borne might be as much as two hundred pounds.

Returning to his windbreak the hunter would silently hand his bow to his wife to hang up and throw the meat on the ground near the fire or hang it on a tree. No one would pay any attention to it, for it was considered bad manners to show elation at the success of the hunt or merriment at the prospect of food. After sitting around in sullen silence for half an hour, the hunter would casually ask his wife why she did not cook some meat, and she would then do so. But until given leave she would not touch the meat, as it was his but not her property.

Seals were killed with arrows, and sometimes they were caught in strong nets of seal-hide. The example we illustrate in fig. 3.5 measures four by eleven feet. It was found in a long-abandoned wigwam near Lake Fagnano, and evidently it was made many years ago. The meshes today are uneven because breaks have been repaired by knotting the ends of the ruptured sections.

Cururo were dug up and killed with a stick. Apparently the Ona did not regularly use a club like their neighbors. "They beat their wives with bow staves," I was told.

Fish were taken by the Ona women in pools on the beach at 


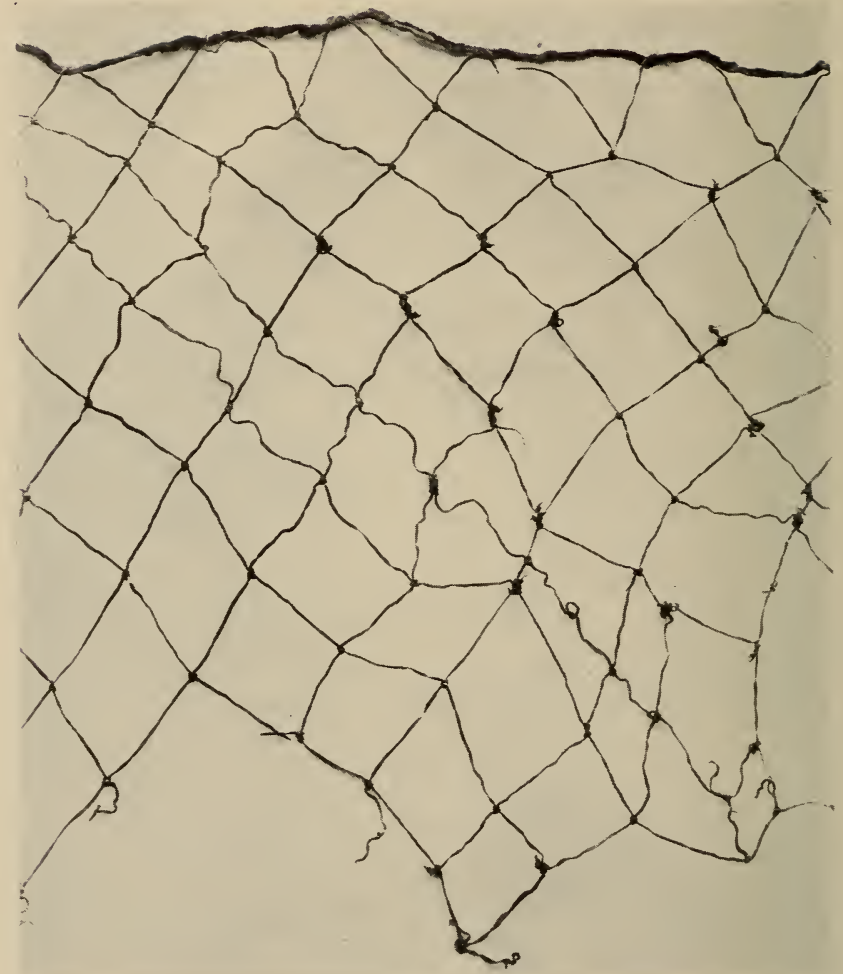

FIG. 35.-Ona seal-net. Width, 3 to $4 \mathrm{ft} . \quad(14 / 2387)$

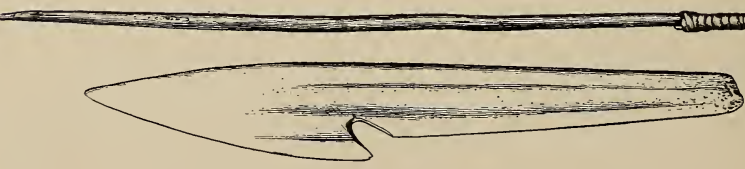

FIG. 36.-Ona fish-spear. Length, 37 in. (14/2396) 
low tide with the aid of a short spear (fig. 36). The shaft of the weapon is of wood, painted red, while the point is of guanaco-bone. Evidently this little weapon-it is only three or four feet long-was adapted by the Ona from the large heavy spears of the Yahgan. Pictures of Ona women fishing have been published by Gallardo (1910) and De Agostini (a). Members of this tribe are said to have taken fish with weirs and nets, but the writer saw neither.

Birds were caught with snares (fig. 36A, after Gallardo) like those used by the Yahgan. They also captured birds, especially those roosting on the cliffs of the east coast, with the aid of a torch, either a bark affair like the Yahgan torch or else a bundle of long dry grass-stalks $(k e k l)$. The method employed was to go down to the beach beneath a cliff during the night with the torch in one hand. The birds aroused and dazed by the light often flew into it and were struck down or seized.

The southern Ona killed birds with a sling, but it is doubtful if this weapon was in use among the northerners. From this distribution it might well be argued that the Ona had learned the use of the sling from the Yahgan, yet there are several reasons for believing the contrary. In the first place, the Ona name (shinkai) is not related to the Yahgan (watewá). Secondly, the Yahgan sling has braided strings, while the ()na used strips of guanaco-hide. Thirdly, the methods of discharge were different, for the Ona wrapped the long end around the forefinger, while the Yahgan inserted

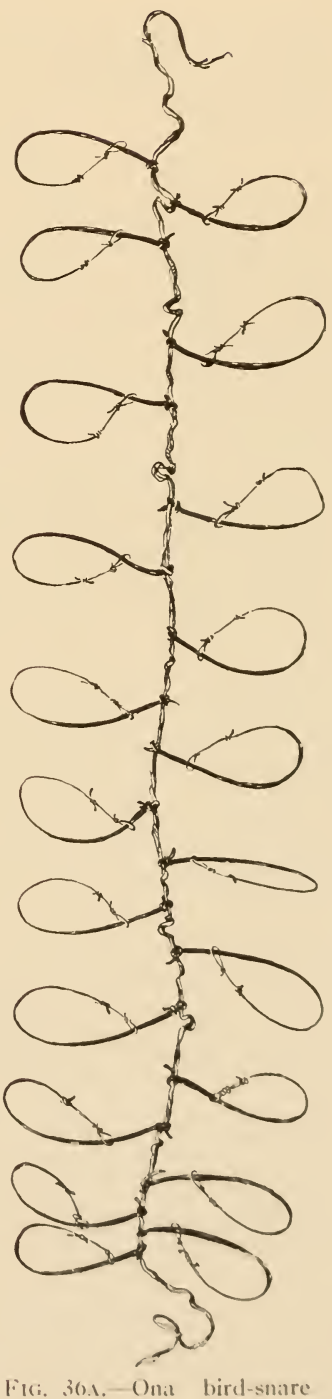

Fin, 30.1.-Onat bird-snare 
it between the fourth and the little finger, so that it extended across the palm of the hand. Finally, as pointed out by Cojazzi (p. 329), the use of a sling is mentioned in a supposedly ancient Ona legend.

\section{Social Organization}

Clans, gentes, moieties, and the other divisions commonly found in primitive society were unknown to the Ona, who were split into bands based on consanguinity and the necessity of maintaining their right to hunt over certain territory. Each such band controlled a fixed area which usually extended from the mountains to the sea and thus embraced a diversified food-supply. Within this region, except in the case of war, or wrestling, or the stranding of a whale, large gatherings rarely took place, for large encampments with many dogs frightened the game and hence became an economic liability. An informal authority over the people of a given district might be exercised by its ablest member, but such leadership became apparent only in times of stress.

\section{KINSHIP}

Among an exogamous people who, like the Ona, accept group responsibility, it is quite natural that kinship should be a matter of exact knowledge and that every relative should be designated by an exact term. Descent and kinship were calculated in both the male and the female line, the terminology being complicated by inability to express abstract relationship. Thus it is necessary to add "my," "your," "his," or "her" ( $y a, m a$, or $t a$ ) to each name, and the resultant form is often contracted.

Relatives in general were called ya k'chon, "my man," or ya k'na, "my woman"; the latter also means "my wife." Unrelated individuals were described as táni ya k'chon, "that is not my man," or tónika hánash pemrrh, "from far away he is."

The table of relationship terms subjoined was obtained from Mr. William Bridges and later checked on separate occasions by two Indians. To save space the expressions for cousin are given only in the first person, as they are all compounds based on elements given in full elsewhere. 


\section{TABLE IV.-ONA RELATIONSHIP TERMS 1}

$\begin{array}{ll}\text { my father } & \text { Faaín } \\ \text { your father } & \text { maaín }^{e} \\ \text { his (her) father } & \text { taain }^{e}\end{array}$

\section{BROTHER ${ }^{2}$}

$\begin{array}{ll}\begin{array}{l}\text { my elder brother } \\ \text { your elder brother } \\ \text { his (her) elder brother }\end{array} & \begin{array}{l}\text { yorrek } \\ \text { morrek } \\ \text { torrek }\end{array} \\ \begin{array}{ll}\text { my younger brother } \\ \text { your younger brother } \\ \text { his (her) younger } \\ \text { brother }\end{array} & \begin{array}{l}\text { machi } \\ \text { tachi }\end{array} \\ & \end{array}$

\section{UNCLE}

my mother's brother his mother's brother machéen

$\begin{array}{ll}\text { my father's brother } & \text { yipóot } \\ \text { your father's brother } & \text { mapóot } \\ \text { his father's brother } & \text { tapóot }\end{array}$

\section{GrandFather}

my mother's father

yam k'aine you mother's father mam k'aine takám k'aíne

my father's father, yaain k'ain $^{e}$, yihoq your f's father, maaíne k'aine, mahoq his father's father, taain $k^{\prime}$ ain ${ }^{e}$, tahoq

\begin{tabular}{ll} 
& \multicolumn{2}{c}{ HUSBAND } \\
my husband & yashi \\
your husband & mashi \\
her husband & tashi
\end{tabular}

SoN

$\begin{array}{ll}\text { my son } & \text { yilal } \\ \text { your son } & \text { malal } \\ \text { hisson } & \text { talal }\end{array}$

\section{Mother}

$\begin{array}{ll}\text { my mother } & \text { yam, yami } \\ \text { your mother } & \text { mam } \\ \text { his (her) mother } & \text { takám }\end{array}$

SISTER ${ }^{2}$

$\begin{array}{ll}\text { my elder sister } & \text { yorrkan } \\ \text { your elder sister } & \text { morrkan } \\ \text { his elder sister } & \text { torrkan }\end{array}$

my younger sister yaan your younger sister maan his younger sister taan

\section{Aunt}

$\begin{array}{ll}\begin{array}{l}\text { my mother's sister } \\ \text { your mother's sister } \\ \text { his mother's sister }\end{array} & \begin{array}{l}\text { yipóon } \\ \text { mapóon } \\ \text { tapóon }\end{array} \\ \text { my father's sister } & \text { yikán } \\ \text { your father's sister } & \begin{array}{l}\text { makán } \\ \text { takán }\end{array}\end{array}$

\section{GRANDMOTHER}

my mother's mother yáme your mother's mother máme his mother's mother táme

$\begin{array}{ll}\text { my wife } & \text { WIFE } \\ \text { your wife } & \text { ya k'na, yashi } \\ \text { his wife } & \text { mak'na, mashí } \\ \text { ta k'na, tashi }\end{array}$

\section{Diughter}

$\begin{array}{ll}\text { my daughter } & \text { yitam }^{n} \\ \text { your daughter } & \text { matam }^{n} \\ \text { his daughter } & \text { tatam }^{n}\end{array}$

\section{First Cousin ${ }^{3}$}

my elder brother my father's brother's son my younger brother my father's brother's son my elder brother my mother's brother's son my younger brother my mother's brother's son my elder brother my father's sister's son my younger brother my father's sister's son

\author{
yorrek yipóot k'lal \\ yachi yipóot k'lal \\ yorrek yichéen $k^{\prime} l a l$ \\ yachi yichéen $k$ 'lal. \\ yorrek yikan k'lal \\ yachi yikan k'lal.
}

\footnotetext{
${ }^{1}$ For the alphabet used in recording native terms see page 215.

2 To specify brothers and sisters more exactly it is necessary to use some such expression as "the second claughter of my mother."

3 Cousins were addressed as "brother" or "sister."
} 
my elder brother my mother's sister's son my younger brother my mother's sister's son my elder sister my father's brother's daughter my younger sister my father's brother's daughter my elder sister my mother's brother's daughter my younger sister my mother's brother's daughter my elder sister my father's sister's daughter my younger sister my father's sister's daughter my elder sister my mother's sister's daughter my younger sister my mother's sister's daughter

\author{
yorrek yipóon k'lal \\ yachi yipóon k'lal \\ yorrkan yipóot k'tam ${ }^{n}$ \\ yaan yipóot k'tam ${ }^{n}$ \\ yorrkan yichéen $k^{\prime}$ tam $^{n}$ \\ yaan yichéen $k^{\prime}$ tam $^{n}$ \\ yorrkan yikán k'tam ${ }^{n}$ \\ yaan yikán k'tam \\ yorrkan yipóon k'tam ${ }^{n}$ \\ yaan yipóon k'tam ${ }^{n}$
}

\section{Marriage}

Marriage of blood relations down to second cousins was regarded as incest by the Ona, so that a man usually was forced to seek a wife at a distance. At times this could be done in friendly fashion by making arrangements with the girl herself and her father, in which case it was customary to make gifts to the father of the bride. Often, however, a wife was secured from a hostile Ona group, or even from one of the other Fuegian tribes. This might be accomplished by stalking a strange woman until the chance occurred to cut her off from her family-silence and obedience being enforced by a threat to arrow her. Also women were secured by group warfare, for the families of the slain might be captured by the victors. Encampments were raided at times for the sole purpose of capturing women.

Polygyny was practised when possible by the Ona, though it was rare to find a man with more than two or three wives at the same time. Halimink, an Ona of whom the writer saw much, had had seven wives and was looking for an eighth. The first of his wives, by that time an old and feeble woman, was still alive. Halimink's oldest living son, Nana, ${ }^{1}$ had married a mother and her daughter - a custom often found among the Fuegians. Marriage of two or more sisters to the same husband was also of frequent occurrence.

In recent years, with the great diminution in numbers of all the Fuegian tribes, the normal marriage systems have been upset, for the men have been put to it to find wives at all.

1 This man has been described by Rockwell Kent. He was unusual among the Ona in having a mustache which hung at either side of his mouth like black icicles. He enjoyed considerable local fame as a killer and was generally believed to have done away with the daughter mentioned above, as she mysteriously disappeared. 


\section{Children}

The Ona, from what the writer saw, were as kind to their children as most Indians, who in general are noted for indulgence toward their offspring. This statement does not imply that the parents did not maintain rigid discipline, but it was always tempered with genuine affection.

At the time of birth, according to Gallardo (p. 229), the Ona mother brings in a load of earth that the child may be sturdy, and after delivery has taken place she washes herself if a sufficient body of water is nearby. For some time thereafter certain foods are tabooed. During this critical period the father is expected to maintain the aloof indifference which these stalwart people were trained to exhibit to hunger, fatigue, and cold-indeed it was considered bad form to display even the slightest curiosity as to the occurrence of the event or the sex of the new-born.

\section{FEUDS}

The Ona were a hunting people, and as a result they lived in small family groups which could move quickly and easily. Each group had definitely located hunting rights, and to trespass on another's territory was a cause for war. Even a dog, wandering to alien precincts to worry the game, might start hostilities. Wifecapture also led to fighting. Sometimes a neighboring group was attacked simply because opportunity offered and it was thought advisable to grasp the chance to reduce the strength of possible future enemies.

At the moment of white colonization of Tierra del Fuego, during the last quarter of the nineteenth century, the island is said to have been over-populated; hence hunting rights were more aggressively maintained than ever. Indeed it is stated by some that Ona arrows reduced the population as much as ever the merciless rifles of professional head-hunters. Feuds, once started, lived long.

When a grievance arose, three methods of procedure were open to the Ona: (1) there might be war, (2) there might be a wrestling bout, or (3) an individual duel. These practices and the method of peace-making we shall examine.

$$
\text { I. -WAR }
$$

Warriors in Tierra del Fuego were garbed in no ceremonial costume, nor was warfare hedged about by any restrictions. The 
first intimation of attack was the swish of hostile arrows, and the first move was to run for shelter until the strength and nature of the attack could be determined. Relatives had to be summoned and the largest possible company assembled before attempting a counter-movement. Some time might therefore elapse before the attack was returned.

The Ona usually did not torture their male captives, but killed them on the spot. Women and children who fell into their hands were sometimes killed in the heat of combat, but were often spared and incorporated in the victorious group.

\section{II.-WRESTLING}

While wrestling was a sport to be indulged in among friends, it was also an alternative to war, resorted to when the attacked party was not in a position to return the aggression. While warfare was conducted with but little organization and no formality, the wrestling bouts were enacted with all the punctilio of an eighteenthcentury duel. A formal challenge initiated the contest. It was usually carried by an old woman, a relative of both parties, if possible, but too old in any case to be desired as a captive. Through her a day and a place were set. There was never an act of treachery at such meetings. War was not the order of the day, so they left all arms behind.

The first arrivals at the place selected were the challengers. Everybody came-men, women, and children-and formed a semicircle with the men in front. Then came the challenged party and formed a similar group facing the others but leaving an open space some fifteen yards across between the two sides (fig. 37).

Next an old man of the challengers harangued their opponents, the original aggressors in the feud. Now the Ona language is harsh, guttural, and explosive, so that even a friendly argument to unaccustomed ears sounds like a violent altercation, but on this uccasion the voice was not raised. The challenged party, in a quiet tone but with deadly seriousness and great detail, were told what they had done and just what the challengers thought of them. One of the challengers now stepped across the open space, stretched out his left hand to an opponent, who grasped it with his right hand and allowed himself to be pulled to the middle of the ring. There they gripped each other around the body, each with his right arm beneath the other's left, and the contest began. 
There seem to have been few rules. Biting, indeed, was not considered comme il faut, and it was thought manly to stand erect. Grips were shifted and the men strained, often twisting the neck by the jaw, until one of them was thrown. This however did not constitute victory, for no man was beaten who was willing and

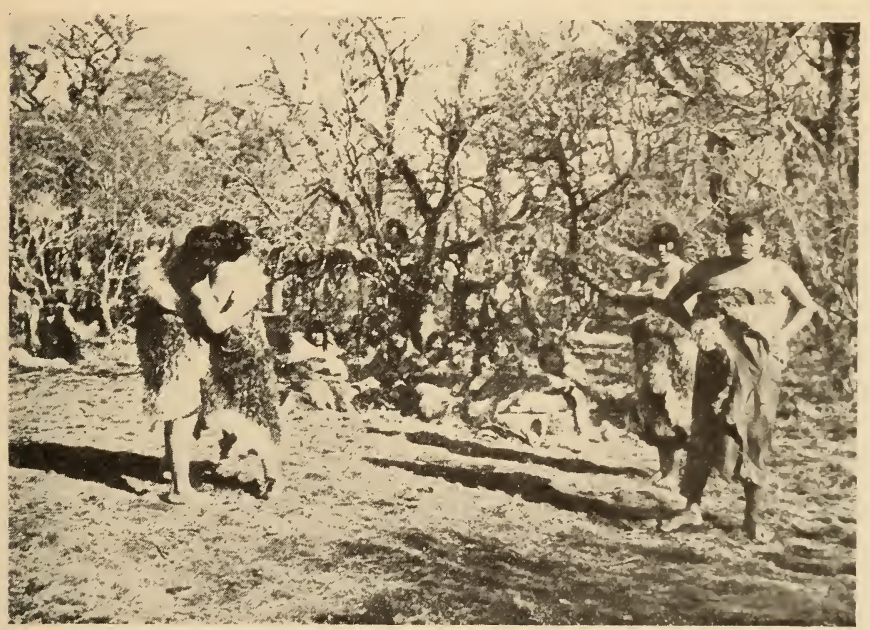

FIG. 37.-Ona wrestling contest. (From Alberto De Agostini, I Miei Viaggi nella Terra del Fuoco.)

able to continue. When one man was exhausted, another from his side took his place, or sometimes a special opponent was selected by the man who happened to be in the ring. Thus the wrestling continued, perhaps for many hours, until no more challenges were forthcoming.

Then the two sides parted with scowling glances and angry words, threatening what they would do to one another when they next met. But during the wrestling they were very polite, and they did not praise their own men directly but rather their opponents, saying such words as "You must be a fine man to do so well against my brother."

Such then were the wrestling bouts. That they were not tame affairs may be judged from the fact that Mr. Lucas Bridges, himself well over six feet and unusually strong and agile, emerged from 
one of these contests with two broken ribs. He had lent an Indian his rifle in order to hunt guanaco, but instead the Indian had used it to kill two men. Hence Mr. Bridges and his brothers were included in the challenge to the angry wrestling which followed.

\section{III.-THE DEEL}

If a man belonging to an aggrieved group had a personal enemy in a hostile band. and if his hatred could be satisfied neither by wrestling nor group-fighting, he sent his enemy a challenge. On an appointed day he would appear stripped naked at the enemy encampment and would halt about seventy yards away. His opponent would then come out in front of his windbreak with a bow and a quiver containing six or eight arrows, drop on one knee, and start shooting. These arrows the challenger dodged. To show his scorn of enemy marksmanship he moved as little as possible to aroid them, and after each shot he advanced a few yards toward the archer. Thus, if he were brave and agile. he might be within twenty-five or thirty yards of his enemy when the last shaft was loosed. Then the two changed places, and the challenger, who had subjected himself to hostile arrows, had his chance to kill or wound his enemy. or to shame him by keeping him at a distance with accurate marksmanship. If the challenged warrior were not an adept at arrow-dodging, a relative might take his place, so that the group as a whole would not be disgraced by a clumsy performance.

\section{IV.-MAKING PEACE}

Peace overtures were initiated by a third party and usually were not successful unless both sides could be persuaded that theyhad gained the advantage. If a meeting were arranged, each man brought five arrows. From these they removed the heads and wound a strip of rawhide around the shaft, about three-quarters of an inch from the tip, to form a disc, so that the arrow would wound but not kill. Reaching the appointed place, each one of the aggressive party sought out the man he regarded as his most personal enemy and gave him the arrows. Then he retired about fifty yards away.

The man who had received the arrows, with scowling looks put four in his mouth, strung the fifth, and shot at his opponent just 
as hard and as fast as he could draw bow. As the first shot left the bow the unfortunate target began to run at full speed toward the archer, dodging arrows as he came. Sometimes a man would escape untouched, but more often he received a wound before all the arrows were discharged.

When all the aggressors had thus run the gauntlet, their opponents' turn to shoot at their enemies came, and thus by all-round blood-letting the feud was finished. It is to be noted that each man had a chance to shoot at his personal enemy, and that no arrow which he had not himself prepared was discharged at any individual.

\section{Amusements}

Although repressed by a code which forbade the display of emotion or eagerness, the Ona were essentially a fun-loving people with a keen sense of humor and a fondness for horse-play. Yet they had little in the way of formal amusements. Wrestling in earnest we have already described, but in addition the Ona indulged in friendly wrestling as a sport. Target-shooting with bow and arrows or dodging blunted arrows often assumed the nature of play, yet essentially these exercises were training in manly activities necessary to the maintenance of life itself. Every Ona must expect to "get" his man or himself be arrowed.

Foot-racing was another of their sports. Sometimes the runners would encircle a lake. More often, however, two groups would start at opposite ends of the course and would run to meet at at point estimated to be in the middle.

The Ona also indulged in a simple ball game which consisted of no more than throwing and catching the ball. The ball (cháto), about the size of a baseball, is made from the skin of a large gull (kaprrh) known locally as the "black stinker," which looks rather like an albatross. It is stuffed with dried grass.

\section{DEPORTMENT}

In connection with hunting and fighting we have seen that these Indians had very distinct ideas about what constituted good manners. Living in a state that placed fortitude and physical endurance at a premium, it is but natural that their cocte of etiquette forbade the display of emotion or eagerness which might he mistaken for cowardice and agitation. Consequently the ()na youth was 
schooled to endure cold, fatigue, hunger, and thirst without outward display of his feelings.

Many explorers of Fuegian waters have commented on the indifference of the natives to the wonders of European civilization displayed to them. But the failure has been not on the part of the Fuegians to admire, but on the part of the Europeans to discern the cause or even the existence of native reticence. Thus Hawkesworth ${ }^{1}$ writes of the Haush who boarded Cook's ship at Good Success bay that "they eat some bread and some beef, but not apparently with much pleasure, although such part of what was given them as they did not eat they took away with them." To have gobbled their food in the presence of foreigners would have been to the natives the height of bad manners. This is well illustrated by the way the Ona treated a stranger of their own tribe.

If a stranger appeared at an Ona encampment unaccompanied by a member of it, he was likely to be deemed a poacher and promptly arrowed, so only in the most desperate circumstance would a man approach a group where he was unknown. When brought in by a friend, a stranger would sit down some fifty yards away from the camp and take no notice of what was going on. A few minutes later the owner of a shelter would call out to him to visit his wigwam, and perhaps ten minutes later the stranger would stroll up to the outer circle of those around the fire, and, being duly urged, in time would sit beside the fire. Meat was then cooked, but the stranger was not supposed even to look at it. When a piece was handed to him he would take it with the utmost indifference and wait quite a while before eating it. It was considered a compliment to the host to hand over one's bow and arrows and ask him to keep them dry.

Under such rigorous etiquette it is easy to understand why shipwrecked crews, ignorant of native usage, fared badly at the hands of the Ona.

\section{INITIATION}

All young men in the old days had to pass through a period of initiation lasting for about two years. During this time they were regarded as undergraduates or probationers (klókten). Most of the period was spent in solitude, except for the aid and company of a single dog, living on the lean meat of adult male guanaco that

\footnotetext{
${ }^{1}$ Ed. 1773 , vol. II, p. 44.
} 
they might become strong and swift. For several weeks the novitiate was brought frequently to the initiation lodge (fig. 38), where he was terrified by masked men representing various spirits. Here also he was instructed in tribal lore and inculcated with all manly virtues, while he had to prove indifference to pain by allowing wood splinters thrust in his arm to burn themselves out against his flesh. Finally, when deemed fit for manhood, the true nature of the spirits that had terrified him were revealed, after he had been sworn to secrecy especially as regards the women and children, who were terrified at intervals by the masked apparitions.

The native explanation of these rites was that long ago there was a petticoat government, and the women held the men in abject slavery, because

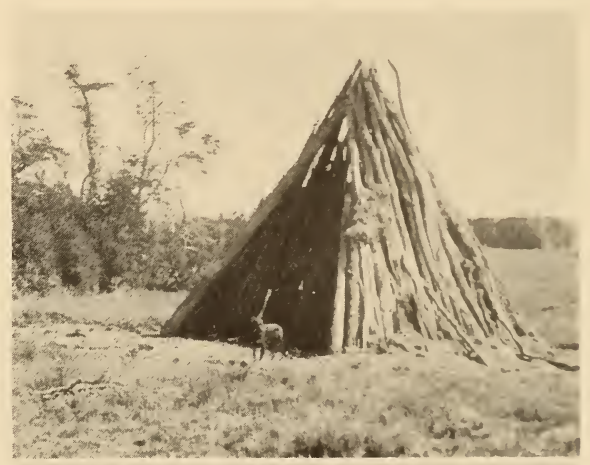
they, by certain

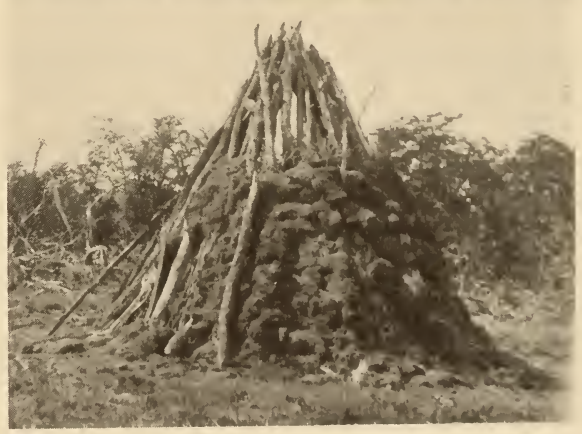

FIG. 38.-Ona ceremonial lodge near Laguna de Pescados.

magical ceremonies not known to the men, could summon fearful spirits to their aid. There came a day when the men learned that the apparitions that terrified them were only their wives in disguise. so they forthwith fell upon the women and killed all those initiated in the secret, with five exceptions. Of these, one was thrown headlong in the fire, but she crawled out and ran to the sea, where she became 
the moon. Today you may see the scars on her face. A second was cast into a waterfall and amidst its spray was changed into the snowy-white kelp goose (fig. 90, $b$ ). Another became the steamboat duck, the fourth a swan, and the fifth a woodcock (Strickland's snipe?). After this wholesale slaughter and metamorphosis of the women, the Ona men talked it over and decided that the system was a sound one, and so they turned it to their own account to keep the women and children on their good behavior. Possibly this tale reflects an ancient matriarchal system subverted long ago by masculine aggression.

The lodge in which part of the initiation was held and whence issued the spirits to cow the unitiated was called haine, a word obviously connected with kina, the central Yahgan term for the initiation lodge. Among the Ona (and probably also the Haush and eastern Yahgan) the lodge was a large solid tipi of heavy logs partially covered with sod. Front and back views appear in fig. 38 of the lodge built for Gusinde in 1922. Each log was assigned to an individual and had a name such as "seal," "kelp-goose," "duck," "grass," "sea." I could not discover any totemic bond between these names and the individuals who sat in front of them. The doorway, whicl faced away from the encampment, was very wide. Within were benches.

The masks are tall and conical like the Yahgan masks (figs. 92, 93), and are made of hide or bark appropriately painted. According to Barclay, who obtained his information from Mr. Lucas Bridges, the characters represented were:

"Sh'ord, a malicious underground spirit with crooked legs. $\mathrm{He}$ was represented covered all over with the feathers of birds (stuck on with grease).

"IHaci' $i$, the spirit of the moss and lichen-covered rocks. He was painted slate color, with daubs of red and yellow clay, and wore horns.

"H'alpin was a woman, the spirit of the clouds and mists. She was dressed all in white, and had a very long head. This shape was given by binding twigs to the back of the head, which were then covered with skin and painted.

" $\operatorname{Tan}^{\prime} u$ " was the spirit of the streams and lakes. She was the sister of H'alpin, and was adorned in the same way except that her color was red.

${ }^{1}$ This name is given as Fan' $u$, a typographical error, as there is no $f$ in Onan. 
" $K$ 'mantu i was the spirit of the beech forests, and was clothed with tree-bark and moss.

"IIash'ai was very squat and had a claw on the forefinger of each hand. He was always gathering firewood, but never made a fire. This spirit seems to have been an embodiment of that nervous fear which makes itself felt in the deep forests, when branches creak and twigs snap for no apparent reason. Finally there was-

"Olimin'kke, the little surgeon-doctor, who attended to the ailments of all this crew."

Cojazzi gives a similar list with an additional name; the interpretation is slightly different from that of the Barclay-Bridges list.

Schort: $\quad$ spirit of white stones.

Halpen: spirit of the clouds; wife of Schort.

Táne: $\quad$ sister of Halpen.

Gketermen: son of Schort.

Harciai: $\quad$ spirit of black stones.

Gkmánta: spirit of live trees.

Háse: $\quad$ spirit of dead trees.

Holemin: spirit of the sky.

Yahgan, Haush, and Alacaluf initiation ceremonies differed in detail from the Ona rites, but were so essentially similar that interborrowing must have taken place. Of Tehuelche initiation rites for boys we know practically nothing, but Musters (1871, pp. 76, 175) has left an account of the ceremony for girls which shows little resemblance to Fuegian practice beyond the fact that a special house was set up and dances were held.

In the Amazon valley, however, we find an initiation and dance complex strikingly like that of Fuegia. Without going into detail we may list the parallel features from the Amazon region as follow:

1. The use of tall conical masks that conceal the identity of the wearer.

2. Ceremonial lodges from which women and children are rigorously excluded.

3. Belief that the authority and superiority of man must be maintained, and the women and children impressed with their inferiority by these ceremonies. "

4. Infliction of physical pain upon the novices.

II have changed $c$ to $k$ to conform with the phonetic system herein employed.

2 See F. Gow-Smith, The Arawana, of Fish Dance, of the Citrajal ludlians of Matto Grosso, Brazil; Indian Notes, II, 1925, 1). 99. 


\section{Religion}

The Ona, according to Gusinde (1924a) believed in a supreme deity called Temáukl, who created the heavens and the earth. This god had the giving of life and death, and the Indians openly reproached him when death occurred. Beauvoir (p. 166) says that Pimaukel (sic) was not a universal god but the first man, endowed with certain divine powers and the creator of much animal and plant life.

More intimately in contact with everyday life were a great number of local spirits. Sometimes these were the spirits of trees, mountains, lakes, or animals; sometimes they were the ghosts of mighty shamans of the past. In general they were to be avoided, or, if encountered, to be treated with respect, except by powerful shamans who could defy them with impunity. In addition to these spirits, the women and children were supposed to believe in the divinity of the masked apparitions seen during the klókten rite.

\section{SHAMANS}

Among the Ona certain men were accepted as having power to prophesy, to control the spirits of nature, and to cure or create sickness. This power was acquired by friendly association with the ghost of a departed master of the trade.

Sickness, said the Ona, was the result of some foreign object lodged in the body through the machinations of the moon or of some malevolent shaman. To effect a cure this must be removed. When summoned to attend a patient, the doctor painted himself in style and put on a kelp-goose down diadem (fig. 11). After an examination of the sufferer he informed the relatives of the nature of the illness and who had inflicted it. Next the sick man was stripped and seated on a guanaco-skin. Around him for some time walked the shaman, chanting incantations to break the spell of the disease. Then grasping his patient the doctor violently massaged the affected part. Finally the point of pain was lustily sucked, and then the shaman vomited forth the ostensible cause of the disorder-an arrowpoint, a pebble, a bit of wood, or some such object.

If a cure could not be wrought at once, then this process was repeated at the discretion of the physician. While at times it must have caused great pain to the sufferer, yet it is undoubtedly true that cures were effected. If the patient's case was pronounced 
hopeless, he was strangled by his family in order to terminate his supposedly useless sufferings. Cojazzi writes that individuals in this critical state have been spared by missionary intercession, and, recovering, have lived for many years. The compassionate execution of the aged or infirm is a custom of world-wide spread. In the New World it extends from the Arctic to Tierra del Fuego.

Ona witch-doctors were thought to control the powers of nature. Mr. Lucas Bridges told Cojazzi (1914, p. 15) how he encountered a great storm when exploring Mount Hewhuepen. His Indian companions believed that the storm was sent by the spirit of the mountain, enraged at the intrusion of her privacy. To master this spirit a shaman was called into action, who defiantly discharged blazing arrows into the clouds. This measure failing, Mr. Bridges was asked to fire his revolver, and this had the desired effect, for the storm soon ceased.

\section{Beliefs Concerning the Dead}

When an Ona died his personal possessions were thrown away or burned in the house where he died (fig. 39), and his dogs were given to distant relatives. This was done partly in the belief

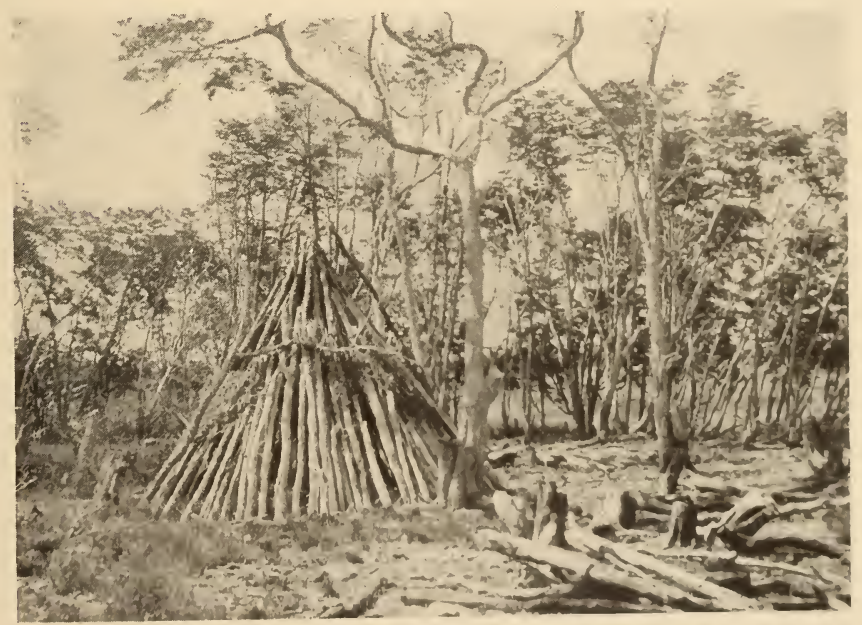

FIG. 39.-Abandoned Ona camp, showing destruction of houses after the death of an occupaint. 
that the dead man's property was not a good thing to keep and partly because its presence would constantly have reminded his family of their loss. For instance, the large arrowshaft polisher illustrated in fig. 27 had belonged to the father of old Halimink, from whom it was obtained. When the father died it was buried and abandoned. Years passed, but Halimink remembered the stone because it was a particularly fine one, so at length he dug it up and used it himself.

When death occurred, a certain amount of formal ululation was expected of the female relatives, and at times the breast and arms were lacerated. Among the men no set performance was expected; however, their grief was obviously genuine. For instance, Halimink often spoke of his wife (number seven) who had died three years previously, and said that he missed her greatly. But he never mentioned her name. All her property was burned on the spot shown in fig. 39. Yet in spite of his sincere grief, Halimink was rather regretful that the property had been destroyed because if the things had been kept he could have sold them to the writer and profited by the transaction.

The Ona believed in the future existence of the soul, yet thought the spirits of ordinary persons had no contact with this world. Only the souls of super-shamans had influence after death.

The body of the dead was wrapped in skins and lashed between saplings; it was then placed in a hole in the ground which was filled; the sod was carefully replaced, and finally a fire was built over the grave to remove all traces of interment.

\section{Mythology}

For the study of Ona mythology we have fairly rich material, though not so detailed as one would wish. Though abundant, the published Ona myths are often difficult of access for they have appeared in print in many countries and languages. It has therefore seemed well to summarize those tales that have come to my notice.

\section{CREATION MYTHS}

The Ona believed, according to Furlong (1915), that the first man and woman descended from the sky by means of a rope which broke so that they were forced to remain on the earth. This first man, named Pimaukel according to Beauvoir (p. 166), or Kenós according to Gusinde (1924a), made many of the plants and animals. 
The Ona believed that there was once a great flood and attributed it to the machinations of their hero Kuanip. Also they had a legend 1 about bearded white men. In this we may see connection with the Viracocha-Quetzalcoatl myth cycle of more developed cultures. Evidently the white-hero cycle goes to the very base of New World beliefs.

\section{HERO MYTHS}

There is an elaborate myth cycle relating to the Ona national hero, Kuanip or Coan-yi-pej, a being with supernatural powers. It is to be noted that Kuanip was not a culture bearer but that he had much to do with the present state of things because he transformed various people into animals. The longest detailed account of Kuanip, recorded by Cojazzi (1914, p. 351 et seq.), runs as follows:

Kuanip was the Ona national hero. He was begotten in the earth, for his mother was a red mountain near Harberton and his father was Cape Kayel (a little south of Cape Santa Inés). IThen the Indians saw him, they asked: "Who is this? Who begot him? Whence does he come?" And others replied, "Son of the stone."

Kuanip grew up but remained incomprehensible to the Indians. Twice they tried to kill him, but as they were about to discharge their arrows into his back he turned suddenly and forbade them to move. And thus they remained until they died.

Siaskels was a bad man who lived on a mountain in the interior. His food was human flesh. One day he said to his friend Kuanip, "Please give me two of your sons, born of my sister Kokersé."

"Why?" asked Kuanip.

"To help me get the guanaco when the dogs kill them. I am old and the dogs eat the meat before I arrive."

So Kuanip lent his sons for two years. When the time expired he went to Siaskels' wigwam where he found his sons, but not the owner, who was hunting guanaco. "What does that man eat?" he asked one of the boys.

"He eats dung and human flesh the whole year round," replied the lad. And in fact they both had filthy hands, for their work consisted of cleaning the intestines of the people Siaskels killed. Kuanip growing angry then asked, "Where is Siaskels" sister?"

The sons replied, "She is up there making housetops with the skins of dead men and gathering up their hair."

\footnotetext{
${ }^{1}$ Vide Cooper, 1917 , p. 162. The concept underlying the white grod in the Americas has been discussed by Brinton in his Myths of the New Wortel.
} 
"Bring me flint!" cried Kuanip. He took it, and, rubbing it with his hands, cast it to the ground, exclaiming, "I command all things; never shall fire issue from this stone, and thus may this traitor die!" And thus it was; the flint no longer gave out fire.

When Kuanip was disposed to depart, his sons begged with tears that he should take them with him; but he did not desire it, and told them: "It is not fitting that ye come now, for if this beast comes and does not find thee, he is capable of playing me some dirty trick. But follow my counsel: when he bids ye look for firewood, go forthwith, and see that ye go to a greater distance each time. I will be on that hill called Siaxis. The fourth time ye carry firewood, come ye with me."

And it came to pass thus: One day the boys were carrying firewood and they escaped to the hill. Siaskels took note of it and followed them with his most famous hounds. And he was already certain of catching them, for the two fugitives had to cross a very broad river, when Kuanip, to whom all things were possible, caused the two banks to draw near together and his sons crossed easily and were reunited with him. Siaskels, believing that he could take advantage of the prodigy, jumped, and while he was in the air Kuanip returned the river banks to their former position, and Siaskels fell in the middle where it was deepest. Three hours he spent in the water and his back was aching so that he cried out:

"Who is trying to kill me in the water?"

Then from afar Kuanip asked: "Who are you? Why do you call?"

"I am Siaskels; I adore my native land; do not overwhelm me, my back hurts."

Suddenly the water disappeared and Siaskels got up and took the road to the hill Siaxis, where Kuanip was. When he arrived he said to Kuanip: "What have you done with the water? IWhy didn't you let me get up?"

Kuanip answered, “Because I didn't want to; but why don't you stand erect?"

"I cannot," replied Siaskels. "Put your feet on my back, because I am weary from struggling with the water and have lost all my strength."

Then Kuanip said to the boy who was nearest, "It is better that you get up and put your feet on Siaskels' back," and at the same time he ordered within himself that the boy's feet should become 
knives. The lad put his feet on Siaskels' back and made three pieces of him which were stoned by the sons of Kuanip with missiles which they cast from slings. From the eyes of the dying one there issued two little flies, one called $z i-i-i$ and the other doi-doi. Not content with this terrible punishment, Kuanip ordered five men to kill Siaskels' sister; and in order that she should not learn of their coming and that they should not hear her cries and laments, he commanded the birds to surround the house, singing and chirping. The envoys found her cleaning the hides of the dead, and set in wounding her until they left her dead. But before death she spoke with Kuanip and begged him, "Burn all my things." And so he did, after which her spirit (men) appeared to Kuanip and he asked it, "How are things up there?"

"Fine!" she replied. "Up there it is better than here; charming outlook and no illness."

Thereupon Kuanip left Tierra del Fuego; and to improve his lot he transformed himself into that red star which shines by night. According to Beauvoir (p. 202), Kuanip with his wife and two sons now form the Southern Cross.

\section{TRANSFORMATION MYTHS}

In the preceding section we have seen how Kuanip created Hies and stars. There were many tales among the ()na of a similar nature, in some of which Kuanip again figures. ()f these Cojazzi relates two, of which the first has been published also by I)abbene (p. 77 ).

Long ago, when the sun first pursued the moon, there was nothing but day, for the two traveled around the horizon. It happened that Kuanip wanted to take a young girl to wife; lout she silil she did not want to marry, with the sun and moon watching all the time. So Kuanip sang a beautiful song, ordering the sun and the moon to hide for a while. And so they did. Howerer, with alternate rising and setting the days are getting erer shorter, so that ultimately it will be perpetual night.

The other tale is that long ago, before they hecame birds, () krisen (the white male owl) and ()klta (the female bat) were lorolier and sister. (Okrisen was the most handseme, strong, and dentrous hunter of guanaco. Oklta was the most beatutiful of 1 ementh. Neither of them wished a family, hecause ()kisen had never met a woman as delightful as his sister, while ()kilta h.tel mever en- 
countered a man so handsome and strong as her brother. Thus they lived a long time content with fraternal love.

But Kuanip appeared, and trouble ensued, for he fell in love with Oklta, who was by no means displeased. But Okrisen did not approve, and said to his sister, "Do not marry Kuanip, because he has other women, and, when he forgets you, you will be the slave of the others; you will not have guanaco to eat, nor skins to cover yourself, nor harmonious bird-feathers for adornment."

When these exhortations reached Kuanip's hearing, he became angry and changed Okrisen into a bird of ill omen, that is, the owl. Thereupon Oklta would not be Kuanip's wife, for which she was transformed into a winged brute of ill omen as well-the bat. But before consummating these transformations, Kuanip told the former: "You shall not chase guanaco by day; but shall hunt rats by night; and you shall not endure the light of day because your eyes will be feeble." To the second he said: "You shall be uglier than your brother; you shall be unable to see the light of day; you shall hide yourself by day, for even the shadow will be dangerous for you; you shall eat worms and not the flesh of guanaco."

The ablest arrow-makers, said the Ona, after death become female white owls who must not be killed. Naturally arrow-shape stones are their handiwork and are potent talismans.

One of the most curious Ona myths, also preserved by Cojazzi, is that the whale married the wind and begot the hummingbird. Evidently the tale alludes to the vapor from the whale's breathing. rising into the air and disappearing.

In the autumn the leaves of the roble (beech) turn red, but in ancient days all the trees retained their green leaves. Once it happened that a young man named Kamschoat journeyed far to the north where it was very hot; on his return he said that the great trees of that land were green in summer but red in autumn. As no one would believe this, he set out again and returned as a paroquet, laden with cardinal leaves (feathers) to display to the incredulous. On his arrival he settled in the trees, which, as he drew near, turned red. And as the paroquet is very talkative, the Ona believe that he is still making fun of them, saying when he speaks, "Would you believe that I was a liar?" In the Ona tongue this bird was called by the onomatope kerk-perrk.

When the pitirrojo (sckiga) and the chinkol (seip) were men 
they had a quarrel which degenerated into fisticuffs and left both contenders changed into birds with the following markings: the pitirrojo pulled the chinkol's hair and there remained plumes on his head and a mark on his neck; the former received a punch on his nose, and preserves on his chest the smear of the blood that flowed out.

These tales are all set down by Cojazzi (1914), who also records the following one. We have, however, followed the more detailed version of Barclay.

Kwa-u-ishen, the Flat-crested Vulture, came from a country in the far south. It is so cold in that country that all the water is frozen, and the marrow in the bones of Kwa-u-ishen dried up, because he could find no water to drink. All the same, he was a very fierce, strong man, and he came to the land of the Ona to challenge them to wrestle. There stood up to meet him Kti'aishe, the Shag, who was a good wrestler, but a smaller man than the other. When they joined hands, the vulture got the lower grip, and putting out all his strength he pulled toward him, breaking the other's back. For that reason the shags now sit up very straight, with their backs a little hollowed in. But meantime Kti'aishe had caught him by the throat with one hand, driving the blood from it, so that it remained white, and with the other hand he tugged at the top of the head, and Kwa-u-ishen's head has been bald and wrinkled since that time. So neither of them won; but in shame because he had boasted of victory, Kwa-u-ishen changed his name, and now he is called Karkaai. He is the doctor of the south wind, and when he calls storms come, and mist and snow. Cojazzi adds that of Karkaai it is said that to kill him it is necessary to wound him in such a manner that he cannot make a sound; for if not thus incapacitated he calls the snowfalls to aict him in escaping.

Cojazzi also has recorded two transformation myths which are epilogues to the tale of killing the women given on page 9.3. ()ne of the five women to escape became the kelp)-gouse. As she had many children, she tried to cover and defend them. Seeing that this was useless, she took flight, but with her arms ever extended in the hope that they might follow her and receive protection. And even to this day she has the same illusion and continues to stretch out her wings.

One of the men who took part in the killing of the women was 
a little fellow, but he was so furious and worked so hard that the sweat ran down all over his head. Changed to a little bird, he still retains the marks of the drops of perspiration on his head.

When the Ona are unsuccessful in hunting and hear a bird sing, they immediately kill it, for they believe it mocks them with the words, "When I was a man I didn't come back to camp without meat."

A different kind of tale has been preserved by Dabbene (page 77). Once on a time the guanaco was not the wild animal he is today: he was tame and used to come peacefully to the Ona camps. One afternoon Coan-yi-pej (Kuanip) and his son passed by one of these animals who drew near on seeing them. But the boy was afraid, and hid himself against his father, who took a brand from the fire and flung it at the guanaco, who fled to the forest. There he met the fox, who said to him, "Don't you know that the men want you only because you help satisfy their hunger?" Since then the guanaco has stayed away from Ona encampments and gone to the hill-crests where he associated with $\mathrm{H}$-gor-re, the yellow clay. As a result their offspring have yellowish skin. According to the Ona, on Mt. Haupin (Hewhuepen) it is forbidden to hunt guanaco because there they have their home, and if the Ona were to kill them there they would soon disappear.

Kr'en, the sun, was once a mighty hunter, and the most beautiful man in Onaland. One day after hunting, as he was coming home with a great load of guanaco meat, he noticed his wife talking to another woman at the edge of a lake. Leaving his load, he crept close to them through the rushes and listened. Here he learned that his wife Kerren, the moon, had discovered the secrets of klokten and was telling them to the other, so that the women might know how the men deceived them and rise in revolt. When Kr'en heard what his wife was saying, he rushed out, and in anger struck her a blow upon the face, from which come the marks that she bears there today. Then she fled from him frightened, and he followed after, pursuing her until at last they came to the edge of a high bluff which overlooks the sea. Being blinded by her fear, the moon sprang out beyond the cliff into the air, and when the sun reached the cliff he sprang out too. So they may be seen, sometimes both in the sky, and sometimes only one; but although he still pursues her, Kr'en, the sun, has never yet been able to catch his wife, Kerren, the moon. 
This story Barclay tells, and also Cojazzi in a slightly different form. The latter records another sun and moon myth as follows:

In the beginning the sun and moon were human beings, husband and wife. One day, on account of a terrible quarrel the sun pinched and burned the moon's face (whence her marks), and even today they angrily follow each other across the sky. The sun does not catch her, because when he draws near the moon, she grows smaller and smaller so that she becomes invisible when the sun passes by. But when he has gone away without seeing her, she appears again. and grows larger until all her face shows. And she mocks the sun when he is safely at a distance.

The Ona believe that the moon grows large when well fed, but that when she is thin and hungry she comes to earth, and waylays and eats a child. So when the moon has waned, Ona mothers tell their children not to wander where they might be devoured. And when the moon waxes, the children run out, shouting, "The moon has eaten now, but she has not eaten me!"

According to Cojazzi the Ona believe that the planets are young unmarried men who once lived on earth. When there is a shower of falling stars it means that they run to the hunt. Barclay says that a single shooting-star means that a young man is looking for a wife.

The four winds once were men. They fought one another and the west wind put the others to flight. Hence the prevailing wind is from the west.

\section{GHOST STORIES}

The Ona have a number of ghost stories, of which only a lew have been recorded. Indeed, they believed that the very mountains and trees have spirits which cry and call to one another. The following tales are all taken from Cojazzi. The longer one is recorded also by Dabbene.

About 150 years ago the lahgan were eating whale, when the Ona saw them. Leaving behind their arms, they drew near and begged for oil. But the lahgan, seeing them unarmed, killed (wo, put the rest to flight, and captured one whom they later released at the request of a young Yahgan girl. Shortly afterward an epidemic came and spread from the south coist to the Ris Citunde. And it happened in this wise: ()ne of the slain ()na was a greall shaman. The Yahgan, after attempting to arrow him, had with much trouble cut off his head. Therenpon the head les.an wo run 
toward the mountains, and, before ascending them, it turned, opened its eyes in a horrible fashion, and began to laugh and make faces. All who saw this head died, including many it passed on the trail to Rio Grande on the east coast. Then it returned to the mountains. It might appear and slay again.

There is an old man in the mountains who cannot make a fire because his wood is damp. When he sees a fire he comes down to it to warm himself and knocks down the toldos weighted with snow. Barclay (1926) tells of a similar ghost named Yose. He often comes to the encampment to sit beside the fire, but he is transparent, so no one has ever seen him.

In addition it is recorded that the Ona pick up and remove from the trail a certain black beetle because they believe that it is the spirit of a certain shaman and therefore must not be stepped on.

\section{THE HAUSH}

THE small mysterious tribe known in modern literature as the Haush, formerly inhabitants of the eastern tip of Tierra del Fuego (pl. Iv), have faded from existence, leaving but scanty records of themselves or of their past. To the Yahgan the Haush were known as Italum Ona, "the eastern Ona," while the Ona called them Haúsh. They themselves called their own people Mánekenkn.

The Haush language has been recorded in several short vocabularies, of which those of Cojazzi (1914), of Lucas Bridges which was published by Lehmann-Nitsche (1915), and of Ramón Lista (1887), are the most important. These establish that Ona and Haush are closely related to each other and to the Tehuelche.

The geographical position of the Haush in the eastern tip of Tierra del Fuego raises the suspicion that they were the first migratory wave of Foot Indians to reach the island. Additional grounds for this belief can be derived from the native place-names, for, according to Mr. Lucas Bridges, Haush place-names were found in Ona territory far to the north and west of the Haush habitat. Thus it seems clear that the Haush had been driven back by the Ona not so very long ago.

It can be definitely stated that the Haush were Foot Indians like the Ona and that they did not use canoes, yet they seem to have derived their livelihood from the sea-beaches more than did the Ona. At times the Haush and Ona camped together, but 


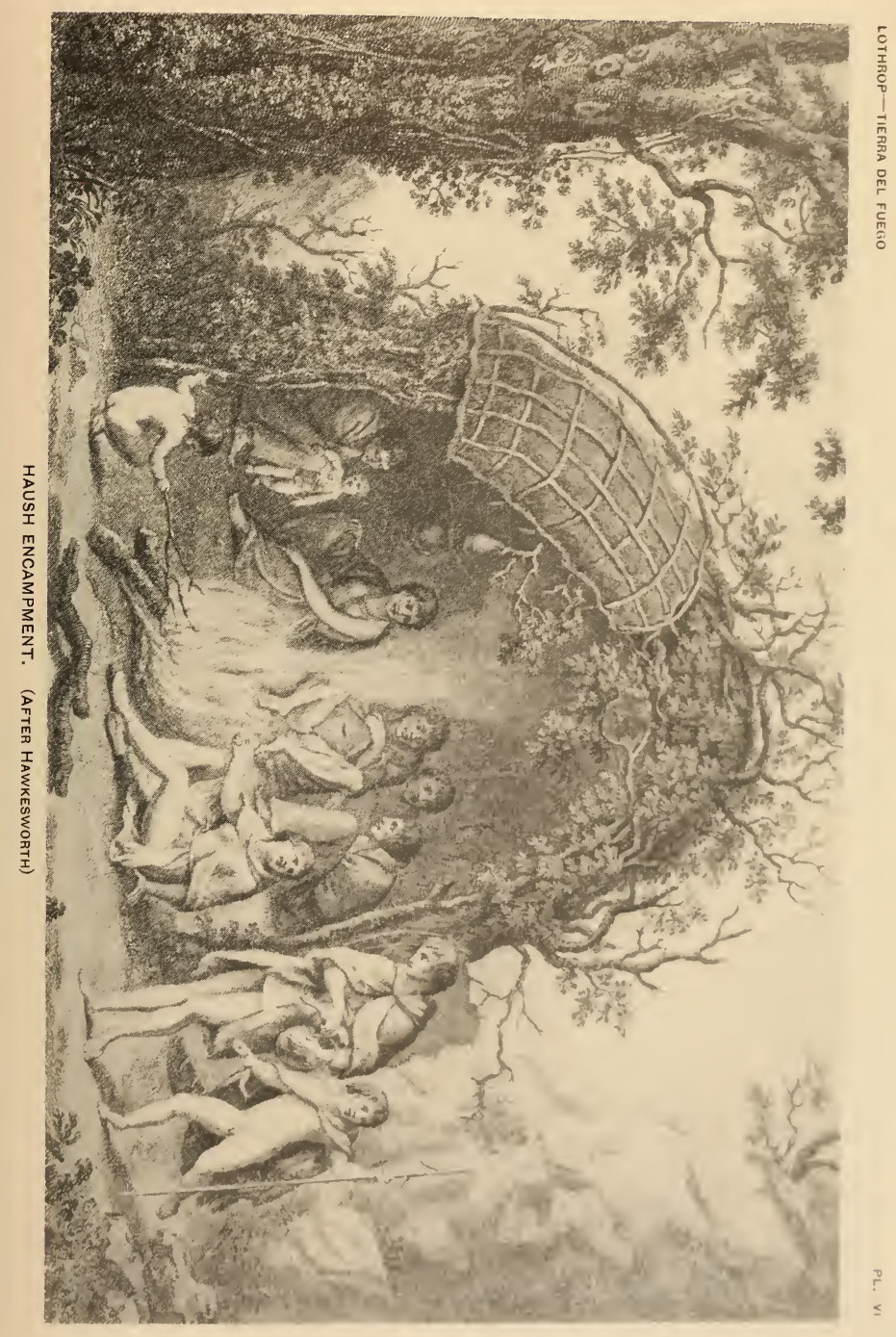



they rarely camped with the Yahgan except when a dead whale drifted ashore in a locality accessible to both. Physically the Haush are said by the Bridges to have resembled the Iahgan as much as the Ona.

On the cultural side, elements of both Ona and Yahgan practice were utilized by the Haush, but the greater relationship seems toward the Ona. Thus the Haush speared their seal (of which they ate many) with spears in Yahgan fashion, but they hunted guanaco with bow and arrow like the Ona. Also they usually dressed like the Ona in guanaco (not seal or otter) skins and used a guanaco-hide forehead cap like the Ona. Furthermore, they generally lived in a windbreak of Ona type rather than in a Yahgan hut. So Mr. William Bridges remembers them. However, I suspect that there may have been cultural changes in the last two centuries, because earlier accounts picture them with more Iahgan cultural features, such as houses of Yahgan type. In pl. VI we reproduce the Haush encampment sketched by Banks' artist during Cook's visit in 1769. Here the house is obviously of Yahgan type; also the harpoon, the shell necklace, and the short cape worn by the man behind the fire are Yahgan features. The basket, of the coiled technique, is Yahgan in style, and from the Haush name (tawal) given by Lista ${ }^{1}$ we judge that it was woven in the manner called tawéla by the Yahgan, illustrated in figs. 59 and 61. Ona cultural features in this picture are the long fur robes and the cincture worn by a woman in the foreground.

Cojazzi (1914) has placed on record several interesting observittions in regard to the Haush. He says that the method of burial was different from that employed by the Ona, because the Haush dug very much deeper graves. In these, wrapped in skins, corpses of ordinary individuals were placed face upward, but shamann were buried face downward in order that their spirits might talk with the spirits of the earth. This distinction in grave types maly prove important in archeological studies in eastern Tierra del Fuegu.

The Haush had an initiation ceremony like the () na klokten. () the masked spirits who appeared during it, one Was Kisorten, a male earth spirit who was supposed to issue from the lire in the ceremonial lodge. Evidently he corresponds to the spirit called

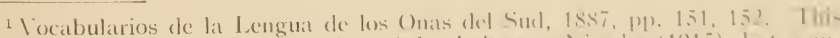

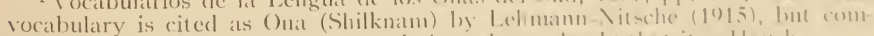

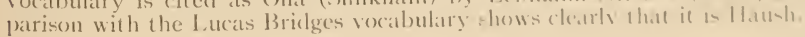


Sh'ord among the Ona. To the Haush he came naked and painted. His skin was as hard as hide or stone. Although he never spoke, he was supposed to understand the words of men; yet he was capable of crudely expressing himself, for, mirabile dictu, he was known to have cried out when bitten by a dog. Ksorten had the peculiar attribute of being unable to cross even the smallest stream, but had to be carried over it. It was considered useless to kill him, because a host of similar beings would issue from his head. During the course of the initiation ceremony, he made the rounds of the encampment, where, if he saw a woman, he seized a basket and threw it at her.

Another masked spirit was Kela, who corresponded to the Ona H'alpin. She was a naked female, with a very tall pointed head, who was supposed to live in the sky, whence she could be summoned by a shaman. She issued from the initiation lodge with closed fists beside her thighs, stamping her feet and shouting " $\mathrm{Ka}$-la-lala-la!" The witch-doctors surrounded her and the other men crowded closely, but women and children stood at a distance.

Haush mythology, says Cojazzi, was much like the Onan. For instance, they had their own version of the Kuanip myth cycle. He went to the sky, they said, from a spot called Koschen near Good Success bay, where his footprint still may be seen. His sons are now twin stars.

The Haush had a myth cycle concerning the fox, who appeared usually in the guise of a trickster. Once, it was said, all the animals were tame, and, living near the abodes of men, they sang in unison "Ekelé, ekelé, ekelé!" This happy state of affairs came suddenly to an end, for somebody put something evil-smelling under the nose of the fox and he at once became wild. Furthermore, he invited the other animals to join him in his wildness, which they all did. In the Ona myth of how the guanaco became wild, it will be recalled that the fox played a part.

The moon was greatly feared by the Haush. When it was ruddy they said it was caused by the blood of those it had consumed.

Owing to the scarcity of data concerning the Haush, we quote at length a description of the natives of that tribe encountered at Good Success bay by Cook in 1769, as compiled by Hawkesworth:

The inhabitants of this town were a small tribe, not more than fifty in number, of both sexes and of every age. Their colour resembles that of the rust of iron mixed with oil, and they have long black hair: the men 
are large but clumsily built; their stature is from five feet eight to five feet ten; the women are much less, few of them being over five feet high. Their whole apparel consists of the skin of a guanicoe, or seal, which is thrown over their shoulders, exactly in the state in which it came from the animal's back; a piece of the same skin, which is drawn over their feet, and gathered about the ancles like a purse, and a small flap, which is worn by the women as a succedaneum for a figleaf. The men wear their cloak open, the women tie it about their waist with a thong. But although they are content to be naked, they are very ambitious to be fine. Their faces are painted in various forms: the region of the eve was in general white, and the rest of the face adorned with horizontal streaks of red and black; yet scarcely any two were exactly alike. This decoration seems to be more profuse upon particular occasions, for the two Gentlemen who introduced Mr. Banks and the Doctor into the town, were almost covered with streaks of black in all directions, so as to make a very striking appearance. Both men and women wore bracelets of such beads as they could make of small shells or bones; the women both upon their wrists and ancles, the men upon their wrists only; but to compensate for the want of bracelets upon their legs, they wore a kind of fillet of brown worsted round their heads. ${ }^{1}$ They seemed to set a particular value upon any thing that was red, and preferred beads ${ }^{2}$ even to a knife or a hatchet. . . .

We saw no appearance of their having any food but shell-fish; for though there were seals frequently seen near the shore, they scemed to have no implements for taking them. The shell-fish is collected by the women, whose business it seems to be to attend at low water, with a basket in one hand, a stick, pointed and barbed, in the other, and a satchel at their backs; they loosen the limpets and other fish that adhere to the rocks, with the stick, and put them in the basket; which, when full, they empty into the satchel.

The only thing we found among them in which there was the least appearance of neatness or ingenuity, was their weapons, which consisted of a bow and arrows. The bow was not inelegantly made, and the arrows were the neatest we had ever seen: they were of wood, polished to the highest degree; and the point, which was of glass or llint, and barbed, was formed and fitted with wonderful dexterity....

They appeared rather to be a travelling hord than to hate any lixed habitation. Their houses are built to stand but for a short time; the?

\footnotetext{
1 In this custom we see a Tehuelche trait not found among the ()n.t. S.K...

2 The word for beads was learned to be hallece, which might be a compound built on the Haush icha or Ona échi, throat. The word for water is given as oodâ, clearly resembling the Haush ootun, but not the Onis ehoon. The words icha and oolun are from a vocabulary collected by Lucas Bridges and published by Lehmann-Nitsche (1915). S.K.L.
} 
have no utensile or furniture but the basket and satchel, which have been mentioned before, and which have handles adapted to the carrying them about, in the hand and upon the back: the only clothing they had here was scarcely sufficient to prevent their perishing with cold in the summer of this country, much less in the extreme sererity of winter; the sheil-fish which seems to be their only food must soon be exhausted at any one place: and we had seen houses upon what appeared to be a deserted station in St. Yincent's Bay.

It is also probable that the place where we found them was only a temporary residence, from their having here nothing like a boat or canoe, of which it can scarcely be supposed that they are wholly destitute. ...

They did not appear to have among them any gorernment or subordination: none was more respected than another: yet they seemed to live together in the utmost harmony and good fellowship. Neither did we discover any appearance of religion among them, except the noises which have been mentioned, and which we supposed to be a superstitious ceremony, merely because we could refer them to nothing else. . . U Upon the whole, these people seemed to be the most destitute and forlorn, as well as the most stupid of all human beings; the outcasts of Nature, who spent their lives in wandering about the dreary wastes, where two of our people perished with cold in the midst of summer: with no dwelling but a wretched hovel of sticks and grass, which would not only admit the wind, but the snow and the rain; almost naked; and destitute of every convenience that is furnished by the rudest art, having no implement eren to dress their food: yet they- were content. They seemed to have no wish for any thing more than they possessed, nor did àn thing that we offered them appear acceptable but beads, as an ornamental superfluity of life. That bodily pain they might suffer from the sererities of their winter we could not know: but it is certain, that they suffered nothing from the want of the innumerable articles which we consider, not as the luxuries and conveniences only; but the necessaries of life. . . .

\section{ARCHEOLOGT OF EASTERN TIERRA DEL FUEGO}

\section{CAMP-SITES}

THREE archeological camp-sites were inspected by the writer in eastern Tierra del Fuego, all of them on the Bridges' property south of the Rio Fuego. One of them extends beneath the shearing shed of the Estancia Viamonte and across the corrals to the southeast. A second corers the crest of low hills to the west and south. The third is situated on a hill five or six miles to the south, at the point (called Kaitrrh in the Ona tongue) where the Harberton 
trail leaves the coast. As each of these sites is of a slightly different character we shall describe them briefly.

The shearing shed and corral site covers a small hummock some two hundred yards from the beach. Glacial shingle, polished by wind-driven sand, covers the ground. Scattered among the rounded pebbles, numerous worked stones, chips, knives, scrapers, etc., can be picked up. I collected a bucketful in the course of a couple of hours. There are no other signs of human habitation; no rubbish of any kind is visible. A workshop site.

Between a quarter and half a mile to the south and west of the corrals rise low hills covered with stunted trees and grass. Wandering along the seaward slope just below the crest, the presence of shells may be detected. Usually they are concealed by the grass, but in places in the deep shade or where the ground has recently been disturbed they show clearly. There was no great concentration of rubbish at any special locality apparently: no specimens could be discovered on the surface on account of the grass. The whole site covers perhaps half or three-quarters of a mile in length by fifty to a hundred yards in width.

The southern end of this site extends beyond the trees to the beach. Owing to the shifting of the sand, especially where the coast road crosses it, objects may easily be buried and disinterred. Here it is possible to pick up chipped implements in some numbers.

Five or six miles southward is a hill partly cut away by the sea. In the Ona tongue it is called Kaitrrh. Surface finds were made here, but no trace of shells or of animal refuse could be seen. As the ground consists only of sand for some distance in every direction, all pieces of stone must have been transported thither. Three specimens from this station are pictured in pl. vill, $b, c, c$.

From the sites here listed the writer could obtain no diata on their antiquity. They cover an area larger than the lahgan camping-places, and the refuse is not of great depth. For rea-ons given below, we believe that the ()na arrived some time after the Yahgan, hence we might expect their (amps not to exhithit so much refuse.

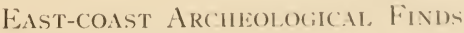

The extreme simplicity of Fuegian culture is well exemplificel hy the archeological remains, which, if not scarce, represent only it few implements most crudely made. In generall the eastecodst finds are large chips of stone, of reculisite shape for their purpone, 
worked on one face only, and usually reworked along the cutting edge. The material is green chert, white quartz, and black basalt. Obsidian implements are found in Patagonia, but not in Tierra del Fuego.

1. Krife-BLADEs.-The commonest form of knife-blade is a leaf-shape, plano-convex flake, three or four inches in length, with secondary chipping along the edges. Knives of this shape, though usually of greater size, can be found along the south coast of Tierra del Fuego; they are also common in Patagonia; examples from the latter region have been published by Outes (1905, figs. 72-79). In our pl. VII, $a, b$, two Fuegian examples are illustrated; both are slightly asymmetrical, as is often the case with Patagonian knifeblades.

A second kind of knife-blade from the east coast of Tierra del Fuego is illustrated in pl. vir, $c, d$. These thin linear chips, about five inches long, with parallel edges sharpened by secondary chipping, are not common. Several blades of this form were noted by the writer in the collection of Mr. John Hamilton at Galliegos in southern Patagonia; Outes (1905, figs. 66-68) pictures three specimens found farther to the north in Patagonia, while Holmes (1912) has illustrated examples from the province of Buenos Aires.

Both forms of knife-blade here described were adapted to hafting on a wooden handle. In recent years the Ona hafted steel blades by inserting them in the split end of a wooden handle or by simply lashing them to the side of the handle (fig. 23). The first method would seem more useful for thin metal blades than for thicker ones of stone.

2. SCRAPERS.-The commonest form of scraper found at archeological sites on the east coast of Tierra del Fuego is an oblong, plano-convex chip with working edge retouched (pl. vIII, $b, c, e$ ). The type has been called the "duck-bill scraper." Sometimes the chip shows a portion of the surface of the nucleus from which it was struck, as in pl. viri, $b$. Occasionally at one end of the blade there is a small incurved section, forming a "spoke-shave" scraper, a type useful for cleaning bones. This feature is illustrated in pl. VIII, $e$. It is found also in Beagle Channel scrapers, as seen in fig. $104, c$.

Scrapers of the "duck-bill" class, designed for scraping hides, presumably were hafted in the fashion of the woman's modern 
LOTHROP-TIERRA DEL FUEGO

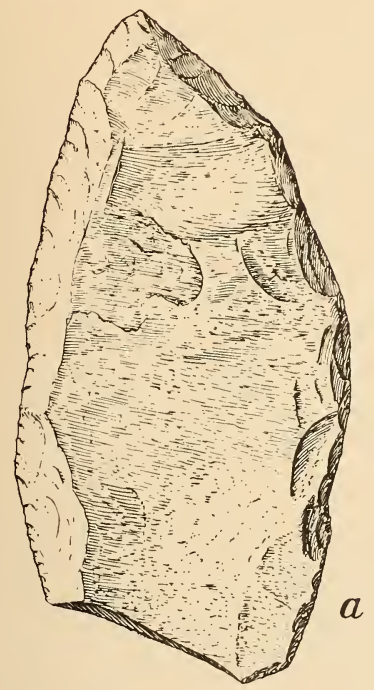

PL. VII
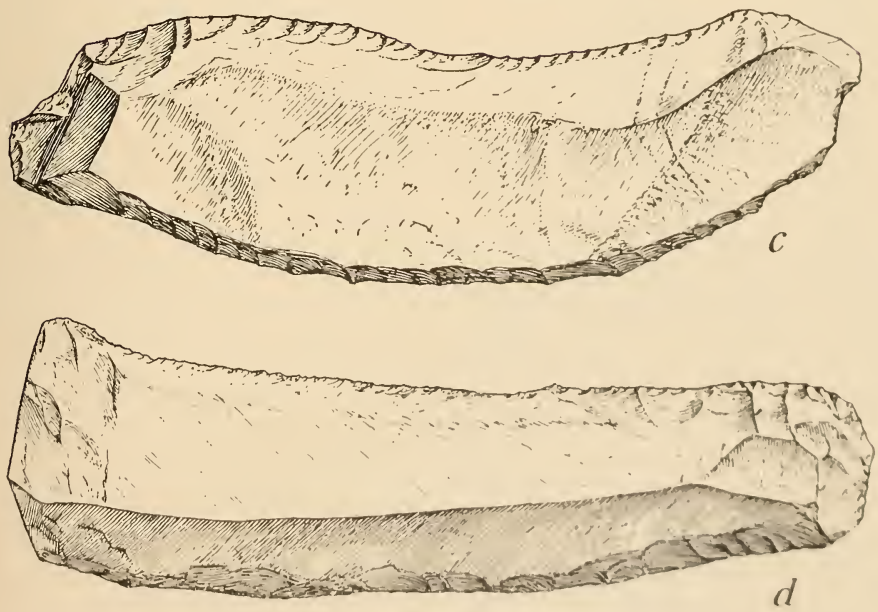

STONE BLADES FOUND IN CORRAL, ESTANCIA VIAMONTE, SIERRA DEL FUEGO LENGTH OF $d$, 5 IN. $(14 / 3 \cup 72)$ 

glass-bladed scraper of the Ona. This has been described in detail above and is illustrated in figs. 24 and $25, b$. In Patagonia, where scrapers of this shape are common, blades were hafted at rightangles to the handle by inserting them in a slot and securing them with resin. This form of hafting is described by Outes (1905, fig. 53), who states that it is of Araucanian origin. A commoner form of Patagonian hafting has been illustrated by Holmes (1912, fig. 30): a flexible sapling has been bent until the ends met, and the blade, bedded in moss, is secured between the ends by hide lashings.

A second east-coast Fuegian scraper is flat on one side, pronouncedly convex on the other, oval in shape, and with a cutting edge completely encircling it ( $\mathrm{pl}$. vilI, $a, d)$. This scraper is not suitable for hafting, and presumably was held in the hand. Many others are so convex (pl. viII, $a$ ) that they may be described as snub-nosed, and these doubtless were pushed away from the body when scraping, as was done by Ona women using their modern tool. Scrapers of this oval class are sometimes found on Beagle channel (fig. 104, a); the writer has seen several examples in the Hamilton collection at Galliegos.

3. Cleaver.-In the collection obtained on the east coast are several heavy oval implements, about twice the size of the oval scrapers. These show signs of battering along the edge, and apparently they had been used as cleavers or hand-axes. During
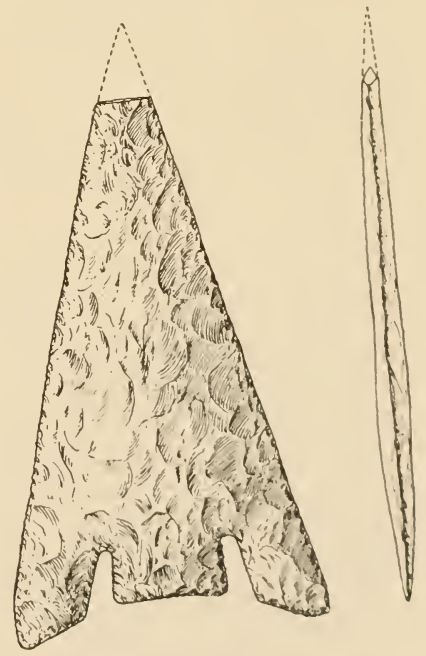

FIG. 40.- Stone blade from Estancia Viamonte, Tierra del Fuego. W'idth, $1 \frac{3}{4}$ in. (Courtesy of Mr. Percy Reynolds, Jr.) my visit the Ona had no tool of this type, but it must be remembered that these remains may have been left by the Haush before they retreated to the eastern tip of Tierra del Fuego and that we have no knowledge of the kinds of tools used by that tribe. The fact that a form of implement not of recent (nat type comes from sites 
near the Rio Fuego might well be a basis for belief that the other remains are not all Ona handiwork.

4. Arrow- or Spear-points.-Occasionally a delicate, symmetrical, and carefully chipped point like that shown in fig. 40 turns up on the east side of Tierra del Fuego. The specimen here illustrated has been worked down on both sides and carefully retouched along the edge. In any part of the world it would be considered a fine example of stoneworking, and it shows that at least an occasional Fuegian artisan could produce first-class implements.

The reader will notice that to form the tang two slots have been sunk in the base of the blade. This is in conformity with recent Ona practice, although the barbs on modern Ona points are set at a different angle because the slots are sunk diagonally from the tip of the blade, as shown in fig. 32, $b$. This is unlike the common Patagonia type (fig. $32, c$ ), from which a bifurcated tang projects behind the barbs. The Fuegian type of arrow- and spear-head was not present in the large collection of Mr. Hamilton, inspected at Galliegos; it is, however, reflected in Patagonian remains, and

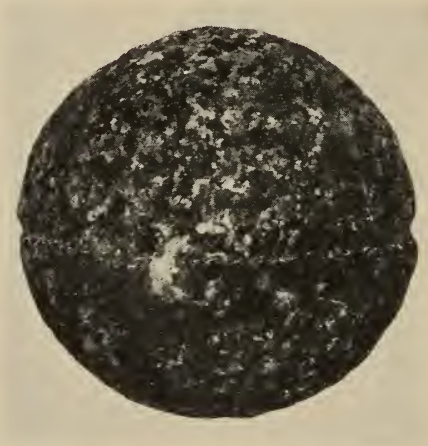

FIG. 41.-Bola from Estancia Viamonte, Tierra del Fuego. Diameter, $2 \frac{1}{2}$ in. $(14 / 3970)$ has been illustrated by Outes (1905, fig. 104); Medina (1882, figs. 52, 54) has published similar points from Chile; Yahgan examples are shown in fig. 105, $c, d$.

Bolas.-Tierra del Fuego has produced few polished stone implements. In fig. 41 we illustrate a bola found near the shearing shed on the Estancia Viamonte and kindly presented to the Museum by Mr. William Bridges. Other specimens labeled Dawson island and Rio Grande are in the museum at Punta Arenas. Outes (1905, p. 427), in his scholarly study of Patagonian archeology, has shown that in the early part of the sixteenth century the bola was used only by tribes living on the shores of the Rio de La Plata-the Beguá, Charrúa, and Querandí. Con- 


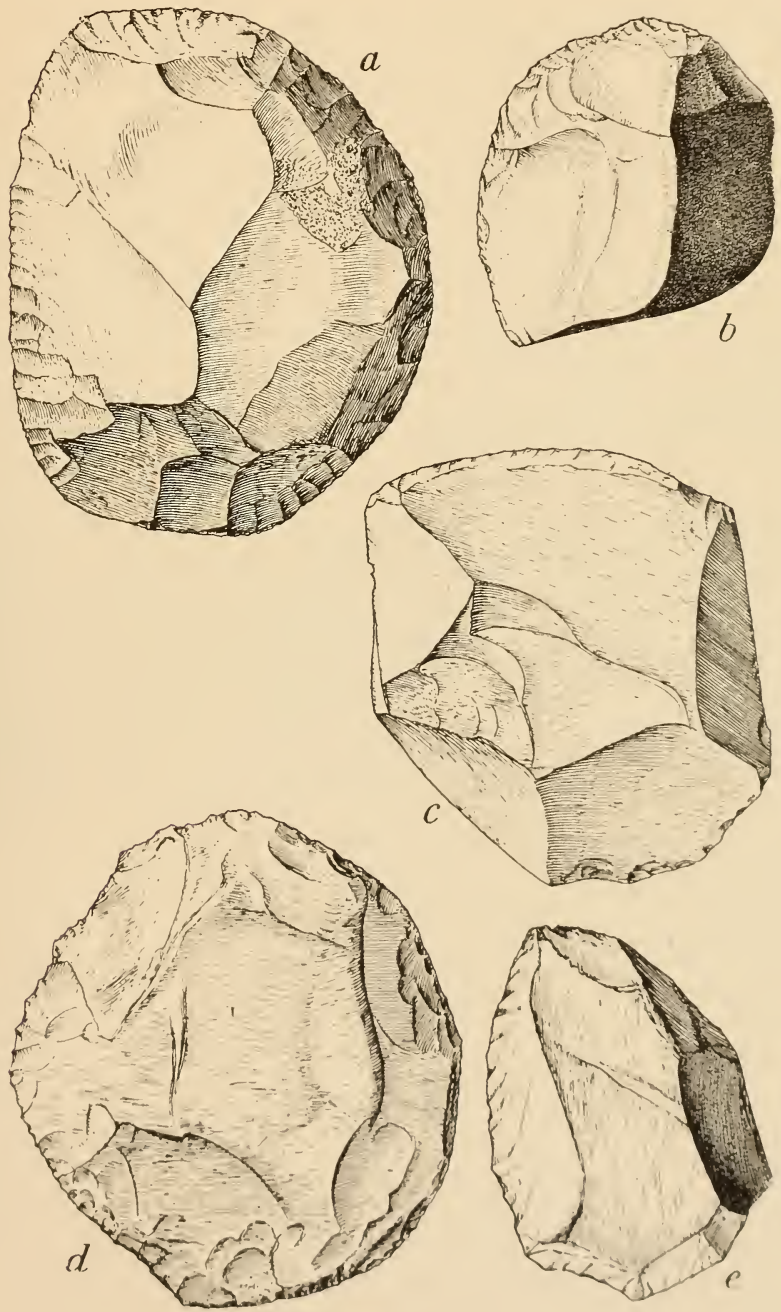

SCRAPERS

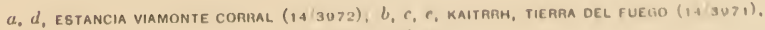
LENUTH OF $d, 3$ IN. 

tact with the Spaniards caused the extermination of these unfortunate natives, but ere that had come to pass the use of the bola had been taken up by the Puelche, among whom it was noted in 1599. From them it spread to the Tehuelche of Patagonia. ${ }^{1}$ All the early voyagers along the Patagonian coast describe native bows and arrows, but the bola is not noted before the voyages of Duclos-Guyot and De la Giraudais (Bahía Posesión in 1766) and of Bougainville (Bahía Boucault in 1777). Thereafter the bola was a commonly described object. In Tierra del Fuego the bola never came into general use. It was known, however, to the northern Ona at the time of the Beagle expeditions (1829-32). ${ }^{2}$ Clearly then the bola was no ancestral arm carried to Tierra del Fuego in remote centuries, but a recent introduction not long antedating the European colonization.

${ }^{1}$ Fig. 16, an engraving based on a drawing by Oviedo made during the second quarter of the sixteenth century, shows two large round objects evidently intended to represent bolas. It thus might disrupt the line of reason advanced above. In counter argument it may be said firstly that Oviedo never visited this part of the world and in making his drawing may have combined data on the inhabitants of the shores of the Rio La Plata and the Straits of Magellan-information he doubtless obtained from the same individual. Secondly, in several instances two or more of Oviedo's drawings have been combined by his publishers. Unfortunately the material on which our fig. 16 is based has been cut out of the original manuscript.

${ }^{2}$ Fitzroy (1839, p. 186, note) states that "Mr. Low has seen Fuegians with balls (bolas) in the northern part of their country." 


\title{
PART II
}

\section{CANOE INDIANS}

\author{
THE YAHGAN
}

$\mathrm{T}$ HE Yahgan Indians, the southernmost people in the world, lived on the southern shores of Tierra del Fuego from Brecknock peninsula to Spaniard harbor, and on the adjacent islands southward to Cape Horn itself (pl. IV). In spite of the tempestuous waters they confronted, they were a seafaring people and derived their livelihood almost entirely from the sea and its beaches.

Like the Ona, the Yahgan had to move freely and frequently in search of sustenance, but their camping-places were limited by the fact that each family was dependent on a fragile bark canoe, for which shelter must be provided. Thus favorable stretches of beach today are marked by great refuse-heaps, of most extraordinary size when one recalls that they represent only temporary stoppingplaces and that no family ever camped on a spot where it was known that a death had occurred. Centuries or even milleniums must have witnessed the building up of these vast agglomerations of bone and shell.

The Yahgan came under missionary influence in the middle of the nineteenth century, and a permanent mission station was maintained among them from $18 ; 0$ until recently. Hence their culture was much modified before they could be studied by trained ethnologists. For instance, by the eighties they had modified their initiation rites. We must add that among the Ona those without missionary training tended to survive the longest, but among the Yahgan the last survivors have almost invariably been mission reared.

Writing nearly a century ago, Fitzroy (pp. 137-139, 186) thus describes the untrammeled Yahgan of his day:

The Tekeenica, natives of the south-eastern portion of Tierra del Fuego, are low of stature, ill-looking, and badly proportioned. Their color is that of very old mahogany, or rather between dark copper and 
bronze. The trunk of the body is large in proportion to their cramped and rather crooked limbs. Their rough, coarse, and extremely dirty black hair half hides yet heightens a villainous expression of the worst description of savage features. . . .

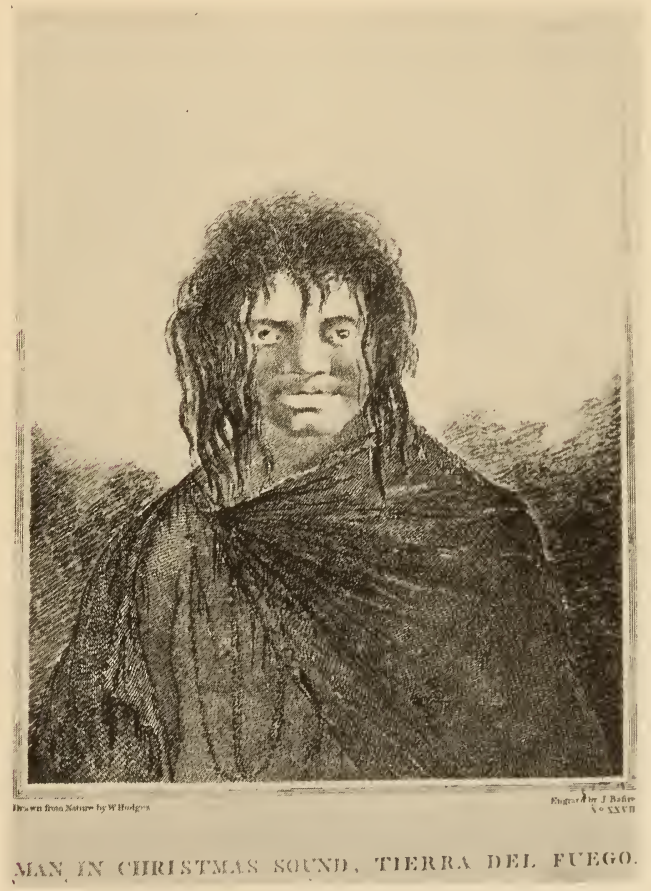

FIG. 42.-Yahgan Indian. (After Hawkesworth.)

Sometimes these satires upon mankind wear a part of the skin of a guanaco or a seal skin upon their backs [fig. 42], and perhaps the skin of a penguin or a bit of bird hide hangs in front; but often there is nothing, either to hide their nakedness or to preserve warmth, except a scrap of hide, which is tied to the side or back of the body, by a string around the waist. Even this is only for a pocket, in which they may carry stones for their slings, and hide what they pick up or pilfer. A man always carries his sling around his neck or waist, wherever he goes. 
Women wear rather more clothing, that is, they have nearly the whole skin of a guanaco, or seal, wrapped about them, and usually a diminutive apron. The upper part of the wrapper, abore a string which is tied around the waist, serves to carry an infant. Neither men nor women have any substitute for shoes.

Both sexes oil themselves, or rub their bodies with grease; and daub their faces and bodies with red, black, or white. A fillet is often worn around the head, which upon ordinary occasions is simply a string, made of sinews; but if going to war or dressed for show, the fillet is ornamented with white down, white feathers, or pieces of cloth, if they have obtained any from shipping. . . .

It is rather curious that each of these natives is trained to a particular pursuit: thus, one becomes an adept with the spear; another with the sling; another with a bow and arrows; but this excellence in one line does not hinder their attaining a considerable proficiency in all the others.

Before entering on the details of Yahgan life we shall dwell briefly on the charges of savagery and cannibalism made by numerous writers. As early as 1600 the Alacaluf were thought to be cannibals, for in that year Van Noort marooned on Santa Maria island one of his officers charged with insubordination, in the belief that he would die of hunger or be eaten by the savages. A quarter of a century later Jaques L'Hermite charged the Yahgan with cannibalism. In more recent years Darwin and Fitzroy have repeated the accusation on hearsay evidence, and their dictum has been widely published. However, no white man has ever witnessed the act of anthropophagy among any of the Fuegian tribes, while in recent years those who have lived with the natives and come to know them well all agree that the idea of eating human flesh is as repugnant to a Fuegian as to a European. According to Martial (p. 193) the Yahgan ordinarily do not eat dog, fox, or rat, because these animals will eat human flesh.

The imputation of barbarity, on the other hand, rests on firmer ground, for there are well-authenticated instances of attack by the Yahgan on European crews. The earliest of these resulted in the death at Nassau bay in 1624 of seventeen men from L'Hermite's ships; the most widely published was the massacre at Woolyia in 1859 of the crew of the missionary schooner Allen Gardiner. What provoked these attacks is a secret intombed with their victims. Early voyagers habitually kidnapped natives to serve as pilots and thus aroused merited resentment. Native women often have 
been a source of contention. Intelligent and amicably intended travelers through ignorance of native customs may easily wound native feelings to the point of rousing open hostility. Of the looting of ships and robbing of their crews, it is but just to remark that the Yahgan, although recognizing personal property, habitually shared their provisions with one another. Also, among primitive people in general the robbing or tricking of strangers often is considered entirely ethical or even especially deserving of praise, though the same performance at the expense of a relative or a friend might be condemned. The Yahgan have suffered in public esteem because their morality has been judged on the basis of Christian ethics.

\section{LANGUAGE}

The Yahgan tongue, although it has been studied since the visit of Darwin, as yet is thought to be related to no other New World language. Through missionary labors, chiefly those of the Rev. Thomas Bridges, three large vocabularies have been compiled. Of these one containing about 4000 words on 137 pages in $\mathrm{Mr}$. Bridges' handwriting is still in possession of the Bridges family in Tierra del Fuego. It covers only eleven initial letters. Inside the front cover is written: "Begun this June 19th, 1879." A second vocabulary compiled by Mr. Bridges, aided by several lay members of the English mission, contains about 12,000 words. It is now in possession of the Rev. John Williams in Punta Arenas. Finally, there exists in Belgium a Yahgan vocabulary in two volumes of about 32,430 words written on 1081 pages. It is the result of Mr. Bridges' life-long contact with the Yahgan extending from 1856 until his death in 1898. During his later years, according to his sons, he was continually working over this manuscript. After his death it was lent to Dr. Frederick A. Cook, who had been to Tierra del Fuego with the Belgian Antarctic expedition in 1897 and 1899. Cook removed the manuscript to Belgium, where it has since remained. Plans for its publication were interrupted by the World War.

For printed source-material in Yahgan, students are further indebted to Mr. Bridges for translations of the gospels of St. Luke and St. John, and the Acts of the Apostles. All these, as well as his manuscript dictionaries, are written in the Ellis alphabet. The Rev. John Williams of Punta Arenas has translated the collects and morning and evening prayers into Yahgan, and also has 
published a broadsheet with the Lord's prayer. Both are written in the ordinary alphabet with a ${ }^{-}$to denote the short vowels and soft $g$.

As for the nature of the Yahgan tongue, in direct contrast to Ona, it is soft and pleasant to the ear. There is a great abundance of vowel sounds, and the pronunciation of consonants presents no difficulties. The line between $p$ and $b$ is loosely drawn. There is a soft and a hard $g$, and also a soft $c h$ sound $(q)$.

According to Mr. Fred. Lawrence, of Remolino, generally regarded as the best living authority on the Yahgan language, in the old days there were five distinct dialects, distributed as follows:

1. Central dialect, including Ushuaia and Murray narrows. This is the speech recorded in the Bridges dictionaries.

2. Eastern dialect, spoken from Harberton eastward and on Lennox island, New island, etc.

3. Western dialect, found from Cape Divide westward.

4. Wollaston Islands dialect.

5. New Year's Sound dialect, spoken to the south and west of False Cape Horn and on the southern part of Hoste island.

These dialects are said to have differed from one another as much as Scotch from Cockney; that is to say, they were mutually intelligible but there was wide variation in accent and the choice of words. Thus the double-barbed harpoon is waiki in the west and wek in the east; the fish-spear is usháwaia in the east and shushróya in the central dialect; bark of the Nothofagus betuloides is aiirshu in the east and aírshun at Ushuaia; a sling is mata wá in the east and watewá in the central dialect, etc. Today it is difficult to know just what dialect one is hearing, because the few surviving Yahgan live together much of the time and have fused their speech. However, the fact that considerable divergence once existed within such a small geographical limit indicates that but little movement of the tribe as a whole had taken place for centuries, at least.

The Yahgan words in the present text were obtained chiefly from Mr. William Bridges and Mr. Fred. Lawrence, who speak the central dialect; from William, born at Halupaí (see fig. 98); from Walter, a Lennox islander; from Charley, son of a Haush called Iniolh and a Yahgan woman; from Mary, a westerner. The four Indians mentioned were all mission-reared and therefore today 
speak the central dialect. The entire vocabulary was checked by Mr. William Bridges and any words not in the central dialect were noted.

The richness of the language is indicated by the more than 32,000 words brought together by Rev. Thomas Bridges. Many of these words, of course, are compounds, but such a vast number are fundamentally due to unusual specialization in meaning.

On the other hand, Yahgan exhibits the lack, usual among primitive people, of abstract ideas and generalizations. In fact, even in English (which, due to missionary training, some of the Indians spoke fairly well) the Yahgan exhibited inability to grasp the concept of generalities.

The manner of counting was even more primitive than the Ona count, for the Yahgan had no words for 4 and 6 , which, to be sure, were compound numbers in the primitive Ona system. The Yahgan count is:

$\begin{array}{rll}\text { 1. } & \text { hikóli } & \text { one } \\ \text { 2. } & \text { kambaíbi } & \text { two } \\ \text { 3. matén } & \text { three } \\ \text { 5. hikóli iirsh } 1 & \text { one hand } \\ \text { 10. } & \text { kambaíiirsh } & \text { two hands }\end{array}$

\section{Clothing}

From Fitzroy's description of the Yahgan, cited above, it appears that there was very little order or regularity in their scanty dress. However, though seemingly inadequate, their clothes were of well-defined forms which we shall describe. It is no exaggeration or overstatement to remark that, considering the climate in which they had to live, this southernmost tribe had less body-covering than any other people in the world. As compared to the Ona, their garments, similar in nature, were deficient in size, while the stiff and unyielding skins they employed from their very nature lacked the warmth supplied by the pliable, voluminous, and snugfitting robes of the Foot Indians. We must add that individuals of both sexes and all ages of ten went entirely naked.

1. CAPE.-The usual cape worn in summer and winter alike by both men and women was a seal or sea-otter skin. Sometimes two

${ }^{1}$ Bove gives the word cupascpa for 5. It was not known to any lahgan Indian or member of the Bridges or Lawrence families encountered by the writer. 


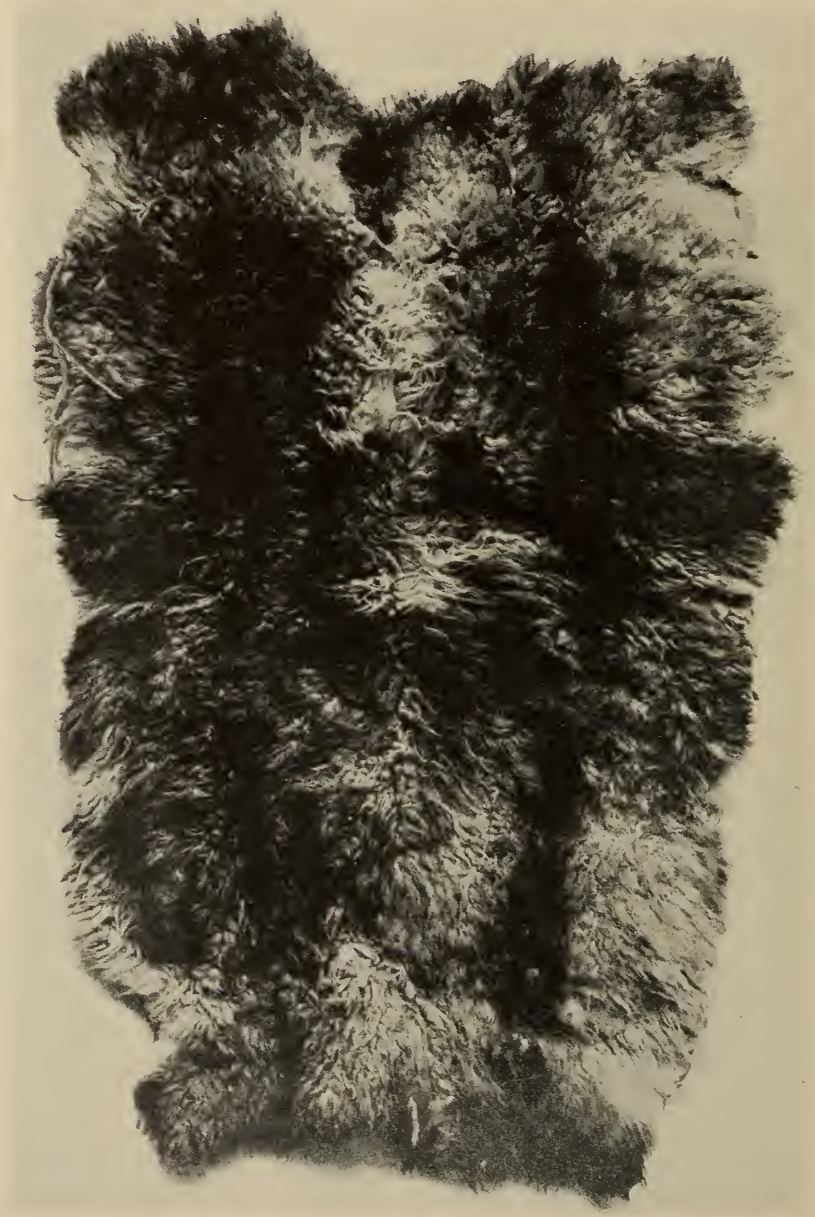

FIG. 43.-Yahgan guanaco cape. Size, 35 by 50 in. (14/2251) 
or more were sewn together. In general, however, this garment extended only to the waist and did not completely encircle the body. It was tied across the chest with thongs. When out-ofdoors it was worn over the windward shoulder. And these people dwelt in a latitude corresponding to that of the Aleutian islands and Labrador!

The eastern Yahgan at times wore capes of guanaco-skin which were bet ter suited to the cold. One of these (fig. 43) we illustrate; it does not attain the size of the Ona robe shown in fig. 6. The western Yahgan and the Alacaluf used skins of the coypu, a small land-otter known to the Yahgan as saiapai.

2. Pubic Covering.-A triangular pubic covering of skin (múshwalána) was usually worn by the women (fig. $44)$.

3. Moccasins.-The Yahgan often went barefoot, but at times they wore moccasins of seal-skin (kíli), which resemble the guanaco-skin footwear of the Ona, but are not made in quite the same way (fig. 45). To begin with, a piece of skin shaped like a truncated triangle is cut out and

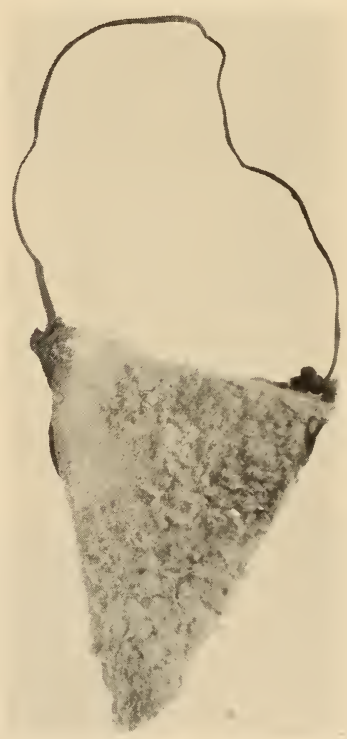

FIG. 44.-Yahgan pubic covering. Width, 9 in. $(14 / 2356)$ trimmed to the proper size. This lacks the attached heel-strap of the Ona moccasin (fig. 8, a). Holes are made across the large end (fig. 46,a), which is fitted snugly around the heel. A short strap is then looped through the upper pair of holes (fig. 46, b) and the heel sewn together. Holes are pierced on the long sides; these are doubled over and laced in the Ona fashion with a strap across the toes and across the instep. These moccasins are worn with the hair-side outward and are stuffed with grass. The writer found them when wet even more foul than the guanaco moccasins, and neither so warm nor so comfortable for walking. 


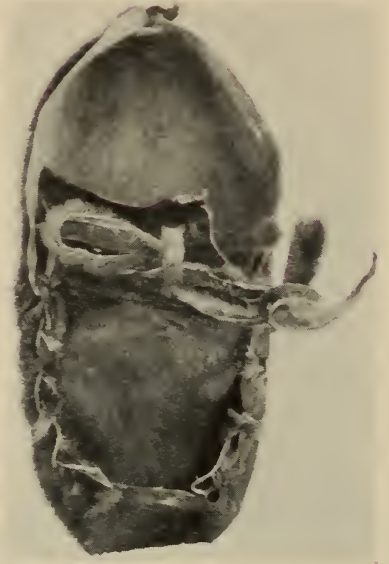

FIG. 45.- Yahgan moccasin. Length, 11 in. $(1+23 \pm 6)$

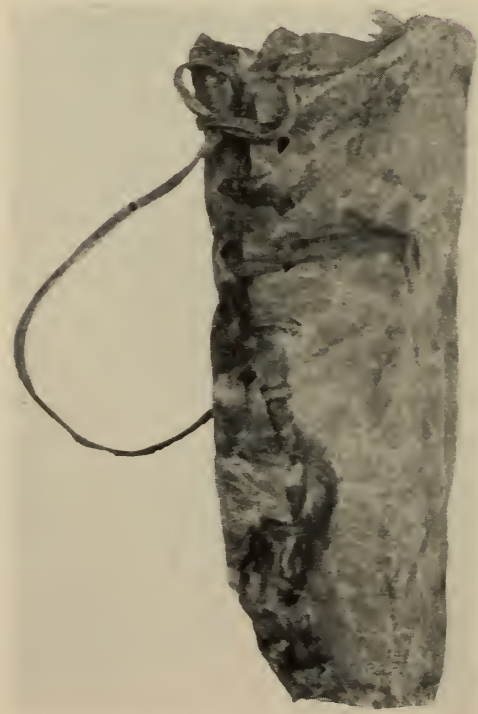

FIG. 47.-- Yahgan legging. Height, 13 in. (14/2266)
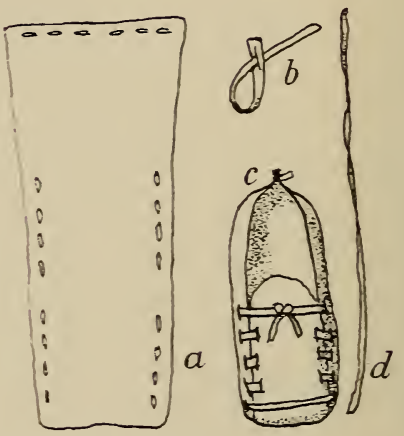

FIG. 46.-Pattern of Yahgan moccasin.

3. LegGirgs.-The eastern Iahgan, who were much more concerned with the guanaco than other members of their tribe, sometimes wore guanaco-skin leggings ( $p a ́ w a)$, such as fig. $4 \bar{i}$, for winter hunting. This garment was also sometimes used by the Ona, from whom the Yahgan probably borrowed it.

\section{ORNAMENTATION}

The Yahgan used no set form of hair-dressing, but allowed their locks to fall in a confused mass, except over the forehead where the hair was cut to form a bang. Facial and body hair they pulled out with a pair of mussel-shells. 
The chief form of decoration seems to have been facial and body painting, which was freely employed in the old days. The materials used are mentioned below. While paint was often applied with the finger, an elaboration over the Ona practice is seen in the use of a small spatula (telákikamána). One of these is illustrated in fig. 69, $d$. The Yahgan did not tattoo.

Feather diadems and goose-down forehead caps were worn at times, but their purpose was more ceremonial than utilitarian or decorative, and will be discussed below.

Wristlets and anklets were worn, but not so

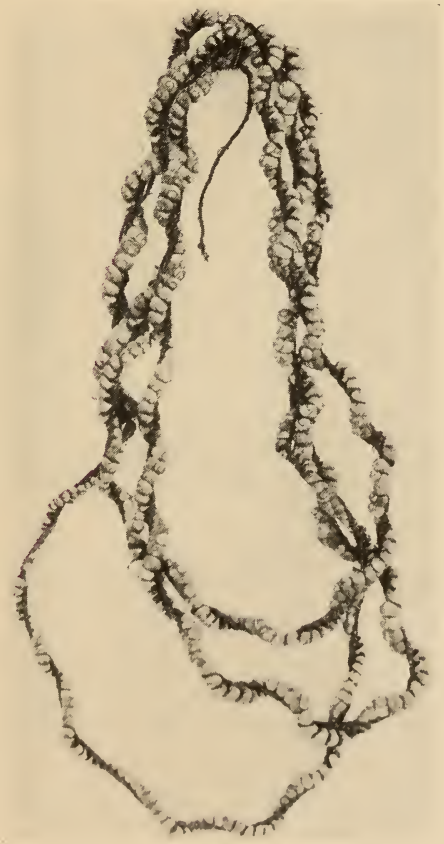

FIg. 49.-Yahgan shell necklace. Total circumference, $96 \mathrm{in.}(14 / 2341)$

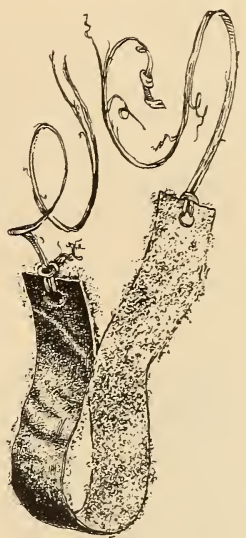

FIG. 48.-Yahgan guanaco-hide wristlet. $(14 / 2358)$ mon type (maíamasár) is not braided of grass or sinew in Ona fashion, but consists of a narrow band of guanacohide painted white (fig. 48). This was attached in place with small sinew laces.

Of necklaces the Yahgan made two kinds. The simpler type is constructed with cylindrical sections cut from the leg-bones of gulls or of ducks and strung on braided sinew. A more elaborate and attractive necklace (opiirrshka) they made from small shells (Latin, Photinula violacea; Yahgan, haúsh undálu) found in the kelp (hanish) which fringes the coast (fig. 49). When polished by use, beautiful opalescent tints appear in these shells. The Yahgan strung them by punching 
a small hole near the lip of the shell. Through these holes a braided sinew cord was run, doubled back on itself, and lashed with spiral wrappings of sinew. This method of stringing is illustrated in fig. 50. The shells thus united are always graded according to size, sometimes with the biggest shell at one end and the smallest at the other, sometimes with the big shells in the middle and the small ones at either end.

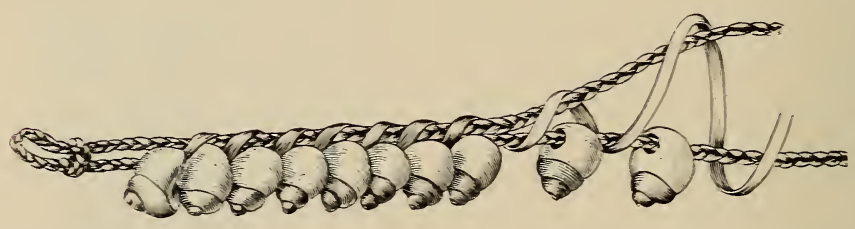

Fig. 50.-Detail of Yahgan shell necklace. Length of shells, one-half in. (14/2339)

\section{USE OF PAINT}

Like the Ona, the Yahgan made regular use of a red paint (imi) obtained by burning earth, a black paint (yaprishak) made of charcoal, and a white paint (tumerápo) of clay. According to Fitzroy (p. 177) and Dabbene (1907, p. 58) these colors have symbolic significance. Thus, white was the sign of war or ceremonial display, black was the mark of grief and mourning: while red denoted peace and happiness. With their paints the Indians adorned their persons, their dance masks, their ceremonial lodges, and some of their tools and utensils. The latter were often embellished with solid color, but body, dance masks, and ceremonial lodges were made the field for painted designs.

In pl. Ix is shown a selection of patterns taken from the frame of a ceremonial lodge. No simpler motives of artistic significance can be achieved, for these designs are mere smudges of color applied with thumb or finger. The elements are a dot, a short line, and, in one instance, a circle. Two lines are combined to form a cross, a $T$, and a chevron. Design units repeat themselves in simple rhythm.

Dance masks are illustrated in figs. 92 and 93. Their designs, though of symbolic significance, are again abysmally primitive. Facial painting may be studied in the photographs published by Koppers (192t); they are similar to the patterns here described. 

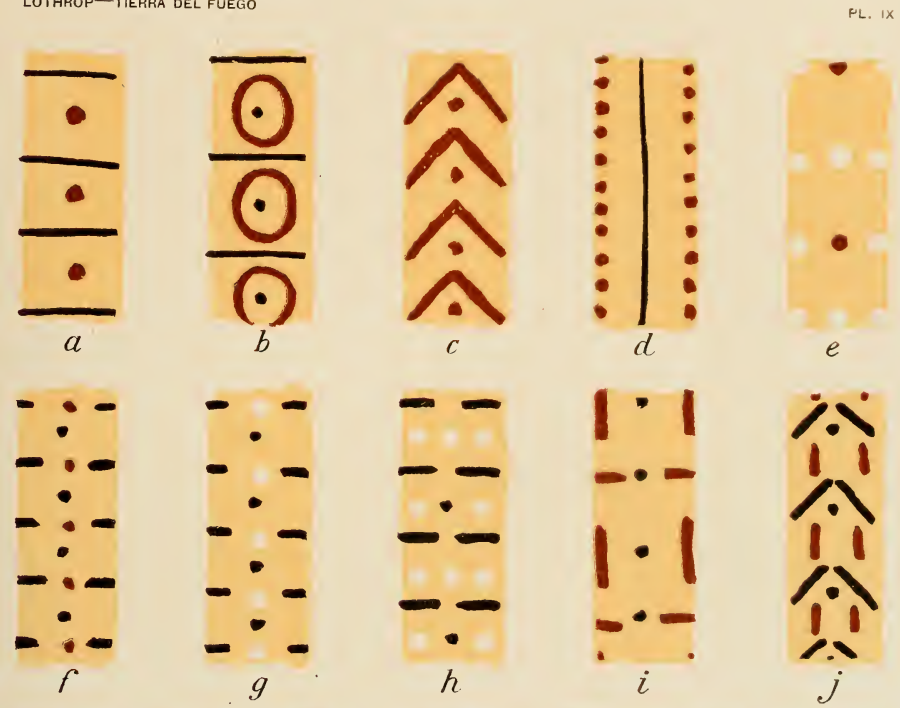

○

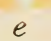

産害主
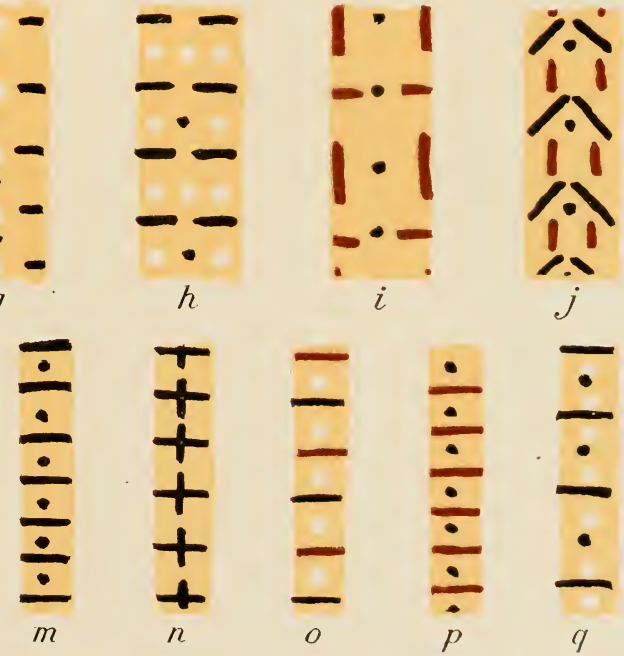

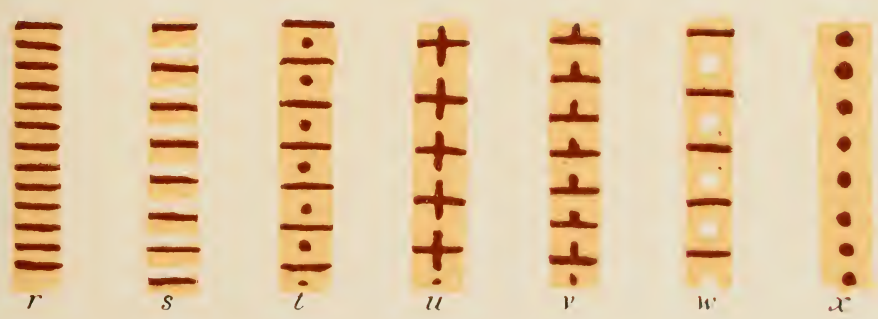




\section{The Encampment}

Yahgan clothes were less suited to the climate than those of the Ona, because they were smaller and gave less bodily protection, and because the skins they used were less suitable for their purpose. Thus, guanaco-skin, regularly employed for Ona robes, is thin and flexible, so that it will readily conform with the contours of the body, while the hair is heavy, so that it will shed water and preserve warmth. In contrast, seal-skin and sea-otter skin of Yahgan capes has a heavy and stiff hide and short hair, and therefore

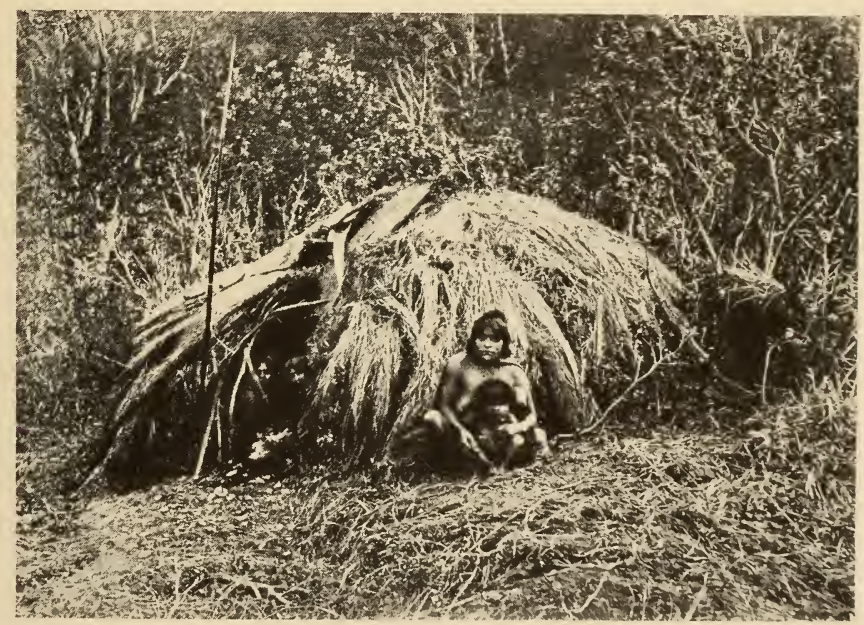

Fig. 51.-Yahgan house. (After Hyades and Deniker.)

gives less protection. As a result of this disparity, to maintain life the Yahgan had to have more shelter than that afforded by an Ona windbreak. And possessing the means of water transportation they could handle heavier equipment than their inland neighbors, though, to be sure, their bark canoes were small and frail to bear much cargo in addition to the human freight.

Normally the Yahgan lived in a wigwam known as cikharh. In the west, like the Alacaluf hut, this was usually a domed affair about the size and shape of a large haycock, framed with saplings set upright in a circle or oval and then bent inward until they met 
(fig. 51). Farther east the wigwam more frequently was pointed, for it was constructed of poles too thick to be bent. The introduction of the ax has increased the use of the pointed house form. Both kinds of houses were covered in summer with leaves, bark, kelp, grass, or whatever was handy. But during the winter months it was necessary further to break the force of the wind, and so the wigwam was overspread with a roof of seal-skins sewn together (kaikis). This was a heavy and cumbersome object to handle, and hence was usually divided into two or even three sections,

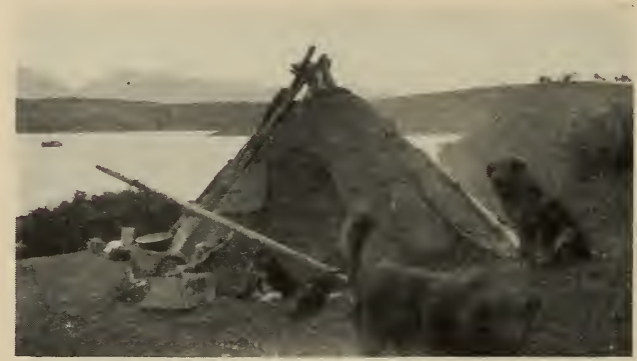

FIG. 52.-Modern Yahgan house. each of which could be transported in a separate canoe. Thus each house sheltered two or sometimes three families, usually closely related. In such a dwelling one family lived on each side, separated by a door facing the beach, a central fire, and sometimes a second door at the rear. The entrances could be closed with a flap of seal-skin.

In recent years the Yahgan have used in summer a log tipi covered with burlap. The small burlap-covered shelter shown in fig. 52 was occupied by eleven individuals in the summer of 1923-24. Thus housed they have had immeasurably poorer protection from the weather than in the days when hunger drove them to secure many seals and consequently many seal-skins were available for housetops.

The Yahgan kept their houses warm by building the tops low, for they appreciated the fact that heat rises. To take further advantage of this propensity they scooped out the floor to a depth of two or three feet or more. Thus the fire could be placed at the bottom of the pit while the inmates occupied a higher level, where bunks were outlined with logs held in position by stakes driven in the sloping floor. In old camp-grounds where the accumulated shell and ash gave excellent drainage, the pitted house floors reach 
as much as five feet below the surface. Here the housetop need scarcely have risen above the ground level, and the people within must have been snugly lodged against winter gales. But the swirling smoke was a constant annoyance, and many accounts speak of the Yahgans' red and inflamed eyes.

Initiation or ceremonial houses differed from the living houses chiefly in size. In the west they were domed and oval in outline, as shown in pl. XIv. In the east they took the form of a heavy solid tipi-shape dwelling of logs like the Ona initiation lodge (fig. 38).

Under mission influence the Yahgan in late years built small plank houses of European type. A group of these was found at Puerto Mejillones and Porto Piedra on Navarin island which were used as winter quarters (pl. XviıI). They were wind- and watertight, and some had wooden floors, bunks, and stoves. The material for their construction was begged, stolen, or picked up on the beach.

\section{Camp Equipment}

Yahgan camp equipment, in spite of superior transportation facilities, was just as primitive as that of the Foot Indians, among whom every article, and the infants as well, had to be carried on the back. Strong and simple as are the objects below listed, they

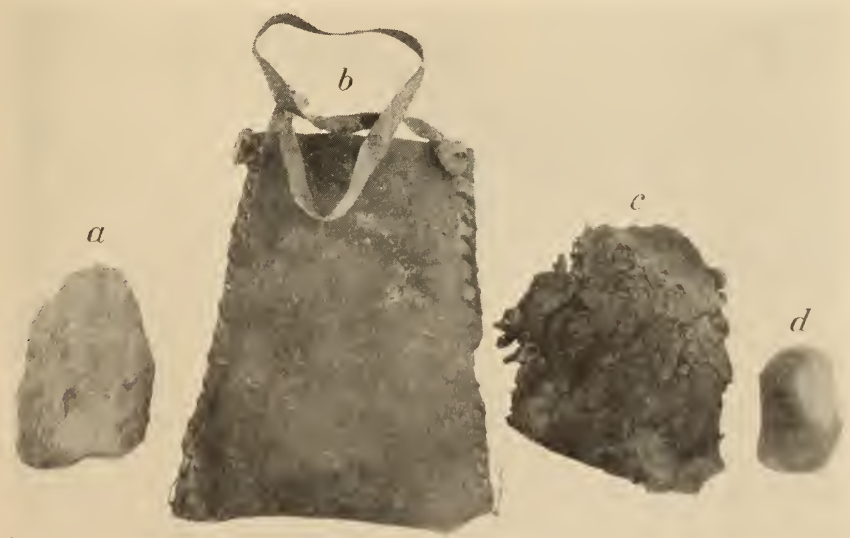

FIG. 53.-Yahgan fire-making apparatus. $a$, Flint; $b$, pouch; $c$, tincler; $d$, pyrites. Width of bag, $5 \mathrm{in.}(1+/ 2352)$ 
afforded a basis for little more than the mere act of existence and mutely testify to the cultural poverty of their makers.

1. Fire-MakiNg APPaRAtus.-By all accounts the Yahgan rarelymade fire. because they carried it with them on the hearths in their canoes. In their semi-nude society to lack fire might mean
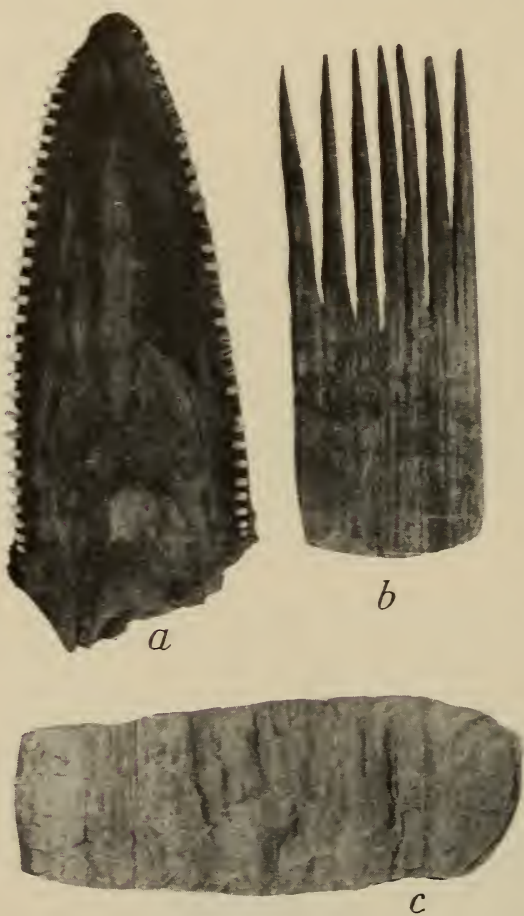

FIG. 5t-a, Porpoise-ja comb: length, 6 in. $(1+2370), b$, Whalebone comb; length, $5 \frac{1}{2}$ in. $(142374)$. c. Seal-throat pouch; length, $8 \frac{1}{2}$ in. $(1+2369)$ removing the objects from it the Yahgan used tongs. These are no more than a stick an inch or so in diameter and a couple of feet long. split for three-quarters of its length. Cultural borrowing is indicated by the name of this implement-láka in Yahgan, 
lákel in Ona,-but there is no means of determining which tribe was the inventor.

3. Hammer and Grease Stone.-On old camp-sites numerous smooth, water-worn stones can be picked up. They were used as hammers to break open various shellfish, and also they served as anvils for cracking hot marrow-bones to allow the grease to solidify on the cool surface, whence it could be scraped up and eaten.

4. Broom.-The Yahgan housewife today occasionally sweeps out her domicile, employing for that purpose the wing of some large bird such as a goose. This custom probably is not aboriginal, but is rather the result of missionary contact.

5. СomB.-The Yahgan sometimes comb their hair, and for this they make rude combs (ushtánim) of whalebone or employ the jaw of a porpoise. Combs of both types are illustrated in fig. $54, a, b$.

6. Spatula.-Another article for beautifying the person, found in the well-ordered Yahgan house, is a small spatula (telákikamána) used for painting the face and body. One of these appears in fig. $69, d$.

7. Bucket.-Under the Ona manner of existence a bark bucket (fig. 55 ) would have been of little serv-

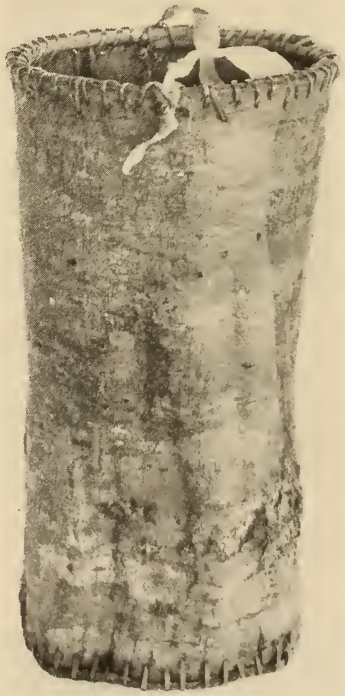

FIG. 55.-Yahgan bark bucket. Height, $12 \frac{1}{2}$ in. $(14 / 2267)$

ice, for it would soon be broken un-

der the exigencies of their system of transport; but the Yahgan found the bucket (atakála) an extremely valuable object, and used it to bail their canoes and to store water in their camps. Like the canoe itself the bucket was made from the bark of the evergreen beech, but while the canoe was man's work, the bucket was woman's work. Hence the bark for the bucket was removed from the tree with the woman's barking tool (téshupu), which is a chisel-like device made from the leg-bone of the guanaco (fig. 68 ). The inner fat lining of the bark was then scraped off, and a rec- 
tangular piece was cut for the sides and a circular piece for the bottom of the bucket. Narrow strips of whalebone were then scraped thin and pliable, and the bottom and sides were sewn tightly together (fig. 56, b). Around the inside of the lip a strip
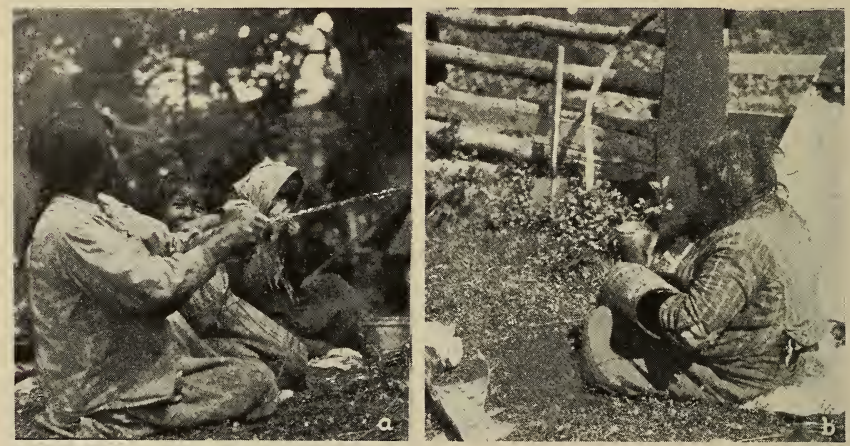

FIG. 56.-Yahgan women. $a$, Rope-making; $b$, Making a bark bucket.

of wood-le $\tilde{n} a$ dura, Winter's bark, or barberry-was introduced to give additional strength and to prevent the bark from splitting. Finally a hide thong was attached to serve as a handle, and the whole outside was painted red.

In general the Yahgan buckets are taller in proportion to their width than those of the Alacaluf. The Alacaluf seem to have

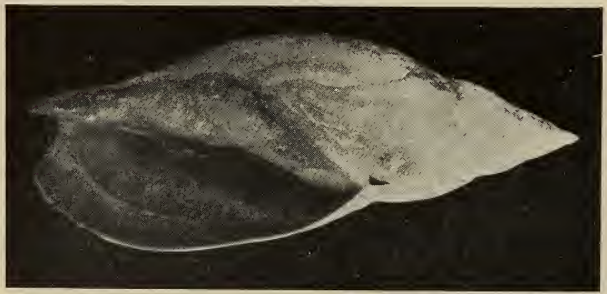

FIG. 57.-Yahgan shell cup. Length, 6 $\frac{1}{2}$ in. (14/2372) been better craftsmen than the Yahgan, hence their buckets are usually more neatly finished.

8. Cup.-A Yahgan refinementover the Ona is the use of a shell cup (auflán). As seen in fig. 57 , this is nothing more elaborate than a simple shell, its shape in no way modified. Such a receptacle could be used to dip water from a bark bucket, but would have been of little service in removing water from the Ona skin water-bag. 
9. Pouches And Bags.-For storage the Yahgan used various pouches, bags, and baskets. While there seems to have been a tendency to employ the most readily available material, at the same time certain definite types of bags were normally used for distinct purposes. For general storage, bags were made from the skins of the seal, penguin, and guanaco. For keeping the fire-making apparatus, a small guanaco-hide bag covered with red paint was used (fig. 53, b). A larger bag of guanaco-hide (humulúf) covered with white paint was employed by the shaman to store his ritualistic paraphernalia (fig. 94). For porpoise- or whale-oil, containers were made from water-proof substances, such as seal-gut (kália), seal-bladder (athhlaháni), or a species of giant kelp (shówen) which grows around the seaward islands. In fig. 58 we illustrate

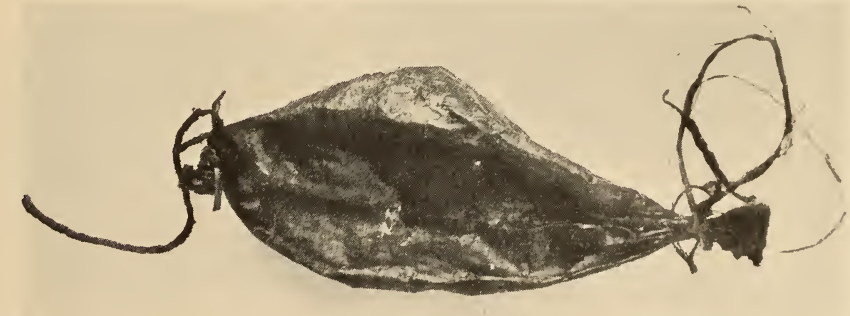

FIG. 58.-Yahgan seal-bladder oil container. Length, $7 \frac{1}{2}$ in. (14/2338)

an oil container of seal-gut. Red paint they habitually stored in small sacks (yái) made from the throats of seal (fig. 54, c). A recent invention is the otter-tail pouch (yeten) employed at the present time for carrying tobacco.

10. Baskets.-All the Canoe Indians of Tierra del Fuego and the west coast of Chile to the north make baskets. This art is probably the most intricate technological achievement of the Yahgan, Alacaluf, and Chono, so that we shall consider the making of baskets in some detail. Among the Yahgan, the writer found that four types were manufactured, of which only one has been adequately described. Two of these are based on half-hitches around a coiled foundation; one has half-hitches without foundation; while the fourth, employed as a dip-net, is a wrapped stitch.

The material used for all four kinds of baskets is a native grass 
(Juncus magellanicus) known to the Yahgan as mápi. This is a coarse, round-stemmed grass, about 18 inches in height, which resembles the grass of our saltwater marshes. It is picked by the

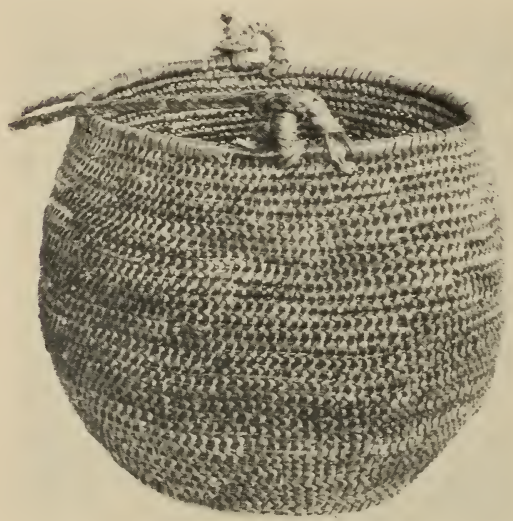

FIG. 59.- Yahgan basket of tawělla type. Height, 6 in. $(14 / 2317)$ women and carried to the encampment in long bundles. The handsomest baskets are those woven in the fall when the frost has changed the greens to red, but this brilliant color fades after a few weeks. During the course of manufacture, each grass-stem is chewed to flatten it and to make it more pliable.

In discussing the various kinds of Yahgan baskets below, the different weaves have been designated by their na-

tive names. These types are:

a. Tawělla.-This class of basketry, normally called "Fuegian basketry" in ethnological literature, is by far the commonest kind in use (fig. 59). It may be described as a half-hitch or buttonhole stitch over a coiled foundation.

The process of manufacture starts with selecting three or four stems of grass, placing them together, and bending them to form a

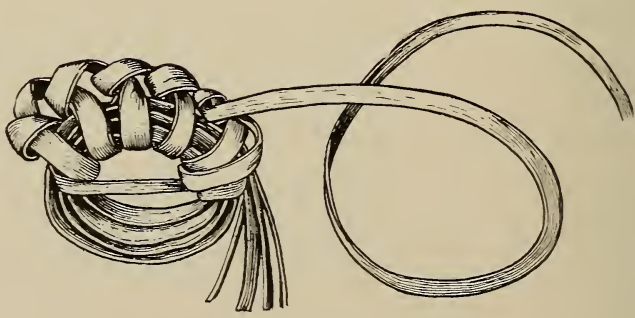

FIG. 60.-Method of beginning a tawéla basket. $(14 / 2319)$

little circle about half an inch in diameter which becomes the bottom of the basket. The loose stems forming this circle are 
then lashed in place by a series of half-hitches, which leave the part of the foundation stems not included in the circle projecting at a tangent from it. Fig. 60 illustrates this initial step in the manufacturing process.

Next the projecting grass-stems are bent to form a second circle around the original one. In this position they are lashed by a second series of half-hitches, which are inserted through the loops of the first row with the aid of an awl (fig. 69). This process may be studied in fig. 61. It is repeated, additional grass-stems being

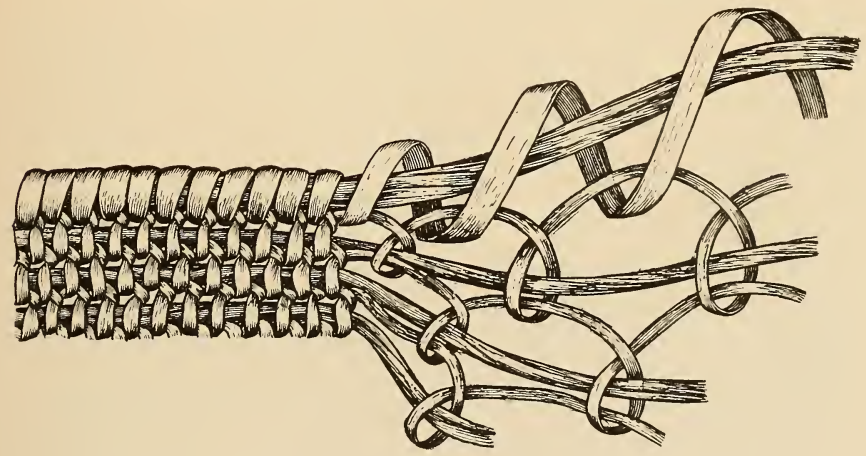

FIG. 61.-Detail of tawělla basket. Height, 1 in. (14/2288)

added as necessary, until a circular piece of woven material two or three inches in diameter is created.

At this stage it becomes necessary to curve the sides of the basket, so the finished fragment is suspended at a suitable height by passing a cord through the hole in the center of the base and tying it to a small toggle. In this position, mouth downward, both hands are free for the weaving, and the foundation coils can be controlled to give the desired shape.

When the body of the basket has been completed, the edge is finished by a simple spiral wrapping considerably broader than is used in the rest of the weaving.

Next, two loops are attached at opposite points of the rim, and also are covered with spiral wrappings. To these loops a handle of braided grass is fastened, and the basket is completed.

In comment on this kind of basket we should point out that 
coiled baskets are found along the entire west side of the New World in practically unbroken distribution, and also to the west across the Pacific. The Fuegian or half-hitch coil is also found across the Pacific, a fact that has given rise to much unrestrained speculation on the origin of the Fuegians. Variants of the halfhitched coil, somewhat similar to the uloánastába basket presently to be described, have been noted by the writer in Basket-maker collections from the Southwest and in collections from Kentucky cares, both of great antiquity.

Several authorities have argued that coiled basketry is not a very ancient type. With this the writer does not agree, because, in the New World at least, coiled basketry is the most widely distributed kind known, and also because it is almost the only type of basketry associated with the most ancient New World archeo-

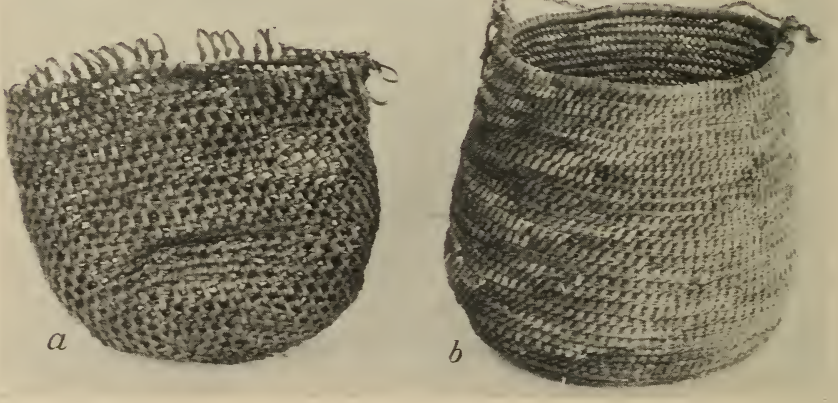

FIG. 62.-Yahgan baskets of gairchim and uloánastába types. Height of $b, 6 \frac{1}{2}$ in. $(14 / 2312,2288)$

logical finds now known. In other words, it seems to the writer that one would expect $a$ priori that the basketry of an isolated and backward people like the Yahgan would be of the coiled variety.

The hitch-coil is typical in South America only of the Yahgan, Ona, and Alacaluf, but it turns up sometimes in the Amazon valley and to the northward. A Surinam hat illustrated by Goeje ${ }^{1}$ is woven in a fashion exactly like the Yahgan tawéla.

b. Uloánastába.- This weave, illustrated in figs. $62, b$, and 63 , is very rarely employed among the Yahgan, and a single specimen

\footnotetext{
${ }^{1}$ Intern. Archiv für Ethnogr., Bd. xvir, Suppl., 1936, pl. rx, fig. 13.
} 
was secured only with difficulty. Like the tawéla weave it is a series of half-hitches built up over a coiled foundation, and the steps taken in the manufacture of the two types are the same. Also the rims and the handles in both types are identical.

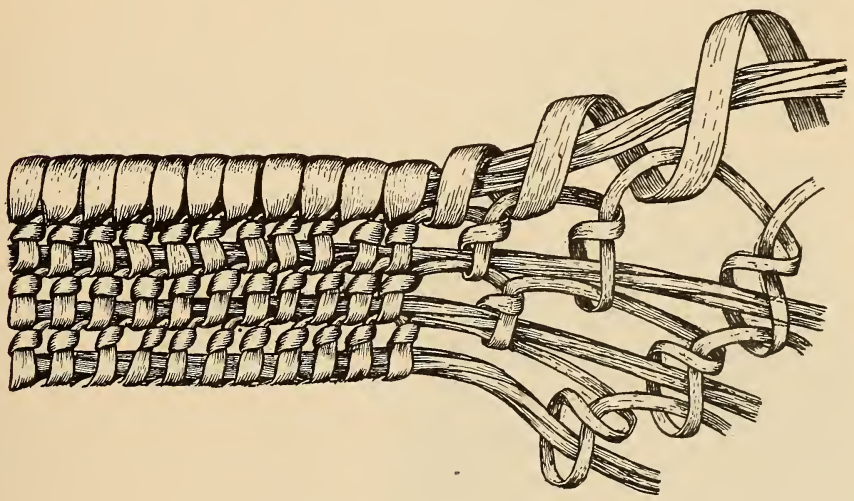

FIG. 63.-Detail of uloánastába basket. Height, 1 in. (14/2317)

The difference between the tawéla and the uloánastába lies in the fact that the former is a simple half-hitch while the latter is a twisted half-hitch, for at each knot the weft takes a half-turn around itself. This distinction may be seen by comparing figs. 61 and 63 .

More elaborate twisted-hitched-coiled baskets are found in Central America, notably among the Pipil and Lenca of Salvador, in collections from Pacific islands near the meeting point of Polynesia, Melanesia, and Micronesia, also in Africa, and among Bush negroes in the Guianas, and doubtless elsewhere. This world-wide distribution of the type leads to the belief that it may be an ancient form of basketry. The only exact New World parallel to the uloánastába which has come to the attention of the writer is an Alaskan specimen illustrated by Mason, ${ }^{1}$ a bark vessel to which a wooden lip has been sewn in a manner identical with the Yahgan stitch.

${ }_{1}^{1}$ Aboriginal American Basketry, Rep. U. S. Nat. Mus, for 1902, fig. 9(), Washington, 1904. 
c. Gaiichim.-A third class of Yahgan basketry, not very common at least in recent years, may be described as a knotted weare without any foundation (fig. 65). The body of the basket is built

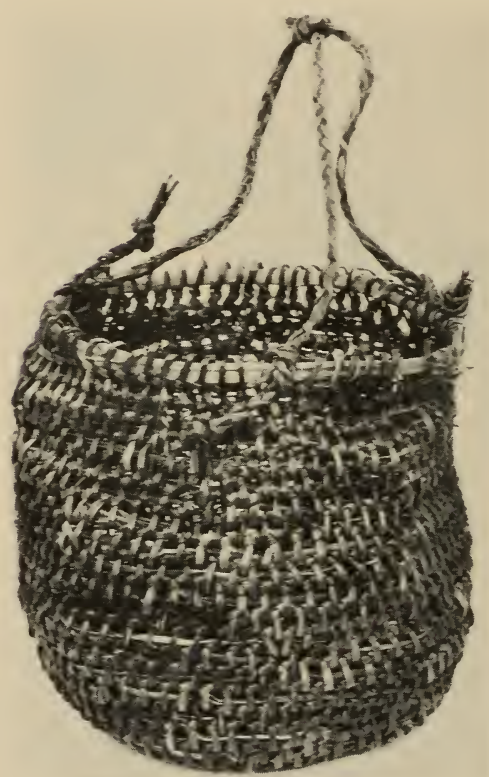

FIG. 64.-Tahgan basket of gaiichim type. Height, $4 \frac{1}{2}$ in. $(1+2313)$ up in a series of interlocking knotted loops, resulting in a soft and flexible container (fig. 62, a). In order to stiffen the basket and to secure a wide-open mouth, the rim is finished off in a series of loops and in these a circle of wood - Winter's bark or barberry - is inserted, as shown in fig. 64 . To this rim is attached a threemember braided handle.

When completed the gaichim often shows irregularities, so the interior is packed tightly with sand or small pebbles which are kept moist until the basket has assumed a symmetrical shape. The result of this stretching process is seen by comparing figs. 62 , $a$. and 64 .

d. Chiwanish.-A fourth type of Yahgan basket, illustrated in fig. 89, was lashed to a pole and used as a dip-net for catching small fish. The completed net with the handle may be seen in the bow of the model canoe in fig. 73 .

The chiwanish consists of a circular opening of Winter's bark or barberry wood, to which four $L$-shape members of the same material were secured. The interstices were then filled in with strips of grass of the kind above indicated, looped about the solid frame. 


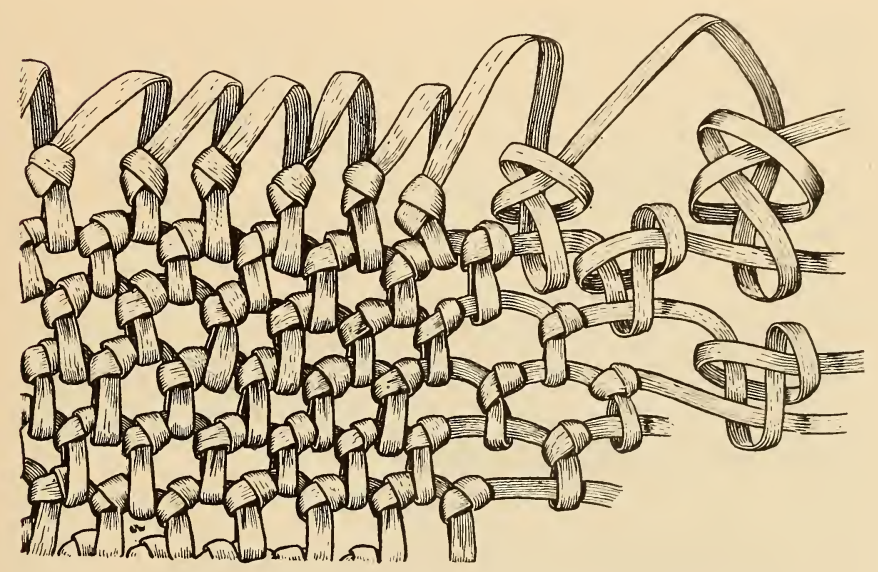

FIG. 65.-Detail of gaiichim basket. Height, 2 in. (14/2312)

\section{Tools}

Yahgan tools are just as primitive as the Ona tools, although adapted to different uses. The Yahgan have a constant tendency when making something to pick up the first object that comes to hand - a bit of shell, a fire-flaked stone - and employ it, rather than to take the trouble to get steel tools which would better serve their purpose.

1. Scraper.-The old-time Yahgan scraper $\left(t u^{g} w e^{\prime} n a\right)$ was a mussel-shell blade (káluf) set on a stone handle (áwi). The shell blade was not the ordinary mussel-shell, but a giant variety (chiamúnka), four or five inches in length, which now grows on the beaches of the outer islands toward the Antarctic. Formerly, however, it must have flourished on Beagle channel, as many examples were found in the interior of a shellheap at Harberton. To set this shell blade on the stone handle, the edges of the base of the shell were carefully broken away in order to reduce the curve and make the blade lie flat against the stone. However, the blade could not be attached directly to the stone, or it would have broken too easily, hence it was bedded on a small bunch of shredded barberry wood (chélerr ${ }^{1}$ ) or a wad of moss (hánakóhl). These two

1 This word was obtained from a Lennox islander. I am not certain whether it means "shredded barberry" or whether it is a dialectic variant of the central 
variant forms are seen in pl. $\mathrm{x}, a, b$. For lashings on scrapers the Yahgan used either a seal-hide thong (tuwawáru, pl. $\mathrm{x}, a-c$ ) or else a braided whale-sinew line (tápim, pl. $\mathrm{x}, d$ ) such as was employed for fishing.

Since the European settlement the natives have substituted a steel blade (hárfkar) for the shell whenever possible, and the resultant tool is called wána. It is illustrated in fig. 66, a. They
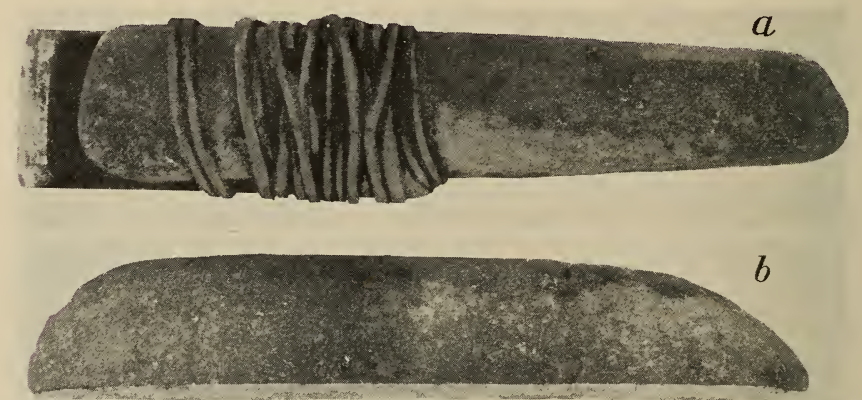

FIG. 66.-Yahgan scraper and whetstone. Length, 11 and $9 \frac{1}{2}$ in. $(14 / 2367,2325)$

now also set the steel blade in a split wooden handle in the same fashion as the Ona, as can be seen in pl. $\mathrm{x}, c$.

The scraper was the most important tool to the Yahgan and served a great variety of purposes. Owing to the weight of the stone handle it could be used not only for scraping but also as a serviceable hand-ax. When the shell blade became chipped or dull it was sharpened on a stone (chipi) with a long flat surface (fig. 66, b). In type this scraper corresponds to the Ona wood scraper (fig. 25, a).

In the old days before steel was available, the Yahgan are said to have used a tool like the transverse Ona flesh-scraper (fig. 25, b). This was denied by Yahgans whom I questioned, but was affirmed by Mr. William Bridges, whose statement was supported by the discovery of ancient stone blades apparently designed for transverse hafting (fig. 104, $b, c$ ). The abandonment of the transverse scraper may be due partly to the use of steel, but also may be accounted

Yahgan chélia, which means "barberry" in general (Berberis ilicifolia). Shredded barberry was also employed as a towel after bathing. 

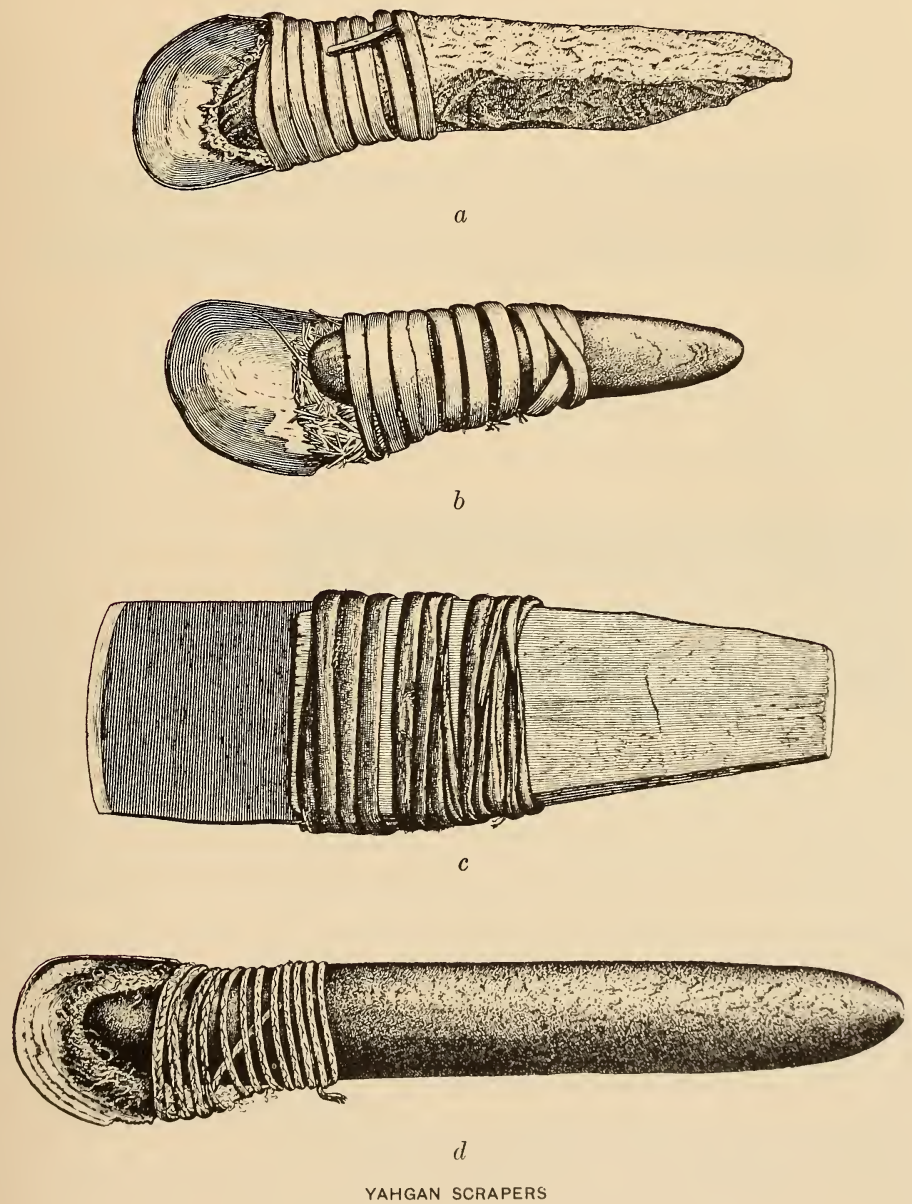

$a, b, d$, PRIMITIVE TYPE; LENGTH, 14, 10/2, 9 IN. $(14 / 2364,2366,2365)$. c, MODERN TYPE; LENGTH, 6 IN. $(14 / 2368)$ 

for on the ground that since the Yahgan have ceased to use skin houses and skin clothing they have much less need of such an implement.

2. KNIFE.-Ancient knife-blades from Beagle channel are described on page 190. In recent years the Yahgan, like the Ona, have made knives from any available scrap iron or steel.

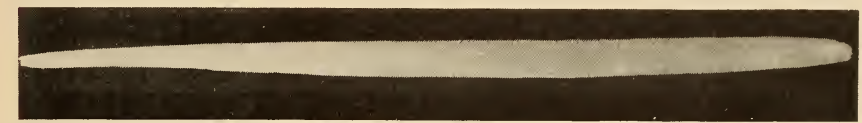

Fig. 67.-Yahgan man's bark-working tool. Length, 31 in. (14/2332)

3. Barking Tools.-The Yahgan employ two kinds of tools for removing bark from trees. One of these (sánakaí), used exclusively by the men (fig. 67), is made from a large piece of the jaw-bone of a whale and has a blade usually at each end. The woman's tool (téshupu) is part of a guanaco leg-bone and consequently is much smaller

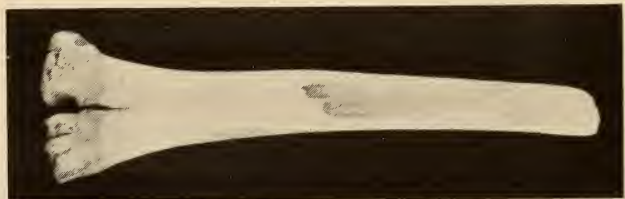

FIG. 68.--Yahgan woman's bark-working tool. Length, 9 in. $(14 / 2331)$ (fig. 68); it has a single chisel-like blade, while the other end, the articular extremity of the bone, forms a convenient handle.

4. AwL.-The old-time awl (ámi) was a sharpened bit of wood or of bone (fig. $69, c, e$ ), but in recent years the Yahgan have used a nail set in a wooden handle (fig. 69, $a, b$ ). Awls were employed for piercing skins to make clothes, housetops, and bags; to pierce bark in the manufacture of canoes, bailers, and buckets; and also for the weaving of baskets.

Like the Ona, the Yahgan had no drill, and so their material culture was limited by the fact that they were unable to make holes in such a relatively soft substance as wood.

5. Hammerstones.-Usually present on Yahgan camp-sites are a number of stones which show marks of abrasion (fig. 70). The 


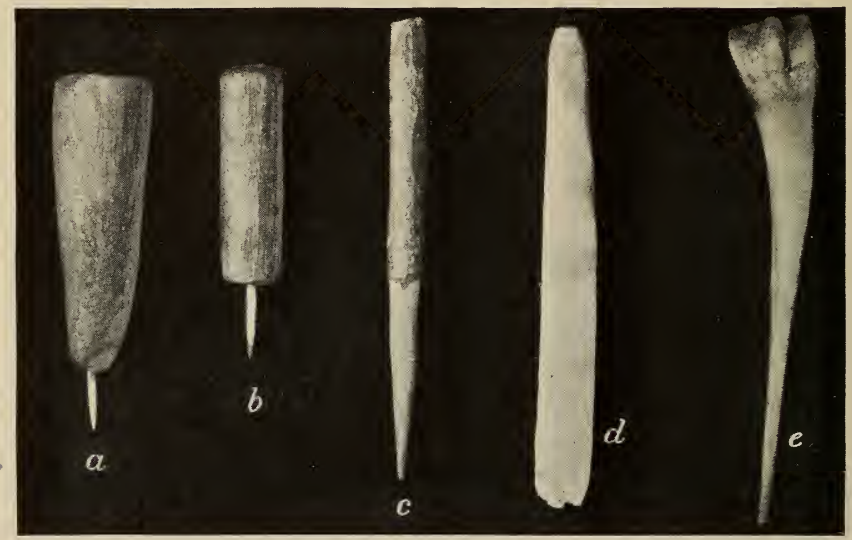

FIG. 69.-Yahgan awls and spatula. Length, $3 \frac{1}{4}$ to $5 \frac{1}{2}$ in. $(14 / 2376,2376,2378,2333,2334)$

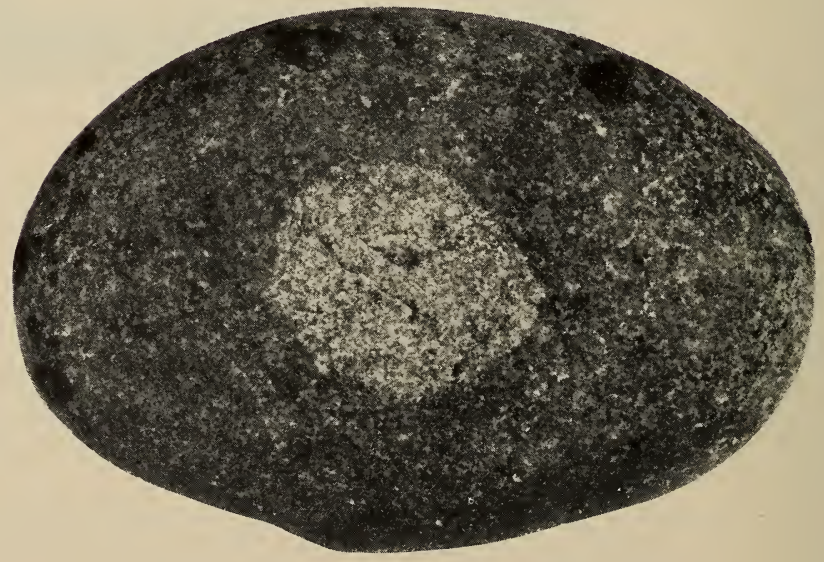

FIG. 70.-Yahgan hammerstone. Length, 5 in. (14/3984) 
principal purpose for which such stones were used was opening shellfish. These stones never were hafted.

6. Sharpening Stones.-For sharpening knife and scraper blades the Yahgan employed a smooth stone (chipi) such as is shown in fig. $66, b$. They can frequently be picked up on old camp-sites. The rounded hammerstones may also have been employed for sharpening.

7. Pumice.-For polishing, in place of our sandpaper or the Ona fox-skin and grit, the Yahgan used pumice (hiól). This material (fig. 71) is found on Picton island and on the coast of Tierra del Fuego to the north. It frequently floats down Beagle channel and may be picked up

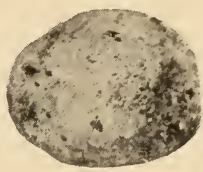

FIG. 71.-Yahgan pumice polisher. Length, $2 \frac{1}{2}$ in. $(14 / 2224)$ on the beach.

\section{BoAts AND BoAting \\ BARK CANOE}

In the old days the Yahgan used a curved bark canoe which in outline is well described by Goicueta's phrase, "like a moon of four days, with raised tips." The last one ever afloat is shown in fig. 72 .

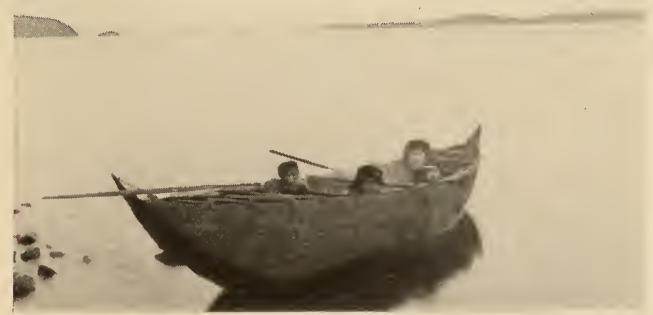

FIG. 72.- The last Yahgan bark canoe ever used.

(Courtesy of Rev. John Williams.)

The bark employed (aíirshun) was taken from the evergreen beech (Nothofagus betuloides), known to the Yahgan as sischi. It had to be stripped from the tree in the spring (Octoler or November) when the sap was rising. For this purpose a tool made from the jaw-bone of a whale (sánakaí) was employed (fig. 67), and the 
men ascended the tree by means of a thong of seal-skin (wursh). An industrious and forehanded man often removed two pieces of bark at the right season of the year in case his canoe might be wrecked. The extra piece was placed under water in a running stream to keep it flexible and was held there by means of stones. The piece intended for immediate use was scraped with a shell scraper (tu"ué"na) until the fat inner bark (ushkaq) had been remored. The bark was then cut to pattern, three cigar-shape pieces usually serving for the skin of the canoe.

The bark was next tightly sewn together with pieces of whalebone, or, if none were obtainable, with saplings warmed before the fire and shredded when very hot. Split saplings were then set close together for ribs (ushkulakin), and the ends of these were held in place by tapering gunwales (curri) lashed to the bark sides (fig. 73 ).

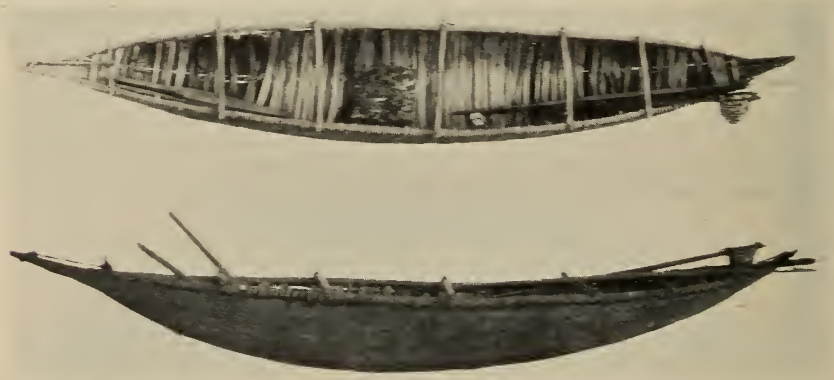

FIG. 73.-Model of Yahgan canoe. Length, $40 \frac{\mathrm{T}}{\mathrm{i}}$ in. $(1 \pm 4331)$

Across from gunwale to gunwale, thwarts, usually six in number. were lashed in order to keep the sides from collapsing. Finally the slender bow and stern were joined to the nearest thwart by a seal-hide thong or a braided grass rope in order to give additional strength to the extremity of the ressel.

To complete the canoe a fireplace (af) was installed amidships, for even in these days of matches and European clothes no Yahgan goes to sea without his fire. The fireplace consisted of a heavy piece of sod with much earth attached. Over this was a layer of pebbles, and the whole was soon covered with ash. In the bow a rest for harpoons was installed. 
When fully equipped, the Yahgan canoe carried the following articles:

two or more paddles

three kinds of baskets

two fire-tongs

four spears (fish, seal, crab, and limpet)

\author{
dip-net \\ club \\ grass mooring rope or thong \\ bark bucket \\ fish-line.
}

Such was the bark canoe in which these Indians often ventured far from shore and even attacked whales. Its great virtue was that it could be made with few tools; indeed in an emergency it could be created with no more than fire and a knife. Furthermore, its high pointed ends made it seaworthy. On the other hand, the seams often leaked and the beech-bark is brittle-much more so than the birch-bark of the North American canoes. The canoes of bark found nearest to Tierra del Fuego are those of Brazil. Their construction is so different, however, that there seems no possibility of relationship between the two types.

\section{DUGOUT CANOE}

The first dugout canoe used by the Yahgan was made near Ushuaia about 1880 by an Indian known as "John Furness." This innovation apparently was an independent invention, instigated through the introduction of metal tools during the previous decade. At any rate the idea rapidly became popular, for the advantage of the stronger construction over the bark canoe

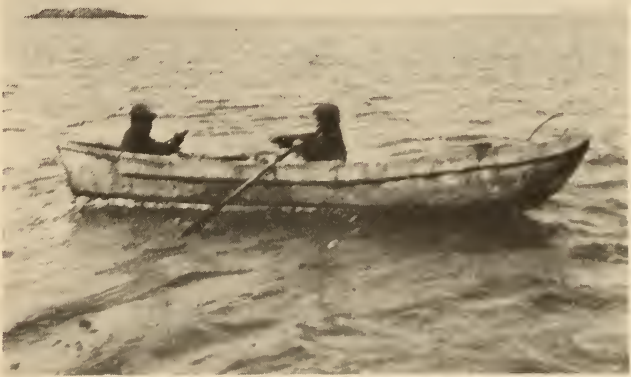

F1G. 73A.-Yahgan dugout canoe. (Courtesy of J. L. Weld, Esq.) was patent, and indeed the Alacaluf soon seized upon this type and abandoned their plank canoes. 
In outline the dugout canoes resembled their bark prototypes, modified by the material of which they were wrought. Thus, through ineptitude or a fault in the wood, one end sometimes was not pointed but was cut off square. Into the opening a tail-board

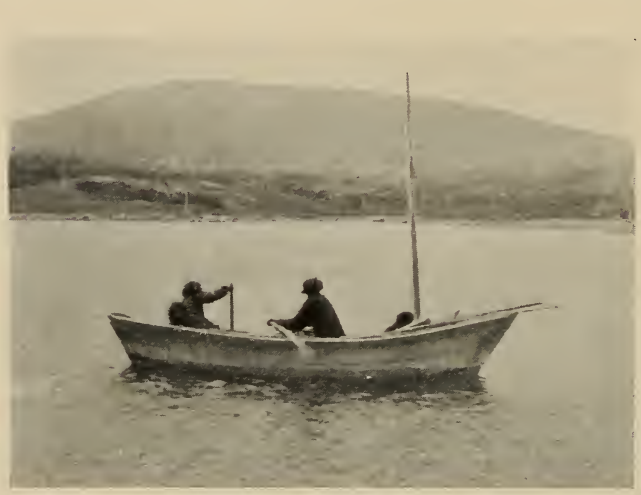

FIG. 74.-Modern Yahgan boat. (Courtesy of J. L. Weld, Esq.) was then fitted. This usually leaked. The sides of the canoe often were raised by nailing on boards.

With the coming of Europeans the Yahgan adopted the use of oars and sails. The latter were raised on temporary masts and could be employed only

when running before the wind.

The Yahgan bark canoe has gone entirely out of use today, and the writer was unable to discover an Indian competent to make one properly, although models can yet be obtained. The dugout canoe is still in use, but it is many years since a new one has been launched. The last double-ended dugout afloat (fig. 73A) was purchased and is now in the Museum. It is 16 feet 6 inches long, 3 feet wide, and 2 feet 7 inches deep. When purchased it had been in the water many years and was unbelievably heavy. Also it was the most unstable vessel in which the writer has ever set foot.

\section{DORY}

Today the few surviving Yahgan use a flat-bottom dory with square stern and high-pointed bow (fig. 74). This boat is of European manufacture and carries no mark of native identity except a fireplace. Today the fireplace is no picturesque affair of sod, but usually is an upright five-gallon gasoline tin, half-filled with stones, and with a hole cut in the side to facilitate the draft. 


\section{PADDLES}

The old-fashioned paddle (ápi) had a long pointed blade and a short rounded handle (fig. 75). The blade was diamond-shape in

section, so there was a tent-like ridge centrally down each side. Today most of the blades have rounded tips, a shape which the Yahgan may well have adopted from the Alacaluf.

The women, who were the paddlers, often joined their men folk in fighting, using their paddles with deadly effect.

\section{MOORING ROPES}

Canoes were moored either with a seal-skin thong (wurrsh) as shown in fig. 76 , or more commonly with a braided grass rope (shukami) such as is seen in fig. 77. The process of braiding the rope is illustrated in fig. 56.

\section{CANOE BAILER}

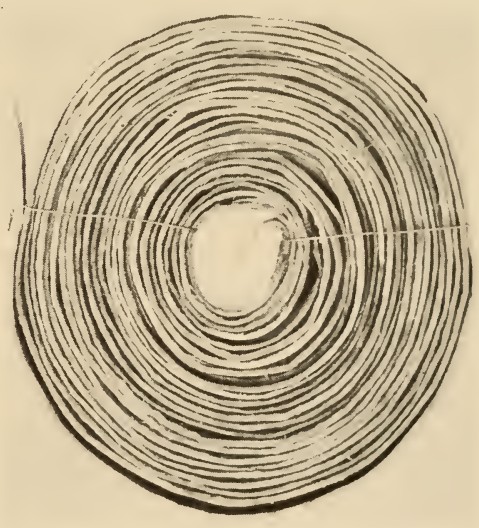

FIG. 76.-Yahgan seal-hide thong. Diameter of coil, 8 in. $(14 / 23+7)$

As all the Yahgan ca-

noes leaked more or less, some kind of a bailer was imperative to keep them afloat. For this purpose a bark bucket like the waterbucket, but not so tall, normally was used (fig. 78). The writer has seen small seal-skin buckets said to have been used for this purpose.

\section{CARE AND MANAGEMENT OF TIHE CANOE}

The canoe was paddled by the women, who sat in the stern, while the men crouched in the bow to cast the spears. When paddling, owing to the short handle, one hand was under water. 


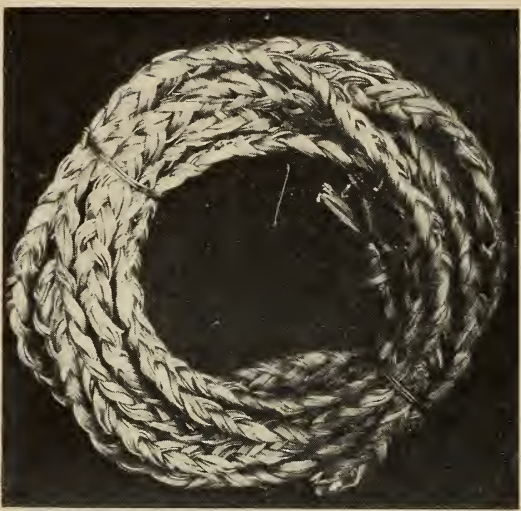

Fig. 77.-Yahgan grass rope. Diameter of coil, $5 \frac{1}{2}$ in. $(14 / 2349)$
As a result of the exercise, the women were very strongly developed above the waist, but poorly developed in the legs.

When it was desired to make a landing the canoe was paddled in to the beach, bow-on, and the man of the family and the children stepped ashore. The wife then paddled the canoe out to a piece of kelp, moored it, and swam ashore. As a result all

the women were able to swim, while few of the men could do so.

The canoe was kept in the water habitually, because hauling it up on the beach was difficult owing to the fragility of the bark. When it was necessary to make repairs, the beach was carpeted with wet kelp to make a soft and slippery surface over which the canoe could be dragged with ease. The dugout canoes, however, were a different proposition, so for them runways were made by removing the stones (pl. XI). Stakes were driven at the head of the runways to which the canoes were tied. Campsites used habitually since the invention of the dugout may be distinguished by the presence of such runways.

\section{Weapons And Methods of Hunting SPEARS}

Yahgan weapons were the spear, club, sling, and bow. In their fashion of living, spears were almost as import-

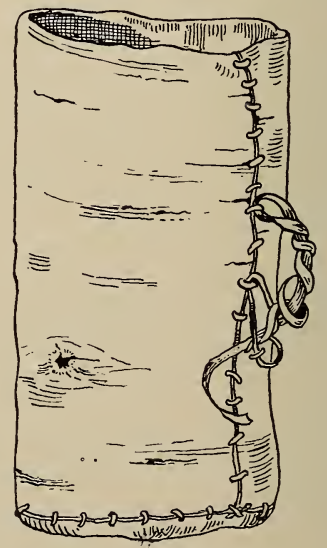

Fig. 78.-Yahgan bark bailer. (After Hyades and Deniker.) 


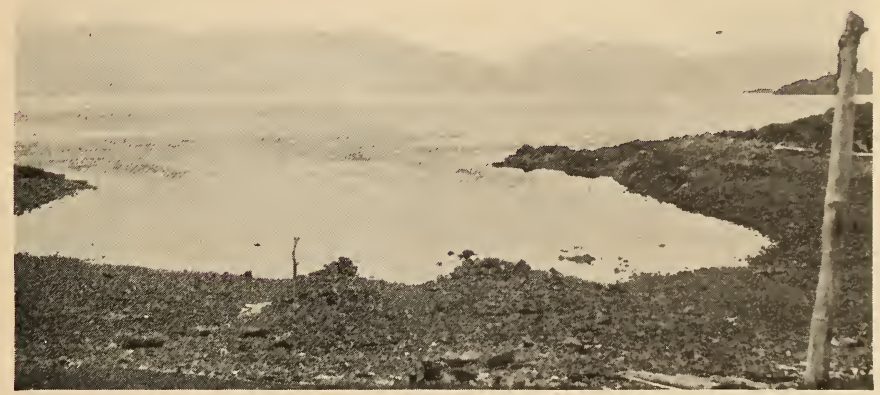

PORTO PIEDRA

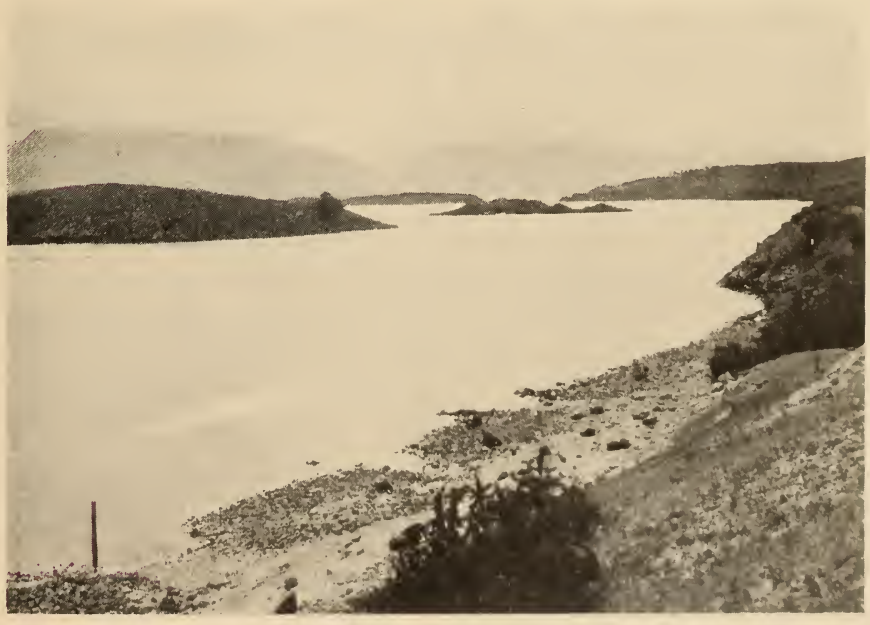

PUERTO MEJILLONES

CANOE RUNWAYS, NAVARIN ISLAND 



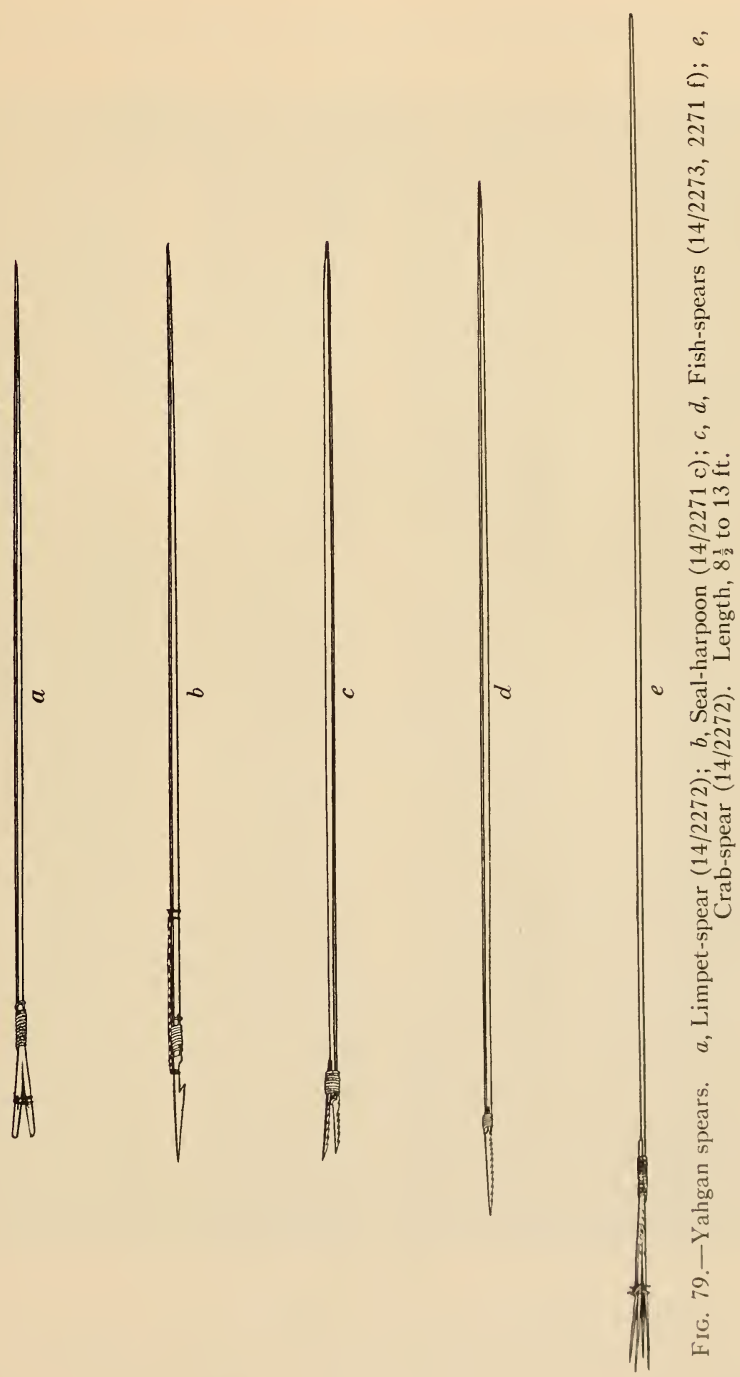


ant as the bow among the Ona. The use of this weapon was taught from childhood; practice in casting a headless spear, usually with an old basket as a target, was a frequently enacted sport. The basket was slung far ahead from the end of a spear; then all the young men present would cast at the target. walk up to recover their shafts, and toss the basket ahead again.

In fig. 79, drawn to scale, are shown

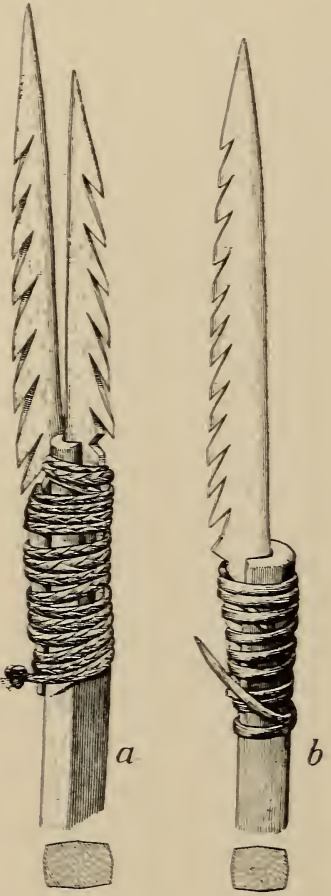

Fig. 80.-Yahgan fishspears. Length of point of $b, 10 \frac{3}{4}$ in. $(1+2273,2271)$ five types of Yahgan spears, each designed for a special purpose, differing in point, shaft, and lashing. These details and certain regional variations we shall discuss at length.

1. BIRD- AND FisH-SPEAR. - This spear (shushróya) is an all-purpose spear, but it was specifically intended for capturing fish and birds. It was commonly used in warfare. It may be briefly described as a beechwood shaft tipped with a serrated whale-bone head lashed in place with seal-hide or braided sinew (fig. 79, c, d).

The shaft of this spear (called shoshaia) is eight-sided, as can be seen in fig. 80 , having four wide and four narrow surfaces. In casting, the flat of the shaft was placed on the palm of the hand. The head of the shaft is about three-quarters of an inch in diameter; the central diameter is nearly twice as much; at the butt it tapers to a point. Red or sometimes black paint covers the completed shaft. On one side of the head-end of the shaft a slot is cut, into which the tang of the spearhead is inserted and there lashed with a sealhide thong. This is shown in fig. $80, b$.

The head of the fish-spear is cut from the lower jaw-bone of a whale. In the old days whales were plentiful in Beagle channel and the waters to the south, but since the establishment of whaling 


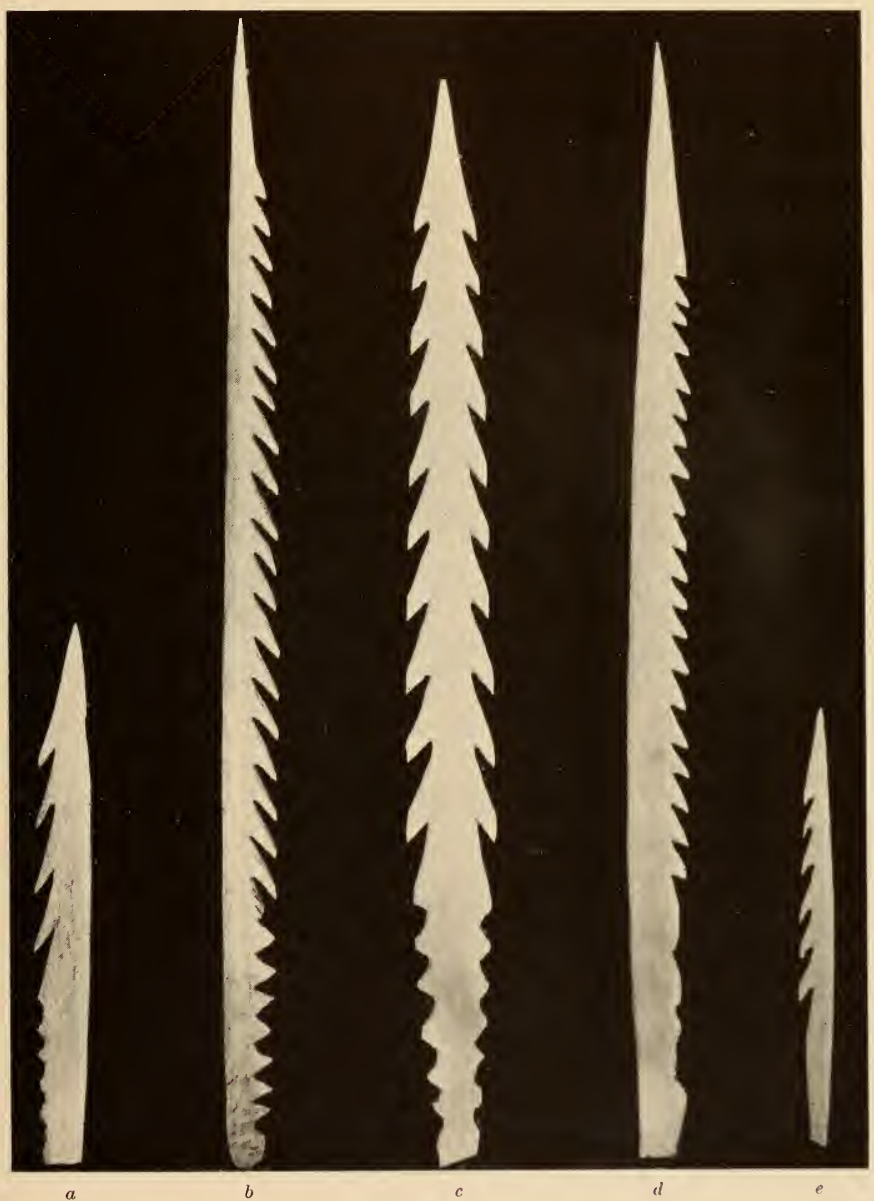

FISH-SPEAR HEADS

$d(14 / 2253)$, ALACALUF; OTHERS $(1+/ 2329,10 / 9833,14 / 2330,2329)$, YAH(3AN.

LENGTH, 6 TO $16 \mathrm{IN}$. 

stations on South Georgia, ${ }^{1}$ some years ago, they have become exceedingly rare. During the writer's visit to Beagle channel the supply of whalebone became completely exhausted, and it was said that four years had elapsed since a whale had come ashore.

Details of the spearhead hafting appear in fig. 80. The usual assemblage is that shown in $b$ where a single point has been set in a deep notch and secured there by heavy spiral lashings. Sometimes, when the presence of certain kinds of fish made it desirable, a second point was set against the side of the shaft opposite the notch and there secured by lashings of the usual kind.

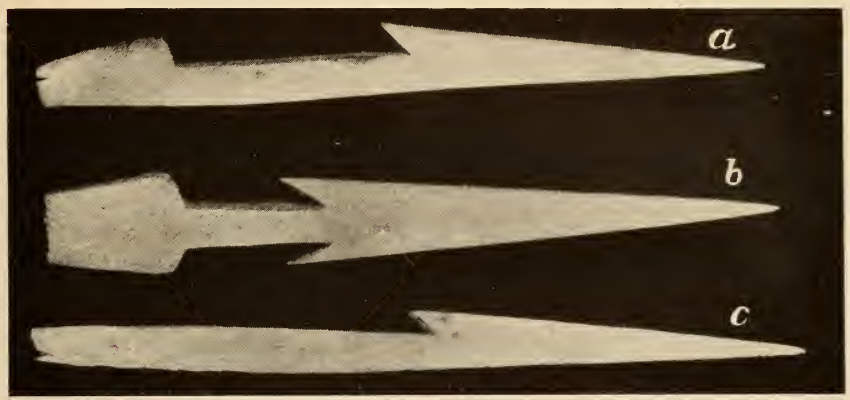

FIG. 81.-Yahgan spearheads. $a, b$, Seal spearheads $(14 / 2327,2328) ; c$, Guanaco spearpoint (14/2321). Length, $11 \frac{1}{2}$ to $12 \mathrm{in.}$

In size fish-spear heads range from six to eighteen inches, with anywhere up to twenty barbs. Eastern and central Yahgan points (pl. XII, $a-c$ ) have barbs along one side only. In the west this type, and also points with barbs along both sides, were used (pl. $\mathrm{XII}, c$ ). Among the Alacaluf, I was informed, both single and double rows of barbs were employed. Pl. XII, $d$, shows a point made by an Alacaluf living with a Yahgan wife on Navarin island; it differs from Yahgan workmanship in the superior finish.

The tools employed in manufacturing the spearpoint were: (1) a stone hammer to secure a bone fragment of proper size, (2) a shell scraper or knife to shape the blade, and (3) a piece of pumice to polish it.

Yahgan fish-spear heads are strikingly like bone spearpoints

${ }^{1}$ A recent account of this industry will be found in Morley and Hodgson's Whaling North and South, New York, 1926. 


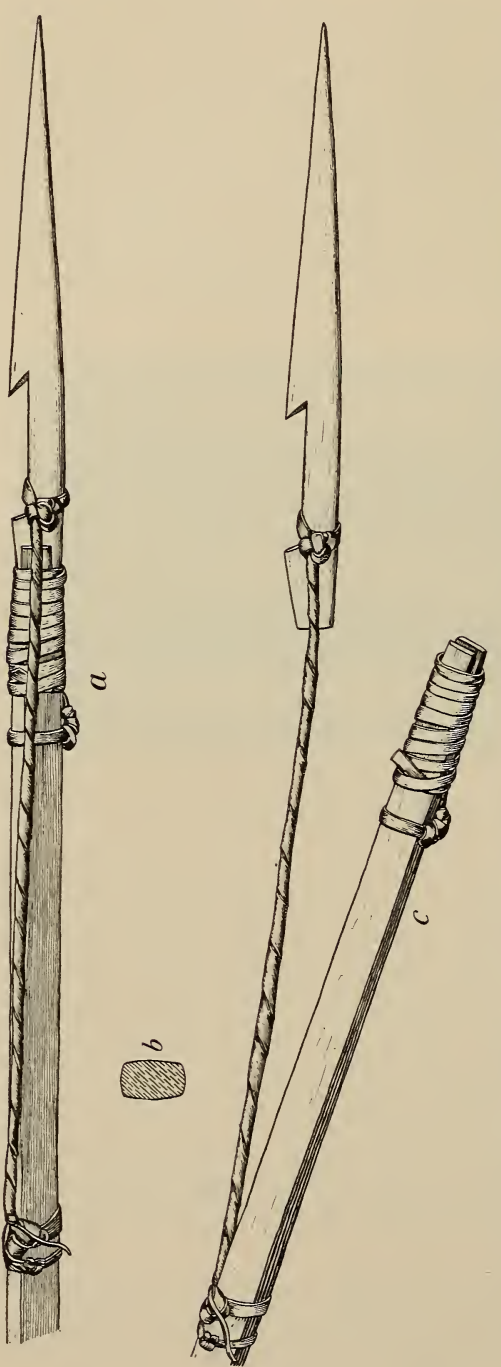

discovered in late Paleolithic deposits in Europe, yet between the Yahgan and the Magdalenian peoples of Europe roll great oceans of time and space.

2. HARPOONS. - In the pursuit of seal, porpoise, and whale, the Yahgan employed a harpoon with a heavy shaft and a detachable head joined to the shaft by a thong (fig. 79, $b$ ).

The shaft differs from the fish-spear shaft in material and in weight: it is heavier than the fish-spear and consequently will deliver a harder blow; it is usually made not of beech but of cypress wood. Cypress grows only along the western channels of Tierra del Fuego, but in the old days the wood passed thence in trade to Beagle channel and the southern islands.

There are regional differences in the kind of point attached to the cypress shaft: in the east a single- 
barbed head (awaía) was used (fig. 81, a); in the west a doublebarbed form (fig. $81, b$ ) was employed. In both regions, however, the head had a flat-base tang with an expanded foot.

In assembling the weapon, the tang of the spearhead was inserted in a slot which ran completely through the head of the shaft, where it was loosely lashed by an encircling sealhide thong (tuwawáru). It was held in place by a second thong (tamutú) tied to the tang and attached to the shaft two or three feet from the head. As illustrated in fig. 82, $a$, this thong was twisted until its length was lessened and it acted as a spring to hold the butt of the tang firmly against the bottom of the slot in the spearhead. The tension of this thong was a matter of constant adjustment, for it varied according to the wetness or dryness of the thong and even with the state of the weather.

When the seal-spear had been buried in the flesh of a porpoise, whale, or seal, the point promptly pulled out of the socket and the shaft then acted as a drag, as shown in fig. 82, c. But owing to the fact that the thong from the shaft to the head was tied near one end of the shaft, it dragged at an acute angle, so that sufficient pressure to break the thong or the shaft was not produced. The Yahgan apparently did not employ inflated skins or bladders for this purpose.

3. Guanaco-spear.-In the eastern part

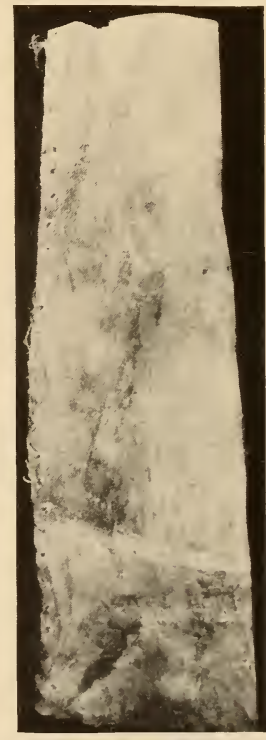

Fig. 83.-Yahgan spearpoint case. Height, 14 in. (14) $2370)$

of Beagle channel and on Lennox and New islands the Yahgan hunted the guanaco with a special kind of spearpoint (i'unaí), shown in fig. $81, c$. It resembles the seal-spear in having a single barb, but lacks the projection seen on the seal-spear's tang. It was lashed on the light hexagonal shaft of a fish-spear. This kind of weapon apparently was in use only among the eastern Yahgan, for it was unknown to Messrs. William Bridges and Fred. Lawrence. The example illustrated was obtained from a Lennox islander. To spear guanaco the animal was chased into a swamp or else the 

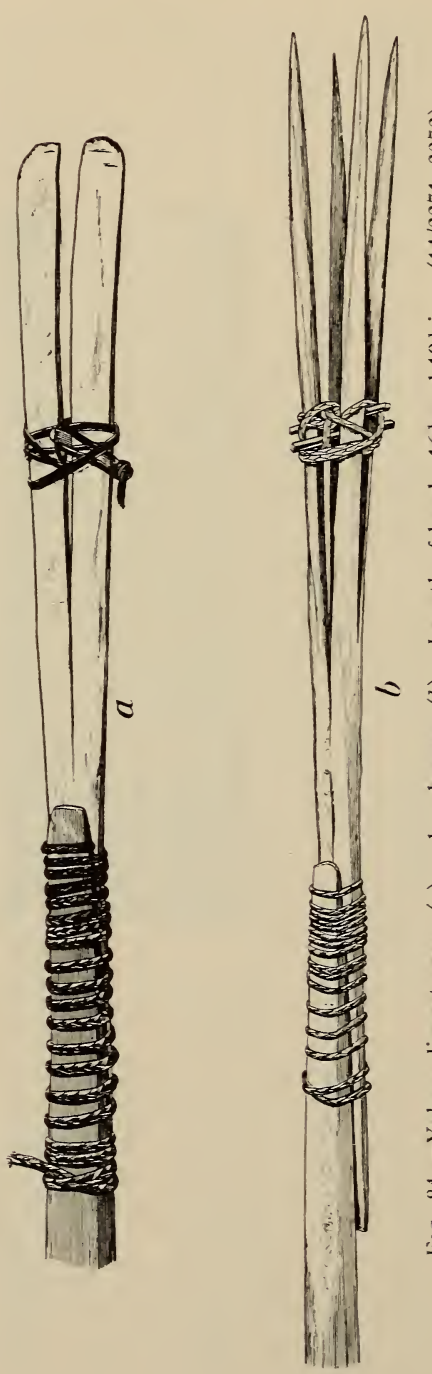

hunter climbed a tree over a guanaco runway in the woods and waited there until an animal passed beneath him.

The three spear types described all had bone points, specialized in type but of approximately the same length. To carry the extra points that might be needed were the one in use to become lost, the Yahgan employed a small case made of seal-hide with the hair side inward. Old-time containers were simply a rectangle of skin folded double and sewn up the side and bottom (fig. 83). In recent years the Yahgan have followed the pattern of the Ona quiver (fig. 33) and have inserted a small oval piece of hide at the bottom of the case.

\section{Crab and SEA-Urchin} Spear.-As shown in fig. 79, $e$, this spear (akwisimána) was considerably longer than the other Yahgan spears, for it was designed to secure crabs and sea-urchins under water.

The shaft was not octagonal like the other spears considered, but was round. It was covered with minute flutes like the Ona bow, but they were not so carefully worked.

The head of the crab-spear (sita) was a piece of yellow barberry wood split at one 
end to form four prongs which were sharpened and hardened in the fire (fig. 84, $b$ ). These prongs were wedged apart with small wooden toggles held in place by a lashing of either braided grass or whalebone. The head was lashed to the shaft with a seal-hide thong.

5. LimpeT-SPEAR.-The limpet-spear (kaliáno) had either the fish or the crab spearshaft. It is seen with the former in fig. $79, a$. The head (fig. 84, a) had but two prongs with flat, chisel-like blades. They were forced slightly apart by a small toggle.

\section{BOW AND ARROW}

In the old days, according to all accounts, the Yahgan habitually used the bow and arrow, but during the last half of the nineteenth century this weapon rapidly fell into disuse, until by the end of the century the bow had become a toy for children.

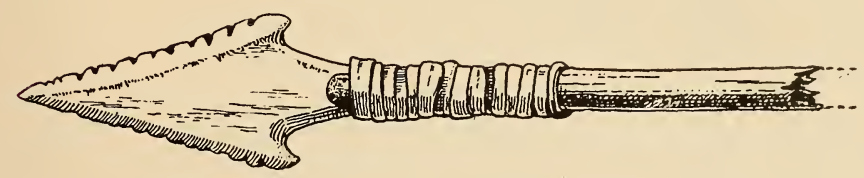

FIG. 85.-Yahgan bone arrowpoint. (After Hyades and Deniker.)

According to Fitzroy $(1839$, pp. 184, 187) the Yahgan everywhere arrowed birds and, in the east, guanaco. Their bows he described as three or four feet long and "quite plain." The arrows were two feet in length, well polished, and with the points so loosely attached that they remained in the flesh when the shaft was withdrawn (fig. 85).

An example of Yahgan bow which the Rev. John Williams kindly allowed the writer to examine had been given to his children several years ago as a toy. In general type it resembled the Ona bow, like which it was fluted, a characteristic due, I suspect, to contact with the Ona at Harberton. However, it was much shorter than the Ona bow, and much more curved, especially at the ends. This latter feature may have been accidental, for guanaco-sinew has a tendency to shrink for many years, and the writer has noted in museums Ona bows unduly curved owing to the increasing tension of the cord.

The arrows were short, clumsy, and untapered-very crude 
indeed compared with Ona workmanship. The arrowhead was of bone, cut to the Ona pattern with two barbs; but it had a long tang and was loosely attached to the shaft with heavy lashings like the Yahgan spears. Notches in the blade of the specimen illustrated (fig. 85) suggest the lithomorphic protype seen in fig. 105, $b$.

In the Peabody Museum at Salem are two old Yahgan bows, one the gift of Capt. B. Morrell, Jr., who obtained it in 1825, the other collected by Lieutenant Wilkes, probably at Orange harbor or Wollaston island. These bows, illustrated in pl. XIII through the kindness of $\mathrm{Mr}$. L. W. Jenkins, are respectively $3 \mathrm{ft} .9 \frac{1}{2} \mathrm{in}$. and $4 \mathrm{ft} .1 \mathrm{in}$. from tip to tip. Though the general outline and cross-section recall the Ona bow, the fluting typical of the handiwork of that tribe is absent. Both specimens appear to be made of beechwood, but this has become dark through age, much handling, and the application of grease. Bowstrings are of guanaco-sinew; they are attached in Ona fashion with a slip-noose at the bottom (to the right in pl. XIII) and with several turns secured by a halfhitch at the top.

\section{CLUBS}

Yahgan clubs (kiwa) are short stout sticks, painted red when new (fig. 85A). These weapons were intended for killing seal on

FIG. 85A.-Yahgan club. Length, $47 \frac{1}{2}$ in. (14/2271)

shore, or for killing birds at night with the aid of a torch of beechbark (aiirshun). Also they were commonly used in fighting.

\section{SLINGS}

Slings (watewá) were an extremely effective weapon among the Yahgan, for some are said to have been so dextrous in their use that they often brought down flying birds. The usual sling (fig. 86) has a pouch of guanaco- or seal-hide suspended on braided whalegut lines. The ends terminate in knots enlarged with a little guanaco wool. In discharging a stone, one knot is placed between the fourth and the little finger with the cord running across the palm of the hand; the other knot is held between the thumb and forefinger as the sling is whirled around the head.

The Alacaluf, as well as the Yahgan, were skilful users of slings, but of the Ona only those in the south had slings. At first glance 


$$
1)
$$



it would seem clear that the Ona had acquired knowledge of this weapon from the Yahgan. However, the Ona word for sling (shinkai) is not taken from the Yahgan, while slings are mentioned in a supposedly ancient Ona legend. Possibly then the Ona might not have borrowed the sling from their Yahgan neighbors, but in all probability they did.

\section{BIRD-SNARES}

Three different forms of snare were applied to the capture of birds by the Yahgan. In all of these, active prehensile function was performed by a noose of whalebone scraped thin to make it flexible. The simplest procedure was to set such a noose over a bird's nest during its absence. Also a series of nooses might be set on a cord, staked down in an open spot, and covered with suitable bait (fig. 36A). Finally, a whalebone noose was set on the end of a pole (aurum), as illustrated in fig. 87. With this implement it was possible to snare roosting birds during the night.

\section{BIRD-CATCHING BY HAND}

In addition to killing birds with arrows, slings, club and torch, and snares, the Yahgan sometimes took birds by a method which, if successful, often resulted in prodigally wasteful and unnecessary slaughter. At night a man would paddle silently to a rock where birds, preferably shags, as they are heavy sleepers, were roosting. He would steal silently ashore, and then seize the nearest bird with one hand around its wings and with the other hand pinch its windpipe so that it could neither flap its wings nor make an outcry. Then he bit off the head, placed the corpse on the ground, and

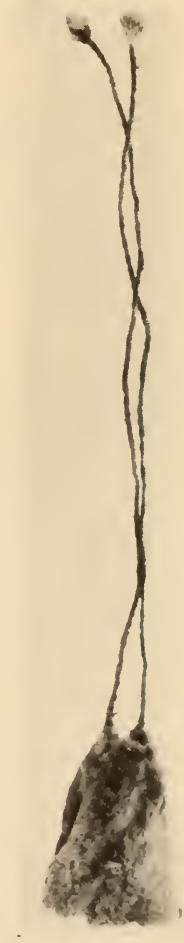

FIG. 86.Yahgan sling. Length, 27 in. $(1+/ 2351)$

went for the next bird. Thus with luck great numbers might be taken. But the steamboat duck (Tachyeres cinereus), a light sleeper, could seldom be captured by this method, and, if any were roosting on the rock selected, they usually gave the alarm. Fitzroy (1839, p. 184) says that the Yahgan dogs were trained to catch birds by stealing upon them as they roosted during the night. 


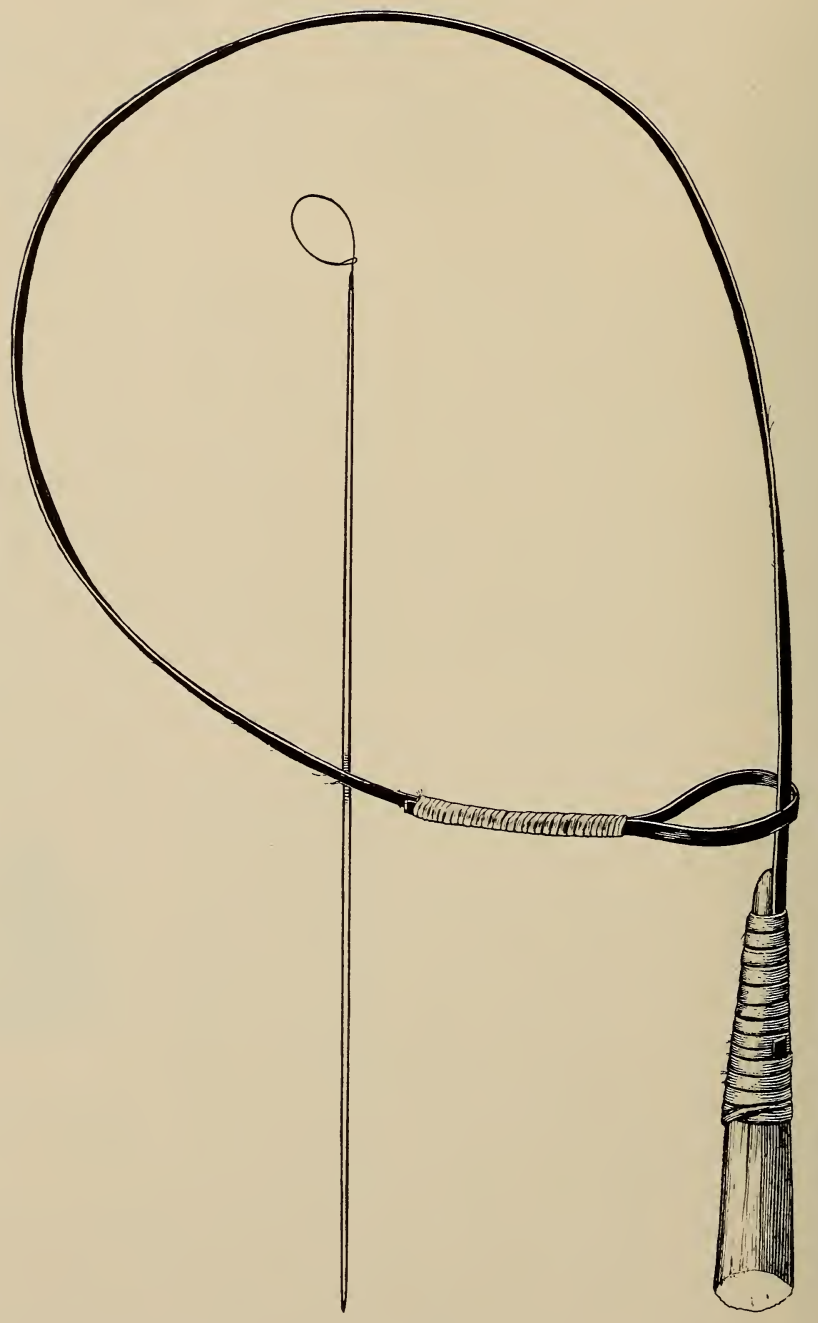

FIG. 87.-Yahgan bird-snare. Diameter of loop, 6 $\frac{1}{2}$ in. (14/2276) 
On Gable island and other places where birds nested the Yahgan captured the young and tamed them to frequent their wigwams until they were large enough to be eaten. The writer has seen young upland geese and gulls thus tamed. Also, in the sum. mer, the Yahgan had special bird hunts near the breeding places, because at this time of year the birds, though nearly full-grown, have not learned to fly and may be captured by running them down.

\section{FISH-LINE}

The Yahgan fish-line, shown in fig. 88 , consists of three elements: line (tápim), sinker (társhir), and bait noose (tukaléna). The line is of braided whale-sinew and is ten to twelve feet long. The sinker is a small stone with notches knocked in opposite sides. The noose, like the bird nooses, is a narrow strip of whalebone scraped thin and flexible with a bit of shell. In an emer-

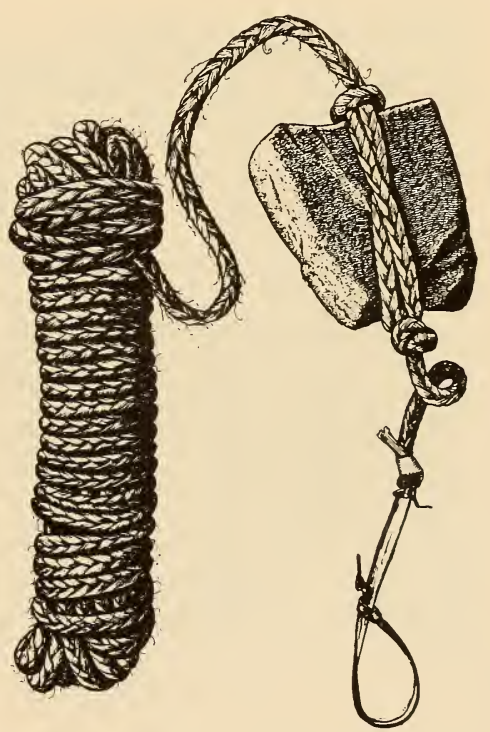

Fig. 88.-Yahgan fish-line. Length of coiled line, 6 in. $(1+/ 2375)$ gency a piece of kelp was used as a fish-line.

In order to fish, the Yahgan women paddled in their canoes to a shallow reef. There they anchored the canoe by inserting the handle of the paddle under a gunwale so that the blade projected outboard on the other side. A heavy piece of kelp was hauled across this, which not only served to prevent the canoe from drifting but also steadied it. Bait was then inserted in the noose and the line was lowered. When a fish had nibbled at and partly swallowed the bait it was pulled to the surface, seized by a quick dart of the hand, and killed by biting it in the head. Fish were cleaned as soon as they were caught by biting a hole in the belly through which the guts could be extracted with the finger. 


\section{FISH-NET}

At certain seasons of the year Beagle channel is infested by small sardine-like fish which the Yahgan captured in dip-nets

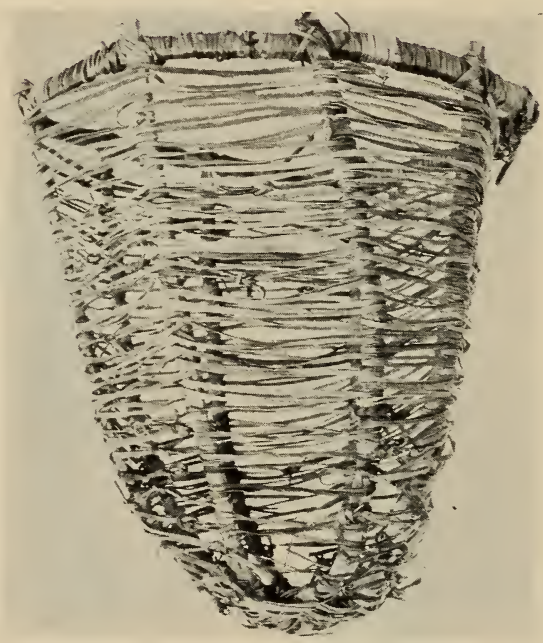

FIG. 89.-Yahgan dip-net. Height, 12 in. $(14 / 2321)$ (chiwanúsh) woven of grass. A rather poorlymade example of these is shown in fig. 89 . It will be noted that there is a light wooden frame enclosed by parallel stems of grass tied to the members of the frame. This was lashed to the end of a pole and with it the fish were dipped out. A model of this implement appears in the bow of the canoe in fig. 73 .

\section{FISH-WEIRS}

According to Hyades (1891, p. 372) the Yahgan sometimes erected in suitable places fish-weirs consisting of a row of stakes. Of these I saw no trace in Tierra del Fuego.

\section{Social Organization}

Yahgan society was based on the family. There was no higher unit. However, related families usually paddled their canoes in couples, as the skin housetop was heavy for a single canoe, and they divided the common roof into two parts, of which each carried one. While the Yahgan were rovers, they usually stayed regularly in one district, where most of the people were their relatives.

All observers of the Yahgan comment on their lack of leadership. Medicine-men asserted a certain authority through the fear they inspired, but at times they were roughly handled, so their power was in no wise secure. As no communal enterprises were undertaken, there existed no need for chiefs. 


\section{KINSHIP}

The Yahgan kinship terms, like the Ona, were compounded with the possessive adjectives "my," "your," "his," or "her" (háwa, sina, kichin). These whole expressions may or may not be contracted. Additional complications were introduced by the fact that different terms in some cases were used when speaking of a person nearby or far away, and again when two people or several people took part in the conversation.

The kinship terms listed below were obtained in part from Mr. Fred. Lawrence and in part from Yahgan at Puerto Mejillones, and have been checked by Mr. William Bridges. It is difficult to gather these words, because much time has passed since many of them were used. ${ }^{1}$ We have given many terms only in the first person when the second and third persons are regularly formed.

\section{TABLE V.-YAHGAN RELATIONSHIP TERMS}

\section{FATHER}

my father

your father

his (her) father (when nearby)

his (her) father (when afar)

my mother (when two speak) my mother (when several speak) your mother

his (her) mother (when nearby) his (her) mother (when afar)

my elder brother

your elder brother (when nearby)

your elder brother (when afar)

his elder brother

my middle (of 3) brother your middle (of 3 ) brother

his middle (of 3 ) brother

my younger brother your younger brother

his younger brother

my brother next to my elclest my brother next to my youngest my brother next to my second háwahimun, háwimun sinahimun, sinimun kichinhimun, kichimun kúnchiminhimun

\section{MOTHER}

háwadábe

hídabéyan

sinadábe

kichindábe

kidabéan

\section{BROTHER}

háwawaíamun

sinawaíamun

waimhaki

kichinwaiamun

háwayínatápawaíma

sinayínatápawaíma

kichinyínatápawaíma

háwaashuwá, híwaashuwaíki

sínaashurvá, sínaashuwaiki

kichinashuwá, kichinashuwaíki

háwawaímakinchigaíakigaíaki

háwaashuwaíakinchigaíaki háwaishpaki háwayénatawaímakinchigaíakigaíaki

${ }^{1}$ Both Fitzroy and Darwin comment on the extraordinary rapidity with which the Yahgan and Alacaluf taken to England in the Beagle forgot how to speak their native tongues. 
my sister

my elder sister

my younger sister

my sister next to the oldest

my sister next to the youngest

my father's elder brother my father's younger brother my mother's elder brother my mother's younger brother my paternal uncle

my mother's elder sister my mother's younger sister my maternal aunt my paternal aunt

my mother's father

my wife

my son

my daughter

my grandson

my father's sister's son

my father's sister's daughter my brothers and cousins (in general) my sisters and cousins (in general)

my family

\section{FAMILY}

\section{SISTER}

háwamukuiskipan

háwawaíkipan

háwaáshkípan

háwawaíkipánchigaíakigaíaki

háwayénatapawaíkipan

\section{UNCLE}

háwahimúnchiwaíamun háwahimúnchiashuwá

háwadabeinchiwaíamun háwadabeinchiashuwá háwa ̌́'man

\section{Aunt}

háwadabínchiwaíakipan háwadabínchiáshkípan

háwayěhadábe

háwatemapúa

\section{GRANDFATHER}

háwakolúna

WIFE

háwakuloána

Sox

háwamákun

\section{DACGHTER}

háwamakipan

\section{GRANDSON}

háwamágutsa

\section{Cousin}

\section{háwawáturu}

háwakipawáturu

háwamákusyérmalin

háwamákuskípayérmalin

háwamamakuísawála

\section{MARRIAGE}

The Yahgan addressed cousins of the first and second degree as "brother" or "sister," and were not allowed to marry within that range of consanguinity. A man spoke of his female relatives with whom marriage was forbidden as háwamákuskípayérmalin; a woman's prohibited relatives she named collectively háwamákusyérmalin. The restriction was absolute. 
Among the Yahgan, marriage by capture seems to have been less common than among the Ona. A woman given in marriage by her father against her will soon abandoned the undesired husband. In fact the Yahgan showed a tendency to change husbands and wives not infrequently, which we may term progressive polygamy. According to Rev. Thomas Bridges (1884, p. 206) a man might have from one to four wives at a time, but the number was not fixed by custom.

Infidelity resulted in no fixed form of punishment, but both the offending man and woman were apt to be beaten. Shortly before our arrival a Yahgan man had disappeared. It was rumored that his wife, enraged at his amours, had beaten him with a paddle and accidentally killed him.

\section{CHILDREN}

In the old days, to judge by the number of deserted orphans set down in the mission records, the Yahgan did not greatly devote themselves to the care of the children. Abortion seems to have been a common practice, and infanticide we judge was not rare. To reach the facts is somewhat difficult because early explorers did not have sufficient knowledge to describe such practices, and the mission contact soon put an end to them or drove them under cover.

Soon after birth had taken place the Yahgan mother bathed in the sea and the new-born child was also immersed in order to toughen it. This was a rather terrible ordeal for an infant, for the sea temperatures of winter and summer range from $40^{\circ}$ to $50^{\circ}$ Fahrenheit, while the air at best could be described as no warmer than temperate. We have no figures to show what mortality this custom entailed, yet cannot but believe that soon after birth all but the most vigorous and robust infants were thus ruthlessly eliminated.

After delivery, not only the mother but the father as well was expected to rest for a week or more. In this custom we see incipient couvade.

\section{Games and Amusements}

The Yahgan to pass the time indulged in various simple games and in singing and dancing. Of necessity the young boys devoted much care and time to practice with spear, bow and arrow, sling, and stones; but while these exercises often assumed the form of 
sport, the practical aspect of gaining a livelihood and a desire to imitate the grown men must have been the underlying motive. Wrestling was not uncommon, and was an extremely rough sport, so much so indeed that death sometimes ensued. Rev. Thomas Bridges $(1884$, p. 179$)$ recognizes two types of wrestling: one between individuals known as kahleka, another between two groups known as ungiana.

Of the simpler amusements the children had several of the "followmy-leader" type, they used a swing, they had a simple ball-game like the Ona, and they painted themselves in the style of their elders and inserted short sticks in their lips, nostrils, and eyelids. Games of these kinds have been studied by Koppers (1924).

Of Yahgan songs Mr. Bridges (op. cit., p. 177) recognizes several varieties. The first group, called loima, are songs of blood revenge; another type, called telania, are songs of mourning; the arua songs are peculiar to the medicine-men; finally there are songs called jacos which are sung by everybody. This last class are usually mythological in subject matter. The same authority says that the dances are called uona. People may dance alone, in couples, or in groups, and in a circle holding hands or in line.

The Yahgan had no foot-racing or water sports of any kind.

\section{FEUdS}

In general the Yahgan were not an amicable people, according to most accounts. When two groups camped together trouble usually arose, and the weaker group moved away. This as well as the food quest accounts for their frequent changes of residence. Sometimes a fight might start between two individuals and then all their friends and relatives joined, probably in an endeavor to stop the encounter but sometimes to aid their man. Clubs, paddles, spears, slings, and stones were the weapons used. General mêlées, however, can not have been common, for Rev. Thomas Bridges sponsors the statement ${ }^{1}$ that in the thirteen years between 1871 and 1884 only twenty-two murders had taken place. I have no figures for the Ona, but killings must have been much more frequent among them than among the Yahgan.

The causes of quarrels among the Yahgan were such as are found among all primitive tribes, namely, insult, theft, adultery, and the

\footnotetext{
${ }^{1}$ In South American Missionary Magazine, London, 1884, p. 224.
} 
death of a relative. All these called for vengeance, but the Yahgan seem to have felt antipathy rather than hatred, so vengeance might be deferred for several years, during which time mutual friends might compose the quarrel.

Blood loyalty was recognized among the Yahgan, but apparently was not fiercely cherished as among the Ona. Rev. Thomas Bridges states that when a murder occurred the friends and relatives of the victim would take revenge, but the family of the murderer abandoned him and made no effort to defend him. This certainly is not customary among primitive people with a highly developed consciousness of consanguinity like the Yahgan, and perhaps Mr. Bridges' statement represents the result of missionary contact rather than the original state of affairs.

Organized warfare, during which any member of one group would kill at sight any member of another group, as among the Ona, was unknown to the Yahgan, but blood revenge was sometimes executed on a relative of a murderer.

\section{INITIATION}

Thanks to the studies of Gusinde and Koppers full and complete information about the Yahgan initiation rites is available, and the reader desirous of fuller information than is given here is referred to their various publications on this subject listed in the bibliography. Two ceremonies were in use among the Yahgan, known as shieháus and kina. The first of these, celebrated by both sexes. apparently is the ancient Yahgan rite, while the other corresponds closely to the Ona klókten ceremony and represents culture borrowing from that tribe. Both may be described as a systematic educational course for the youth of the tribe- "going to school," the Yahgan called them.

For the shieháus ceremony a large domed hut (mánaga), elliptical in outline, was erected near the encampment. The framework was of split saplings an inch or two in diameter, bent and set up to form arch-like ribs, and secured in place by a few horizontal beams (pl. xiv). These timbers were held together by lashings of gut. At either end of the hut were doors, one large to admit spectators, one small for the use of the candidates. On the roof they piled branches of the evergreen antarctic beech to afford shelter to those within, but the sides were left open to the weather. Rows of logs staked in place on the floor divided it into a central gangway 
flanked by benches, built up by branches covered with skins. In the middle of the gangway burned a fire.

The house we have described was the type used by the central and western Yahgan. Our illustrations show the lodge erected in

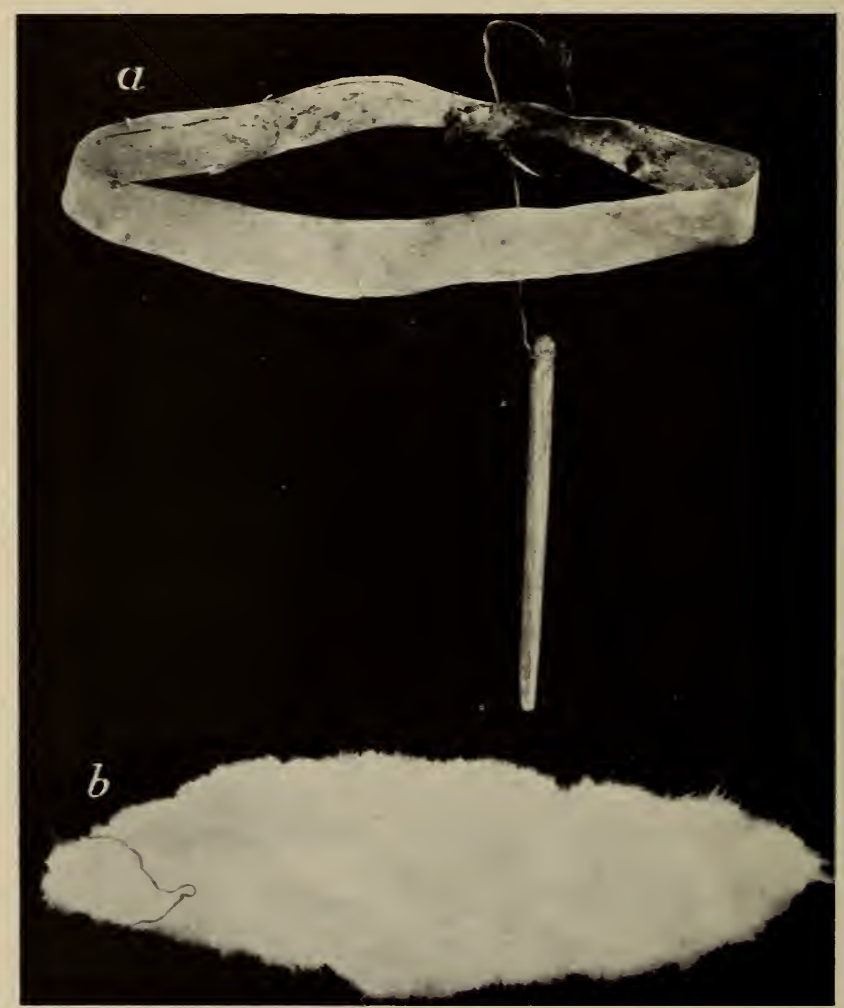

FIG. 90.- $a$, Eastern Yahgan initiate's headband and scratching-stick (1+2.361); length of stick, 5 in. b, Kelp-goose down headband (14/2344); length, 19 in.

1922 at the instance of Gusinde and Koppers on Navarin island. The eastern Yahgan, I was informed, did not use a domed hut for this rite, but a pointed conical wigwam like that seen among the Ona (fig. 38). 

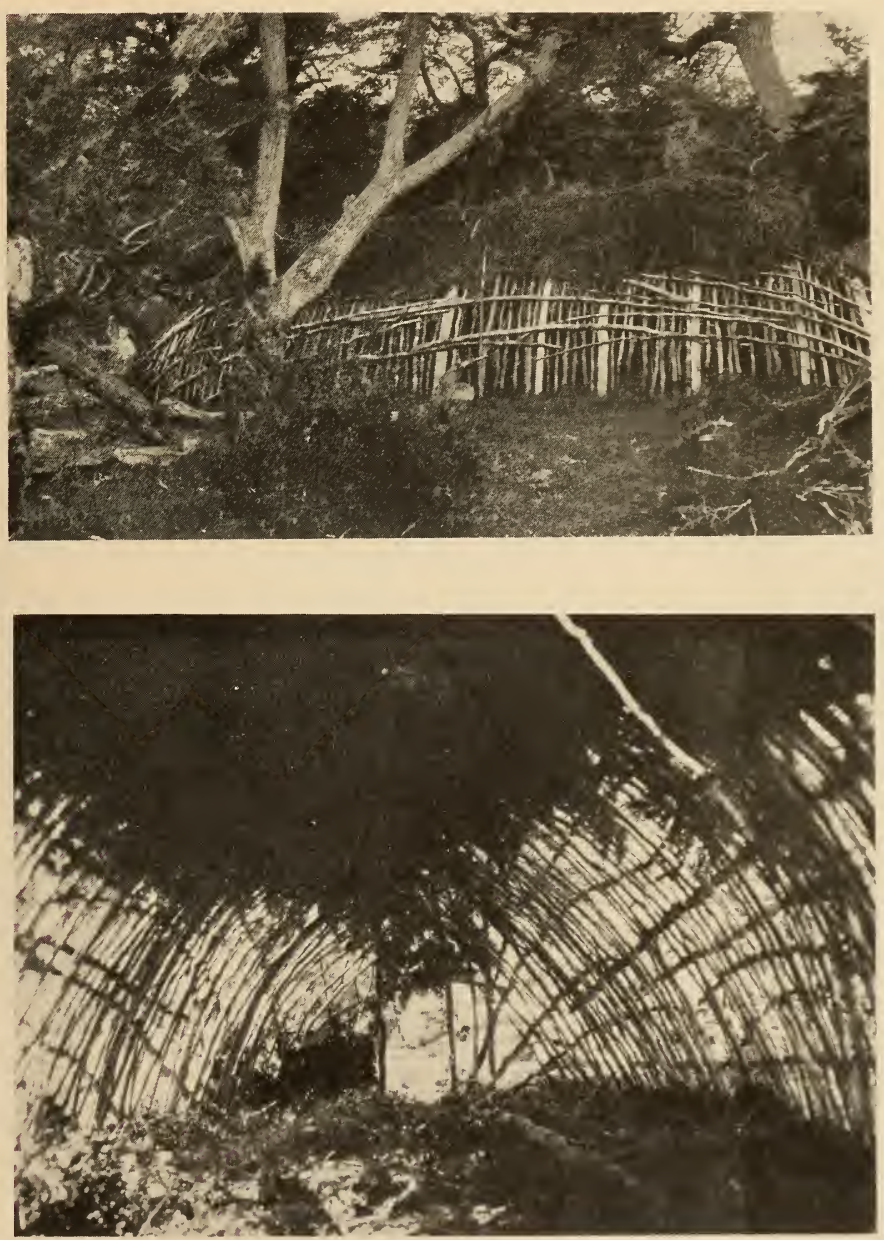

YAHGAN CEREMONIAL LODGE, PUERTO MEJILLONES, NAVARIN ISLAND 

To beautify the initiation lodge, the flat inner surface of the split saplings constituting the framework was painted with red, white, and black paint. Broad boards, inserted at regular intervals in the frame, as may be seen in the upper view in pl. XIV, received similar decoration. The nature of the embellishment is shown in pl. IX, a series of designs copied from the lodge we have described. When a ceremony was in progress the hut was further adorned with small painted tablets hung from the roof, while an additional touch of color came from painted wands (fig. 91) which often were wedged in the frame of the house when not in use.

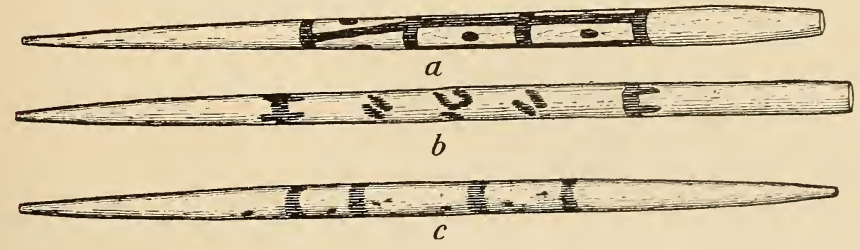

FIG. 91.-Yahgan painted ceremonial wands. Length of $b, 24$ in. $\quad\left(14 / 2227 \frac{1}{2}\right)$

Two hundred feet or so from the initiation lodge a second and smaller hut was erected to serve as a cook-house where meals for the candidates and officials were prepared.

The paraphernalia used during the ceremony we illustrate in pl. $\mathrm{XV}$ and figs. 90 and 91 . It consists of heron-plume headbands (hapawára) worn by the officials, kelp-goose down headbands (paqal) worn by the others present, a narrow hide headband painted white (hehel) worn by the initiate during part of the ceremony, a small stick also painted white (w'matámia) used for scratching, and variously painted wands (tumoistáka). The scratching-stick is assigned to all the Yahgan by Koppers (1925), but I was told that it was used only by the easterners. The wands were held in the hand during the singing and dancing, and were swung in time with the music. When not in use they were thrust upright in the ground or stuck in the frame of the lodge. If one fell on the ground it was considered an evil omen. I was told that these wands were not in use among the easterners. The men in charge of the ceremony kept at hand a seal-hide thong like that pictured in fig. 76, but adorned with closely spaced red dots; it was used to tie up any candidate who became unruly. 
The oldest and most experienced of the men present assembled before the ceremony and agreed on the time and manner in which it was to be conducted. From their number they chose one who was both respected and well liked to be the master of ceremonies. Another they selected as the official instructor of the candidates, while others they designated "policemen." Their duties were to assemble the candidates in the lodge-by force if necessary-to see that they were submissive at all times, to sit on the roof during the ceremony and ward off any threat from without, and to communicate with the cook-house when necessary. Finally each candidate had three godparents, two of his own and one of the opposite sex. Their part was to see that the candidates fulfilled all the ritual properly and to help them as much as possible, for it was to the credit of the godparents if their adopted children did well. In addition to the candidates and the officials, most of the grown people came to celebrate the ceremony. Places were taken in family groups, while the initiates sat with their godparents. All sat with their legs crossed under them and with arms akimbo, thereby taking up as little room as possible so that a large number might receive the warmth of the central fire.

For the first three days of the initiation, candidates maintained a strict fast, for their allowance of food was only from three to five mussels a day. Their water supply also was limited and had to be consumed through a hollow bird-bone. At night they were forced to maintain their cross-legged position, with the exception of four to six hours when they were allowed to sleep. If they relaxed at any other time they were pushed back into position by the older people and perhaps beaten for their lapse.

During the day the initiates received instruction in the art of making a living. The men instructed the boys in the methods of hunting, how to make tools and weapons, how to build canoes and houses, etc. Similarly the women taught the girls how to gather mussels and fungi, how to make baskets, buckets, and necklaces, how to rear children, etc.

At nightfall all the candidates were taken to the beach and forced to bathe in the icy water of the ocean. After the first bath the boys received a sort of tattooing on their chests, consisting of three lines of scratches into which they rubbed red paint. This was not real tattooing, because the cuts were not deep enough to retain the color permanently. 


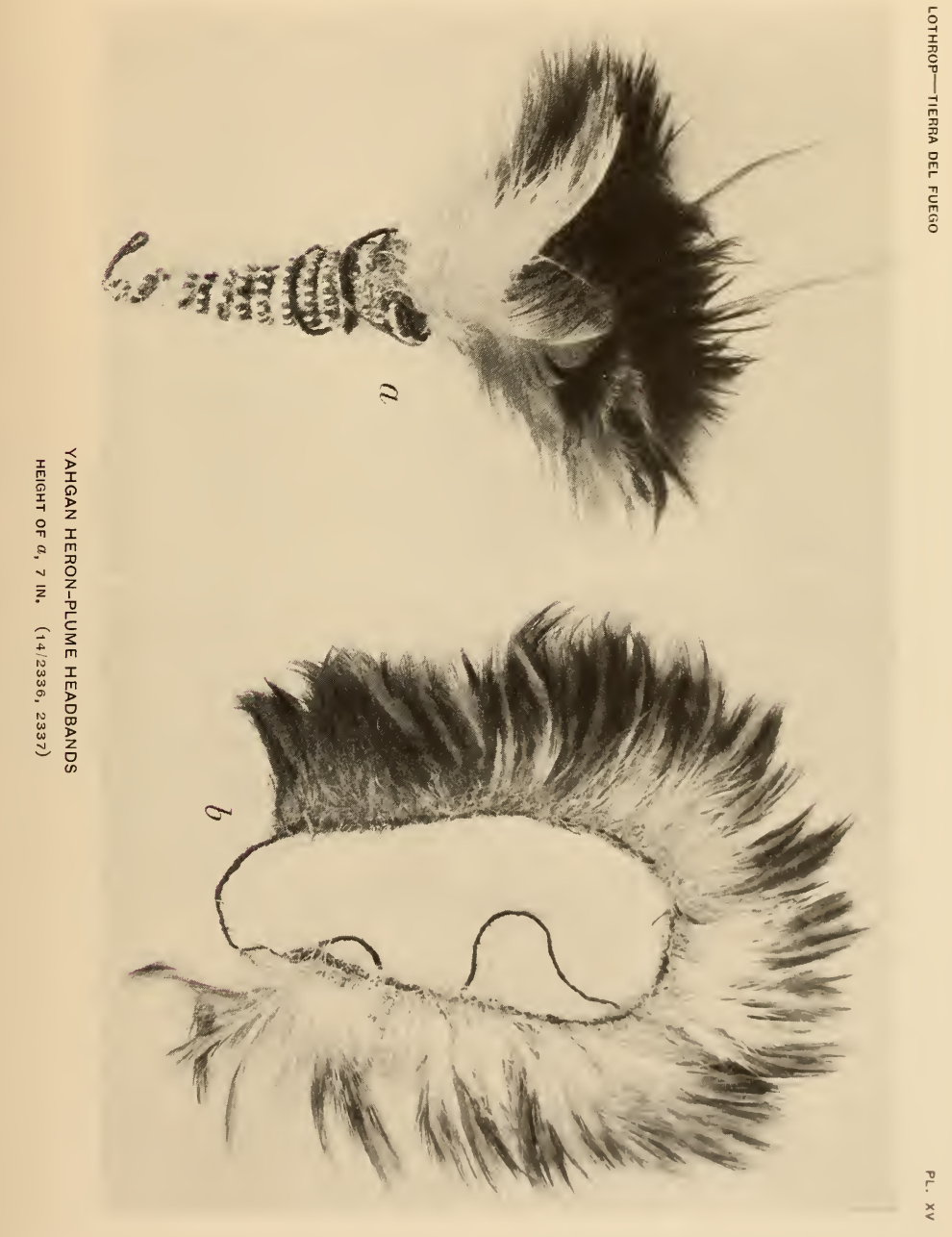



The greater part of the shieháus ceremony was filled with singing and dancing. By means of song they sought both to communicate with and to keep at a distance the Yetaite, a great evil spirit, who, the candidates were told, might seriously injure the occupants of the initiation lodge. Dancing served to neutralize the evil of his presence. To frighten him, the walls of the hut were beaten with sticks. Candidates were told to follow directions exactly or the Yetaite would seize them. Sometimes the Yetaite actually appeared - a man fantastically painted. Finally the candidates were told who it was and were warned that the real Yetaite was much worse than what they had seen.

The master of ceremonies usually was the leader in the singing, though sometimes this duty was assigned to another old man. The dances, which usually came late at night, were named for certain animals. Both the melody and the movements suggested characteristic peculiarities of this animal.

The moral instruction of the candidates they divided between the godparents and the official teacher, at whose feet the initiates had to sit from time to time. They were taught to be altruistic in thought and conduct, and to exhibit the virtues of hospitality and generosity. Respect for the aged was inculcated, for all must grow old in time. The boys they taught to be peaceful and not to make enemies, to treat women with respect, to help the young and the blind. The girls they told to rise early in the morning to get their water and wood, to care faithfully for their husbands and children, not to fuss about trifles, nor to repeat gossip. Behind these instructions stood a certain amount of religious sanction, for the evil Yetaite threatened them, while the supreme Wataninewa observed their every action. This moral code set a standard for the tribe to which in practice they did not adhere too rigidly.

After some days of instruction the ceremony came to a close. At a given hour the candidates assembled behind a curtain at one end of the hut. One by one they were called forth with the master of ceremonies dancing beside them and were ceremonially surrendered to their godparents and therewith accepted as members of the tribe. The godfather gave his child three gifts: a finely woven gaichim basket adorned with feathers, a bird-bone like the one used to drink with, and a scratching-stick.

In the final hours of the last evening the women took charge under the leadership of an old woman. She and the other women 
sang, seated in the central part of the lodge. Finally a mock battle between the sexes was staged.

Such then was the shieháus ceremony. On it the Yahgan believed their well-being depended, and without it no one could have any

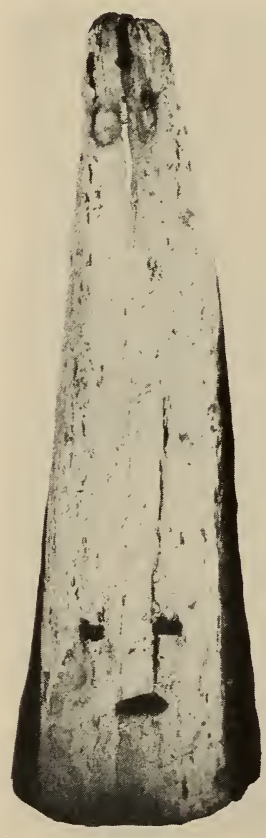

FIG. 92.-Yahgan dance masks. Height of $a$,

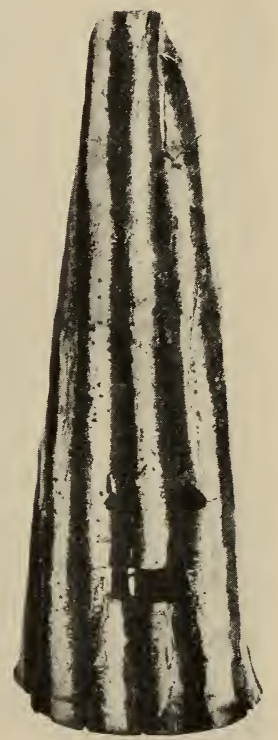

$b$ 27 in. $(14 / 2259,2258)$ standing in the community. In fact each individual repeated the performance two or more times, but received preferential treatment after the first course.

After having experienced the shieháus, Yahgan men were allowed to enter the kina ceremony. This rite resembled the Ona klókten. Gusinde and Koppers believe that it originated among the Ona, pointing out that inequality of the sexes was foreign to Yahgan precept and that it was not taken so seriously by the Yahgan as the Ona. Rev. Thomas Bridges speaks of the ribald laughter among the Yahgan women when a mask fell off a supposed spirit, thus revealing his human character.

This ceremony fell into disuse among the Yahgan as early as the eighties of the last century; but it was revived in 1922 for the benefit of Gusinde and Koppers, to whose accounts of it the reader is referred. While differing in details, it was essentially like the Ona rite except that the treatment of the candidates neither lasted so long nor was so severe as among the Foot Indians. 
In figs. 92 and 93 are illustrated some of the masks used by the Yahgan. The material is either bark (fig. 92) or seal-hide (fig. 93), cut to pattern and sewed together with whalebone and gut respectively. There is usually a small opening at the top for ventilation. As Yahgan paints were not waterproof, a single mask could be adorned to represent many characters by the simple expedient of washing and repainting it.

As to the characters represented by the Yahgan, in fig. 92, $a$, is the rainbow, distinguished by broad red, white, and black bands; $b$ has alternate red and white stripes, and it represents a smelt-like fish. In fig. 93, $a$, is a model of the kalapasha ghost mask, while $b$ represents the sea-hen. The wearers of these masks painted their bodies and limbs with similar decorative patterns.

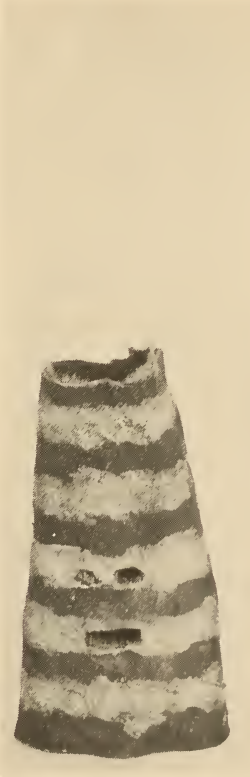

$a$

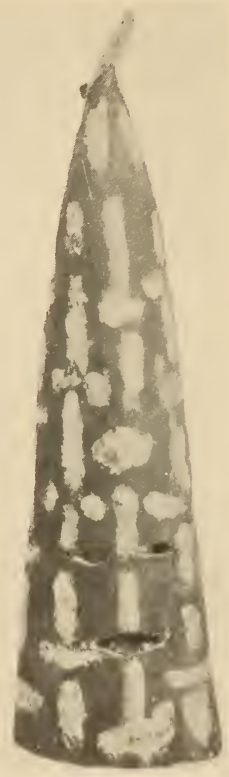

$b$

Fig. 93.-Model Yahgan dance masks. Height of $b, 10$ in. $(1+/ 2362)$

\section{ReLigion}

Although it has been repeatedly stated on excellent authority that the Yahgan had no real religion, I think it definitely established that they had religious beliefs and practices.

The Yahgan world was peopled by innumerable unseen beings: ghosts (kushpig) of departed shamans, spirits of the sea, the rocks, and the trees. These people, for the greater part, were malicious by nature, resentful of intrusion on their privacy, and, when seen by man, terrifying in aspect. Solitary travelers might suddenly find themselves facing a fierce spirit across the light of his camp-fire, 
and might be seized and done to death. However, the shaman usually had power over demons of this type and could give protection.

Apart from and above these lesser spirits was the great Watauinewa, described by Koppers (1925). This supreme being, though not concerned with creation, was the master of all. He sent the great flood in days long past, he causes death, he controls the game and fish supply, he is perfect and almighty. To him prayers were offered in sickness, grief, and thanksgiving, for this was not an aloof god normally forgetful of the affairs of mankind. Rather he was a supreme dispenser of justice, and he always punished the wicked.

\section{The Shaman}

Among the Yahgan both medicine-men and medicine-women existed and played an important part in the community. Supernatural powers were attained by certain individuals thought to have command over a natural spirit and the ghosts of departed witch-doctors. Thus dowered they could either kill or cure the individual and could affect the well-being of the community by controlling the weather or the food supply.

Disease, as among many primitive folk, they accredited to causes no less concrete than wounds. Hence the shaman must work his cure by removing some foreign object lodged in the body of the patient through accident or malice. Usually the doctor, after much massage, manipulation, and incantation, would triumphantly produce a stone or some other object, which he claimed to have extracted from the sufferer. The cures actually wrought can be attributed to the often beneficial results of the massage and to the healing power of suggestion.

According to Koppers (1925), the shaman assumed his function as the result of a "call" coming to either a man or a woman. This inner vocation took the form of a dream in which friendly relations were established with natural spirits and with the ghosts of dead shamans. After several such dreams a personal guardian spirit would be established. To the men a sort of shaman's school was open, but women were barred from this because they had not passed the men's final initiation. During the period of this school dreams were encouraged by rigorous training, much practice was given in the necessary sleight-of-hand tricks, and the proper chants were memorized. The curious spectacle of a man walking on hot 
coals witnessed by Rev. Thomas Bridges (1893, p. 238) may have been part of this training.

Graduation from the shaman school did not insure a successful professional career, for only by repeated proofs of power could the individual's reputation be established. It seems that there was much competition among the medicinemen, and several early observers note a tendency of almost all the older people to work cures, to prophesy, etc.

In fig. 94 is illustrated the guan aco-hide bag in which the shaman carried his impedimenta. The contents were dia-

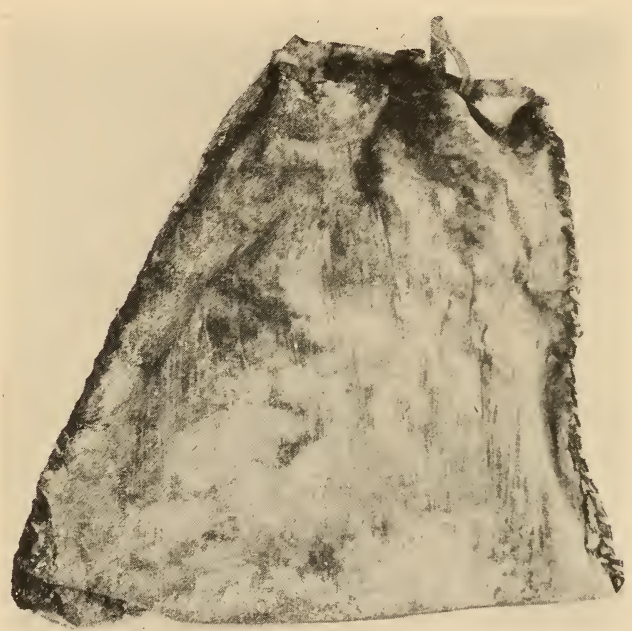

FIG. 94.-Yahgan shaman's bag. Diameter, 11 in. $(14 / 2337)$

dems of heron-plumes and of kelp-goose down, and white paint To these doubtless should be added a number of small hard objects to be shown to the sick as the cause of their pain.

\section{DEATH}

When death took place the corpse was wrapped in old seal-skins and buried outside of the house within twenty-four hours. If the ground were frozen, the corpse might be covered with stones and shrubs to keep off dogs and foxes, or it might be buried in a cave or on a small island. Hyades (1891, p. 379) says that when death occurred far from home the body was carried into the woods and cremated. This was done that the bones might not fall into the hands of enemies and be made into harpoon-points.

For mourning the family of the defunct covered themselves with 
black paint and indulged in formal ululation. They summoned their friends and relatives to the death-dance known as yamalashemoina, which might be repeated at intervals for several months. For it the men and women donned the white kelp-goose headband; the men supplied themselves with clubs of unusual length (fig. 95),

FIG. 95.-Yahgan ceremonial club. Length, $5 \mathrm{ft}$. (14/2261)

and the women carried paddles. As with many primitive tribes, the Yahgan believed death due to some positive and active force, visible or invisible. Hence the mourning ceremony carried the threat of revenge and assumed the character of a sham battle.

It has been both asserted and denied that the Yahgan believed in the immortality of the soul. Testimony on this point secured in recent years from mission-reared Indians might not be considered conclusive, but mythological tales clearly indicate belief in survival. As among the Ona, only unusually powerful and bold spirits, such as those of shamans, were able to maintain contact with the visible world.

\section{Mythology}

The Yahgan possessed the usual collection of myths found among primitive peoples, but these are exceedingly simple in character and lacking in humor or sublety. The most extensive study of the mythology of this tribe was conducted by Gusinde and Koppers, and has been published only in outline. Barclay, Thomas Bridges, Cojazzi, and Martial also have contributed mythological material of importance, while a few scattered tales occur in the works of other writers. It has seemed worth while to summarize these published sources because they often are difficult to obtain and have appeared in five different languages. We have followed the classification of Koppers (1924).

\section{EXPLANATORY MYTHS}

There are a large number of tales which explain the various phenomena of nature such as the slow approach of dawn, the shape of the rainbow, the spots on the moon, the bare tops of the mountains, etc. Such tales of ten form incidents in the more complex myth cycles we shall discuss. 
ETHICAL MYTHS

In this class are various stories dealing with adultery and incest. The wrongdoer is invariably punished and usually dies in disgrace. These stories are told the young during the initiation ceremonies as part of their education.

\section{GHOST STORIES}

Ghosts (kushpig), especially of dead shamans, were greatly feared among the Yahgan, as they were thought at times to intervene maliciously in human affairs. Hence tales exist of close escapes or death at their hands. We should also mention tales of men who had gone mad from some cause. Living in savage solitude, they sometimes terrified the Yahgan by appearing before them or attacking with desperate fury.

\section{“ONCE-UPON-A-TIME" STORIES}

There are many stories of varied character dealing with the escapades of unnamed individuals. Quite often these tales merge in classification with transformation myths. As an example we quote the following story recorded by Cojazzi (1914, p. 32):

"A young girl was playing on the beach, following the retreating waves. A seal saw her and swam in on a big wave which caught and spilled her. He swam off with her on his back to an island where they lived two years. The seal learned Yahgan. They had a son like a man in shape but covered with seal-hide. One day the woman said she would like to visit her family, and the seal agreed; so he loaded the mother and son on his back and swam to the beach, where he waited while the girl visited her parents, who failed to recognize her. But finally they received her with joy and commenced to prepare a feast. And the men, seeing a seal on the beach, ran down and killed it, and they cooked it for the feast and gave it to the mother and son to eat. Then the son said to his mother, 'Isn't seal meat good?' The mother had a horrid presentiment and ran to the beach where she had left her husband and encountered the traces of blood. Furiously she beat her child over the head, and he fell in the sea and became the fish called sciuno."

\section{GIANT STORIES}

To the Yahgan the giants (hamush) were large and fearsome creatures with hairy skin, flowing locks, and ferocious natures. 
Their appearance could not be foretold, with the exception of a few who in ancient times set up as highwaymen on traveled thoroughfares. In general, however, they confined their attention to solitary travelers or to women and children who strayed from the encampment. Martial (p. 213) and Dabbene (p. 66) record the story of a giant shaped like a huge sea-lion, who lived in a cave on Gable island and killed and ate the crews of passing canoes. A young man named Oumoara, small in stature but dextrous with his weapons and courageous in conflict, decided to kill this giant. So he said good bye to his wives and set off alone in a canoe. As he drew near shore he put out the giant's eyes with two successive sling shots; then he poured all his arrows into the giant's body and finished him off with the harpoon.

Once, as the result of the amours of a woman and a block of stone, there was born a giant, who, like Achilles, was vulnerable only in the heel. He lived on the coast of Hoste island where he killed the men and carried off the women. One day he hurt himself in the heel by accident. Oumoara heard of this, and, knowing his weakness, decided to attack him. Thus the giant was slain.

\section{CULTURE-BEARER MYTHS}

Koppers (1924) outlines a complex story dealing with two brothers called Yoā'lox and their sister Yoā'loxtörnikipa. According to Yahgan tradition these three were culture-bearers who introduced the use of fire, the art of killing birds, hunting sea-lion, getting fish-oil, making spears with barbs. They were said to have come from the east by land. Taken in conjunction with the Ona legend of bearded white men, I think it is clear that in Tierra del Fuego we have an outlying trace of the QuetzalcoatlViracocha myth complex, most highly developed in Mexico, Colombia, and Peru. In the art of more developed cultures than the Fuegian, this hero is associated with the plumed serpent or dragon complex which is the most basic and wide-spread of compound symbolic patterns found among the American Indians, for it can be traced from southern Canada to northern Argentina.

The Yahgan version is that the older Yoā'lox was stupid and lazy, and he wished that the fire would never go out, that the spear would return of itself to the hand after the cast, that seawater should be fish-oil, that man should not die. The younger brother, active and intelligent, said that the unguarded fire should 
go out, that the carefully cast spear hits the mark and need not return to the hand, that fish-oil tastes better if one works for it, that it is better to die as one lives again elsewhere. In this the sister, the cleverest of the three, sided with the younger brother.

On arrival in the Yahgan country, the various arts and industries were introduced. There followed a general giving of names, the beginning of sexual intercourse, rules governing menstruation, etc. The two brothers and their sister are now stars in the sky.

\section{DEBACLE MYTHS}

In this myth cycle belong the story of the origin of the initiation ceremonies, and a flood myth. According to Koppers, it is told as follows:

Long ago the women ruled the men, who then performed all the duties today allotted to the women. The weaker sex had gained their power by the kina ceremony. Painted fantastically and disguised by masks, they terrified into subjection their men folk, who believed they were looking at supernatural spirits controlled by their wives. At that time Hanuxa, the moon, was the leader of the women and chief oppressor of the men.

Löm, the sun, was the ablest hunter and bravest of the men. One day, as he was returning from a successful hunt, he hid behind some bushes and listened to the talk of two girls who were bathing, and from them he learned the whole kina secret: there were no ghosts or spirits, only the women themselves. Then a great rage seized Löm, and with other men whom he quickly aroused he rushed into the kina hut and killed all the grown women, so that only young and ignorant girls remained living. Since that day the kina ceremony has been celebrated by and for the benefit of the men, who thus keep the women in subjection. According to Martial (p. 213), this event transpired near Ushuaia at a time when the Ona were encamped there, so that the two tribes uprooted their social systems together.

Hanuxa, the leader of the women, escaped the general massacre, but she was badly beaten and immediately went to the sky where she became the moon, and today the result of her beating shows in the spots on her face. Discomfited and angry at what had transpired she planned revenge, and so she sent a great flood which covered all the earth except a few mountain-peaks where some people managed to survive. 
Later Löm took to the heavens and became the sun; his father, Taruwa Löm, became a star (Venus?); his brother, Akainix, became the rainbow.

Several variants of the flood myth have been recorded in Yahganland. Koppers himself speaks of another version in which Laxuwakipa, the ibex, in rage once sent a great cold spell so that vast quantities of snow fell. Later this all melted and a destructive flood followed. Cojazzi (1914, p. 31) records that among the central and eastern Yahgan they say the moon once fell in the sea. Hence the waters rose above everything but the loftiest mountainpeaks, where a few men and women took refuge with the animals. When the moon climbed back into the sky, the survivors descended and feasted on a dead whale that they found. Another version given by Cojazzi (loc. cit.) is that at the time of the flood Gable island became loose at the bottom and floated like a great ship, on which many were saved. According to Rev. Thomas Bridges (1884, p. 18) it was not the moon but the sun who fell in the sea and caused the flood.

\section{THE ALACALUF}

OF the Alacaluf, the second tribe of Canoe Indians found on Fuegian shores, only two members were seen by the writer. We therefore have no contribution to make on the Alacaluf. In general Alacaluf material culture was almost identical with that of the western Yahgan. They were, however, slightly better workmen than the Yahgan, so that at times their manufactures can be distinguished from those of their neighbors by the superior finish. For a useful summary of Alacaluf literature the reader is referred to Dr. Cooper's Bibliography.

\section{ARCHEOLOGY OF SOUTHERN TIERRA DEL FUEGO}

\section{CAMP-SITES}

THE shores of Beagle channel are dotted with the refuse of former Yahgan camp-sites. Composed of ash, bone, stone, and shell, and partly denuded of vegetation, these middens can be recognized from afar by their peculiar pearl-gray color, which differs from the green-gray rock and the brown-gray soil. They are found in sheltered places, where there is a beach for landing, kelp off-shore for mooring canoes, and where water and firewood are readily available. 
Examination of the surfaces of the middens reveals on top a series of pits which represent house-sites (fig. 103). These pits are from ten to fifteen feet in diameter, anywhere up to six feet deep (two feet being an average figure), and are circular in outline. Within the pits are traces of inhabitation-hammers, grease stones, etc.-usually today half engulfed by grass. Sometimes house-sites can be determined by small circular patches of unusually luxuriant grass fertilized by refuse, where various utensils can be found.

Like the Ona, the Yahgan did not speak of the dead or camp on a spot where death was known to have occurred. So certain house-pits on any given site must at times have remained unoccupied during many decades until the memory of one who died there had passed. The other pits were occupied but intermittently by the ever-roving Yahgan. Rarely did they pass even a few weeks at any given spot. This factor makes difficult any attempt to estimate the age of these great shellheaps by calculating their cubic contents in relation to the probable number of inhabitants.

The seaward slopes of the middens are fronting the beach and stand so close to the waters that they are occasionally dashed with spray, and many are undercut by the waves for a foot or two at the base (pl. XvI). From this, slight submergence of the land since the heaps were commenced may be argued. As the shellheaps are really great terraces built out from rising ground toward the beach, the seaward slopes are steep. This steepness is increased by the undercutting of the waves, which often cause small landslides. Thus the vegetation is removed and large sections of refuse are exposed for examination as well as if trenches had been dug. At the same time the shells, bone, and ash brought down to the beach by erosion are carried away by the sea, but the heavier stone implements are left at the base of the exposed face where they may be readily gathered.

An interior feature frequently exposed by erosion is that the shells have in places solidified into a breccia, which forms a floor a foot or so in thickness. These spots occur sporadically and at no uniform depth, and it was impossible to determine the special conditions which had given rise to them.

It must be remembered that, as the Yahgan had no cookingvessels, many of the shells in the refuse have been exposed to the action of fire and hence are calcined. From this it follows that they are very brittle and have been crushed by passing feet when 

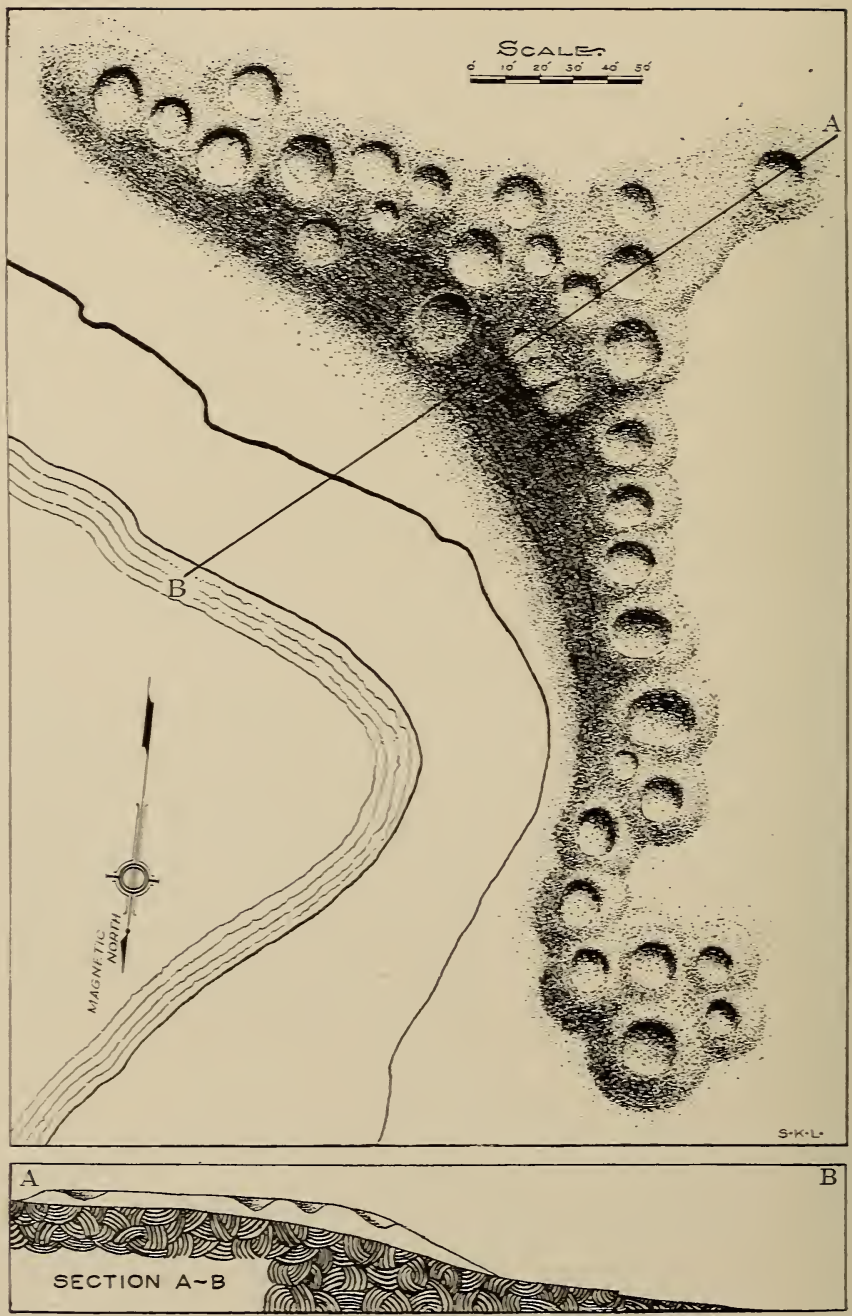

FIG. 96.-WVápisatumánakulum shellheap, Harberton, Tierra del Fuego. 


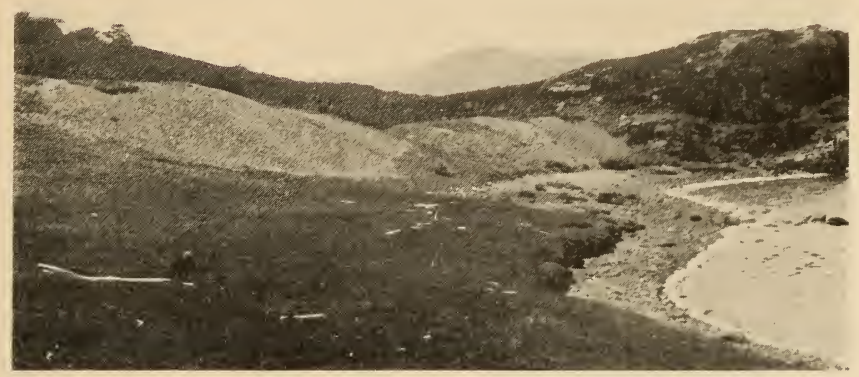

UKAIKAWAIA

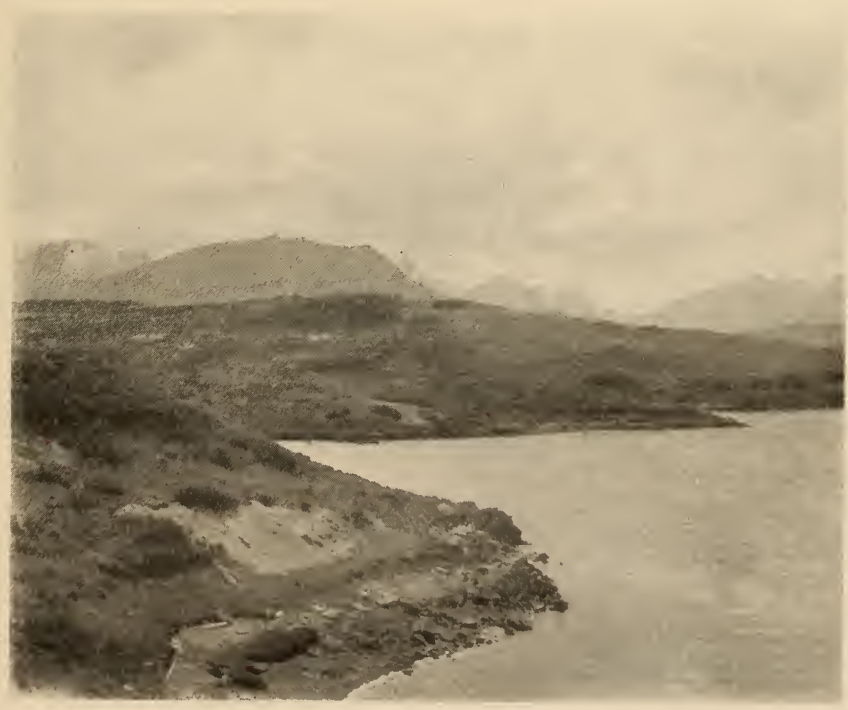

POMEGASHAKA ISLAND

GABLE ISLAND SHELLHEAPS 

they were on the surface and perhaps again centuries later by the weight of the superposed débris. Any theory that the rotting of shells is due solely to age would therefore seem to be untenable.

As a typical example of a Beagle Channel shellheap we shall describe a site (No. 2 in fig. 98) at Harberton. The Yahgan called it Wápisatumánakulum, meaning "the dead whale floated away," in reference to a long past yet tragic alimentary loss. A plan of this midden we show in fig. 96, while a photograph of the southern arm appears in fig. 97. As is usually the case, it stands just above the beach, here composed of shingle on which many shellfish can be picked up. The site fronts on a small cove facing eastward and thus is protected from the prevailing westerly winds and storms. The land has been cleared, but formerly the peninsula was forestcovered and supplied abundant firewood. There is now no water

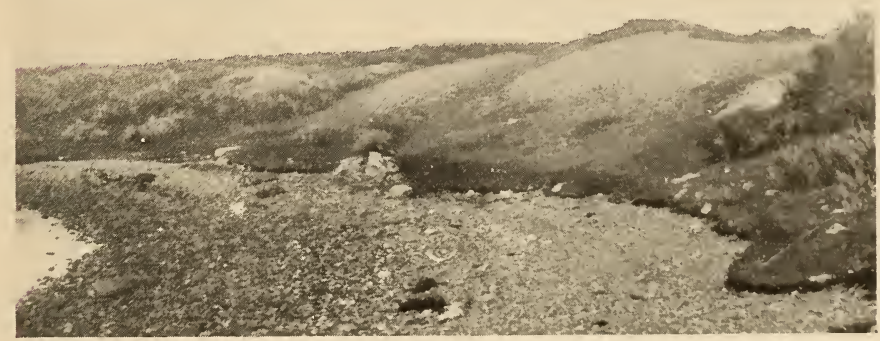

FIG. 97.-Wápisatumánakulum shellheap, Harberton, Tierra del Fuego.

supply nearby, but there may have been a spring on the peninsula which has dried up since the trees were cut down.

The thirty-odd house-sites pitting the upper surface of the shellheap face the cove in an irregular line. They vary greatly in size, for it seems that some of them have been abandoned for many years and partly filled in. The southern arm of the midden appears to have been longest inhabited, because additional housepits in front of the original line were placed in the rubbish as it was built out toward the sea. In some of the larger shellheaps as many as four or five rows of house-pits can be distinguished. 


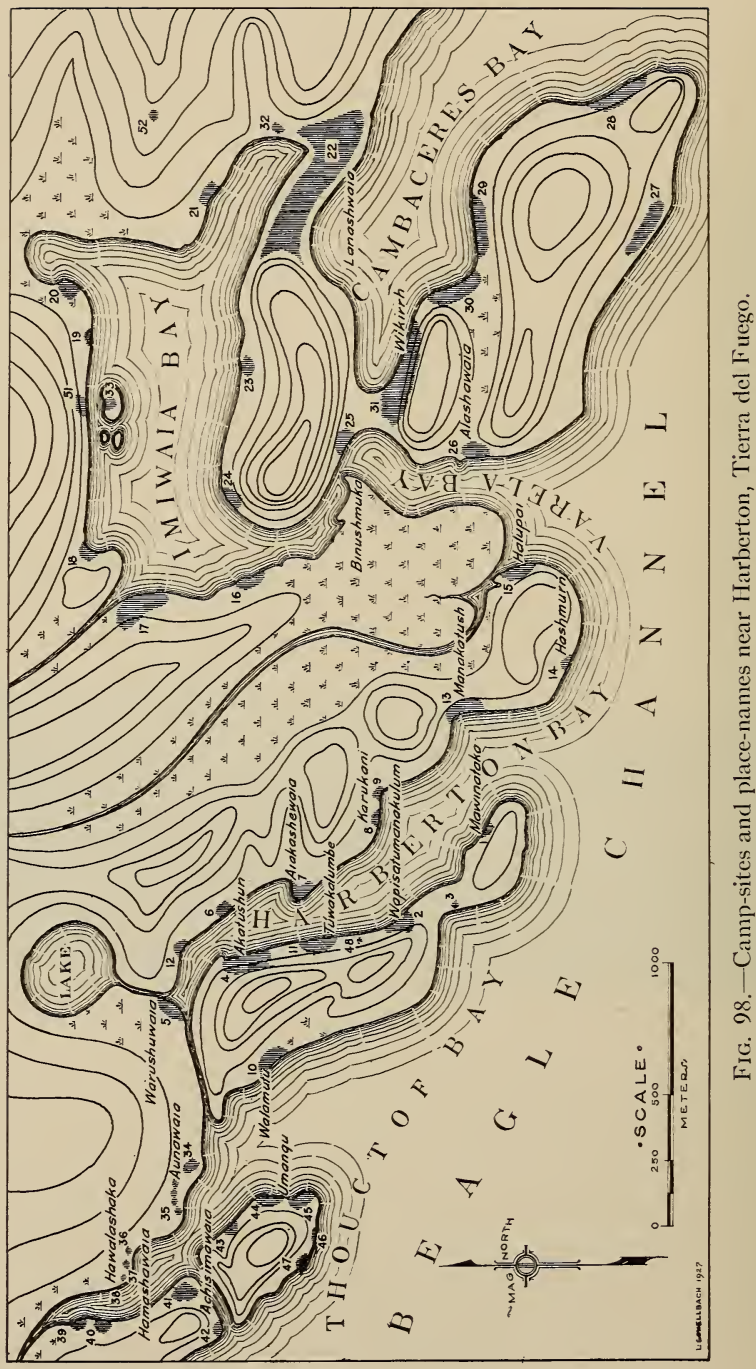


Excavation of a test pit (just behind the bushes at the right edge of fig. 97) yielded the following results:

1. The interior shells were found to be as solid as those on the surface.

2. Finely powdered wood-ash had not been washed away, although the drainage was good.

3. At a depth of a little more than a foot appeared a type of mussel-shell which could not be found on the beach locally. To this too great significance should not be attached, as it is well known that shellfish types migrate rapidly. Near San Julian in Patagonia the writer also found giant oyster-shells of a type not known locally.

4. Animal bones are common. At the bottom, long-bones, although wet and very cold (the frost often does not leave the ground till after Christmas), were as strong and sound as if only a year or two old. Vertebræ, ribs, scapulæ, etc., on the other hand, were usually badly rotted and often crumbled at a touch.

5. No distinction between stone objects on the surface and in the interior of the mounds could be detected.

6. The shellheaps throw little light on the culture or antecedents of the Yahgan except for two points:

a. It seems that no other people except the Yahgan erer occupied southern Fuegia.

$b$. It seems that the Yahgan have lived there for a very long time.

On several sections of the coast of Beagle channel a careful examination of the shellheaps was made, because, while an individual mound might give no clue to the density and antiquity of the migratory population in pre-European times, it seemed that a group of mounds might do so. The districts thus studied were: (1) the adjacent Varela, Cambaceres, Imiwaia, Harberton, and Thouctof bays; (2) the channels between Gable island and Tierra Mayor; (3) Puerto Mejillones and the vicinity on Navarin; (4) Róbalo bay on Navarin island. Other localities on Beagle channel or on the islands down to the Horn might equally well have been selected, but the above-mentioned places were convenient and accessible. The location of each shellheap was carefully plotted and an accurate count of the hut-pits made at each site. These counts usually were made by two observers independently to insure their correctness.

Turning now to fig. 98, a map is shown which locates fifty-two shellheaps. In an air-line this map extends from east to west a little more than three miles, but the ever-curving shoreline covers 
approximately sixteen miles. Fresh water flows into all of these bays and is found in a pond on Cambaceres peninsula behind middens 29,30 , and 31 ; small springs are encountered in several places. Firewood is obtainable anywhere except on the marshes flanking the Varela river. Shellfish abound everywhere except in the upper part of Imiwaia bay. Excellent shelter in case of storms is amply provided, and, except in the roughest weather, it is possible to round the various peninsulas in a canoe owing to the heavy bands of kelp that encompass them off-shore. It is an ideal region for a people materially equipped to face life as were the Yahgan.

The number of house-pits counted-1215-indicates that the Yahgan fully appreciated the advantages of the district. The size of each individual camp-site is shown in the following table:

TABLE VI.-YAHGAN CAMP-SITES AND HUTS NEAR HARBERTON

\begin{tabular}{|c|c|c|c|}
\hline CAMP-site & Number of Huts & CAMP-SITE & Number of Huts \\
\hline \multirow{25}{*}{$\begin{array}{r}1 \\
2 \\
3 \\
4 \\
5 \\
6 \\
7 \\
8 \\
9 \\
10 \\
11 \\
12 \\
13 \\
14 \\
15 \\
16 \\
17 \\
18 \\
19 \\
20 \\
21 \\
22 \\
23 \\
24 \\
25 \\
26\end{array}$} & \multirow{25}{*}{$\begin{array}{c}12 \\
35+ \\
2 \\
40+ \\
50+ \\
12 \\
31 \\
8 \\
2 \\
43 \\
50+ \\
5 \\
43 \\
7 \\
25 \\
18 \\
67 \\
15 \\
2 \\
10 \\
9 \\
130+ \\
13 \\
15 \\
21 \\
35+\end{array}$} & 27 & $16+$ \\
\hline & & 28 & $22+$ \\
\hline & & $\begin{array}{l}29 \\
30\end{array}$ & $\frac{26}{75}$ \\
\hline & & $\begin{array}{l}30 \\
31\end{array}$ & $114+$ \\
\hline & & 32 & 5 \\
\hline & & 33 & $8+$ \\
\hline & & 34 & 14 \\
\hline & & 35 & $22+$ \\
\hline & & 36 & 6 \\
\hline & & 37 & 5 \\
\hline & & 38 & 5 \\
\hline & & 39 & $10+$ \\
\hline & & 40 & 11 \\
\hline & & 41 & $25+$ \\
\hline & & 42 & \\
\hline & & $\begin{array}{l}43 \\
44\end{array}$ & 14 \\
\hline & & $\begin{array}{l}44 \\
45\end{array}$ & $\begin{array}{l}28 \\
27\end{array}$ \\
\hline & & 46 & 6 \\
\hline & & 47 & 13 \\
\hline & & 48 & 13 \\
\hline & & 49 & 4 \\
\hline & & 50 & $25+$ \\
\hline & & 51 & $\begin{array}{l}8 \\
4\end{array}$ \\
\hline & & & \\
\hline & & $\begin{array}{l}\text { Total } \\
\text { Average }\end{array}$ & $\begin{array}{r}1215+ \\
23+\end{array}$ \\
\hline
\end{tabular}




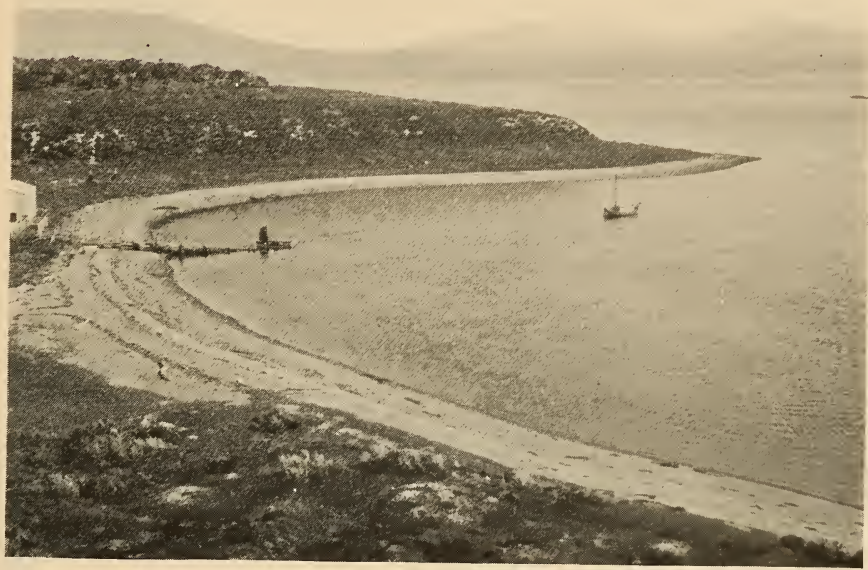

SHELLHEAP 25 , VARELA BAY AND NAVARIN ISLAND

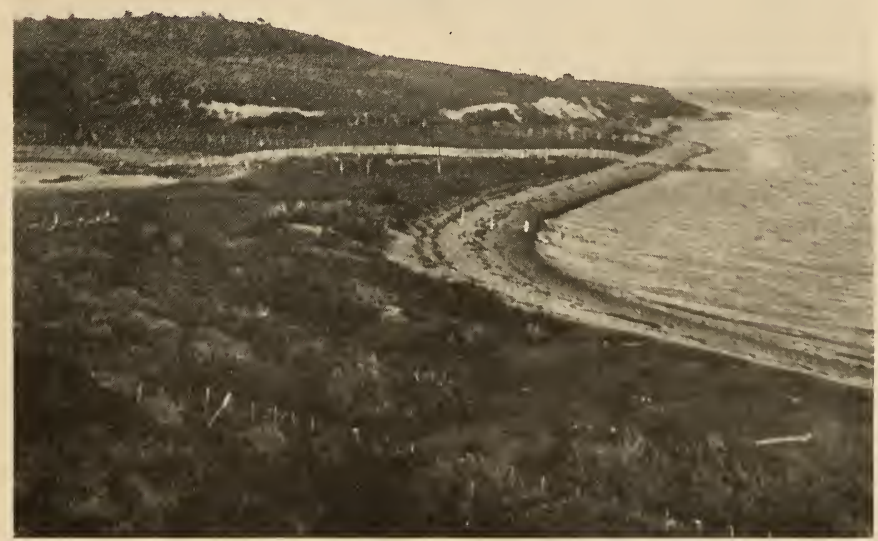

LANÁSHWAÍA SHELLHEAP, CAMBACERES BAY AND PICTON ISLAND SHELLHEAPS 
The densest population in this group centered on Cambaceres bay, where 367 hut-pits were counted. The camp-sites on the south side, known to the Indians as Wíkirrh, display unusually deep house-pits, while Lanáshwaía (pl. xvII, $b$ ) on the opposite

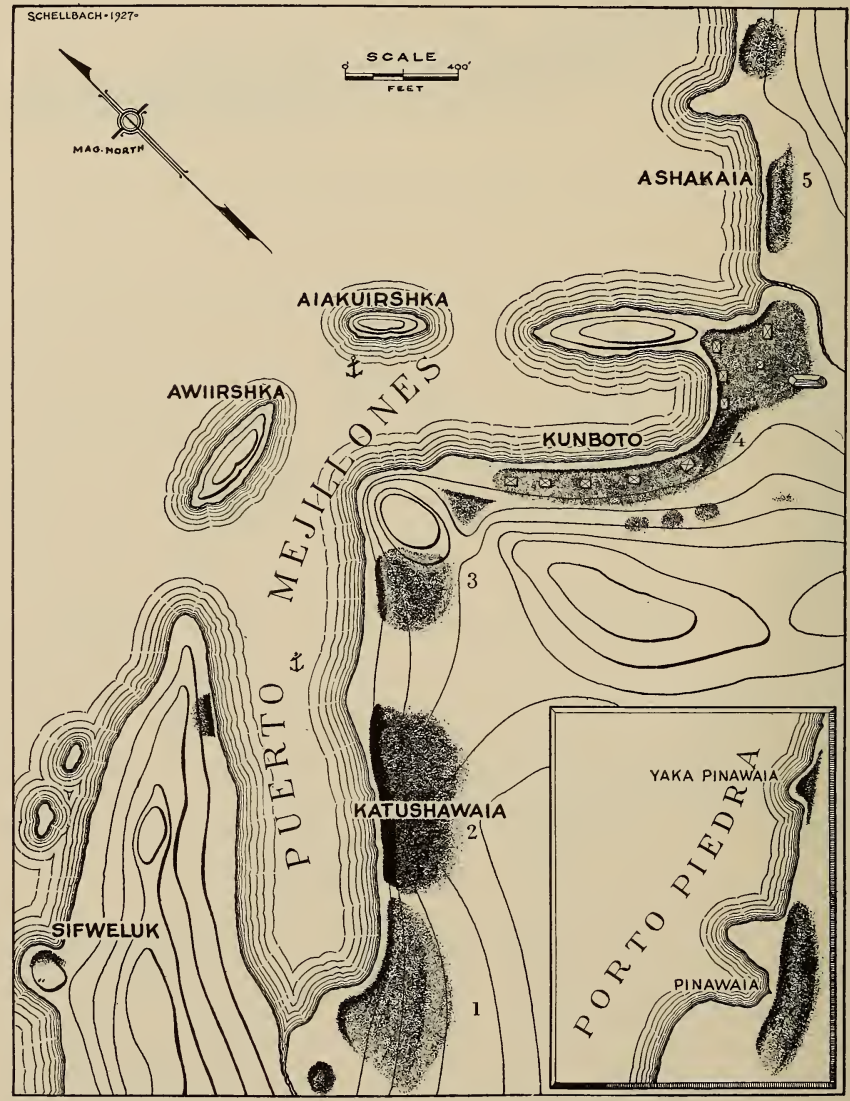

FIG. 101.-Puerto Mejillones and Porto Piedra shellheaps, Navarin island.

shore was evidently a later or less popular settlement, as the pits are relatively shallow.

About 1880 there occurred here one of those tragedies which must have been not uncommon among the Yahgan. A dead 
whale floated ashore, and Ona and Haush came to join the local Yahgan in the ensuing feast. But all were poisoned by the meat and most of the company died-so many indeed that the survivors fled, leaving the bones of their relatives to whiten the beach for many years afterward.

Imiwaia bay (pl. III, lower) is completely landlocked and the tide runs strongly through the narrow entrance. Hence it is not readily accessible. The large heap No. 22 (Lanáshwaía) backs on it, but the principal access to this camp must have been from the Cambaceres side. In the northwest corner, however, there is a large and very deep midden (No. 17), of which we give a section in fig. 99. This is conveniently situated beside a small stream, and its approach from the entrance channel is sheltered from the prevailing westerly winds. Heap 51, on the north shore, was evidently abandoned long ago, as large beech-trees had grown on top of the refuse- the only case of this kind observed by the writer. The upper end of Imiwaia bay is shallow and muddy, and not suited for camp-sites.

Harberton bay, the headquarters of the Bridges' sheep ranches on the south coast, is ideally suited for camp-sites, and no fewer than fifteen were inspected. Of these, No. 2, which has been described above (page 181), and Nos. 4, 5, 11, and 13, are large and important. No. 6 was occupied by Indians in the summer of 1923-24. This bay well illustrates the Yahgan tendency to give every few hundred yards of coast-line a separate name.

The Thouctof bay middens, although numerous, are for the greater part small, and offer no peculiarities.

The other groups of shellheaps examined differ in no material way from the Harberton cluster. In fig. 100 we show the settlements along the channel between Tierra Mayor and Gable island, a sheltered, well-watered, and well-wooded region, which affords a convenient resting place at the end of an exposed strip of coast to the westward. The size of some of the middens is as follows:

\begin{tabular}{c|c|c|c}
\hline \hline Camp-site & Number of Huts & Camp-site & Numiber of Huts \\
\hline 4 & 6 & 9 & 8 \\
5 & 34 & 10 & 40 \\
6 & 7 & 11 & 12 \\
7 & 1 & 12 & 8 \\
8 & 8 & 13 & 12 \\
\hline
\end{tabular}


Of these, No. 4 was occupied by the Yahgan during the summer of 1923-24. No. 10, seen in pl. xvi (upper view), was an unusually deep midden conveniently situated beside a spring.

Another group of Yahgan camp-sites, at Puerto Mejillones and at Porto Piedra along the coast to the westward, is seen in pl. XI and mapped in fig. 101. Here practically all the Yahgan now come to pass the winter months, living on the proceeds of the skins they have sold during the preceding summer or on their wages earned on various sheep ranches. They dwell in poorly constructed houses built of ill-fitting boards. The size of the shellheaps is as follows:

\begin{tabular}{c|c|c|c}
\hline \hline Camp-site & Number of Huts & Camp-site & Number of Huts \\
\hline 1 & 55 & 5 & 20 \\
2 & 50 & - & 6 \\
3 & 25 & Pinawaía & 75 \\
4 & 10 & Yaka Pinawaía & 12 \\
\hline
\end{tabular}

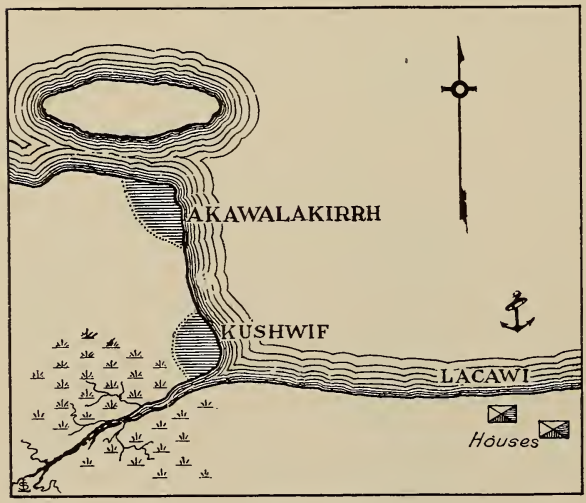

FIG. 102.-Róbalo bay, Navarin island, showing the location of shellheaps.
Puerto Mejillones really is one continuous site, and the original number of housepits was much greater than that given above, but they have been trampled flat by cattle. The greatest depth of deposit was seen at site 2 , where the débris appeared to be 12 or 15 feet thick (pls. XI, XVIII).

One of the Porto Piedra shellheaps is of unusual size. This site today is crowned by several modern houses and the house-pits have been trampled down by cattle.

At Róbalo bay of Navarin island are two large shellheaps containing 43 and 56 house-sites. The one called Akawalakirrh in 

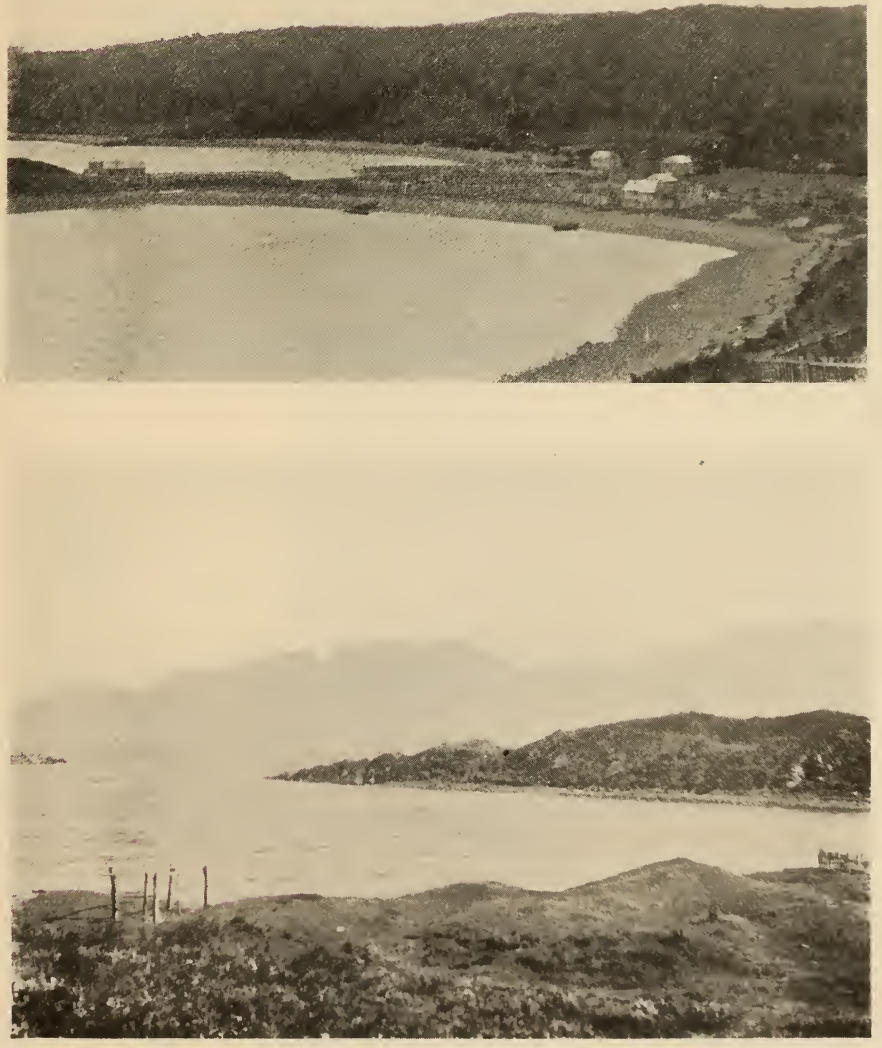

KUNBOTO SHELLHEAP, PUERTO MEJILLONES, NAVARIN ISLAND 

fig. 102, pictured in fig. 103, is an exceptionally deep midden; it towers over the head, although situated on flat land. On the seaward side this heap has been undercut by the waves, which have exposed a large and solid layer of breccia near the bottom of the refuse.

\section{ARCHEOLOGICAL FINDS}

We have discussed at some length the nature of the Yahgan camp-sites and now must take up the very primitive remains to be found in their débris.

First, however, we should remark that the Yahgan, even today when metal tools are readily available, show a marked tendency to use anything which comes to hand, be it a shell fragment or a
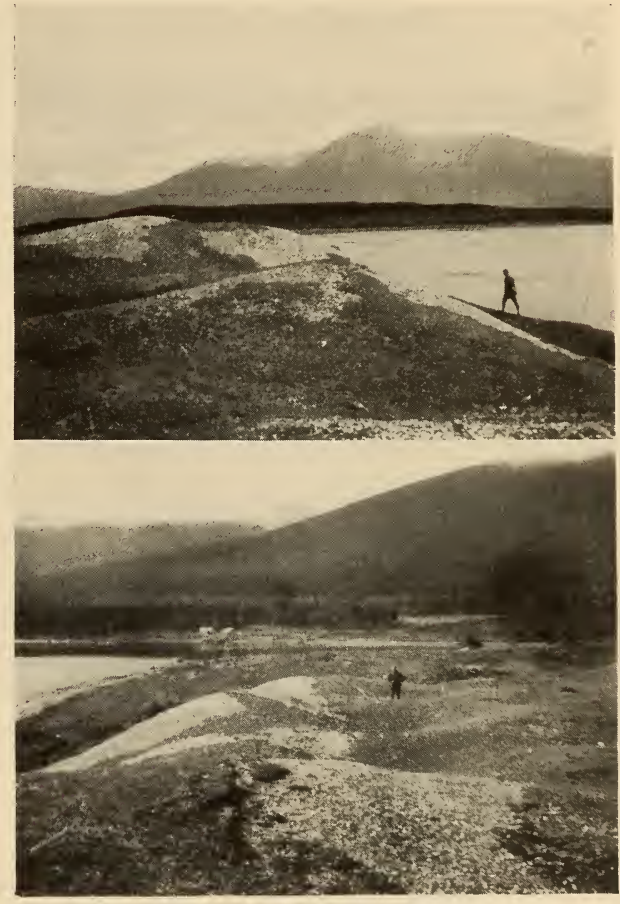

FIG. 103.-Akawalakirrh shellheap, Róbalo bay. flint chip. Consequently, in the old days they must have accomplished much of their handiwork with such eolithic implements, and probably used their more formal tools principally for the arduous or very delicate tasks. This tendency is brought out by the small number of really well-wrought implements which have come from the middens in comparison with the comparatively great number of crude or half-finished ones.

The specimens illustrated were picked up on the seaward slope of various middens where the undercutting of the waves had 
disturbed the surface. In consequence there is no evidence from what level they had come originally.

1. Knives.-Chipped blades apparently intended for use as knives normally are leaf-shape, from two to five inches long, and, unlike the Ona knives, are worked on both sides. In pl. xIx, $a, b$, are shown two examples of large knives, each with a small nock near one end to assist in the hafting. Smaller blades appear in $c, d$, and $e$ of the same plate; these may well have served as knives or conceivably might have been barbless tips for spear or arrow.

2. Scrapers.-Although two kinds of scrapers come from the shellheaps, neither is very common, probably because the Yahgan did most of their scraping with shell. In fig. 104, $a$, we show a

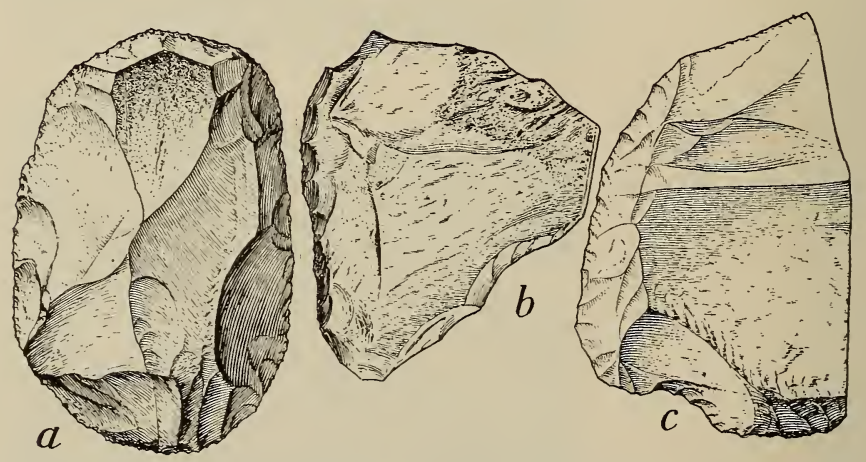

FIG. 104.-Scrapers from Wápisatumánakulum, Harberton, Tierra del Fuego. Length of $a, 2 \frac{3}{4}$ in. $\quad(14 / 3977)$

disc scraper with a cutting edge completely encircling it. Fig. 104, $b$ and $c$, both seem to be scraper-blades fashioned for hafting in the manner of the modern Ona flesher. One of them $(c)$ has a recessed curve at one end of the blade; this may have been intended for cleaning bones, or possibly it served merely to give additional grip for the lashings.

The Yahgan with whom the writer came in contact denied that they had ever used this type of scraper. Mr. William Bridges however, stated that he had seen them employed, an assertion borne out by the discovery of these archeological specimens. 

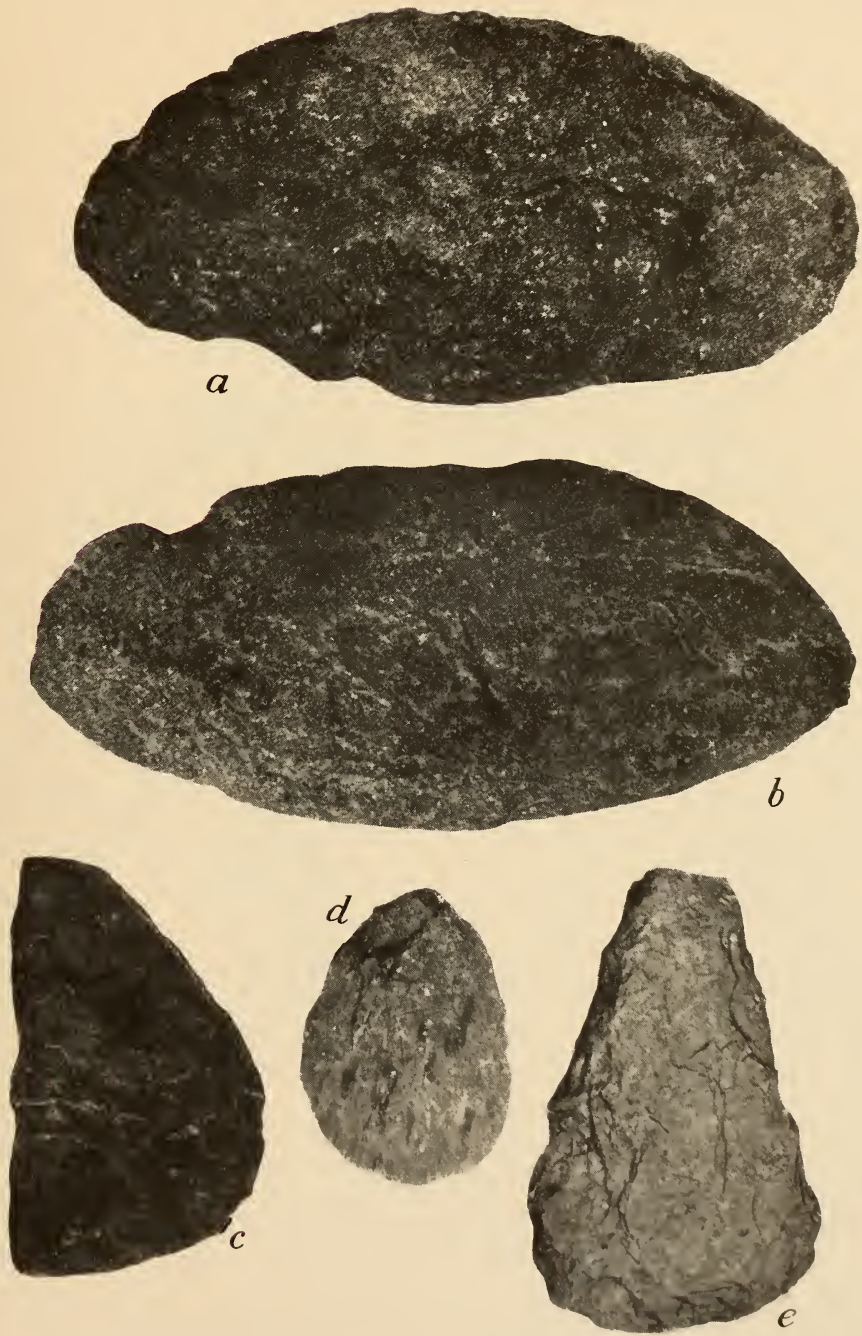

STONE BLADES, WÁPISATUMÁNAKULUM, haRBERTON, TIERRA DEL FUEGo LENGTH OF $b, 6$ IN. (14/3977) 

3. Spearpoints.-Four spear- or arrow-points are illustrated in fig. 105. Of these, $a$ is a triangular blade with barbs but no tang,
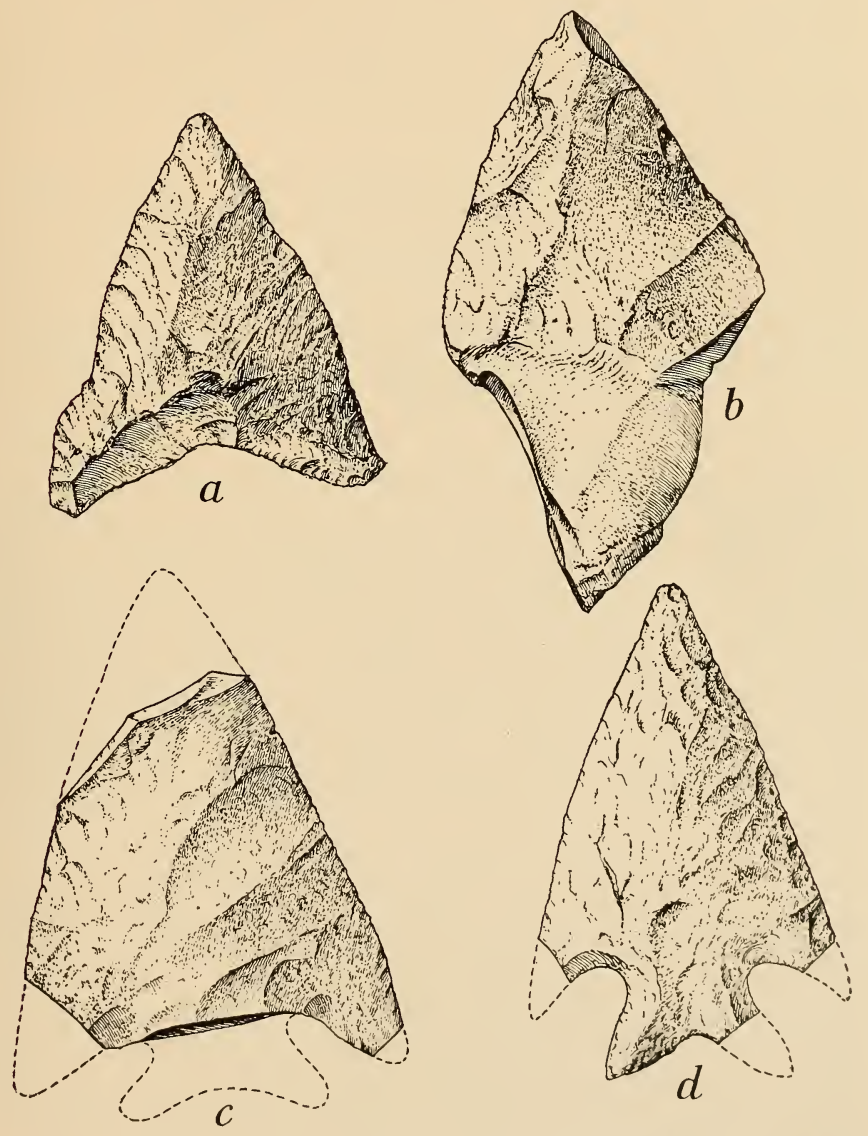

FIG. 105.-Stone blades. $a$, Near Gable island $(5 / 8544) ; \quad b, c$, Wápisatumánakulum, Harberton (14/3977); $d$, Róbalo bay, Navarin island (14/4002). Length of $b, 3$ in.

while $b$ has a tang but no barbs. However, $c$ and $d$ had both tang and barbs, and this seems to be the dominant Beagle Channel 
type, because several other specimens have been published by Bove (1883) and Hyades (1891). The general shape of these points is similar to that of modern Ona arrowpoints and ancient stone points from eastern Tierra del Fuego. Yahgan workmanship, on the whole, is cruder than Ona, and to the writer's knowledge no points have been found on the south coast equal to the delicate blade illustrated in fig. 40 .

4. Hammerstones, Anvils, Grease Stones.-Every Yahgan family carried an oval water-worn stone which was used for a variety of purposes, such as hammering. These stones (fig. 70) may be picked up at every ancient camp-site.

5. Bone Tools.-Bone tools of modern type sometimes are found in shellheaps under conditions implying considerable antiquity.

\section{Age of Archeological Remains}

The age of the archeological remains on Beagle channel is a problem that has intrigued the writer from the moment of his arrival there, and every effort was made to collect data for its solution. It should be frankly stated at the outset of this discussion that there is no exact answer, but it is nevertheless possible to deduce an approximate figure. There are several methods by which the problem may be attacked; thus we shall discuss (1) the variations in Yahgan speech, (2) known historical movements in other parts of South America, (3) the internal evidence of age in Fuegian shellheaps, and finally (4) their probable rate of accumulation.

\section{ANTIQUity OF THE YAHGAN DIALECTS}

As explained above, the Yahgan spoke five distinct though mutually intelligible dialects. This is rather surprising because (a) they were a roving people occupying only a small territory, (b) they were exogamous, and (c) the total population was only about 3000 individuals. Assuming, as seems probable, that the Yahgan reached Tierra del Fuego more or less as a unit speaking a single tongue, how long did it take them to modify their language in five distinct ways?

In the more civilized parts of the world linguistic change also has taken place, and, because language is not only spoken but written, the archaic forms are preserved and can be studied. For instance, the breaking up of Latin into the modern Romance 
languages, mutually intelligible only to a very slight extent, can be observed and checked in various stages. In this instance the Latin tongue was grafted on the native speech of various conquered peoples, who undoubtedly pronounced it from the beginning with local flavor so that the separation into dialects began at the outset, its course being retarded by the educated classes. Latin, however, was spoken over a very wide area with relatively poor communications, hence there existed every facility for rapid linguistic change.

The contrast between this condition and that of the Yahgan is obvious. We should not expect the Yahgan dialects to differ nearly so much in a given time as the Romance tongues. In fact, granted the circumstance, it is surprising that there were any Yahgan dialects at all. The very presence of these Yahgan dialects shows that the tribe had remained stationary as a whole for a great many centuries at least.

\section{CULTURAL AND HISTORICAL EVIDENCE}

The Yahgan are the southernmost unit of a group of primitive fisherfolk who at various times have lived on the west coast of South America. In southern Peru this fishing population was displaced by the rise of the typically Peruvian agriculturists who later built the great structures seen in ruins today on that coast. While there is yet no exact chronology for Peruvian archeology, the two leading authorities, Tello ${ }^{1}$ and Uhle, $^{2}$ agree that this event must have materialized at least 2000 years ago in order to explain the known stratigraphy of Peruvian remains.

It is a far cry from Peru to Tierra del Fuego, but in the displacement of the Peruvian coastal population there is an ostensible cause for the general shunting to the south of all the coastal peoples. If, as we shall presently show, Fuegian camp-sites give evidence of occupancy at that remote period, then we may at least tentatively consider that the displacement of the Peruvian fisherman and the settlement of Fuegia are correlated, because this change of population in Peru is the only remote migration in South America which archeology has definitely yielded to the realm of history.

In Chile there seems to have taken place a similar displacement of the early population by the Araucanian tribes. Stratigraphical

\footnotetext{
${ }^{1}$ Julio C. Tello, Introducción á la Historia Antigua del Peru, Lima, 1922.

2 Max Uhle, Los Principios de las Antiguas Civilizaciones Peruanas; Boletin de la Sociedad Ecuatoriana de Estudios IIistoricos Americanos, IV, no. 12, Quito, 1920.
} 
studies clearly prove this. Cooper (1917a) has pointed out the general resemblance of the earlier culture at such sites as Taltal with the historic culture of the Magellanic archipelago. He lists as features shared in common with the Canoe Indians: the use of spear and harpoon, and disuse of the bow, nets, coiled basketry, combs, shell necklaces, and supine burial. To this should be added the strikingly close resemblance in physical type. Granted this relationship, however, we lack sufficient evidence to translate it into historical terms, for we cannot say how long ago the Araucanians displaced the earlier culture. Possibly the change in population in coastal Peru pushed the Yahgan into Tierra del Fuego, while a later shift on the coast of Chile may have been responsible for the presence of the Alacaluf; but this is mere conjecture.

\section{INTERNAL EVIDENCE OF AGE IN FUEGIAN SHELLHEAPS}

For several reasons an inspection of Beagle channel shellheaps leads to the conclusion that they mark camp-sites inhabited for many centuries. We list these reasons as follows:

A. Bulk.-The first and most obvious sign of age is the very size of the refuse-heaps. Clearly it must have taken a great many centuries to deposit such vast masses of débris. Below we have attempted to calculate the cubic contents of the refuse near Harberton.

B. Breccia.-The formation of breccia in the lower levels of middens, to the writer is not a positive criterion of great age, because so little is understood of the reasons which cause shells to unite in a solid mass. If some climatic change of temporary nature caused the formation of hard floors at one time in all shellheaps, then a valuable means of determining relative age would be available, because the depth of the breccia varies.

c. Trees.-In one instance, shellmound 51 in fig. 98, large trees were found growing on top of an ancient camp-site. This midden was discovered on the afternoon before our departure for the north, so that there was no opportunity for cutting down a tree to count the rings and thus learn how long ago the site was abandoned. The site is a small one, with only eight house-pits situated at the base of a steep slope rising sharply from the beach.

D. Land Subsidence.-Many instances of the undercutting of the base of middens on both shores of Beagle channel (as can be seen 
in $\mathrm{pl}$. XvI) seem to indicate slight submergence of the land since the first settlement. This conclusion is not in agreement with that of Lovisato (1885), who believes that the Elizabeth Island shellheaps have been elevated several meters. N. O. G. Nordenskjöld concludes that Tierra del Fuego has risen about sixty meters since relieved from the pressure of general glaciation. The slight and recent submergence noted by the present writer may be a local adjustment since the general rising of the land.

E. Animal Bones.-Considerable age may be argued from the presence of badly rotted animal bones in a Harberton shellheap. In general this is an almost worthless criterion of age, but in Tierra del Fuego, where the frost scarcely leaves the ground, all animal remains tend to be preserved. The body of a sailor buried in the South Shetland islands was exhumed after several years with the flesh in perfect preservation, ${ }^{1}$ so that Beagle channel is only 400 miles from land where animal remains do not decay at all.

\section{RATE OF ACCUMUlation OF REFUSE-HEAPS}

Mr. N. C. Nelson ${ }^{2}$ has most ingeniously worked out the probable age of California shellheaps by determining three factors: $(a)$ the total former population, $(b)$ the bulk of the débris, and $(c)$ the probable daily rate of deposit. While lacking the concrete data to apply this method of determining age as accurately as has Nelson, nevertheless we shall persist with it, because a definite figure can be reached by this method, a figure not incompatible with criteria for age already discussed. We therefore shall examine the three factors above enumerated, which are not without interest in themselves.

Nelson's estimate of the total population was simply obtained, because he dealt with a permanent village-site. In Tierra del Fuego, however, no site was occupied for more than a brief period at a time, so the population of any camp or even the portion of the year it was occupied cannot be exactly determined. Yet, although the Yahgan were rovers, they wandered in rather fixed limits, hence the number of inhabitants for an area might be calculated in relation to the food supply.

Nelson assumed that each Californian family consists of six individuals. This number might be thought too large for the

\footnotetext{
${ }^{1}$ Geographical Journal, pp. 65-66, London, 1830.

5 Shellmounds of the San Francisco Bay region; Univ. Calif. Pub. Amer. Archcol. and Ethnol., viI, no. 4, p. 345.
} 
Yahgan family, but Martial (p. 215) assures us that six individuals was the average seen in more than 200 canoes. More specifically he states that 388 people of all ages were counted in 65 canoes, which results in an average of 5.97 .

How much shore-line did an average family need to keep it supplied with mussels, conchs, limpets, crabs, fish, and sea urchins? Let us assume that they required from a third to two-thirds of a mile. This does not seem unreasonable when we recall that meat and vegetal foods also formed part of their diet. This would mean that around Thouctof, Harberton, Varela, Imiwaia, and Cambaceres bay on the average there stood 12 to 24 wigwams, containing 24 to 48 families, or 144 to 288 individuals of all ages. Furthermore, from one to two percent. of the house-sites would always be occupied at any given moment. That house-sites were tabooed where death had occurred would not affect this calculation over many years, because these places were reoccupied when the deceased had been forgotten.

A means of checking this broad estimate of the population exists in the census of the Yahgan ${ }^{1}$ made by Rer. Thomas Bridges. The figures he gives are:

$\begin{array}{lr}\text { Navarin island } & 237 \\ \text { Hoste island } & 258 \\ \text { Tierra del Fuego (south coast) } & 218 \\ \text { Picton, Lennox, New islands } & 55 \\ \text { Wollaston and Hermite islands } & 65 \\ \text { Gordon island } & 36 \\ \text { Cuguawaluf (Londonderry?) island } & 20 \\ \text { Other western islands } & 60\end{array}$

From this table it appears that in 1883 there were 218 Yahgan on the south coast of Tierra del Fuego between Spaniard harbor and Brecknock peninsula. This figure represents a much reduced population, and it must be multiplied by $3+$ to determine the population in the days when the whole tribe numbered 3000 . We thus find that the total population of this area exceeded 654 . As the western part of Beagle channel is precipitous and pierced by glaciers, most of the inhabitants lived east of Yendegaia bay, and in fact centered on Ushuaia and Harberton. Hence the assumed population of 144 to 288 for the Harberton and adjacent bays means that between twenty-two and forty-four percent. of the

\footnotetext{
${ }^{1}$ Published in the South American Missionary Magazine for 1884, p. 224.
} 
total population of the south coast of Tierra del Fuego resided there. The true figure probably falls between these limits, so we may continue to assume that the average population of Varela, Harberton, Thouctof, Cambaceres, and Imiwaia bays was between 144 and 288 individuals.

To measure the volume of shellheaps accurately would be an endless task. However, the average house-pit with its adjacent share of débris, on the basis of exact measurements, covers approximately 570 square feet. The average depth of deposit runs about two feet, so that each house-pit accounts for 1140 cubic feet of rubbish, and the 1215 house-pits on Thouctof, Harberton, Varela, and Imiwaia bays represent 1,385,100 cubic feet of deposited material.

In order to find the daily rate of deposit, Nelson assumed that each individual ate fifty shellfish a day. By trial he proved that 5000 shells, the daily allotment of 100 people, can be packed into 1200 cubic inches which may be raised to a cubic foot when ash, earth, and animal bones are added. These figures were worked out for California Indians, but we believe that they also will apply to the Yahgan, for if they ate less vegetal food they ate more meat, which would not greatly change the proportion of rubbish.

We may now state our problem and its answer succinctly as follows:

(a) Probable number of inhabitants: 144 to 288 .

(b) Total contents of shellheaps: $1,385,100$ cubic feet.

(c) Probable rate of deposit: 1.4 to 2.9 cubic feet per day.

(d) Number of years sites were inhabited: 1300 to 2600 years.

In criticism of the age deduced for the shellheaps we may point out that while no factor-even the number of heaps in the area discussed and the number of house-pits in those visited-is certain, nevertheless there is no reason that the errors should be cumulative. At any rate, the application of Nelson's method to Tierra del Fuego shows that it has been settled a very long time. To the writer it seems that the larger limit selected for the population is too great, and that the bulk of the shellheaps might well be considerably greater than estimated, because the assumed depth is certainly a very conservative figure.

In view of these figures and the other criteria for age already adduced, it seems not unwarranted to believe that the south coast of Tierra del Fuego has been occupied for 2000 years at least. 
PART III

\section{COMPARISONS AND CONCLUSIONS}

\section{ORIGIN OF THE FUEGIANS}

$7 \mathrm{HE}$ origin of the tribes of Tierra del Fuego is obscured in the mists of the past, but study of their physical type, their language, and their cultural development make it possible to trace them far to the north. Evidence of all kinds blends in agreement that the Yahgan and Alacaluf, the Canoe Indians, came down the west coast of South America, where the remains of their ancestors or relatives can be identified at least as far north as Peru. Furthermore, the Foot Indians, Ona and Haush, clearly are connected directly with the inhabitants of Patagonia and perhaps with the tribes of the Chaco and the Amazon valley. The evidence on which these conclusions rest we shall examine in detail.

1. Somatological Evidence.-Along the west coast of South America a short-statured, dolichocephalic strain repeatedly has been discovered under conditions indicating great antiquity. These people, if not the direct ancestors, may well have been collateral relatives of the Canoe Indians of Tierra del Fuego and Patagonia Occidental. This physical type, for reasons too complex for discussion here, ${ }^{1}$ is now regarded by discreet and cautious students as the most ancient human strain in the New World. The anthropometry of the Yahgan, herein discussed, indicates that, while they may basically belong to this physical group, they have acquired a short-statured and brachycephalic mixture, generally regarded as the second type to reach the Western Hemisphere. Somatological evidence indicates then that the Yahgan are a cross of the two most ancient types of man in the New World.

The Ona, on the other hand, mesocephalic like the Yahgan, but exceedingly tall, appear to be a cross of two tall strains and of varied head forms. The dolichocephalic factor in this tribe may be

${ }^{1}$ This subject has been covered by Dixon (1923), and by Hrdlička in Proc. Amer. Philos. Soc., LxV, pp. 157-160. 
of the early variety correlated with short stature, but proof is wanting. At any rate it seems obvious that relationship exists between the Ona and the Tehuelche, legendary giants of Patagonia. To be sure, the modern Tehuelche are brachycephalic, but their heads may be shortened by deformation and the use of a cradleboard, for ancient skulls from Patagonia are mesocephalic or even dolichocephalic.

2. Linguistic Evidence.-Connection between either the Yahgan or Alacaluf tongue and any other linguistic group has not been demonstrated. Ona and Haush are clearly related to each other and to the Tehuelche of Patagonia, thus forming a linguistic family.

3. Culture Evidence.-For the Canoe Indians of Tierra del Fuego we have a well-developed cultural chain leading northward along the west coast of South America. From the Yahgan culture to the Alacaluf, and from the Alacaluf to the Chono, more than 600 miles north of the Straits of Magellan, there is but little change in material equipment or manner of life. From Chiloe island far northward archeological remains underlying those of the historic tribes of the coast may be attributed to the ancestors or collateral relatives of the Fuegians. Skeletal remains of the early shellheap culture are dolichocephalic and short of stature, and so belong to the principal strain of the Canoe Indians. Material culture of the coast north of the Chilean islands cannot closely resemble that of Fuegia, for the climate and character of the country rapidly change from moist woodlands to arid desert; yet, as we have already pointed out (pp. 193-194), significant parallels exist. To these we may add that in the balsa with high pointed ends, typical of the desert coast, we have a possible prototype for the Fuegian canoe, shaped like the new moon. On the Atlantic coast of South America there are no sea-going canoe Indians south of the equator.

The Foot Indians, Ona and Haush, we have shown to be linguistically allied with the Tehuelche of Patagonia. Physical resemblance between the tall Tehuelche and Ona tribes is striking. Among cultural features found in common we may list the skin robe, skin petticoat, man's bag, moccasin type, house type, transversely hafted scraper, skin water-bag, use of fungus for tinder, tattooing, bow and arrow, etc. Clearly this evidence indicates that the three tribes lived together on the Patagonian plateau long enough to develop a typical culture in common. A further proof 
that the Ona once dwelt in Patagonia, according to Mr. William Bridges, is that they have a legend concerning a large flightless bird, which obviously refers to an ostrich, or rhea, found in Patagonia but not in Tierra del Fuego.

We can trace then with reasonable certainty the Foot Indians of Tierra del Fuego to the Patagonian plains, but to say when and whence they came to Patagonia is a difficult problem, to solve which but slender evidence exists. I am inclined to see relationship with the tribes of the Chaco and the upper Amazon valley. This relationship is probably rather with an earlier population than with the historic peoples. Mysterious remnants of these earlier settlers exist in the upper Amazon valley. Apparently they are held by the dominant population in a position intermediate between slaves and pet animals. Little is known of their manner of life, except that they are nomadic hunters using the bow and arrow but having no canoes or houses. If a list of culture parallels between the Amazon tribes and Fuegian Foot Indians be made, the features in common, it will be found, with but few exceptions are those we shall show presently to be basic to all Indian culture. It therefore follows that no exact deductions can be made from existing data, chiefly characterized by the primitive state of all the peoples involved. We find exceedingly significant, however, the parallel development of masked dances and initiation in each region, a similarity already indicated (page 95).

4. Chronological Evidence.-One can but wonder when and how the natives reached Tierra del Fuego. The first-comers doubtless were the Yahgan, for we have advanced positive evidence that they had occupied their historic territory for somewhere around twenty centuries. Next to arrive in all probability were the Alacaluf, unless it is thought that the Yahgan, to reach southern Fuegia, pushed through the Alacaluf country after its occupancy. Beauvoir (1915) records a tradition among the Ona that they reached Tierra del Fuego by a land bridge, but afterward a cataclysm formed the Straits of Magellan and isolated them. This tale will hardly bear the scrutiny of geological opinion, and so we are forced to the conclusion that the Foot Indians were ferried across-by the Alacaluf presumably, because they had canoes capable of carrying fifteen or twenty people, while the Yahgan had only small ones. 
This sequence of settlement is based on the theory that the Foot Indians could not and did not carry themselves across the straits. To be sure, the Tehuelche stuffed their hide toldos with saplings and made rude coracles like the bull-boats of North America. ${ }^{1}$ In these, with numerous wettings and considerable peril, they crossed the Patagonian rivers. But by no stretch of the imagination could the storm-vexed tide-ripped waters of Magellan strait be navigated successfully in such flimsy craft.

Mr. William Bridges assured me that neither the Ona nor the Haush, to the best of his knowledge, had ever used a boat. In the summer of 1907 certain Indians were taken to Navarin island to tend sheep, and displayed great apprehension upon the waters of Beagle channel. No Ona could swim, and this tribe crossed swift rivers by forming a huddle so that any individual who stumbled would not fall and be drowned. Lacking all knowledge of navigation, unable to swim a stroke, and inherently afraid of deep water, how could the Foot Indians have crossed to Tierra del Fuego without the aid of others?

Of the Foot Indians, evidently the Haush came first. This is indicated by their geographical location in the southeastern corner of the island, and is corroborated by the existence of place-names of Haush derivation in territory occupied in recent times by the Ona.

The linguistic diversity of the Haush, Ona, and Tehuelche implies separation into distinct groups a very long time ago, because language in that part of the world is known to be exceedingly stable and slow to change. Thus Lista ${ }^{2}$ significantly points out that the tongue of Patagonia has undergone little change since Pigafetta, the historian of Magellan, collected a vocabulary in 1520. Similarly Cooper $(1917$, p. 28$)$ remarks that the Alacaluf vocabulary made by La Guilbaudière not later than 1696 indicates linguistic stability since that date.

We have no archeological indication of when the Foot Indians reached Tierra del Fuego. Yet no aspect of Ona culture implies separation from the Patagonia mainland by more than a few centuries before the voyage of Magellan.

${ }^{1}$ Bourne, 1853, pp. 132-134.

21880 , p. 116. Comparative vocabularies of Pigafetta (1520), Viedma (1781), d'Orbigny, Musters, and Lista, while not identical, are closely similar. 


\section{FUEGIAN, CULTURE STATUS}

We have considered the Foot and Canoe Indians of Tierra del Fuego as they have revealed themselves to modern investigation and as they have been reflected in archeological remains. Before closing this account it will be well to fix their position in relation to cultural development and adaptation to environment in other parts of the world. We shall therefore examine the attainments of the Paleolithic and Neolithic inhabitants of Europe, of the Seri Indians of Mexico, and of the Eskimo-all in the light of Fuegian culture.

\section{A.-Fuegiass Compared with Primitite Europeass}

Assayed by the standards of Old World archeology, the Fuegian tribes stand definitely in the early Neolithic stage of culture, for they understood the use of the bow, made coiled basketry, used canoes (which may or may not have existed in Paleolithic Europe), and they had domesticated dogs. As for stoneworking, however, aside from some of their arrow- and spear-points (which are not only well made but barbed), Fuegian implements are fully equaled by finds dating from the Acheulean and Mousterian floors in Europe; that is to say, the latter half of the lower Paleolithic period. ${ }^{1}$ In fact, in the stone drill, invented during the Mousterian age and perfected in the Aurignacian, Europeans possessed a tool unknown to the Fuegians, who could puncture nothing harder than hide or bark with their bone awls. By the time of the Aurignacian period Europe also had dereloped the bone needle with a pierced eye to which the Fuegians did not attain.

Magdalenian Europe offers strong likeness to the Canoe Indians of Tierra del Fuego, owing to the very similar types of barbed bone harpoons used in both regions. Yet by this time in Europe the chipping of stone had risen to the level of an art, the spearthrower was widely used (an implement which one suspects that the Fuegian tribes may have forgotten), clothes were carefully

\footnotetext{
${ }^{1}$ It is unfortunate that the names attached to the great primary periods of human life should denote technological methods of manufacturing stone implements, for current practice distinguishes these epochs and their subdivisions by the fauna and by the kinds of utensils in use rather than br the manner in which they were made. This change in classification became necessary when it was recognized that the Paleolithic technique persisted into the Veolithic and even the Metal ages. We must emphasize that these terms are without chronological significance in the New Vorld.
} 
tailored (as attested by the finding of bone buttons), elaborate three-strand necklaces were manufactured, and, above all, sculpture was common and painting had reached both relatively and absolutely a very developed plane. The depiction of masked human figures suggests parallel religious phantasmagoria in both regions. In contrast the Fuegians were totally devoid of sculpture, and their painting was limited to the crudest daubs. Their necklaces were most primitive. Their garments were merely wrapped around the body and held in place by hand, or, if they did not completely envelop the body, were tied on by thongs crossing the bare flesh.

As to polished stone implements, Tierra del Fuego has produced few. In fig. 41 we show a bola from the east coast. Outes (1905, p. 427) has fully demonstrated that the true home of this weapon is in the northeastern Pampas and that it was unknown in Patagonia until the eighteenth century. Clearly it is no ancestral arm carried to Tierra del Fuego by Foot Indians in remote centuries, but rather a recent introduction, not long antedating the white colonization. Also we have seen a stone spike excavated in Yahgan territory. Apparently it has been shaped in part by pecking; at best it is an isolated instance of the Neolithic technique.

The rarity of polished stone implements in Fuegia is to be explained not by the lack of aptitude but by the indolence of the natives. To so-called civilized man the chipping of stone seems a mysterious craft, while it is patent that anyone who takes the time can grind a stone to the desired shape. As a matter of fact, the chipping of serviceable tools can be learned with a few days' practice, though of course the more delicate flaking, as with all handicraft, can come only as the result of long experience. And furthermore, chipped implements can be turned out quickly,-it takes only ten or fifteen minutes for a skilful Ona to finish a most delicate arrowpoint,- while ground stone implements require patience, mental discipline, and foresight.

This point is one to recall in estimates of all or any phases of Fuegian culture, for it will be found that deficiencies arose not from any innate mental or physical handicap, but from laziness and lethargy. This generalization applies not so much to the necessaries as to the conveniences of life. Thus the Ona bow and the Yahgan spear are admirable weapons, but the houses of both tribes were woefully inadequate. Yet there is no reason why the Yahgan and Ona should not, with forethought and initiative, 
have made themselves as comfortable as other tribes occupying an equivalent environment. That they did not, to the writer indicates a lack of something vital in their mental makeup.

The brief comparison we have made between primitive European and Fuegian cultures shows that although the Fuegians had partly attained the technological plane called Neolithic in the Old World, nevertheless in most respects they were scarcely better off than the semi-simian Neanderthal man of Europe. Clearly then they were laggards or backsliders in the development of mankind, so that in depicting their manner of life we are justified in assuming that we are recreating a vista of life in Europe or elsewhere many thousands of years ago.

However, the tribes of Tierra del Fuego are not a unique phenomenon, as we shall show by comparison with an equally though differently untutored New World group.

\section{B.-Fuegians Compared with the Seri}

The Seri, who inhabit a barren territory on the eastern shore of the Gulf of California and the adjacent islands, of which the largest is Tiburon, are one of the most primitive Indian tribes on the North American continent. Their climate is hot and dry. Their food supply is abundant-both marine and terrestrial. Like Fuegia the region occupied by the Seri is isolated from the main stream of cultural development, so that the native society probably represents a form of life much more wide-spread long ago.

Like the Fuegians, the Seri had no agriculture and no domestic animals except the dog, which indeed seems to have been half-wild. Their most important food was the turtle, which they caught with a harpoon having a detachable head tied to a cord. This may be compared to the Yahgan seal-spear. Long ago they used a two-headed barbed spear with the barbs facing inward to catch fish. The Yahgan also employed a two-headed fish-spear, but did not set the barbs inward. For boats the Seri made reed balsas with high pointed ends, a seaworthy craft but one which can be used only in warm climates because in rough weather the crew are drenched with spray or wet by water coming through the floor. These balsas the Seri propelled with clam-shells or boards held in the hands. In addition to spearing fish off-shore the Seri also caught them with their hands in shallow pools at low tide like the Ona, and they obtained on the beach large quantities of shellfishchiefly clams and oysters. 
On shore the Seri gathered various wild vegetal foods. They clubbed roosting pelicans at night. They caught also many deer and rabbits. We use the word caught advisedly, for usually the Seri, fleet of foot and hardy, ran these animals down and literally caught them in their hands. Meat was eaten raw except when there was an oversupply. Then it was partly cooked to tempt their jaded appetites. At times in hunting and regularly in war they employed a bow and arrows of simple type. The arrow had a wooden tip, rarely a chipped stone point.

For tools the Seri used a bone or a wooden awl, a wooden marline spike, a stone hammer and anvil, and a clam-shell. The latter served as a knife, but its shape was not modified, nor was it set in a handle. Manual dexterity was at a minimum among these people, and their implements and weapons were even more primitive than those of the Fuegians.

The fundamental Seri garment was a pelican-skin robe, which, like the Yahgan cape, was shifted from side to side with the wind in inclement weather. Also they wore at times a kilt and sleeved shirt of woven material, and thus they placed themselves on a higher cultural plane than the Fuegians, for they not only had acquired the art of weaving, but of tailoring their garments, neither of which were known to the Indians of Tierra del Fuego. In addition, the Seri wore a belt, often of snake-skin, and sometimes sandals of turtle-flippers. They adorned their persons with necklaces of seeds, of wooden beads, of shell, and of hair. They painted designs on the faces much more elaborate in character than those of the Ona and Yahgan.

Seri houses, scarcely better than the Ona windbreak, were arches of saplings partly shingled with sponges and turtle-shells. Inadequate even in a warm climate, yet they offered more protection comparatively than the Fuegian houses. As the Seri were constantly moving from place to place, these rude shelters were frequently abandoned to be reoccupied on some other occasion.

Of household furniture the chief article was a globular pottery water-jar, because water was scarce in Seriland and had to be transported long distances. A yucca ring-base was provided for the water-jar, and at times two jars were transported in nets slung on a shoulder yoke. In addition the Seri sometimes made a cooking-pot, an open dish, miniature vessels, and crude figurines; they also used a shell cup, and made simple coiled baskets. Their 
babies they carried on wooden frames like the Ona. Fire they made with a drill.

From the above remarks it appears that other inhabitants of the New World lived on a technological plane different in detail but no higher than the natives of Tierra del Fuego. Indeed in many respects - notably the lack of a knife and a scraper-the Seri are the more primitive. Yet their need was not so great, because the climate they enjoyed did not make such demands on their vitality.

When we examine social institutions we find the Seri on a markedly higher plane than the Fuegians. The tribe as a whole had marked national consciousness. It was divided into exogamic totemic clans based on maternal descent. Authority was lodged in the matrons, delegated to the elder brother for such masculine occupations as war and hunting. Religious concepts and practices also were on a higher plane than in Tierra del Fuego.

On the whole then we may say that the Seri, like the Fuegians, were a marginal group representing an early cultural stream; that both peoples were markedly deficient in houses, tools, and accouterments; but that the Seri, being closer to the fringe of higher culture, had borrowed in rudimentary form such higher arts as pottery-making and weaving, and had become endowed with more advanced religious and social practices. In both cases it seems that, although migratory by nature, their peregrinations had been circumscribed within fixed limits with resultant cultural atrophy, so that centuries had passed with little modification in their form of life.

The status of very primitive groups like the Fuegians and the Seri has bearing on the unknown pioneers who settled the New World, for the simplest and crudest tribes of the present may reflect the condition of their primitive migratory ancestors. We shall examine then the evidence afforded by such backward groups to throw light on the time when the Americas were settled and on the nature of the culture that was first introduced.

Boas, ${ }^{1}$ Wissler, ${ }^{2}$ Kroeber, ${ }^{3}$ and others have brought forward evidence that man reached the New World in a state of cultural development corresponding to the beginning of the Neolithic period in Europe. This hypothesis rests on fairly well assured

1 The History of the American Race; Annals N. Y. Acad. of Science, xxI, 1912.

2 The American Indian, New York, 1917.

3 American Culture and the Northwest Coast; Amer. Anthr., N.S., Xxv, no. 1. Also Anthropology, New York, 1923. 
ground. In the first place, no American tribe, past or present, living on the Paleolithic plane of culture has yet been detected. In other words, all American Indians, even the most primitive such as the Fuegians and the Seri, have Neolithic elements in their culture. Hence with justification we can assume that man did not reach America until the Neolithic epoch. Furthermore, the absence from the Western Hemisphere of all typical Old World domesticated plants and animals, except the dog, shows that all significant migration to America had ceased before these elements had been developed. Thus the settlement of the Americas is fixed by these limits: the close of the Paleolithic period, but before the Neolithic period had fully dawned.

When did the Neolithic period begin? According to the elaborate chronological yard-stick developed for European archeology, this would take us back more than 10,000 years. But Europe geographically is only a peninsula of Asia, and archeological evidence denotes that the Neolithic culture developed in Asia and spread to Europe long afterward. Primitive Neolithic arts and industries may have reached America as soon as, if not before, they penetrated Europe. At present we cannot say whether the migration to the New World was completed in a century or in a thousand years. We cannot hope further to correlate Old World and New World archeology until stratigraphical and chronological studies in Asia have yielded the secret of the development of Neolithic culture.

To the above remarks we may add that, according to current geological opinion, glaciation need not be considered a barrier to migration, because the ice sheets were not in existence at the period (as indicated by the cultural evidence) when the settling of America took place. Of the three North American ice sheets, the Cordilleran or western field, which alone could have proved a barrier to travel from Asia, was the first to disappear. The Labrador sheet, the last and most recent, is estimated to have released Niagara Falls from 20,000 to 35,000 years ago. ${ }^{1}$

Well documented New World archeological finds, obviously of great antiquity, have been unearthed in North, South, and Central America during the last two decades. The remains to which the greatest age is assigned, however, Basket-maker in the United States and "Archaic" in Mexico and Salvador, all indicate a much higher technological plane than that of the Fuegians or Seri.

\footnotetext{
${ }^{1}$ See A. P. Coleman, Ice Ages, Recent and Ancient, New York, 1926, p. 69.
} 
Hence it seems that the limits of our definite knowledge of the past are far from extending back to the time of the first immigrants. However, as pointed out by Kroeber, ${ }^{1}$ the primitive American cultural traits can be deduced by listing the elements of primitive nature having a wide distribution through both continents. On this basis it is not unsound reasoning to assume that characteristics common to widely separated primitive tribes in radically different environments, such as the Seri and the Fuegians, are basic in American culture. These features are:

1. A windbreak or domed house of saplings covered with the most readily available materials.

2. Untanned skin robe sewed with sinew.

3. A small kilt-like garment.

4. Use of facial and body painting.

5. Simple necklaces.

6. Cradle with cross-slats.

7. Coiled baskets.

8. Fire-drill. (This the Patagonians had, and probably once the Fuegians.)

9. Boats or rafts with high pointed ends.

10. The self bow and stone-tipped arrows.

11. The harpoon with single, double, and detachable heads.

12. Shellfish, fish, game, and wild vegetables as food.

13. Domesticated dogs.

From this list we gain a definite picture of the material culture enjoyed by the first settlers in the New World. It is not a complete visualization, however, of their manner of life, because it does not include social and religious customs. Among these in all probability should be included shamanistic control of spirits and disease, puberty rites attended with the infliction of physical suffering, masked ceremonials, and social organization based on local groups of blood relations. All these added features were characteristic of all the tribes of Tierra del Fuego.

We have listed as probable features of primordial American culture certain traits not included by Kroeber. On the other hand he incorporates others not found in Tierra del Fuego, such as the spear-thrower, twined baskets, mats, mortars, rattles, whistles, and flutes. Their absence from Tierra del Fuego may indicate that they should not be considered as primitive American traits,

1 op. cit. 
because they are objects which would have been valuable to the Fuegians, because they could have been made from materials easily obtainable, and because they were not superseded by other inventions. If the Fuegians had enjoyed these features, I can see no reason why they should have given up using them; yet some of the listed traits, the spear-thrower for instance, have such wide New World distribution that it is hard to place them on any but the earliest cultural plane.

\section{Fuegians Compared with the Eskimo}

We have seen that the natives of Tierra del Fuego lived on a cultural plane comparable with that of the early inhabitants of Europe, who were the advance guard of culture-bearers from central Asia toward the west, just as the Fuegians may have been toward the east. We have also seen that the low plane on which the Fuegians lived was not an isolated phenomenon in the New World, but was approached or duplicated elsewhere. We shall now compare the cultural status of the Fuegians and the Eskimo, because their respective habitats are environmentally parallel and their necessities were similar. In fact the Eskimo are called on to face the more rigorous conditions of the two, for they live in higher latitudes where the winters are darker and colder, while the lack of trees in many places forces them to exercise great ingenuity to find substitutes for wood.

The Eskimo inhabit the Arctic coast of North America and the adjacent islands, including Greenland. As in Fuegia, the vegetation of their habitat is not rich enough to support life, so that they have to subsist principally on animal food. During the winter the polar seas freeze over, and the Eskimo spear seals as they rise to their blowholes in the ice. When open water forms, they take to the sea in boats made of a wooden frame covered with hide, which in every way seem stronger and more seaworthy than the Yahgan canoes. In these they spear seal, walrus, and whale. In summer the Eskimo spear fish and birds, and make long trips inland to shoot deer with bow and arrow. With the return of winter, seal again becomes their only food supply.

For houses, in the summer the Eskimo use skin tents or stone walls roofed with skin which give better protection than the Yahgan wigwams and are infinitely superior to the Ona windbreak. In winter they make themselves snug in ingeniously constructed, 
multi-chambered, snow houses, usually provided with skin linings, windows, and ventilation holes. They take advantage of the propensity of heat to rise, locate their houses on sloping ground, and place their living-quarters in the uppermost part of the house. Under favorable circumstances the temperature can be maintained at above $70^{\circ}$ or $80^{\circ}$ Fahrenheit by means of an oil lamp.

As for clothing, the Eskimo are as well provided as the Fuegians were deficient. Their carefully tailored fur garments not only supply warmth and protection to every part of the person, but are so skilfully designed that adequate ventilation is supplied as well. Arctic explorers of recent years have been unable to design garments better suited to the climate and have adopted the Eskimo dress.

The chief weapons of the Eskimo are the harpoon and the bow. Their harpoons are made with detachable heads like the Yahgan seal-spear, but the points are designed to turn in the flesh of the wounded animal so that they form a toggle when it tries to escape. Harpoons of slightly different size and type are employed for small seals, for ordinary seals, for walrus, and for whale. To secure the larger animals a cord leading from the harpoon-head is attached to inflated seal-hides or hoop-drags, which enables them to tire out the wounded animal rapidly. The great superiority of the Eskimo equipment lies partly in their ability to drill bone and wood, so that they can lash or rivet joints more securely than the Fuegians. Also all the accessories, the ivory support for the hand lashed on the shaft, the loop with ivory clasp to hold the harpoon line, ivory plugs to stop the wounds of the slain animal, ivory swivels, ivory toggles, etc.-all these show a control of material never attained by the Fuegians. Furthermore, these details show mental superiority in that the Eskimo look beyond the bare necessities of the chase and provide themselves with comforts and conveniences.

The Eskimo bow is made of one or more pieces of spruce-wood riveted together, or of antler. It is sinew-backed - an adequate and powerful weapon in spite of a lack of proper material for bows. The arrowhead is usually ground stone riveted to a foreshaft lashed to a main shaft. In addition the Eskimo have a specialized type of bird-spear and fish-spear far superior to anything in Fuegia. Also they propel lances with throwing-sticks. Furthermore, they catch fish with hook-and-line, and with an ivory minnow for bait.

When we examine Eskimo tools it is found that their makers are neat and finished wcrkmen, and that they provide for their primitive 
necessities most adequately. Their knives and scrapers are ordinarily of iron or, when metal is unavailable, of stone ground down to thin, uniform, and symmetrical blades, which are hafted to wooden or ivory handles with rivets or gut lashings. Other tools include ivory needles, thimble, sharp graving tool, arrowshaft straightener, and-most important of all-the pump-drill. This last implement makes possible the rapid drilling of bone, stone, and wood, which contrasts strongly with the inability of the Fuegians to pierce anything harder than bark or skin. Among other elements of Eskimo material culture we should mention the stone lamp, fork and spoon, drinking tube, snow-goggles, and the sled with harness, traces, and toggles for pulling it.

Esthetically the Eskimo are not on a low plane. Their garments are distinctly beautiful from the juxtaposition of contrasting furs and are further adorned with beadwork. Their carvings in relief are realistic and charming. Incised drawings on bone and ivory show vigor and imagination. Their games, including cat's-cradle, are much more complex than Fuegian pastimes.

Like the Fuegians, the Eskimo lack definite social organization larger than the family. Both groups are polygynous. The Fuegians trace blood lines farther and are more rigid in debarring marriage of relatives.

Religiously the Eskimo are on the same plane as the Fuegians, but their religious activities played a larger part in their lives. In general they believed in supernatural beings, most of whom were malevolent, and they attempted to appease these creatures by prayer and offerings.

We have given but the briefest outline of Eskimo culture, for it is too complex to be summarized in a few words; yet enough has been said to indicate that the Eskimo live entirely as a hunting people, but in almost every aspect of life they are better off than were the natives of Tierra del Fuego. And this in spite of the more rigorous climate the Eskimo have to face. However, the comparison is not entirely fair, because the Fuegians were completely isolated, while the Eskimo received cultural impulses from more civilized neighbors such as the tribes of the northwestern coast of Canada or of northeastern Asia. The belief is not unjustified that climate and environment are the limiting factors with the Eskimo, and that, given better opportunities, they would work out a superior mode of existence. 
We have already pointed out that the lack of mental vigor seemingly underlay the cultural deficiencies of the Fuegians. This in turn we may trace to their manner of life, thus forming a vicious circle. Partial nakedness in the snows of winter is possible only to those endowed with a constitution we cannot help but admire, yet it can only result in unusual demands on the vitality and in the stunting of mental growth. Out of such pictures as the naked mother nursing a naked new-born child with driving sleet melting on them both, described by Darwin (1839, p. 235), one cannot envisage the breeding of mentally alert human beings. The Yahgan, writes Barclay (1904), mark "the limit to which a man may strip himself of all aid and comfort and yet survive and perpetuate his kind." "Their skill," says Darwin, "in some respects may be compared to the instinct of animals; for it is not improved by experience."

The writer does not regard the climate of Tierra del Fuego as a necessarily stunting factor; indeed the ample and hospitable scale of living introduced by the sheep ranchers proves that it is far from so. Wild foods-vegetal, game, and fish-can be procured with comparative ease. The discomforts of aboriginal life could well have been eradicated by forethought and a more aggressive mental attitude. This the missionaries tried vigorously if unsuccessfully to instil, and so the Fuegian tribes have quietly melted away in the face of the competition of our ruthless civilization. 
APPENDIX 



\section{HOUSEHOLD EQUIPMENT}

bag: (1) large fox-skin bag, hásin; (2) small fox-skin bag, kólwe; (3) guanaco-hide bag, shetelóli; (4) horseskin bag, háchilqin; (5) water-bag, sĕ.

ball, cháto.

basket, tai. (This word is used for grass, grass-seeds, baskets, and anklets woven of grass.)

\section{HUMAN BODY}

skull: (1) top of, áletárrh; (2) front of éyukoq; (3) zygoma, kochi; (4) nasal bone, orrh.

jaw, astilq.

hair, áliq.

ear, shĕ.

throat, échi.

breast, charrh.

ribs, parrh.

heart, toql.

diaphram, káich, kéit.

stomach, kat.

collar-bone, kolchten.

scapula, keuq.

\section{MATERIALS}

ashes, ápel.

bone, $k o$.

charcoal, karrh.

clay, white, kaístrrh.

feather, shitrrh.

fungus, edible, yóken.

grass, tai.

guanaco back sinew, yuh.

See page 50 .

\section{NUMBERS}

\section{TOOLS}

arrowshaft polisher: (1) of skin, sho- knife, péye.

shróshtel, shoshróshtel; (2) of stone, scraper: (1) for hides, cham; (2) for ham k'yarr.

awl, móoh.

beater for skins, árrte kaíyekásh.

bone chipping tool, ko heúrrhásh. whetstone for chipping tool, yarr heúrrhásh.

\section{WEAPONS}

arrow, $y a h^{n}$.

arrow feather, sho shitrrh.

arrowhead, heurrh.

bird-snare, tiih. The handle is láki. bow, $h a$. bowstring, ha kyuh. quiver, iull. seal-net, sheu. sling, shinkai. spear, chóhin. 


\section{MISCELLANEOUS}

man, chon.

woman, na.

child, télken.

infant, kaúlqen.

fire, hauk

flame, yálue. earth, wuh.

sky, $\operatorname{sh}^{e} \mathrm{o}$

afternoon, gringaiirsk.

sunrise, makoh.

rain, chálo.

initiation lodge, haine.

\section{YAHGAN VOCABULARY}

\section{ANIMALS AND BIRDS}

coypu, saiapaí

fish: (1) locally called mullet, haímush;

(2) locally called sardine, takápi. goose, kelp, shákush. guanaco, amarapáwa.

heron, túwuch. porpoise, shawiano.

\section{CANOE PARTS AND EQUIPMENT ${ }^{1}$}

bark of Nothofagus betuloides, aiirshun. canoe: (1) of bark, ánan; (2) of wood, lapatáganan.

fireplace, $a f$.

gunwale, wurri. mooring rope, shukamí.

mooring thong, wurrsh.

paddle, ápi.

ribs, ushkulakin.

whalebone, tirsh.

\section{DRESS AND ORNAMENT}

guanaco-skin cape, maiáka.

headband: (1) of heron-feathers, ha-

pawára (eastern dialect, hapawurrh);

(2) of kelp-goose down, paqal.

leggings, páwa.

\section{HOUSEHOLD EQUIPMENT}

basket: (1) hitched coil ("Fuegian" basketry), tawĕlla; (2) twisted hitched coil, uloánastába; (3) knotted hitch without foundation, gaiichim; (4) wrapped, chiwanúsh.

bucket, atakála.

comb, ushtánim.

fire-tongs, láka.

fungus used as tinder, awachiq.

house, ákharh.

housetop of seal-hide, kaikis.

moccasin, kíli.

necklace of shell, opirrshka.

pubic covering, múshwalána.

wristlet or anklet, maíamasár.

pouch: (1) of guanaco-hide for firemaking apparatus, asánu; (2) of guanaco-hide for shaman's paraphernalia, humulúf; (3) of otter-tail for tobacco, yeten; (4) of seal-bladder for oil, athhlaháni; (5) of seal throat for paint, yái; (6) of seal-gut for oil, kália.

pyrites, sewálli.

shell cup, aufán.

stick for painting face, telákikamána.

\section{MATERIALS}

grass, mápi.

guanaco-sinew, ushwámi.

kelp: (1) ordinary variety, haúsh; (2)

broad-leafed variety, shon (eastern dialect, shówen).

moss, hánakóhl.

pumice, hiól.

seal-hide thong: (1) for joining har-

poon-point and shaft, tamutu;

for circular lashing, tuwawáru;

for mooring canoes, wurrsh.

shell: (1) for drinking-cup, auflín;

(2) for necklace, haúsh undálu; (3)

for scraper-blade, chiamúnka.

whalebone, tirsh.

wood. See Table I, page 29.

\footnotetext{
${ }^{1}$ See also household equipment, and weapons and hunting equipment.
} 
See page 121 .

\section{NUMBERS}

\section{TOOLS}

awl, ámi.

bark remover: (1) for man, sánakai;

(2) for woman, téshupu.

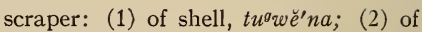
steel, wána.

sharpening stone, chipi.

\section{WEAPONS AND HUNTING EQUIPMENT}

bird-snare, aúrum.

club, kíwa.

dip-net, chiwanúsh.

fish-line, tápim. The sinker is társhir; the bait noose is tukaléna.

harpoon: (1) single-barb type, awaía (eastern dialect, uaía); (2) doublebarb type, waiki (eastern dialect, wek). The shaft is called shoshaia; the thong around the socket is tuwawáru; the thong from point to shaft is támutu.

harpoon-point case of seal-hide, yamiku. knife (steel), hárfkar.

sling, watewá, matåwá.

spear: (1) for fish, shushróya (eastern dialect, usháwaia); (2) double-headed fish-spear, ámpa, úmpa; (3) crabspear, sita (the shaft is akwisimána); (4) limpet-spear, kaliáno; (5) guanaco-spear, wunaí.

torch (made of bark of Nothofagus betuloides), aíirshun (eastern dialect, aiishu). 


\section{BIBLIOGRAPHY}

[This bibliography contains all works to which reference is made in the main text. In addition I have listed all available titles published since 1917 in order to form a supplement to the Bibliography brought out by Cooper in that year. In many cases I have not been able to obtain copies of such recent works and have no knowledge of their contents-S.K.L.]

A. B.

1920 Noticias históricas del Museo Regional "Mayorino Borgatello" por el Salesiano A. B. Punta Arenas.

Contains account of the formation and administration of the local museum and photographs of ethnological interest.

Agostini, Alberto M. DE

[1923] I mei viaggi nella Terra del Fuoco. Torino.

Contains a truly remarkable set of photographs, representing years of travel in Fuegia. One chapter is devoted to the Indians.

1924 Zehn Jahre im Feuerland; Entdeckungen und Erlebnisse. Leipzig. Contains remarkably fine pictures.

[N. D.] Los Onas. Torino.

A series of twelve post-cards issued in a book.

\section{Agostini, Giovanni de}

1891 Geographische und ethnographische Aufzeichnungen über das Feuerland. Gotha.

Alvarez O, Auristela

[N. D.] Monografía histórica del Territorio de Magallanes. Concepción.

Contains a brief account of the Indians, and two photographs.

Barclay, William S.

1904 The land of Magellanes, with some account of the Ona and other Indians. In Geographical Journal, vol, XxiI, no. 1, London.

1926 The land of Magellan. London.

Contains an excellent summary of the history of the island, various observations on the Indians, an account of the Caushel family (Ona) written by Lucas Bridges, and some good photographs.

[Beauvoir, José Maria]

1915 Los Shelknam, indígenas de la Tierra del Fuego. Buenos Aires.

Bertacchi, Cosimo

1924 La Terra del Fuoco nel libro di un missionario italiano. In Nuovo

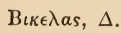
Antologia, Sept., Rome.

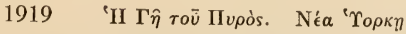

An account based largely on Darwin, Willems, and Rousson. Map and illustrations. 
Bórgatello, Maggiorino

1922 I popoli della Patagonia meridionale e Terra del Fuoco. In $L a$ Terra e la Vita, vol. I, Rome.

1924 Nella Terra del Fuoco, Memorie di un missionario salesiano. Torino.

Contains map, 49 plates, and 171 text figures.

Bourne, B. F.

1853 The captive in Patagonia. Boston.

Bove, Giacomo

1883 Expedicion Austral Argentina. Informes preliminares presentados á S.S.E.E. los Ministros del Interior y de Guerra y Marina de la República Argentina. Buenos Aires.

BRIDGES, THOMAS

1884 Mœurs et coutumes des Fuégiens. [Translated by Hyades from a MS. prepared in 1866.] In Bull. Soc. d'Anthr. de Paris, ser. III, vol. VII, Paris.

1886 El confin sur de la República: La Tierra del Fuego y sus habitantes. In Boletin del Instituto Geográfico Argentino, tomo viI, cuaderno Ix, Buenos Aires.

1893 La Tierra del Fuego y sus habitantes. Ibid., tomo xIV, cuadernos 5-8, Buenos Aires.

\section{Brosses, CharLes DE}

1756 Histoire des navigations aux terres australes. 2 vols. Paris.

Cojazzi, Antonio

1914 Los indios del archipiélago fueguino. In Revista Chilena de Historia y Geografía, tomos, Ix-x, Santiago de Chile.

Cook, James. See Hawkesworth

COOPER, JoHN M.

1917 Analytical and critical bibliography of the tribes of Tierra del Fuego and adjacent territory. Bull. 63, Bur. Amer. Ethnol., Washington.

1917a Fuegian and Chonoan tribal relations. In XIX Intern. Congr. Americanists, Washington.

1925 Culture diffusion and culture areas in southern South America. In XXI Intern. Congr. Americanists, Göteborg.

An important summary of material culture and literary sources, together with a sound analysis of chronological relationships.

DABbene, Roberto

1907 Viaje á la Tierra del Fuego y á la isla de los Estados. In Bol. Inst. Geogr. Argentina, tomo xxi, Buenos Aires.

\section{DARWin, Charles}

1839 Narrative of the surveying voyage of His Majesty's ships Adventure and Beagle between the years 1826 and $1836 \ldots$ vol. III. Journal of researches into the geology and the natural history of the various countries visited by H. M. S. Beagle. London.

DENIKER, J.

1892 Anthropologie Fuégienne. In VIII Intern. Congr. Americanists, Paris. 
Dixon, Roland B.

1923 The racial history of man. New York. London.

Contains a useful discussion of the multiple origin of the American Indians (pp. 393-397, 447-452) and a summary of Fuegian somatological data (pp. 454-455).

Fagalde, Alberto

1901 Magallanes, el país del porvenir. Valparaiso.

Fitzroy, RoBERT

1839 Narrative of the surveying voyages of His Majesty's ships Adventure and Beagle between the years 1826 and 1836 ... Vol. II. Proceedings of the second expedition. London.

\section{Fuentes Rabe, Arturo}

1922-23 Tierra del Fuego. 2 vols. Valdivia.

Contains (pp. 150-183) an account of Fuegian somatology based on Hyades, Lapham, and original observations; a transcript of Ona mythology from Cojazzi; details on treatment of the Ona by white settlers.

FuRLONG, C. W.

1912 Hunting the guanaco. In Outing, vol. LxI, no. 1, New York.

1915 The Haush and Ona. In XIX Intern. Congr. Americanists, Washington.

1917 Tribal distribution and settlements of the Fuegians. In Geographical Review, vol. III, no. 3, New York.

Contains a full discussion of the subject, based on data obtained from the Bridges family.

Gallardo, Carlos R.

1910 Los Onas. Buenos Aires.

Gusinde, Martin

[Father Gusinde made four journeys to Tierra del Fuego to study the Indians for the Museo de Etnología y Antropología of Santiago. The results of his researches are still appearing in print as this work goes to press, so that the titles herein given do not form a complete list. The importance of these studies, based on painstaking field studies, can scarcely be overstated.]

1922a Expedición á la Tierra del Fuego. In Museo de Etnología y Antropologia, Publicaciones, tomo II, pp. 9-43, Santiago de Chile.

1922b Die Feuerlaender, einst und jetzt. In XX Intern. Congr. Americanists, Rio de Janeiro.

1922c P. M. Gusinde's vierte Reise zum Feuerlandstamm der Yagan. In Anthropos, Bd. xvi-Xviı, San Gabriel-Mödling.

1922d Segundo viaje à la Tierra del Fuego. In Museo de Etnología y Antropología, Publicaciones, tomo II, pp. 133-163, Santiago de Chile.

1922e Tercer viaje a la Tierra del Fuego. Ibid., pp. 417-436.

1924a Cuarta expedición á la Tierra del Fuego. Ibid., IV.

1924b Meine vier Reisen durch das Feuerland. In XXI Intern. Congr. Americanists, pt. $\mathrm{I}$, The Hague.

1924c P. M. Gusinde's vierte Reise zum Feuerlandstamm der Ona und seine erste Reise zum Stamm der Alakaluf. In Anthropos, Bd. xvin-xIx, San Gabriel-Mödling.

1925a Elemente aus der Weltanschauung der Ona und Alakaluf. In XXI Intern. Congr. Americanists, Göteborg. 
1925b Geheime Männerfeiern bei den Feuerländern. Ibid.

1925c Intermezzi di Etnologia. Idee religiose in Terra del Fuoco. In Rivista Illustrata della Esposizione Missionaria Vaticana, vol. II, Rome.

1925d Meine Forschungsreisen ins Feuerland und deren Ergebnisse. In Anthropologischen Gesellschaft in Wien, Bd. Lv, Wien.

1926a Anthropologische Beobachtungen bei den Ona-Indianern auf Feuerland. In Tagesberichte der Deutschen Anthropologischen Gesellschaft, Augsberg.

1926b Die Eigentumsverhältnisse bei den Selk'nam auf Feuerland. In Zeitschrift für Ethnologie, Jahrg. 58, pp. 398-412, Berlin.

1926c Das Lautsystem der feuerländischen Sprachen. In Anthropos, Bd. xxI, San Gabriel-Mödling.

1926d Männerzeremonien auf Feuerland und deren kulturhistorische Wertung. In Zeitschrift für Ethnologie, Bd. LviII, Berlin.

1926e Zur Ethnik der Feuerlaender. In Internationale Woche für Religions-Ethnologie, IV Tagung (Mailand, 17-25 Sept. 1925), Paris.

1928 Das Höchste Wesen bei den Selk'nam auf Feuerland. In $P$. W. Schmidt Festschrift, Wien.

Gusinde, Martin, and Lebzelter, Viktor

1927 Kraniologische Beobachtungen an feuerländischen und australischen Schädeln. In Anthropos, Bd. xxII, pp. 259-285, San GabrielMödling.

Measurements of eleven Ona, thirty Yahgan, and six Alacaluf skulls.

HAwKesworth, JoHN, ed.

1773 An account of the voyages ... performed by Commodore Byron, Captain Carteret, Captain Wallis, and Captain Cook . . . drawn up from the journals which were kept by the several commanders, and from the papers of Joseph Banks, Esq. 3 vols. London.

Holmes, W. H.

1912 See HRDLIČKA

HRDLIČKA, ALEŠ

1912 Early man in South America. [In collaboration with W. H. Holmes, Bailey Willis, F. E. Wright, and C. N. Fenner.] Bull. 52, Bur. Amer. Ethnol., Washington.

Hyades, P. D. J., and Deniker, J.

1891 Mission scientifique du cap Horn. VII-Anthropologie, ethnographie. Paris.

KENT, ROCKWELL

1924 Voyaging southward from the Strait of Magellan. New York and London.

Contains brief descriptions of Indians.

KOPPERS, WILHELM

[Father Koppers accompanied Gusinde on his third visit to Tierra del Fuego. His studies still are published only in part. Like those of his companion they are of the highest importance.]

1922a Bericht über die von Gusinde-Koppers zu Anfang 1922 zu dem Feuerlandstamm der Yaganes veranstaltete Forschungsreise. In XX Intern. Congr. Americanists, pp. 309-314, Rio de Janeiro.

1922b Die Feuerlandreise von Gusinde-Koppers zu Anfang 1922. In Anthropos, Bd. XVI-XVII, pp. 520-524, St. Gabriel-Mödling. 
1922c Drei Fahrten zu den Feuerländern. Ibid., Bd. xv-xvI, pp. 11301132.

1924 Unter Feuerland-Indianern. Stuttgart.

Contains an important account of the Fuegians seen by Gusinde and Koppers, with thirty illustrations and a map.

1925 Die geheime Jugendweihe der Yagan und Alakaluf auf Feuerland. In XXI Intern. Cong. Americanists, pt. II, Göteborg.

1925a Mythologie und Weltanschauung der Yagan. Ibid.

1926 Wo befindet sich das Manuskript letzer Redaktion des grossen Yamana- (=Yagan) Lexikons von Th. Bridges? In Anthropos, Bd. XXI, San Gabriel-Mödling.

1927 Die fünf Dialekte in der Sprache der Yamana auf Feuerland. Ibid., Bd. xxII, Heft 3, 4, St. Gabriel-Mödling.

1928 Individualforschung unter den Primitiven, im besonderen unter den Yamana auf Feuerland. In P. W. Schmidt Festschrift, Wien.

LAHILLE, F.

1926 Matériaux pour servir a l'histoire des Oonas indigènes de la Terre de Feu. In Revista Mus. de la Plata, tomo XXIX ( $3^{\mathrm{e}}$ ser., t. v) and supplement.

Contains excellent photographs of physical types.

\section{LEBZELTER, V.}

1925 Ein Onaschädel aus Feuerland. Zur Frage des Vorkommens eines australoiden Rassenelementes in Süd-Amerika. In $X X I$ Intern. Congr. Americanistes, pt. II, Göteborg.

See GuSinde, M., and LEBZELTER.

\section{LehmanN-Nitsche, Roberto}

1914 El grupo lingüístico Tshon. In Revista del Museo de La Plata, tomo XXII ( $2^{a}$ ser., t. IX), Buenos Aires.

This important paper discusses the nomenclature of tribes, and, by comparative vocabularies, fully demonstrates the linguistic affiliation of the Ona, Haush, and Tehuelche.

1915 Études anthropologiques sur les Indiens Ona (groupe Tshon) de la Terre de Feu. Ibid., tome XxIII ( $2^{\text {me }}$ sér., tome $\mathrm{x}$ ), Buenos Aires.

An anthropometric study of seven Ona sent to an exposition in Buenos Aires in 1898. There are nine excellent photographs taken in Buenos Aires and Tierra del Fuego.

1915a Relevamiento antropológico de una India Yagan. Ibid.

A detailed study made in 1902 on a young Yahgan woman.

1927 Estudios antropológicos sobre los Onas. In Anales del Museo de La Plata, tomo II, entrega $2^{\mathrm{a}}$, Buenos Aires.

An important contribution to Ona somatology, containing a useful summary of previous studies and measurements of twenty men and thirty women.

Lista, RaMón

1880 Mis exploraciones y descubrimientos en Patagonia. Buenos Aires.

1887 Viaje al país de los Onas: Tierra del Fuego. In Revista Soc. Geog. Argentina, tomo v, Buenos Aires.

\section{LOTHROP, S. K.}

1925 Museum expedition to Tierra del Fuego. In Indian Notes, vol. II, no. 4 , New York.

Contains an outline of the work of the Museum of the American Indian, Heye Foundation, in Tierra del Fuego, remarks on Fuegian environment and temperament, and ten photographs. 
LOTHROP, S. K., and WELD, J. L.

1925 Ona and Yahgan. In The Independent, Nov. 21, Boston.

Contains twelve photographs and a short descriptive text.

Medina, J. T.

1882 Los aboríjenes de Chile. Santiago.

Milanesio, Domingo

1917 Estudios y apuntes sobre las lenguas en general y su origen divino. Particularidades sobre los idiomas de la Patagonia. Buenos Aires.

Musters, G. C.

1871 At home with the Patagonians. London.

Outes, Felix F.

1905 La edad de la piedra en Patagonia. In Anales del Museo Nacional de Buenos Aires, tomo XII ( $3^{\mathrm{a}}$ ser., t. v), Buenos Aires.

1906 Instrumentos modernos de los Onas. Ibid., tomo XIII ( $3^{\text {a }}$ ser., t. vI), Buenos Aires.

,ed.

1926 Datos sobre la ergología y el idioma de los Yamana de Wulaia (isla Navarino), reunidos por el misionero R. R. Rau, con anterioridad a 1866 y anotados por Don Jorge Claraz. In Revista del Museo de la Plata, tomo xxx, Buenos Aires.

Contains an account of Yahgan culture, grammatical notes, and vocabulary somewhat different from that in 1866.

1926a Sobre el idioma de los Yamana de Wulaia. Materiales reunidos por el misionero Rau con anteriordad a 1866. Ibid.

Contains a Yahgan vocabulary of 521 words and a full and important list of works treating Yahgan linguistics.

Oviedo y Valdez, Gonzalo Fernandez de

1851-55 Historia general y natural de las Indias y Tierra-Firme del Mar océano. 4 vols. Madrid.

Pusso, Santiago

[N. D.] Viajes por mi tierra. Barcelona.

Contains brief account of Indians at Harberton in 1909, and four illustrations.

Rau, R. R. See Outes, F. F., ed., 1926

Ribeyrolles, A. B.

1925 Climatología de los territorios nacionales de Santa Cruz y de Tierra del Fuego, y sus accidentes de trabajo. Indígenas de Santa Cruz y Tierra del Fuego. Enfermidades más comunes y causas originarias. In Crónica Mensual del Departamento Nacional del Trabajo, Boletin Oficial, viII, Buenos Aires.

Rivet, Paul.

1923 Nouvelles études sur les Yahgan. In Anthropologie, t. xxxı1, Paris. SснміDт, P. W.

1925 Die Stellung des Genitivs in den südamerikanischen Sprachen und ihre Bedeutung für den Sprachaufbau. In XXI Intern. Cong. Americanists, pt. II, Göteborg.

SKotTSBERG, CARL

1911 The wilds of Patagonia. London. 
SPEgazzini, Carolo

1887 Fungi fuegini. In Bol de la Acad. Nacional de Ciencias en Córdoba, tomo XI, Buenos Aires.

\section{SPEgazzini, Carlos}

1923 Relación de un paseo hasta el cabo de Hoorn. Ibid., tomo xxvir, Córdoba (Argentina).

1924 Disquisiciones filológicas. In Physis, vol. vir, Buenos Aires.

TONelir, D. A.

1926 Grammatica e glossario della lingua degli Ona-Selknam della Terra del Fuoco. Torino.

Valle Carbajal, Lino del

1900 Le missioni Salesiane nelía Patagonia e regioni Magallaniche. S. Benigno Canavese.

An historical account of missionary contact with the natives.

Vargas Ponce, José de

1788 Relación del último viage al estrecho de Magallanes de la fragata de S. M. Santa María de la Cabeza en los años de 1785 y 1786. Madrid.

Vignati, M. A.

1925 Los arpones óseos de los Indios de Tierra del Fuego. In Physis, tomo VIII, p. 264, Buenos Aires.

1926 El tipo de habitación actual de los Indios Onas de Tierra del Fuego. Ibid., no. 30.

Wolfe, G.

Describes $\log$ tipi house types. Two photographs.

1924 Language and religious customs of the Yahgan Indian. In South Pacific Mail, Sept. 25, Santiago de Chile.

Describes manuscript dictionary of 12,000 Yahgan words in possession of the Rev. Mr. Williams of Punta Arenas. 

I N D E X 



\section{INDEX}

Abortion among Yahgan, 163

Acheulean culture of Europe, 202

Admiralty sound, situation of, 17

Adornment, see Body-painting; Facepainting; Ornamentation; Paint

Adultery, cause of quarrels, 164 ; stories regarding, 175

Adventure, voyage of the, 21. See Beagle

Africa, basketry of, 137

Age of archeological remains, 192-197

Aged, execution of, 97; respect for, inculcated, 169

Agostini, Alberto $M$. de, photographs by, $24,28,52,60,62,79,83,89$

Agriculture in Tierra del Fuego, 34-35; lacking among Seri and Fuegians, 204

Airro, Ona name of Alacaluf, 24

Akainix, mythic personage, 178

A kawalakirrh, a shellheap, 188-189

Alacaluf and Chono relationship, 199 and Yahgan stature, 40; and Yahgan trade, 130; basketry, 133, 136; bows, 72 ; buckets, 132 ; cannibalism ascribed to, 118; canoes, 145 clothing, 33, 123; habitat, 17, 25. houses, 127 ; initiation ceremonies, 95; linguistic relations, 24, 199; migration, 200 ; note on, 178 ; origin of, 194; paddles, 147; population, 25; slings, 156 ; spears, 15 , pl. XII; stature, 39 ; trade in pyrites, 65 ; visit to England, 21

Alaska, basketry of, 137

Allen Gardiner, massacre of crew of, 118

Amazon valley, basketry of, 136; Fuegian migration from 198; initiation ceremony of, 95 ; relationship of tribes of, 200

American Geographical Society, acknowledgments to, 13

Amusements, Ona, 91; Yahgan, 163164

Anatomical terms, Ona, 216

Andes, terminus of the, 17

Aníawaía, a source of flint, 130

Animals created by Kenós, 98; dances named for, 169; in Haush myth, 108; lodges named for, 94; Ona terms for, 215; size of, in Tierra del Fuego, 32, 46; spirits of, 96; Yahgan terms for, 217. See Fauna; Food
Animistic beliefs, Fuegian, 35

Anklets, Haush, 109; Ona, 59; Yahgan, 125

Anson, cited, 20

Anthropometric characters, Yahgan and Ona, 41-47. See Physical type

Antipodes, belief regarding, 18

Anvils of stone, 66, 192

Araucanians, cradles, 58; fire-making, 65 ; in Chile, 193-194; scrapers, 113

Arawana, Caraja ceremony, 95

Archaic culture, age of, 207

Archeology of Fuegia, 110-115, 178-197

Archery, Ona, 78-80, 91. See Arrows; Bows

Arrow-makers, Ona belief regarding, 102

Arrowpoints from ancient camp-sites, 114, 191-192; of Chile and Fuegia compared, 72; Ona, 57

Arrows, Eskimo, 209-210; Haush, 107; in dueling, 90; in Yahgan myth, 176; of Patagonian coast, 115; Ona, 70 71, 73-78, 199, pl. v; Tehuelche, 199 ; spirit mastered with, 97 ; stonetipped, distribution of, 208; used by boys, 163; used in peace-making, 90-91; Yahgan, 118, 155-156. See Bows; Fire-arrows; Weapons

Arrowshaft polishers, Ona, 70-71, 98. See Polishers; Smoothing stones

Arrowshaft straightener, Eskimo, 211

Art of the Eskimo, 211

$A$ sh used in arrow cement, 74

A sia, culture developed in, 16; Eskimo influenced from, 211

Atacama desert, bow from cave in, 72 Atlatl, see Spear-thrower

A ugustine quoted, 18

Aurignacian period of Europe, 202

Awls, Ona, 69-70; Seri, 205; Yahgan, 141-142

$A x$, metal, introduction of, 62-64, 128; stone, unknown to Fuegians, 35 . See Cleavers; Metal

Baake, William, acknowledgment, 13

Babies, see Children; Infants

Bags, disbribution of, 199; Ona, 31-32, 56-57, 62; Yahgan, 133, 173. See Pouch; Storage-bags; Water-bags

Bahía Boucault, explorers at, 115

Bahía de la Victoria, windbreak near, 61 
Bahia Posesión, explorers at, 115

Bailers, Yahgan, 131, 147-148. See Buckets

Ball game, Ona, 91; Yahgan, $16 t$

Balsas, range of use of, 199; Seri, 204. See Boats

Banks, Joseph, among the Haush, 109; cited, $10 \tau$

Barbarity, see Culture status

Barberry, arrows of, 73; buckets rimmed with, 132; crab-spears of, 154; fire-tongs of, 66; shredded, for bedding scrapers, 139; used in basketry, 138

Barclay, iT. S., cited, 20, 94, 95, 103, $105,106,17 t, 212$

Bark, bailers of, 147 ; buckets of, 131-132; canoes of, $127,143-146$; houses covered with, 128; masks of, 171 ; spirit personage clothed in, 95 ; torches of, 83, 156

Barking tools, Yahgan, 131-132, 141

Basalt, objects of, on camp-site, 112

Basket-makers, age of remains, 207; basketry of, 136

Basketry, awls used in making, 69, 141; coiled, distribution of, 208; coiled, non-use of, 194; twined, unknown to Fuegians, 208

Baskets given to initiates, 169; Haush, 107, 109-110; Ona, 62, 67-68; Seri, 205; used as targets, 150; Yahgan, 133-139

Bat in Ona myth, 101-102

Battle, sham, among mourners, 174. See Feuds; Fighting; Wrestling

Beads, Haush, 109; Ona, 59; Yahgan, 125. See Necklaces; Ornaments

Beadwork, Eskimo, 211

Beagle, royage of the, 21, 115, 161

Beagle channel, Bridges and Lawrence home on, 21; Camargo probably in, 19; camp-sites on, 11, 178, 189, 192, 194; fishing in, 160; guanacohunting on, 153; scrapers from, 112 , 113; spearpoints from, 191-192; view of, pl. III

Beards, how regarded by Yahgan, 40. See Hair; Mustache

Beauvoir, José M., cited, 24, 50, 98, 200

Beech, bows of, 71, 156; in Ona myth, 102; lodge-roof of, 165 ; Ona spirit of, 95 ; on shellheap, 187 ; spearshafts of, 150

Beech-bark, see Bark

Beetle, Ona belief regarding, 106

Beguá, bolas of the, 114

Berries eaten by Fuegians, 29. See Food

Bibliography, 219-225

Bird represented by masked figure, 94
Bird-bone used for drinking, 168, 169

Bird-down used as tinder, 64, 130. See Goose-down; Kelp-goose

Bird-killing, mythic origin of, 176

Birds, how hunted by Yahgan, 155159; how taken by Ona, 83-84; in Ona myth, 102-104; of Tierra del Fuego, 34; Ona terms for, 215; speared by Eskimo, 209; Yahgan terms for, 217. See Fauna; Feathers; Food

Bird-skin, bags made of, 68

Bird-snares, Yahgan, 157. See Snares

Bird-spears, see Spears

Bird-wing used as broom, 131

Blades, stone, illustrated, pl. VII, xIx. See Knives; Scrapers

Blood loyalty among Yahgan, 165

Blood revenge, songs of, 164 . See Feuds; Revenge

Boas, Franz, cited, 206

Boats, distribution of, 208; Eskimo, 209; not used by Foot Indians, 201; Tehuelche, 201; Yahgan, 143-148. See Balsas; Canoes; Rafts

Body-painting by mask wearers, 171; by mourners, $173-174$; by Ona, 58 , 96 ; by Yahgan, 118, 125, 131, 164; distribution of, 208; in Yahgan myth, 177. See Face-painting; Ornamentation; Paint

Bolas, distribution of, 203; from ancient camp-sites, 111-115; used by Tehuelche, 72

Bone, awl handles of, 69; chipping tool of, 31 ; combs of, 68; Haush beads of, 109; Ona beads of, 59; tools of, from shellheaps, 192; Yahgan arrows of, 155-156; Yahgan beads of, 125. See Guanaco-bone; Whale-bone

Bones, animal, age of shellheaps argued from, 195; human, used by enemies, 173 ; in Harberton shellheap, 183

Borrowing of culture, 35-36, 66, 130$131,155-156,165,206$

Bougainville, L. A. de, voyage of, 115

Bounty on Feugian heads, 23

Bourne, B. F., cited, 15, 201

Bove, Giacomo, cited, 22, 41, 121, 192

Bows, distribution of, 208; Eskimo, 209-210; Haush, 107; how carried, 53; in Peabody Museum, Salem, 13, pl. v; of Patagonian coast, 115; Ona, $71-73,78-80,194,203$, pl. v; Ona and Tehuelche, 199; used by boys, 163; Yahgan, 118, 155-156, pl. XIII. See Archery; Arrows; Weapons

Bow'strings, Ona, 57, 72; Yahgan, 156 Boys, Yahgan, training of, 163-164, 168-169. See Initiation; Training 
Bracelets, Haush, 109. See Ornaments; Wristlets

Brachycephaly among aborigines, 43, 47 ; of South American natives, 198199

Brazil, see Amazon valley

Brecknock peninsula, character of, 17; Yahgan boundary, 116, 196

Bridges family, acknowledgments to, 12; labors of, 21; sheep ranches of, 185. See Estancia Viamonte

Bridges, Lucas, information given by, $11,22,94-95,97,106,107$; initiated by Ona, 22; in wrestling contest, 89-90

Bridges, Rev. Thomas, cited, 29, 65, $130,163-165,170,173,174,178$, 196; dictionary of, 121 ; ethnologic knowledge, 22; linguistic work, 119

Bridges, William, information given by, $11,22,25,48-50,72,79,84,107$, $114,120,121,140,153,161,190$, 200,201 ; initiated by Ona, 22

Brinton, D. G., cited, 99

Brooms, Yahgan, 131

Brosses, Charles de, cited, 20

Brouwer, Hendrick, voyage of, 19

Brunswick peninsula, situation of, 17

Buckets, bark, of the Yahgan, 131-132. See Bailers

Buenos Aires, stone objects from, 112

Burdens, how borne by Ona, 62-63, 81

Burial, see Mortuary customs

Burlap, Yahgan shelters covered with, 128

Bush Negroes, basketry of, 137

Butterflies in Tierra del Fuego, 34

California, shellheaps in, 195, 197

Camargo, discoveries of, 19

Cambaceres bay, shellheaps on, 183, 186, 196, 197, pl. XvII; Yahgan at, 11

Cambaceres peninsula, fresh water on, 184

Camp equipment, Ona, 36, 64-68; Yahgan, 36, 129-138

Camps, winter, of Yahgan, 188. See Encampment

Camp-sites of eastern Fuegia, 110-111; of southern Fuegia, 178-197. See Shellheaps

Cannibalism ascribed to Fuegians, 16, 118; in Ona myth, 99

Canoe equipment, Yahgan terms for, 217

Canoe Indians, account of 115-178; application of term, 38, 198; culture of, compared, 194, 199; quivers of, 78. See Alacaluf; Fuegians; Yahgan

Canoes, effect of, on physical type, 40 , 44; of Alacaluf, 200; of Fuegians, 199; of Yahgan, 13, 127, 131, 143-
$146,159-160$, 196; runways for, pl. XI. See Balsas; Boats

Cape Divide, Yahgan dialect boundary, 120

Cape Froward, situation of, 17

Cape Horn, characteristics, 15, 27; situation, 17; when and by whom named, 19; Yahgan boundary, 116. See False Cape Horn

Cape Kayel, father of Kuanip, 99

Cape Peñas, Salesian mission at, 23

Cape Pilar, Drake at, 19

Capes, Haush, 107; Ona, 33, 79; Yahgan, 121-123. See Clothing

Caps, Haush, 107; Ona, 31, 55-56. Yahgan, 125. See Clothing; Headband

Captives, Ona treatment of, 88

Capture, marriage by, 86, 87, 163

Caraja, ceremony of, 95

Cartography of Tierra del Fuego, 18-20

Carvings of the Eskimo, 211. See Sculpture

Cat's-cradle of the Eskimo, 211

Cattle, size of, in Tierra del Fuego, 46

Cave, a giant's home, 176; bow found in, 72; dead deposited in, 173

Cement, see Pitch

Cephalic index, see Physical type

Ceremonial lodge, Ona, 63; Yahgan, 165-166, pl. XIV. See Initiation; Lodge

Ceremonial objects, Fuegian, 37

Ceremonies, Fuegian, 35. See Initiation; Mourning

Chaco tribes, relationship of, 198, 200

Characters, anthropometric, Fuegian, 41

Charcoal used for paint, 58-59, 126; used in tattooing, 58

Charles $V$ names Tierra del Fuego, 20

Charley, a Haush-Yahgan native, 120

Charrúa, bolas of the, 114

Chert, objects of, on camp-site, 112. See Stone implements

Chiefs lacking among Yahgan, 160

Childbirth, see Children

Children, amusements of, 163-164; attitude of initiates toward, 93; barred from ceremony, 95; how carried, 118, 206; Ona, 58, 79, 87, 96, 105; taught spearing, 150; Yahgan, 163, 212. See Boys; Captives; Girls

Chile, bow from cave in, 72 ; culture of, compared with Fuegian, 19t, 199; stone objects from, 77,114

Chiloe island, archeological remains on, 199

Chinkol, a bird, in Ona myth, 102103 
Chipped implements, Ona, 76, 203. See Stone implements

Chipping tools, Ona, 31, 69-70, 75

Chiuchiu cave, bow found in, 72

Chono and Fuegian relationship, 199; basketry of, 133; bows of, 72

Christmas sound, Yahgan of, illustrated, 117

Chronology, a basis of Fuegian origin, 200

Civilization, effect of, on Fuegians, 23. See Missions

Clam-shells as knives, 205; as paddles, 204. See Shell

Clans, see Social organization

Clarence island, pyrites from, 65, 130; situation, 17

Clark, Barbara, acknowledgments to, 12,40

Clarz, Cornelius, map of, 19

Clay in Ona myth, 104; used for paint, 58, 73, 94, 126; used on arrowshaft, 75. See Paint

Cleavers at ancient camp-site, 113. See Stone implements

Climate and physical type, 47 ; culture influenced by, 206, 209, 211-212; of Tierra del Fuego, 25-27, 34; variability affected by, 42

Cline, Walter, acknowledgments to, 12, 40

Clothing, effect of, on Fuegians, 23; Eskimo, 210-211; Fuegian, 36, 203, 212; Haush, 107, 109, 110; in Ona myth, 102; of early Europeans, 202203; Ona, 31-32, 51-58, 87; Seri, 205; skin, distribution of, 199, 208; Yahgan, 117-118, 121-124, 127. See Dress; Skin

Clouds, Ona spirit of, 94-95

Clubs of the Yahgan, 156; uses of, $64,71,81,174$. See Weapons

C'mantu, see $K^{\prime}$ mantu

Coan-yi-pej, see Kuanip

Cojazzi, Antonio, cited, 84, 95, 97, 99, 101-103, 105-108, 174, 175, 178

Coleman, A. P., cited, 207

Color, see Paint

Combs, non-use of, 194; Ona, 68; Yahgan, 130, 131

Conchs, see Food; Shell; Shellfish

Constanduros, Thos., acknowledgments to, 12

Cook, Capt. James, men of, frozen, 26; voyage of, 107-108

Cook, Frederick A., takes Bridges dictionary to Belgium, 119

Cooking by Ona, 67; containers unknown to Fuegians, 35, 179

Cooking-pots made by Seri, 205

Cooper, Dr. John M., cited, 11, 24, 38, $64-65,99,178,194,201,219$
Cormorant, see Food

Cosmology, Ona, 101, 105

Counting, Ona, 50. See Numerals

Couvade, incipient, among Yahgan, 163

Coypu-skin, capes made of, 123

Crabs eaten by Fuegians, 32-34. See Food

Crab-spears, see Spears

Cradle-board, deformation by use of, 199

Cradles, distribution of, 208; Ona, $57-58$

Creation myths, Ona, 98-99

Creator, Ona belief in, 96

Cremation of dead by Yahgan, 173

Cuguawaluf island, Yahgan population of, 196

Cultural traits, distribution of, 208

Culture, age determined by, 193; of Amazon tribes, 200; of Chile and Fuegia compared, 193-194, 199; origins determined by, 16, 199-200; status of Fuegians, 35-38, 118-119, 202-212

Culture-bearer myths, Yahgan, 176-177

Culture hero, see Hero myths

Cups, shell, of Seri, 205; shell, of Yahgan, 132

Currant wood, arrows made of, 73

Cururo eaten by Ona, 32; how hunted, 81. See Tucotuco

Cypress, harpoon-shafts of, 152

Dabbene, Roberto, cited, 101, 104, 105, 126, 176

Dances, Yahgan, 163-164, 169, 174

Dante, "Hill of Purgatory" of, 18, 20

Darwin, Charles, cited, 21, 29, 30, 118, $121,161,212$

Davenport, C. B., cited, 42,46

Dawson island, bolas from, 114; mission on, 23; situation, 17

Death, a cause of quarrels, 164-165; cause of, in Yahgan belief, 172; Yahgan customs regarding, 173-174. See Mortuary customs

Debacle myths, Yahgan, 177-178

Decoration, Ona, 58; Yahgan, in color, pl. Ix. See Body-painting; Facepainting; Ornamentation; Paint

Deer hunted by Eskimo, 209

Deities, see Spirits

Deniker, Joseph, cited, 38, 40, 41, 127, 147,148

Deportment of the Ona, 91-92. See Etiquette

Descent among Ona, 84; among Seri, 206

Despard, Canon G. P., missionary, 21

Diadem, see Headband

Dictionary, Ona, of Thomas Bridges, 22. See Language; Vocabulary 
Diet and physical type, 42, 45-47; effect on intestines, 40 . See Food

Dip-nets of basketry, 138, 160. See Nets

Disease among Fuegians, 23, 105; controlled by shamans, 172, 208. See Influenza; Measles; Sickness

Dixon, R. B., cited, 38

Doctor, Ona spirit representing, 95. See Shamans

Dog, Ona terms for, 50; tabooed as food, 118

Dog-leash of the Ona, 64, 68

Dogs, domesticated, 202, 204, 207, 208; effect of, on hunting, 84, 87; in Ona myth, 99-100; of dead distributed, 97; of the Fuegians, 33; trained for hunting, 157

Dolichocephaly of American natives, 43, 47, 198-199

Domestication of plants and animals, 207. See Dogs; Taming

Dories of the Yahgan, 146. See Boats; Canoes

Down, see Bird-down; Feathers; Goosedown; Kelp-goose down

Dragon complex, extent of, 176

Drake, Sir Francis, voyage of, 19

Dreams, shamanistic power derived from, 172

Dress, Ona terms for, 215; Yahgan terms for, 217. See Clothing

Drill unknown to Fuegians, 35, 141, 202, 211; used by Eskimo, 210 See Fire-drill; Pump-drill

Drinking-cup absent among Ona, 67

Drinking-tube, Eskimo, 211. See Birdbone

Duck, steamboat, habits of, 157 ; mythic origin of, 94. See Food

Duclos-Guyot, voyage of, 115

Duels, Ona, 90. See Feuds; Wrestling

Dugouts, see Boats; Canoes

Dutch, voyages to Fuegia by, 19

Dwellings, Ona, 59, 63-64. See Houses; Lodge; Windbreak

Eagle-feathers used on arrows, 75

Eels, see Fish; Fishing; Food

Elizabeth island, shellheaps on, 195

Encampment, Haush, pl. vi; Ona, 5968; Yahgan, 127-139

Endurance taught by Ona, 91-92. See Ordeal

England, Fuegians taken to, 161

Environment and stature, 46; culture influenced by, 209, 211

Eskimo and Fuegians compared, 35, 209-212

Estancia Segunda Argentina, pi. I
Estancia Viamonte, Bridges ranch, 12, 21-22; camp-site at, 110; stone objects from, 113, 114, pl. vII; view of, pl. I. See Bridges family

Etiquette in initiation lodge, 168; of the Yahgan, 119; of wrestlers, 89; regarding childbirth, 87; regarding food, 81. See Deportment

Europeans, primitive, Fuegians compared with, 202-204

Exploration, see Cartography

Eyes affected by smoke, 129

Face-painting, distribution of, 208; Haush, 109; Ona, 58; Seri, 205;

Tehuelche, 59; Yahgan, 118, 125, 126, 131, 164. See Body-painting; Paint

Facial index, see Physical type

Fagalde, Alberto, cited, 20

False Cape Horn, Yahgan dialect at, 120

Family, Ona, 48; Yahgan, size of, 196. See Social organization

Fan'u, see $\operatorname{Tan}^{\prime} u$

Fashine, arrows made from, 73

Fasting by initiates, 168

Fauna of Tierra del Fuego, 30-34. See Animals

Feathering, see Arrows

Feathers carried by Ona, 57; headband ornamented with $118,173, \mathrm{pl} . \mathrm{xV}$; in Ona myth, 102; used for arrows, 75 ; worn by masked figure, 94 . See Bird-down; Bird-wing

Fetishism and the Fuegians, 35

Feuds, Ona, 87-91; when forgotten, 33; Yahgan, 164-165

Fighting, mock, in initiation rite, 170. See Battle; Feuds; War; Wrestling

Figurines, Seri, 205

Fillet, see Headband

Fire burned over dead, 98; Haush spirit issues from, 107; mythic origin of, 176; property destroyed by, 97-98, 101

Fire-arrows, spirits mastered with, 97. See Arrows

Fire-drill, distribution of, 208; Seri, 206

Fire-making borrowed, 36 ; by Yahgan, 129-130, 133; Ona apparatus for, $57,64-65$

Fireplace on Yahgan canoes, 14t, 146

Fire-tongs, Ona, 64, 66; Yahgan, 130131

Fire-walking by shamans, 172-173

Firewood accessible to camp-sites, 184 ; in Ona myth, 100

Firewood-gatherer, spirit personator, 95

Fish, importance of, to Fuegians, 3234 ; represented on mask, 171 ; 
supply controlled by a great spirit, 172. See Fauna; Food; Shellfish

Fish dance, Caraja ceremony, 95

Fish-hook not used by Fuegians, 34, 35

Fishing by Ona, 81-83, 204; by Seri, 204; by Yahgan, 138, 159-160; implements, Eskimo, 209-210

Fish-lines, Yahgan, 159

Fish-nets ascribed to Ona, 83; Yahgan, 160. See Nets

Fish-oil in myth, 176

Fish-spears, Alacaluf, pl. xII; Ona, 8283; Yahgan, 204, pl. xII. See Spears

Fish-trap not used by Fuegians, 34

Fish-weirs, Yahgan, 160. See Weirs

Fitzroy, Robert, cited, 21, 115-118, 121, $126,155,157,161$

Fleshers of the Ona, 69-70, 190. See Scrapers

Flies in Ona myth, 101

Flint for fire-making, 64, 129-130; in Ona myth, 100

Floats used by Eskimo, 210

Flood in myth, 99, 177, 178; in Yahgan belief, 172

Flora of Tierra del Fuego, 28-30. See Plants; Trees

Flutes unknown to Fuegians, 208

Folklore, see Mythology

Food, effect of, on stature, 41; of Eskimo, 209; of Fuegian tribes, 15, 29-34, 45; of Haush, 109; of Ona, 81, 204-205; of Seri, 204-205; of Yahgan, 116, 196, 197, 212; storage by Fuegians, 35 ; supply controlled by shamans, 172 ; tabooed at childbirth, 87. See Animals; Deportment; Diet; Etiquette; Fauna; Fish; Fishing; Flora; Hunting

Foot Indians, account of, 48-115; and Amazon tribes compared, 200; application of term, 25, 38, 106, 198 origin of, 200. See Fuegians; Haush; Ona

Foot-racing absent among Yahgan, 164; by the Ona, 91

Footwear, Seri, 205. See Moccasins

Forests of Tierra del Fuego, 28. See Beech; Flora; Timber; Trees

Forks used by the Eskimo, 211

Fox, importance of, to Ona, 32; in Haush myth, 108; in Ona myth, 104; size of, in Tierra del Fuego, 46; tabooed as food, 118. See Food

Fox-skin, bags made of, 67 ; clothing of, 32 ; used in arrow-making, 74, 76

Frost, see Climate

Fuegians, character of, 15-16, 21; origin of, 198-201. See Alacaluf; Canoe Indians; Foot Indians; Haush; Ona; Yahgan
Fuentes Rabe, Arturo, cited, 23

Fugellie, Eric, acknowledgments to, 12

Fungus used as food, 29, 32; used as tinder, 64-65, 130, 199

Furlong, C. W., cited, 48, 81,98

Furness, John, a Yahgan, 145

Gable island, birds captured on, 159; giant's cave on, 176; myth regarding. 178; shellheaps, 183-187, pl. xvז; situation, 17; stone implements, 191; Yahgan at, 11

Gallardo, Carlos $R$., cited, 59, 68, 75, $83,8 \%$; illustration from, 63

Galliegos, collection at, 112-114

Game controlled by a spirit, 172 ; drives ascribed to Ona, 80. See Animals; Hunting

Games, Eskimo, 211; Fuegian, 35, 37; Yahgan, 163-164. See Amusements; Wrestling

Gardiner, Allen, dies in Fuegia, 21. See Allen Gardiner

Geese tamed by Yahgan, 159. See Kelp-goose

Generosity, instruction in, 169

Gentes, see Social organization

Geography of Tierra del Fuego, 15-17

Geology of Tierra del Fuego, 17

Ghost mask, Yahgan, 171

Ghosts, Ona belief in, 96; Yahgan belief in, 171. See Spirits

Ghost stories, Ona, 105-106; Yahgan, 175

Giants, stories of, 175-176

Gifts to initiates, 169

Giraudais, voyage of, 115

Girls, instruction of, 168-169; Tehuelche ceremony for, 95. See Children; Training; Women

Gketermen, an Ona spirit, 95

Gkmánta, see K'mantu

Glaciers and migration, 207; of Tierra del Fuego, 17, 27, 34, 111, 195

Glass, arrowpoints of, $57,76,109$; scrapers bladed with, 69,113

Godparents of initiates, 168-169

Goeje, C. H. de, cited, 136

Goggles, see Snow-goggles

Gold rush, effect of, on natives, 22

Goodall, John, acknowledgments to, 12

Good Success bay, Captain Cook in, 26, 92; Haush sacred locality near, 108

Goose, see Food; Geese; Kelp-goose

Goose-down, Yahgan caps of, 125. See Kelp-goose

Goose-feathers used on arrows, 75

Gordon island, situation, 16; Yahgan population of, 196

Gossip discouraged, 169

Gow-Smith, F., cited, 95 
Grain in Tierra del Fuego, 26

Grass, balls stuffed with, 91; baskets made of, 68, 133-134; braided, on crab-spears, 155; dip-nets made of, 160; moccasins stuffed with, 54; ornaments plaited of, 59; ropes of, 59, 144, 147-148

Grass-seeds eaten by Ona, 29. See Food

Grass-stalks, torches of, 83

Graves, see Mortuary customs

Grease applied to bows, 73; paint mixed with, 59; skin garments treated with, 52; Yahgan bodies rubbed with, 118

Grease stones from shellheaps, 192; Ona, 66; Yahgan, 131

Great Britain, interest of, in Fuegia, 20

Guanaco described in 1520, 55; how hunted, 153-155; hunted by Haush, 107; importance of, to Fuegians, $31-32,45,80-81$; in Ona myth, 99 , 102, 104, 108; Ona terms for, 49-50; size of, 46. See Food; Hide; Skin

Guanaco-bone, barking tools of, 141; for chipping, 70; spearpoints of, 83 . See Bone

Guanaco-hide, bags of, 67, 133, 156, 173; windbreaks of, 59-61; wristlets of, 125. See also Guanaco-skin; Hide; Skin

Guanaco-sinew, arrows attached with, 77 ; bowstrings of, $72,75,156$

Guanaco-skin, clothing of, 51-58, 107 $109,117-118,122-124,127$; footwear of, $53-55,123$; uses of, 31 . See Guanaco-hide; Hide; Skin

Guanaco-spear, see Spears

Guiana, basketry of, 137

Gulf of Peñas, glaciers at, 27

Gulls tamed by Yahgan, 159. See Food

Gull-skin, balls made of, 91

Gum, see Pitch

Gusinde, Martin, cited, 11, 38, 41, 94, $96,98,165,166,170,174$

Gut, Eskimo lashings of, 211; lodgeframe lashed with, 165; masks sewn with, 171. See Intestines; Whale-gut

Habitat, Alacaluf, 25; Eskimo, 209; Haush, 106; of Fuegian tribes, 17, pl. Iv; Ona, 11, 48; Seri, 204; Yahgan, 11, 25, 116

Hach'i, Ona spirit, 94-95

Hahn, Philippe, cited, 41

Hair of the Ona, 39, 40, 56; of the Yahgan, 40; removed by Ona, 58; removed by Yahgan, 124 . See Beards; Mustache
Hair-dressing not practised by Ona, 58; Yahgan, 124

Halakwúlup, the Alacaluf, 24

Halimink, an Ona, 86, 98

$H^{\prime}$ alpin, Ona spirit, 94-95, 108

Halupaí in Yahgan territory, 120

Hamilton, John, acknowledgments to, 12 ; collection of, 112-114

Hamito-Negroids and environment, 46

Hammerstones from shellheaps, 192 Ona, 66; used in spear-making, 151 Yahgan, 131, 141-143. See Stone implements

Hanuxa, the moon, 177

Harberton, author at, 12; a Yahgan center, 196; land grant given Bridges at, 21; sacred mountain near, 99; stone implements from, 190-191, pl. XIx; tinder fungus near, 65; view of, pl. III; Yahgan dialect boundary, 120

Harberton bay, shellheaps on, 180-184, 195-197

Harberton trail, view on, pl. II

Harciai, see Hach'i

Harness used in carrying, 62-63

Harpoon-points made of enemy bones, 173

Harpoons, distribution of, 194, 208; Eskimo, 210; Haush, 107; in Yahgan myth, 176; of Canoe Indians, 202; Seri, 204; Yahgan, 151-152. See Spears

Háse, see Hash'ai

Hash'ai, Ona spirit, 95

Haush, account of, 106-110; and Ona relationship, 40,48-49, 199; and Ona stature, 40; encampment, $\mathrm{pl}$. vi; etiquette, 92; habitat, 17; initiation ceremonies, 94-95; linguistic position, 24-25; population, 25 ; seal eaten by, 33 ; tattooing, 58 ; tools, 113

Hawkesworth, John, cited, 26, 92, 108-110; illustrations from, 117 , pl. vI

Headband, Haush, 109; Ona, 55-56, 96; Yahgan, 118, 125, 166-167, 173 , pl. xv. See Caps

Head breadth, see Physical type

Head-hunters, Fuegians suffer from, 23

Head-length, see Physical type

Heredity and physical type, $42,46-17$

Hermite island, Yahgan population of, 196. See L'Hermite

Hero myths of the Ona, 99-101

Heron-plumes, headbands of, 173 , pl.

xv. See Feathers

Herrera, Antonio de, cited, 20

Heterosis of Fuegians, $46-47$

Heye, George G., acknowledgments to, 12 
$H$-gor-re, yellow clay, in Ona myth, 104

Hide, boats not made of, 33; bucket handles of, 132; used with fleshers, 69. See Guanaco-hide; Guanaco-skin; Horse-hide; Seal-skin; Skin; Thongs Hide-beater, Ona, 64, 71

Hill of Purgatory of Dante, 18

History, age determined by, 193; of Tierra del Fuego, 20-24

Hodge, $F$. W., acknowledgments to, 12

Holemin, see Olimin'kke

Holmes, W. H., cited, 112, 113

Hooton, E. A., acknowledgments to, $12-13,40$; on anthropometric characters of Fuegians, 41-47

Horn island, situation, 17

Horse-hide, Tehuelche moccasins of, 54

Hospitality, instruction in, 169

Hoste island, situation, 16; story of giant on, 176; Yahgan dialect of, 120; Yahgan population of, 196

Household equipment, Ona terms for, 216; Yahgan terms for, 217

House-pits in shellheaps, 183-188, 194, 197

Houses, Eskimo, 209; Fuegian, 36, 203; Haush, 107, 109; Ona, 33, 52, 97; Seri, 205; Tehuelche, 60; Yahgan, 64, 127-129, 188. See Ceremonial lodge; Dwellings; Initiation; Lodge; Windbreak

House type, distribution of, 199

Hummingbirds in Tierra del Fuego, 33; mythic origin of, 102

Hunting equipment of Fuegians, 37; equipment, Yahgan terms for, 218; Eskimo, 209; Haush, 107; in Ona myth, 102, 104; in Yahgan myth, 177; mythic origin of, 176; Ona, 48, 71-84; rites of Fuegians, 15; Seri, 205; territories, Ona, 48, 84, 87; Yahgan, 155-159. See Fishing; Weapons

Hyades, P. D. J., cited, 22, 38-41, $147,148,160,173,192$; illustration from, 127

Imiwaia bay, shellheaps on, 183, 185, $187,196,197$; view of, pl. III

Immortality, Yahgan belief in, 174

Implements, Eskimo, 209-211; for arrow-making, 73-78; for bowmaking, 71-73; Ona, 64-84; Seri, 205; stone, from shellheaps, 189-192. See Metal; Stone implements; Tools

Inca, llama sheared by, 32

Incantation by shamans, 96, 172; in Ona myth, 101

Incest, Ona conception as to, 86; stories regarding, 175
Infanticide among Yahgan, 163; by Ona, 46. See Murder

Infants, Ona, cradle of, 58. See Children

Infidelity, punishment for, 163

Influenza among Fuegian tribes, 11. See Disease

Iniolh, a Haush, 120

Initiation among Ona, 92-95; among Yahgan, 116, 165-171; ceremonies borrowed, 35-36; ceremony of Haush, 107; lodge o fOna, 129; lodge of Yahgan, 129; rite, mythic origin of, 177 ; rites, range of, 200

Insult, cause of quarrels, 164

Intestines of the Yahgan, 40. See Gut; Whale-gut

Iron, Ona implements of, 68-69. See Metal

Islands of Fuegian region, 16-17

Italum Óna, Yaghan name for Haush, 24, 106

Ivory, Eskimo objects of, 210-211

Jenkins, $L$. $W$., acknowledgments to, 13,156

Kaitrrh, a hill, 110-111

Kamschoat in Ona myth, 102

Karkaai, a vulture, in Ona myth, 103

Kela, a Haush spirit impersonator, 108

Kelp for mooring canoes, 178 ; influence of, on canoeing, 184; of Tierra del Fuego, 15, 30, 125; oil-containers made of, 133 ; runways of, 148 ; used as fish-line, 159; used for house-covering, 128

Kelp-goose, mythic origin of, 94, 103; down, headband of, 55, 96, 166-167, 174 ; down, shamans' bag of, 173 . See Bird-down, Goose-down

Kenós, Ona creator, 98

Kent, Rockwell, cited, 86

Kentucky, basketry from caves in, 136

Keppel island, mission on, 21

Kerren, the moon, in Ona myth, 104

Kidnapping of Yahgan, 118

Kina, Yahgan ceremony, 165, 170, 177

King, Captain, expedition of, 21

Kinship, Ona, 84-86; Yahgan, 161-162

Klókten and Kina rites compared, 165, 170; initiation ceremony, 22, 92-96; in Ona myth, 104

$K$ 'mantu, Ona spirit, 95

Knives, clam-shells used as, 205-206; Ona, 57, 68-69; stone, from shellheaps, 112, 190; Yahgan, 141. See Blades; Stone implements

Kokersé in Ona myth, 99

Koppers, Wilhelm, cited, 11, 38, 126, $164-167,170,172,174,176-178$ 
Koschen, a Haush locality, 108

$K r^{\prime} e n$, the sun, in Ona myth, 104

Kroeber, A.L., cited, 206, 208

Ksorten, a Haush earth spirit, 107-108

$K t i^{\prime}$ aishe, the shag, in Ona myth, 103

Kuanip in Haush myth, 108; legend of, 33; Ona culture hero, 99-104

Kunboto shellheap, illustrated, pl. XviII

Kwanten, Charles, acknowledgments, 12

$K w a-u-i s h e n$, a vulture, in Ona myth, 103

La Guilbaudière, cited, 201

Laguna de Pescados, Ona near, 11

Lake Fagnano, Ona on, 11, 81; pyrites from, 65 ; situation, 17 ; tinder fungus at, 65; trail illustrated, pl. II

Lakes, Ona spirits of, 94, 96

Lamps of the Eskimo, 211

Lanáshwaía, shellheap at, 186, pl. XviI

Lance of the Eskimo, 210. See Harpoons; Spears

Land tenure, see Hunting territories

Languages, distribution by, pl. IV; of Fuegians, 24-25, 201; Ona, 48-51, 88; origins based on, 199; variations in, 192-193; Yahgan, 119-121. See Vocabulary

Lawrence, Fred., information given by, $11,12,120,153,161$

Lawrence, John, missionary, 21

Laxuwakipa, the ibex, in myth, 178

Leaves used for house-covering, 128

Le Clerk, Captain, cited, 40

Left-handedness, Ona, 75

Leggings, Ona, 56-57; Yahgan, 124

Legs of the Fuegians, 44-45

Lehmann-Nitsche, R., cited, 38, 41, 48, 106, 107, 109

Le Maire, see Schouten and Le Maire; Straits of Le Maire

Lenca, basketry of the, 137

Lennox island, guanaco-hunting on, 153; situation, 17; Yahgan dialect of, 120; Yahgan population of, 196

L'Hermite, Jaques, on Yahgan cannibalism, 118. See Hermite

Limpets, see Food

Limpet-spears, see Spears

Liquor, effect of, on Fuegians, 23

Lista, Ramón, cited, 106, 107, 201

Llama sheared by the Inca, 32

Loaysa, Fr. G. J. de, discoveries of, 19; on natives near Bahía de la Victoria, 61

Lodge, initiation, of Ona, 93-94; adorned with paint, 126 . See Ceremonial lodge; Initiation lodge

Löm, the sun, in Yahgan myth, 177-178

Londonderry island, Yahgan population of, 196
Lothrop, Mrs. S. K., acknowledgments to, 12

Love, Albert G., cited, 42

Lovisato, Domenico, cited, 195

Low, Mr., cited, 115

Lundberg, Mrs. John, acknowledgments to, 12

Madness in ghost stories, 175

Magdalenian period of Europe, 202

Magellan names Tierra del Humo, 20; on Fuegian moccasins, 54-55; voyage of, 15, 18-19, 201. See Straits of Magellan

Magellanic archipelago, geography, 17

Magic in Haush ceremony, 107; in Ona myth, 100-101

Mánekenkn, Haush self-name, 106

Maps, see Cartography

Markham, Sir Clements, cited, 19

Marriage among the Yahgan, 162-163; customs of Eskimo, 211; of the Ona, 86

Marrow, how procured, 66, 131. See Grease stones

Martial, L. F., cited, 118, 174, 176, 177,196

Mary, a Yahgan woman, 120

Masked ceremonies in Indian culture, 208

Masks adorned with paint, 126; in Haush ceremony, 107-108; in Ona ceremony, 93-95; range of use of, 200, 203; Yahgan, 94, 170-171, 177

Mason, O.T., cited, 137

Massage employed by shamans, 96,172

Material culture of earliest Indians, 208; effect of guanaco on, 31; of Ona and Yahgan, 36

Materials, raw, of Fuegians, 38; Ona terms for, 216; Yahgan terms for, 218

Matriarchy suggested by legend, 94

Mats unknown to Fuegians, 208

Measles, epidemic of, in Fuegia, 25. See Disease

Meat, dog, tabooed, 118; guanaco a source of, 31-32. See Animals; Fauna; Food; Hunting

Medicine-men, see Doctor; Shamans

Medina, José Toribio, cited, 114

Menstruation, mythic origin of, 177

Mercury sound, pyrites from, 65

Merton island, pyrites from, 65, 130

Mesocephaly, see Physical type

Metal, effect of tools of, 128; Eskimo tools of, 211; Ona tools of, 112; Yahgan tools of, 140-141, 145, 189. See Iron

Middens, see Camp-sites; Shellheaps 
Migration from Asia to America, 207; of Canoe Indians, 198-199; of Fuegians, 200; Yahgan, 193-194. See Habitat

Miracle, see Magic

Missionaries, massacre of, 118

Missions, effect of, on natives, 116, $129,131,163,165,174,212$; established in Fuegia, 21-23, 116

Mist created in Ona myth, 103; Ona spirit of, 94-95

Moccasins, distribution of, 199; Haush, 109; Ona, 31, 53-55, 58; Yahgan, 55, 118, 123-124. See Clothing; Footwear

Moieties, see Social organization

Mongoloid element in Indians, 47

Moon, Haush beliefs regarding, 108 in Ona myth, 101, 104-105; mythic origin of, 93-94, 177; sickness caused by, 96

Morley and Hodgson cited, 151

Morrell, Capt. B., Jr., gift of bow by, 156

Mortars unknown to Fuegians, 208

Mortuary customs of Canoe Indians, 194; Ona, 97-98; Ona and Haush, 107; Yahgan, 173-174

Moss, Ona spirit of, 94-95; used with scrapers, 69, 113, 139

Mount Haupin, see Mount Hewhuepen

Mount Hewhuepen, explored by Bridges, 97; Ona belief regarding, 104

Mountain, the mother of Kuanip, 99

Mountains of Tierra del Fuego, pl. II; spirits of, 96-97, 105

Mourning, black a symbol of, 126 by Yahgan, $173-174 ;$ hair shaved during, 58; songs of, 164

Mousterian culture of Europe, 202

Murder among the Ona, 86, 93-94, 97 103; among Yahgan, 164-165; of women in myth, 177. See Infanticide

Murray narrows, Yahgan dialect at, 120

Museum at Punta Arenas, 23, 65

Mushrooms in Tierra del Fuego, 34. See Fungus

Mussels as food, 45. See Food

Mussel-shells, scraper blades of, 69, 139; used for pincers, 39, 40, 58, 124

Mustaches, unusual among Ona, 86. See Beard; Hair

Musters, G. C., cited, 59, 95

Mythology, Haush, 108; Ona, 98-106; Yahgan, 174-178

Ncevi of Fuegians, 39

Name of Tierra del Fuego, origin, 20

Names, mythic origin of, 177 ; of dead tabooed, 98. See Place-names

Nana, an Ona, 86
Nasal index, see Physical type

Nassau bay, massacre at, 118

Navarin island, guanaco on, 31 ; initiation lodge on, 166; Ona temporarily on, 48; shellheaps on, $183,186-188$, pl. XVII, XVIII; situation of, 16; stone implements from, 191; view of, pl. III; Yahgan on, 11, 129; Yahgan population of, 196

Neanderthal man and Fuegians compared, 204

Necklaces, tistribution of, 208; Haush, 107 ; of early Europeans, 203; of Fuegians, 203; Ona, 59; shell, nonuse of, 194; Yahgan, 125-126

Needles unknown to Fuegians, 202; used by Eskimo, 211

Negroids and dolichocephals, 47

Nelson, N. C., cited, 195, 197

Neolithic period, age of, 202, 204, 206-207

Nets, burdens borne by Seri in, 205; non-use of, by Canoe Indians, 194; seals caught with, 81-82. See Dipnets; Fish-nets

New island, guanaco-hunting on, 153; situation, 17; Yahgan dialect of, 120; Yahgan population of, 196

New Year's sound, Yahgan dialect of, 120

Niagara falls, age of, 207

Nielson, Capt. and Mrs. Sigurd, acknowledgments to, 12

Nodal brothers, voyage of, 19

Nomenclature of Fuegian tribes, 24

Nordenskjöld, N. O. G., cited, 195

Numerals of the Yahgan, 121. See Counting

Oazy bay, location of, 61

Obsidian lacking in Fuegia, 112

Occupation and physical type, 40, 42, 44,47

Oerton, $R$. $H$., acknowledgments to, 12 Oil, see Porpoise-oil; Whale-oil

Oil containers, Yahgan, 133

Oklta, a bat, in Ona myth, 101-102

Okrisen, an owl, in Ona myth, 101-102

Olimin'kke, Ona spirit, 95

Omen associated with wands, 167

Ona, account of the, 48-106; and Haush relationship, 106-107, 199; and Tehuelche relationship, 199; and Yahgan artifacts compared, 121, 192; and Yahgan cultures intermingled, 35; and Yahgan intermarriage, 46-47; anthropometric characters of, $41-47$; arrows, 156 ; association of Bridges with, 22; basketry, 136; bolas, 115; bows, 155; fishing, 33-34; habitai, 11, 17, 48; 
leggings, 124; linguistic position, 24-25; material culture, 36 ; measles among, 25; moccasins, 123; mortuary customs, 107; murder among, 164; names of flora, 29; physical type, 198-199; population, 25; seal eaten by, 32-33; slings, 156-157; statistical constants for, 41 ; stature, 39; tattooing, 58; vocabulary, 215. See Foot Indians; Fuegians

Orange harbor, bow probably from, 156 Orbigny, A. D. d', cited, 201

Orchard, Fred. P., photographs by, 13

Orchids in Tierra del Fuego, 34

Ordeal at puberty rites, 208; by Yahgan mothers, 163; of initiates, $93,95,168$; suffered by patients, 96 . See Fire-walking

Organization of the Haush, 110. See Social organization

Orientation of lodges, 94; of Yahgan houses, 128

Origin of the Fuegians, 198-201

Ornamentation by Fuegians, 36; in Ona myth, 102; of ceremonial wands, 167; of initiation lodge, 167 . Ona, 58; Yahgan, 124-126. See Body-painting; Decoration; Facepainting; Paint

Ornaments, Eskimo, 211; Haush, 109; Ona terms for, 215; Seri, 205; Yahgan, 118; Yahgan terms for, 217. See Beads; Bracelets; Combs; Necklaces; Wristlets

Otter, see Coypu; Food

Otter-jaw, combs made of, 68

Otter-skin, clothing of, 33

Otter-tail, tobacco-pouch of, 133

Oumoara, a giant-killer, 176

Outes, F. F., cited, 68, 112-114, 203

Overshoes worn by Tehuelche, 54

Oviedo y Valdés, G. F. de, cited, 72, 75, 115; windbreak illustrated by, 61

Owl in Ona myth, 101-102

Paddles as weapons, 164; carried by mourners, 174; clam-shells used as, 204; Yahgan, 147. See Boats; Canoes

Page, Jesse, cited, 21

Paint applied to clubs, 156; bows finished with, 73; containers for, 67 , 133; hides treated with, 59, 67; how applied, 131; Ona, how obtained, 58; Ona uses of, 57,67 ; on skin garments, $52,53,57$; used by masked figures, 94; used by shamans, 173; used on bags, 133; used on buckets, 132; used on masks, $170-171$; used on spear-shafts, 83 , 150; Yahgan uses of, 126, pl. Ix. See Body-painting; Face-painting; Ornamentation
Painting by early Europeans, 203; by Fuegians, 35, 203; of lodge framework, $167, \mathrm{pl}$. IX; of spirit impersonators, 108; 169 . See Bodypainting; Face-painting

Paleolithic period of Europe, 202, 207

Pampas tribes, fire-making by, 65 . See Patagonians

Paraguay, bows of, 72

Paroquet in Ona myth, 102; in Tierra del Fuego, 34

Patagonia, bolas introduced in, 203; giant oyster-shells in, 183; guanaco in, 31; origin of Foot Indians in, 198-200; stone objects in, 72, 77, $112-114$

Patagonians, stature of, 42. See Tehuelche

Payne, E. J., cited, 18

Peabody Museum, Salem, bows in, 13, 156, pl. XIII

Peace, how made by Ona, 90-91; red a symbol of, 126

Pegs for windbreaks, 59-60

Penguins, see Food

Penguin-skin, bags of, 133; Yahgan clothing of, 117

Peru, origin of Canoe Indians in, 193-194, 198

Physical type, Chilean and Fuegian, 194; Fuegian, 38-47; Haush, 108109; Yahgan, 116-117. See Somatology

Pickett bay, location of, 61

Picton island, pumice from, 143; shellheap on, pl. XVII; situation, 17; Yahgan population of, 196

Pigafetta, Antonio, cited, 201

Pimaukel, Ona deity, 98. See Temáukl

Pincers, mussel-shells used as, 39, 40, 124

Pipil, basketry of the, 137

Pitch, blades hafted with, 113; used in arrow-making, 74

Pitirrojo, a bird, in Ona myth, 102-103

Pits, hunting, ascribed to Ona, 81

Place-names, Haush, 106, 201; near Harberton, 182

Planets, Ona belief as to, 105. See Stars

Plants created by Ḱenós, 98. See Flora

Plumed serpent complex, extent of, 176

Polishers in arrow-making, 74; of pumice, 143, 151. See Arrowshaft polishers

Polygyny among Fuegians and Eskimo, 211; among Ona, 98; among Yahgan, 163. See Marriage

Pomegashaka, shellheaps at, pl. xi

Population of Fuegian tribes, 11, 25. Yahgan, 192, 196-197 
Porpoise hunted by Fuegians, 33, 152-153. See Food

Porpoise-jaw, combs made of, 68, 130-131

Porpoise-oil, containers for, 133

Porto Piedra, canoe runway at, pl. xI; shellheaps at, 187-188; Yahgan at, 129

Porvenir, grain ripens near, 26

Pottery of the Seri, 205-206; unknown to Fuegians, 35

Pouches for fire-making apparatus, 129-130; made of seal-throat, 130; of the Yahgan, 133. See Bags

Power of shamans, 96, 172-173

Prayers to Watauinewa, 172

Property, how regarded by Yahgan, 119; of dead destroyed, 97-98, 101. See Hunting territories

Puberty rites in Indian culture, 208. See Girls

Pubic covering, bags used as, 57; Haush, 109; Ona, 58; Yahgan, 39, 123

Puelche, bolas of the, 115

Puerto Mejillones, canoe runways at, pl. XI; ceremonial lodge at, pl. XIV; kinship terms from, 161; shellheaps at, 183, 186-188, pl. xvIII; Yahgan at, 11,129

Puma-skin, Tehuelche moccasins of, 54

Pumice, polishers of, 143, 151

Pump-drill, Eskimo, 211. See Drill; Fire-drill

Punishment for infidelity, 163; of novices, $167-168$. See Ordeal

Punta Arenas, author at, 12; bolas from, 114; climate of, 26; crabs exported from, 34; museum at, 23, 65; Rev. John Williams at, 25, 119

Purchas, Samuel, cited, 55

Purgatory and Tierra del Fuego, 20. See Hill of Purgatory

Pygmies and environment, 46

Pyrites used in fire-making, 64-65, 129-130

Quarrels, see Feuds; Wrestling

Quartz, objects of, on camp-site, 112

Querandi, bolas of the, 114

Quetzalcoatl complex in Fuegia, 176; myth cycle of, 99

Quivers, Ona, 78, 154. See Spearpoint case

Ración sound, Alacaluf on, 25

Rafts, see Balsas; Boats

Rainbow, mythic origin of, 178 ; symbolized on mask, 171

Rainfall in Tierra del Fuego, 26. See Climate
Rat tabooed as food, 118

Rattles unknown to Fuegians, 208

Raw materials, see Materials

Receptacles, see Bags; Baskets; Buckets; Cooking-pots; Pouches

Refuse-heaps in Yahgan region, 116. See Camp-sites; Shellheaps

Relationship terms, Ona, 84-86; Yahgan, 161-162

Religion, Eskimo, 211; Fuegian, 35; Haush, 110; Ona, 96; Seri, 206; Yahgan, 171-172. See Ceremony; Initiation

Religious objects of Fuegians, 37

Remolino, author at, 12; land grant given Lawrence at, 21

Resin, see Pitch

Revenge for murder, 165; simulated by mourners, 174. See Blood revenge; Feuds

Reynolds, Percy, Jr., acknowledgments to, 113

Rhea in Ona legend, 200

Right-handedness, Ona, 75

Rio de la Plata, bolas from, 114

Rio Grande, bolas from, 114; Salesian mission at, 23

Róbalo bay, shellheaps on, 183, 188; stone implements from, 191

Robes, Ona, of fox-skin, 32; skin, distribution of, 208. See Clothing; Skin

Rocks, spirits of, 171. See Stones

Ropes for mooring, $147-148$; of braided grass, 144; of the Yahgan, 59, 132

Runways for canoes, $148, \mathrm{pl}$. XI

Saint Vincent's bay, Haush on, 110

Salesians, missions founded by, 23

Saliva, paint mixed with, 59; skin garments treated with, 52

Salvador, basketry of, 137

Sandals, Seri, of turtle-flippers, 205

San Julian, giant oyster-shells near, 183; Magellan at, 55

Santa Cruz, Alonso de, map of, 61

Santa Inés island, situation of, 17

Santa Maria island occupied by Yahgan, 118

Scarification by mourners, 98 ; by Yahgan, 168. See Tattooing

Scatology in Ona myth, 99

Schellbach, Louis, acknowledgments to, 13

Schort, see Sh'ord

Schouten and Le Maire, discoveries, 19

Scrapers at ancient camp-sites, 112113; distribution of, 199; from Fuegia, pl. virI; lacking among Seri, 206; of shell, 151; of the Ona, 57 , 69-70; of the Yahgan, 139-141, 
144, pl. $\mathrm{x}$; stone, from shellheaps, 190; used in arrow-making, 73; used in bow-making, 71

Scratching stick of Yahgan initiate, 166-167, 169

Sculpture of early Europeans, 203; Fuegians devoid of, 35, 203. See Carvings

Sea, spirits of the, 171

Sea-food of the Yahgan, 196. See Fauna; Fish; Food; Shellfish

Sea-hen represented on mask, 171

Seal, how hunted, 81, 107, 153, 156; hunted by Eskimo, 209; importance of, to Fuegians, 32-33; in Yahgan myth, 175. See Food

Seal-bladder, bags made of, 68, 133

Sea-lion in Yahgan myth, 176

Seal-skin, bags made of, 68, 133; clothing of, $33,109,117-118,121$, 127 ; corpse wrapped in, 173 ; doorflaps of, 128; masks made of, 171; moccasins of, 123; quivers of, 78 ; scraper lashings of, 140; sling pouch of, 156; thongs of, 144, 147, 153, 167; used for house-covering, 128

Seal-spear, Yahgan, 204, 210. See Spears

Seal-throat, containers made of, 130, 133

Sea-otter skin, Yahgan capes of, 121, 127

Sea-urchin eaten by Fuegians, 32, 34. See Food

Sea-urchin spears, see Spears

Seeds, how cooked by Ona, 67. See Berries; Grass-seeds

Selection, artificial, of Ona discussed, $45-46$

Seri and Fuegians compared, 204-209

Sexual intercourse, mythic origin of, 177

Shaft-polishers, see Arrowshaft polishers; Polishers

Shag in Ona myth, 103

Shamans, how buried, 107; in Haush ceremony, 108; of the Ona, 55-56, 96$98,105-106$; pouches used by, 133 ; power of, 174-175, 208; songs of, 164; spirits of, 171; Yahgan, 160, 172-173

Sharp, John, acknowledgments to, 12

Sharpening stones, Ona, 66, 70, 76; Yahgan, 140, 143. See Whetstone

Sheep in Tierra del Fuego, 21-22, 34. See Estancia Viamonte

Shell, beads of, 109; cups of, 67, 132; necklaces of, 125; scrapers of, 151, 157, 190. See Clam-shell; Musselshell

Shellfish available to camp-sites, 184; eaten by Fuegians, 32, 34, 109, 208; hammerstones for opening, 143; migration of, 183. See Fauna; Fish; Food; Mussels

Shellheaps of Tierra del Fuego, 34, pl. XVI-XVIII; rate of accumulation, 195. See Camp-sites

Shieháus, Yahgan ceremony, 165

Shilknam ${ }^{n}$, application of term, 24

Ships plundered by Fuegians, 15

Sh'ord, Ona spirit, 94-95, 108

Siaskels in Ona myth, 99-101

Siaxis, a hill, in Ona myth, 100

Sickness controlled by shamans, 96; prevented by painting, 59. See Disease

Sinew, clothing sewed with, 52, 208; Eskimo bows backed with, 210; headband made of, 118; ornaments braided of, 59 ; shell beads strung on, 126 ; twine made of, 31 ; wristlets attached with, 125. See Guanacosinew; Whale-sinew

Singing in initiation rites, 163-164, 169

Sinkers for fish-lines, 159

Sioux, stature variation of, 42

Skin, clothing made of, 31-32, 127; dead wrapped in, 98, 107; shaftpolisher of, 71. See Clothing; Guanaco-skin; Gull-skin; Hide; Penguinskin; Snake-skin

Skin-dressing not practised by Fuegians, 35. See Fleshers; Scrapers

Sleds of the Eskimo, 211

Sleeping-bunks of the Ona, 64

Sleight-of-hand practised by shamans, 172

Slings as weapons, 164; in Ona myth, 101 ; in Yahgan myth, 176; of the Yahgan, 118, 156; Ona and Yahgan compared, 83; stones for, how carried, 117; used by boys, 163

Smoke, effect of, on Yahgans' eyes, 129

Smoothing stones for arrow-making, 73-74. See Arrowshaft polishers; Polishers

Snake-skin, Seri belts of, 205

Snares used by Ona, 83. See Birdsnares

Snipe, Strickland's, see Woodcock

Snow created in myth, 103, 178. See Climate

Snow-goggles, Eskimo, 211

Social organization, Eskimo, 211; Fuegian, 35; in Indian culture, 208; Ona, 84; Seri, 206; Y Yahgan, 160

Somatology as evidence of Fuegian origin, 198. See Physical type

Songs of the Yahgan, 163-164, 169

South American Missionary Society, activities, 21

Southern Cross, origin of, 101 
Spaniard harbor, Yahgan boundary, 116, 196

Spaniards, expeditions to Fuegia by, 19-20; natives exterminated by, 115 Spatula for painting, 125, 131, 142

Spearpoint-case, Yahgan, 153-154

Spearpoints from ancient camp-sites, 114, 191-192

Spears as weapons, 164; distribution of use of, 194; Eskimo use of, 209 made in myth, 176; of Haush, 107 of Yahgan, 118, 148-155, 203; used by boys, 163 . See Fish-spear; Harpoons; Seal-spear

Spear-thrower, early use of, 202; unknown to Fuegians, 35, 208-209

Spirits controlled by shamans, 96, 107, 172, 174, 208; how frightened, 169; invoked by Eskimo, 211; of Ona shamans, 106; of the Haush, 107108; of the Ona, 94, 96-98, 105-106; represented by masks, 93-95; Yahgan belief in, 171

Spoons used by Eskimo, 211

Sports, see Amusements; Games; Wrestling

Spruce for Eskimo bows, 210

Staaten island, rainfall on, 26; skirted by Brouwer, 19

Stakes, see Pegs

Stars in Haush myth, 108; Ona belief regarding, 105; mythic origin of, 177-178. See Planets; Southern Cross

Stature, see Physical type

Steatopygy, cause of, 40

Stone, scraper handles of, 139-140. See Grease stone; Rocks

Stone implements from shellheaps, 111115, 179, 183, 189-192; illustrated, pl. vII, vIII, XIx; of Eskimo, 210 211; of Fuegians, 202-203; Ona, 70 , 73-74, 76; Seri, 205; Yahgan, 131. See Arrows; Fleshers; Knives; Scrapers; Tools

Stones, arrow-shape, as talismans, 102; as weapons, 164; Ona spirits of, 95 . See Rocks; Slings

Storage, bags for, 31, 67, 133; of food by Fuegians, 33, 35

Storms created in Ona myth, 103; in Magellan straits, 15; Ona belief regarding, 97

Straits of Le Maire, Camargo in, 19; character of, 15

Straits of Magellan, Alacaluf on, 25; character of, 15; cartography of, 18-19; Francis Drake in, 19; pyrites from, 65

Streams, Ona spirit of, 94

Submergence of shellheap sites, 194-195
Suggestion employed in healing, 172

Sullivan, L. R., cited, 42

Summer, see Climate

Sun in Ona myth, 101, 104-105; mythic origin of, $177-178$

Surinam, basketry of, 136

Swan, mythic origin of, 94

Swan-feathers used on arrows, 75

Swimming, Ona not practised in, 201

Symbolism of mask painting, 171; of the Eskimo, 211; of Yahgan paints, 126

Taboo during initiation, 92-93; marriage, 162; of animal food by Yahgan, 118; of camp-sites by death, 116, 179, 196; of food at childbirth, 87 ; of names of dead, 98

Talismans of the Ona, 102

Taltal, culture of, 194

Taming of birds by Yahgan, 159. See Domestication

Tane, see Tan'u

Tan' $u$, Ona spirit, 94-95

Taruwa Löm, a star, in myth, 178

Tasmanians, character of, 16

Tattooing by Fuegians, 58, 125, 168 , 199. See Scarification

Teeth used in arrow straightening, 73

Tehuelche and Ona relationship, 46, 199; arrows, 75; bags, 57; boats, 201 ; bolas, 115 ; clothing, $31,53,58$; cradles, 58 ; custom of hunters, 81 ; face-painting, 59; fire-making, 65; food, 45 ; footgear, $54-55$; houses, 60 61 ; initiation ceremonies, 95 ; linguistic relations, 106, 199; quivers not used by, 78; stature, 47; tattooing, 58; water-bags, 67 ; weapons, 72. See Patagonians

Tekeenica described, 116-118

Tello, Julio C., cited, 193

Temáukl, Ona deity, 96

Temperature, see Climate

Teniniske, an Ona, 48

Terminology of culture epochs, 202

Terra A ustralis, linked with Fuegia, 18

Theft, a cause of quarrels, 164

Thongs for burden-bearing, 62; for hafting scrapers, 113; for treeclimbing, 144; for various uses, 31 , $54,57,58,75,140,153$. See Guanaco-skin; Hide; Seal-hide

Thorns used for pegs, 59

Thouctof bay, shellheaps on, 183, 187, 196-197

Throwing-stick used by Eskimo, 210

Tiburon island, Seri on, 204

Tides of Magellan straits, 15

Tierra Mayor, Yahgan at, 11 
Tierra Mayor channel, shellheaps on, 183

Timber in Tierra del Fuego, 35. See Flora; Forests; Trees

Tinder, fungus used for, 199; of the Ona, 64-65; of the Yahgan, 129-130

Tobacco, pouch for, 133

Tongs, see Fire-tongs

Tools adorned with paint, 126; for spear-making, 151; Fuegian, 37; Ona terms for, 216; Yahgan, 139143; Yahgan terms for, 218. See Implements; Iron; Metal; Stone implements

Topography of Tierra del Fuego, 17, 28

Torch used in bird-hunting, 83, 156

Torture, see Ordeal

Totemism absent among Fuegians, 35, 94

Tracking, Ona expert in, 80

Trade in cypress wood, 152; Yahgan and Alacaluf, 130

Training of initiates, 175 ; of shamans, 172. See Children; Initiation

Transformation myths, Ona, 101-105

Transportation by Fuegians, 36, 62. See Burdens; Canoes

Travel, see Transportation

Trees lacking in Eskimo region, 209;

list of, 29; on shellheaps, 187, 194; spirits of, 95, 105, 171. See Flora; Forests

Trickster in Haush myth, 108

Tshon, application of term, 48

Tube, see Drinking-tube

Tucotuco eaten by the Ona, 32. See Cururo; Food

Turtle-fippers, Seri sandals of, 205

Turtles eaten by Seri, 204

Tweezers, see Pincers

Twine of the Ona, 31. See Sinerv; Thongs

Uhle, Max, cited, 193

Ukaikawaia, shellheaps at, pl. xvI

Union bay, pyrites from, 65

Urdanete, Andrés de, cited, 19

Useless bay of Tierra del Fuego, 48

Ushuaia, Argentine establishment at,

22; a Yahgan center, 196; climate of,

26; locus of myth, 177; mission station at, 21; Yahgan dialect at, 120

Utensils, paint used on, 126. See Implements; Tools

Van Noort, O., voyage of, 118

Varela bay, shellheaps on, 183, 196. 197 , pl. XVII

Vargas Ponce, José, cited, 20, 57

Victoria, Magellan's ship, 19

Viedma cited, 201
Villages, see Camp-sites; Shellheaps

Viracocha complex in Fuegia, 176; myth cycle of, 99

Vocabulary, Ona, 215; Yahgan, 217. See Language

Volcanoes represented in Tierra del Fuego, 20

Vomiting employed by shaman, 96

Vulture in Ona myth, 103

Vulture-feathers used on arrows, 75

Walking-stick used by Ona women, 62

Walrus speared by Eskimo, 209-210

Walter, a Yahgan, 120

Wands of initiation ceremony, 167

Wápisatumánakulum, a shellheap, 180181; stone objects from, 190-191, pl. XIX

War customs of the Ona, 87-88; for obtaining women, 86; Ona and Yahgan, 105; organized, unknown to Yahgan, 165; white a symbol of, 126

Watauinewa, Yahgan deity, 169, 172

Water, how obtained by the Ona, 67

Water-bags, distribution of, 199; Ona, $31,65,67$

Weapons, Eskimo, 209-210; Fuegian, 37; Haush, 109; Ona, 71-84; Ona terms for, 216; Yahgan, 148-157, 164; Yahgan terms for, 218. See Arrows; Bolas; Bows; Clubs; Slings; Spears

Weather controlled by shamans, 172 . See Climate

Weaving by the Seri, 205-206; unknown to Fuegians, 32,35

Weirs ascribed to Ona, 83. See Fishweirs

Weld, J. L., acknowledgments to, 145-146; companion of author, 1113,54

Whale as food, $48,84,105,107,178$; how pursued, 145, 152-153; importance of, to Fuegians, 33; in Ona myth, 102; natives poisoned by, 186-187; speared by Eskimo, 209-210; stranded, dependence on, 151. See Food

Whalebone, buckets sewn with, 132 ; canoes sewn with, 144; combs made of, 130-131; fish-line nooses of, 159; on crab-spears, 155 ; masks sewn with, 171 ; snare nooses of, 157

Whale-bone, barking tools of, $1+1,1+3$; combs of, 68; spearheads of, 150

Whale excrement, Ona belief as to, $7 t$

Whale-gut, bags made of, 68 ; sling lines of, 156

Whale-oil, containers for, 133

Whale-sinew, fish-lines of, $1+0,159$ 
Whetstone, see Sharpening stones

Whistles unknown to Fuegians, 208

White men in Ona legend, 99, 176

Wigwams, see Houses

Wikirrh, Yahgan camp-site, 186

Wilkes, Lieut. Charles, bow collected by, 156

William, a Yahgan, 120

Williams, Rev. John, acknowledgments to, $12,13,143$; Bridges dictionary in possession of, 119; mentioned, 155; on Alacaluf numbers, 25; translations by, $119-120$

Wind avoided by painting, 59; in Ona myth, 102; Ona belief regarding, 105 . See Climate

Windbreak, distribution of, 208; Haush, 10i; Ona, 31, 59, 63-6t

Winter, see Climate

Wissler, Clark, cited, 206

Witch-doctors, see Shamans

Withsand bay, location of, 61

Wollaston island, bow probably from, 156; Drake at, 19; situation, 17 Yahgan dialect of, 120; Yahgan population of, 196

Tiomen as masked spirits, 108; as rulers in Yahgan myth, 17\%: as shamans, 172 ; attitude of initiates toward, 93; bags used by, 67; Haush, character of, 109; Haush, clothing of, 109; Haush, work of, 109; how treated by Ona, 81; how treated in Haush ceremony, 108; in initiation rites, 168-170; mourning custom of, 174; murdered by Ona, 103; Ona, beliefs of, 96; Ona, clothing of, $5 i-58$; Ona, mourning by, 98; Ona, tradition regarding, 93-94; Ona, work of, 62, 81. prohibited from ceremony, 95 ; regard for, taught, 169; spirits personated by; 94 ; Yahgan, clothing of, 118 ; Yahgan, customs of, 212; Yahgan, source of contention, 118-119; Yah. gan, work of, 131-132, 13i, 147, 159. See Captives; Marriage
Wood for arrow-making, 73. See Trees

Woodcock, mythic origin of, 94

Woodworking, scrapers for, 69-70. See Arrows; Bows

Wool, guanaco, not used by Ona, 32

Woolyia, massacre at, 118

Workshop, ancient, at Estancia Viamonte, 111

Wrestling by Ona, 48, 88-90; by Yahgan, 16t; gatherings at, 84 ; in Ona myth, 103

Wristlets, Ona, 59; Yahgan, 125. See Bracelets; Ornaments

Iahgan, account of the, 116-178; and Haush compared, 107 ; and Haush relations, 106-107; and Ona cultures intermingled, $35,46-17$; anthro. pometric characters of, $11-17$; baskets, 68 ; bird-snares, 83 ; bows, 72 ; clothing, 33, 55, 58; drinking-shells, $6 i$; fire-tongs, 66; fishing, 33-34; food, 33-34; grass ropes plaited by, 59; habitat, 17,25 ; hair, 40 ; houses, 64 ; initiation ceremonies, 95 ; initiation lodge, 94; leggings, 5i, 124 . linguistic position, 24; masks, 94 ; material culture, 36 ; meat stored by, 33; missionary efforts among, 21: moccasins, 55; names of flora, 29; Ona spears adapted from, 83 ; physical type, 39, 40,198 ; population, 25, 196-197; shaman's cap, 56; slings, 83 ; statistical constants for, 41 ; stone blades, 114 ; trade for pyrites, 65 ; torches, 83 ; visit to England, 21; vocabulary, 21\%. See Foot Indians; Fuegians

Iamana, application of term, 24

Yendegaia bay, Yahgan boundary, 196

Yetaite, Yahgan evil spirit, 169

Yoa'lox in Yahgan myth, 176

Yoäloxtörnikipa in Yahgan myth, 176

Yose, an Ona ghost, 106 




39088016090599 